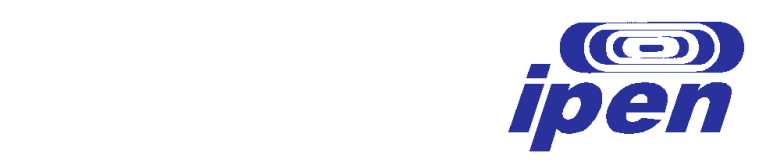

AUTARQUIA ASSOCIADA À UNIVERSIDADE DE SÃO PAULO

ESTUDO COMPARATIVO SOBRE A ADSORÇÃO DE DIFERENTES CLASSES

DE CORANTES EM ZEÓLITAS DE CINZAS DE CARVÃO:

MODELAGEM CINÉTICA E DE EQUILÍBRIO

THARCILA COLACHITE RODRIGUES BERTOLINI

Dissertação apresentada como parte dos requisitos para obtenção do Grau de Mestre em Ciências na Área de Tecnologia Nuclear - Materiais.

Orientadora:

Dra. Denise Alves Fungaro

SÃO PAULO 


\section{DEDICATÓRIA}

Dedico este trabalho a toda minha família e em especial, ao meu marido Julio, ao meu filho Filipe e aos meus pais Ricardo e Mariema. 


\section{AGRADECIMENTOS}

A Deus.

À Dra. Denise Alves Fungaro que me deu a oportunidade de realizar este trabalho sob sua orientação com muita dedicação, compreensão e carinho.

À banca examinadora composta pela Dr. Jairo Pedrotti e pela Dra. Nilce Ortiz.

Ao Instituto de Pesquisas Energéticas e Nucleares e ao Centro de Química e Meio Ambiente.

Ao CNPq pelo incentivo financeiro por meio da bolsa de estudos.

À Usina termelétrica de Jorge Lacerda por ter nos fornecido as amostras de cinzas de carvão.

À Liana Nakamura, pelo auxílio na realização das análises de difração de raios $X$.

Ao responsável técnico Felipe Ferrufino pela realização das análises de massa específica.

Ao Valter (CCTM) pela realização das análises de área superficial.

À Dra. Sandra, por realizar as análises de espectrometria de infravermelho.

Aos funcionários da Biblioteca do IPEN, sempre atenciosos ao atender às minhas necessidades de busca bibliográfica.

Às minhas amigas do CQMA: Juliana Cristina, Flávia, Camila Lange, Juliana Ikebe, Caroline Lima pelo ótimo convívio e ajuda.

Aos integrantes do grupo de pesquisa: Juliana Izidoro, Carina, Patrícia, Gabriel e Raquel.

À Helena, pela grande ajuda em cuidar do Filipe.

A todos os que me ajudaram de alguma forma neste trabalho, meu profundo agradecimento. 
"A coisa mais bela que o homem pode experimentar é o misterioso. É esta a emoção fundamental que está na raiz de toda ciência e arte". Albert Einstein 


\title{
ESTUDO COMPARATIVO SOBRE A ADSORÇÃO DE DIFERENTES CLASSES DE CORANTES EM ZEÓLITAS DE CINZAS DE CARVÃO: MODELAGEM CINÉTICA E DE EQUILÍBRIO
}

\author{
Tharcila Colachite Rodrigues Bertolini
}

RESUMO

As cinzas leves e pesadas de carvão foram utilizadas na síntese das zeólitas (ZCL e ZCP) por tratamento hidrotérmico alcalino. As zeólitas modificadas de cinzas leves e pesadas (ZMSL e ZMSP) foram preparadas pela mistura de ZCL e ZCP com o surfactante brometo de hexadeciltrimetilamônio.

Os adsorventes foram caracterizados por diferentes técnicas, tais como: métodos físico-químicos, fluorescência de raios-X, espectroscopia na região do infravermelho, difração de raios-X e microscopia eletrônica de varredura.

O processo de adsorção dos corantes cristal violeta (CV) e do ácido laranja 8 (AL8) foi realizado em sistema de batelada com o objetivo de investigar o equilíbrio e a dinâmica dos materiais zeolíticos no tratamento de efluentes. Os modelos de cinética de pseudo-primeira-ordem e pseudo-segunda-ordem foram aplicados aos dados experimentais e a cinética de pseudo-segunda-ordem descreveu a adsorção dos corantes sobre os adsorventes. Estudos da difusão intrapartícula revelaram que as velocidades de adsorção não eram controladas somente pela etapa de difusão. O modelo de Freundlich ajustou-se melhor aos dados experimentais para todos os sistemas estudados, com exceção do sistema CV/ZCL, que seguiu o modelo de Langmuir. As capacidades máximas de adsorção das zeólitas modificadas foram maiores do que aquelas obtidas para as zeólitas não modificadas. Este melhor desempenho é devido ao ambiente hidrofóbico proporcionado pela adsorção do surfactante catiônico na superfície do adsorvente.

Os parâmetros das isotermas de adsorção foram usados para prever o design do equipamento para a realização de processo de adsorção descontínuo de estágio simples. 


\section{COMPARATIVE STUDY ON THE ADSORPTION OF DIFFERENT CLASSES OF DYES IN ZEOLITES OF COAL ASHES: KINETIC AND EQUILIBRIUM MODELLING}

\section{Tharcila Colachite Rodrigues Bertolini}

\section{ABSTRACT}

The coal fly and bottom ashes were used in the synthesis of zeolites (ZFA and ZBA) by alkaline hydrothermal treatment. The modified zeolites from coal fly ash and botton ash (ZMSF and ZMSB) was performed by mixing ZFA e ZBA with the surfactant hexadecyltrimethylammonium bromide.

The adsorbents were characterized by different techniques such as: physico-chemical methods, X-ray fluorescence spectroscopy, infrared, X-ray diffraction and scanning electron microscopy.

The adsorption of the dye crystal violet (CV) and acid orange 8 (AO8) was carried out in batch system with the purpose of investigating the equilibrium and dynamics of zeolitic materials in wastewater treatment.

Pseudo-first- and second-order kinetic models have been applied to the experimental data and pseudo-second-order kinetic was found to describe the adsorption of the dyes on the adsorbents. Intra-particle diffusion studies revealed that the adsorption rates were not solely controlled by the diffusion step. The Freundlich model was better ajusted to the experimental data for all systems studied, except system CV/FTA, which followed the Langmuir model. The maximum adsorption capacities of the modified zeolites were higher than those obtained for the unmodified zeolites. This best performance is due to the hydrophobic ambient provided by the adsorption of cationic surfactant on the surface of the adsorbent.

The parameters of adsorption isotherms were used to predict the design of the equipment for performing adsorption discontinuous single stage. 


\section{SUMÁRIO}

Página

\section{INTRODUÇÃO}

2 OBJETIVOS

3 REVISÃO DA LITERATURA

3.1 Cinzas de carvão mineral

3.2 Usina Termelétrica Jorge Lacerda

3.3 Zeólitas

3.4 Zeólitas modificadas por surfactantes

3.5 Corantes

3.5.1 Cristal Violeta (CV) e Ácido Laranja 8 (AL8)

3.6 Tratamentos de efluentes têxteis

3.7 Adsorção

3.8 Isotermas de adsorção 38

3.8.1 Isoterma de Langmuir 40

3.8.2 Isoterma de Freundlich 40

3.9 Modelos cinéticos 42

3.9.1 Modelo cinético de pseudo-primeira-ordem 42

3.9.2 Modelo cinético de pseudo-segunda-ordem 42

3.9.3 Modelo de difusão intrapartícula

\section{MATERIAIS E MÉTODOS}

4.1 Área de estudo 45

4.2 Amostras de cinzas leves e pesadas de carvão 45

4.3 Materiais 46

4.4 Síntese das zeólitas a partir das cinzas leves e pesadas de carvão 46

4.5 Síntese das zeólitas modificadas por surfactante 
4.6 Caracterização dos adsorventes

4.6.1 Determinação do $\mathrm{pH}$ e condutividade

4.6.2 Determinação do Ponto de Carga Zero ( $\left.\mathrm{pH}_{\mathrm{PCZ}}\right)$

4.6.3 Capacidades de troca catiônica (CTC) e troca catiônica externa (CTCE)

4.6.4 Grau de hidrofobicidade

4.6.5 Massa específica

4.6.6 Área específica superficial 49

4.6.7 Difração de raios $x$ 50

4.6.8 Fluorescência de raios $x$ 50

4.6.9 Microscopia Eletrônica de Varrredura 50

4.6.10 Espectroscopia no Infravermelho 51

4.7 Estudos de adsorção

5 RESULTADOS E DISCUSSÃO

5.1 Caracterização dos adsorventes

5.1.1 Propriedades físico-químicas

5.1.2 Composição química

5.1.3 Composição mineralógica

5.1.4 Identificação dos grupos funcionais

5.1.5 Composição morfológica

5.2 Espectro de varredura 72

5.3 Estudos cinéticos 73

5.3.1 Efeito do tempo de contato 73

5.3.2 Estabilidade dos corantes 79

5.3.3 Modelagem cinética 80

5.4 Isotermas de adsorção 96

5.5 Energia livre de Gibbs 108

5.6 Design do processo de adsorção descontínuo 
5.7 Mecanismo de adsorção

5.7.1 Zeólitas de cinzas leves e pesadas

5.7.2 Zeólitas de cinzas leves e pesadas modificadas

6 CONCLUSÕES

7 CONSIDERAÇÕES

APÊNDICES

ANEXOS 


\section{LISTA DE TABELAS}

TABELA 1 - Características Gerais do Cristal Violeta e Ácido Laranja 8

TABELA 2 - Valores medidos de pH inicial dos adsorventes sintetizados

TABELA 3 - Concentração do corante CV e tempo de agitação no estudo da cinética de adsorção

TABELA 4 - Concentração do corante AL8 e tempo de agitação no estudo da cinética de adsorção

TABELA 5 - Propriedades físico-químicas dos adsorventes

TABELA 6 - Composição química dos adsorventes

TABELA 7 - Atribuições das bandas do espectro IV das zeólitas não modificadas e modificadas por surfactante

TABELA 8 - Atribuições das bandas do espectro IV do CV

TABELA 9 - Atribuições das bandas do espectro IV do AL8

TABELA 10 - Comparação dos resultados obtidos no estudo de Cinética do CV

TABELA 11 - Comparação dos resultados obtidos no estudo de Cinética do AL8

TABELA 12 - Parâmetros cinéticos para a remoção do CV sobre os adsorventes

TABELA 13 - Parâmetros cinéticos para a remoção do AL8 sobre os adsorventes

TABELA 14 - Parâmetros dos modelos de isoterma de Langmuir e Freundlich para o corante $\mathrm{CV}$ sobre os adsorventes e valores de Qui-quadrado $\left(\mathrm{X}^{2}\right)$

TABELA 15 - Parâmetros dos modelos de isoterma de Langmuir e Freundlich para o corante AL8 sobre os adsorventes e valores de Qui-quadrado $\left(X^{2}\right)$

TABELA 16 - Comparação das capacidades máximas $\left(Q_{0}\right)$ de adsorção do CV e AL8 sobre os adsorventes 
TABELA 17 - Comparação da capacidade de adsorção máxima do CV em vários adsorventes

TABELA 18 - Comparação da capacidade de adsorção máxima do AL8 em vários adsorventes

TABELA 19 - Energia livre de Gibbs para os sistemas corante/adsorvente 


\section{LISTA DE FIGURAS}

FIGURA 1 - Vista geral da Usina Termelétrica Jorge Lacerda

FIGURA 2 - Disposição inadequada das cinzas pesadas

FIGURA 3 - Representações bi e tridimensionais da rede estrutural de zeólitas

FIGURA 4 - Esquema da conversão hidrotérmica das cinzas de carvão em zeólita

FIGURA 5 - Estrutura do surfactante dodecil sulfato de sódio (SDS): "cauda" 18 hidrofóbica e "cabeça" hidrofílica

FIGURA 6 - llustração do processo de micelização do surfactante em solução aquosa

FIGURA 7 - Estrutura química do brometo de hexadeciltrimetilamônio

FIGURA 8 - Adsorção de surfactante na superfície da zeólita

FIGURA 9 - Descarte de corante em rio

FIGURA 10 - Estrutura molecular tridimensional (3D) do CV

FIGURA 11 - Estrutura molecular tridimensional (3D) do AL8

FIGURA 12 - Equilíbrio entre os tautômeros azo-hidrazona em solução aquosa de AL8

FIGURA 13 - Isotermas de adsorção

FIGURA 14 - Precipitadores eletrostáticos da Usina Jorge Lacerda

FIGURA 15 - Bacia de sedimentação da Usina Jorge Lacerda

FIGURA 16 - Difratograma de raios $X$ da ZCL (Q=Quartzo, M=Mulita, H=zeólita

hidroxisodalita, $\mathrm{X}=$ =zeólita $\mathrm{NaX}$ )

FIGURA 17 - Difratograma de raios $X$ da ZCP (Q=Quartzo, M=Mulita, H=zeólita hidroxisodalita, $\mathrm{X}=$ zeólita $\mathrm{NaX}$ ) 
FIGURA 18 - Difratogramas da zeólita (ZCL) e da zeólita modificada por surfactante (ZMSL)

FIGURA 19 - Difratogramas da zeólita (ZCP) e da zeólita modificada por surfactante (ZMSP)

FIGURA 20 - Difratogramas de raios $X$ das zeólitas não modificadas antes e após adsorção com os corantes (a) ZCL; (b) ZCP (Q=Quartzo, M=Mulita, H=zeólita hidroxisodalita, $\mathrm{X}=$ zeólita $\mathrm{NaX}$ )

FIGURA 21 - Difratogramas de raios $X$ das zeólitas não modificadas antes e após adsorção com os corantes (a) ZMSL; (b) ZMSP (Q=Quartzo, M=Mulita, H=zeólita hidroxisodalita, $\mathrm{X}=$ zeólita $\mathrm{NaX}$ )

FIGURA 22 - Espectros de infravermelho da ZCL e da ZMSL

FIGURA 23 - Espectros de infravermelho da ZCP e da ZMSP

FIGURA 24 - Espectros de infravermelho dos adsorventes saturados do CV

FIGURA 25 - Espectros de infravermelho dos adsorventes saturados do AL8

FIGURA 26 - Micrografia das cinzas pesadas de carvão

FIGURA 27 - Micrografia das zeólitas de cinzas pesadas

FIGURA 28 - Micrografias das zeólitas modificadas (a) ZMSL; (b) ZMSP

FIGURA 29 - Espectro de absorção na região do visível do Cristal Violeta

FIGURA 30 - Espectro de absorção na região do visível do Ácido Laranja 8

FIGURA 31 - Efeito do tempo de contato na remoção do corante CV

FIGURA 32 - Efeito do tempo de contato na remoção do corante AL8

FIGURA 33 - Soluções aquosas do CV antes e após adsorção sobre ZCL em 
FIGURA 34 - Soluções aquosas do AL8 antes e após adsorção sobre ZMSL em

$\mathrm{t}=0$ e $\mathrm{t}$ de equilíbrio

FIGURA 35 - Solução aquosa dos corantes CV (a) e AL8 (b) após adsorção com

flotação do nanomaterial zeólitico organomodificado

FIGURA 36 - Fluxograma do processo de adsorção-flotação para o tratamento de solução aquosa de CV e AL8 sobre zeólitas organomodificadas

FIGURA 37 - Variação da absorbância e do pH do corante CV em função do tempo de agitação

FIGURA 38 - Variação da absorbância e do pH do corante AL8 em função do tempo de agitação

FIGURA 39 - Comparação dos modelos cinéticos da adsorção do CV sobre a ZCL

(a) pseudo-primeira-ordem; (b) pseudo-segunda-ordem; (c) modelo de difusão intrapartícula

FIGURA 40 - Comparação dos modelos cinéticos da adsorção do CV sobre a ZCP

(a) pseudo-primeira-ordem; (b) pseudo-segunda-ordem; (c) modelo de difusão intrapartícula

FIGURA 41 - Comparação dos modelos cinéticos da adsorção do CV sobre a ZBayer

(a) pseudo-primeira-ordem; (b) pseudo-segunda-ordem; (c) modelo de difusão intrapartícula

FIGURA 42 - Comparação dos modelos cinéticos da adsorção do CV sobre a ZMSL

(a) pseudo-primeira-ordem; (b) pseudo-segunda-ordem; (c) modelo de difusão intrapartícula

FIGURA 43 - Comparação dos modelos cinéticos da adsorção do CV sobre a ZMSP

(a) pseudo-primeira-ordem; (b) pseudo-segunda-ordem; (c) modelo de difusão intrapartícula 
FIGURA 44 - Comparação dos modelos cinéticos da adsorção do AL8 sobre a

ZCL (a) pseudo-primeira-ordem; (b) pseudo-segunda-ordem; (c) modelo de difusão intrapartícula

FIGURA 45 - Comparação dos modelos cinéticos da adsorção do AL8 sobre a ZMSL

(a) pseudo-primeira-ordem; (b) pseudo-segunda-ordem; (c) modelo de difusão intrapartícula

FIGURA 46 - Comparação dos modelos cinéticos da adsorção do AL8 sobre a ZMSP

(a) pseudo-primeira-ordem; (b) pseudo-segunda-ordem; (c) modelo de difusão intrapartícula

FIGURA 47 - Comparação dos resultados calculados e experimentais da cinética de adsorção do CV sobre os adsorventes

FIGURA 48 - Comparação dos resultados calculados e experimentais da cinética de adsorção do AL8 sobre os adsorventes

FIGURA 49 - Isotermas de adsorção do CV sobre os adsorventes

$\left(\mathrm{pH}=5 ; \mathrm{T}=25^{\circ} \mathrm{C} \pm 2^{\circ} \mathrm{C}\right)$

FIGURA 50 - Isotermas de adsorção do AL8 sobre os adsorventes

$\left(\mathrm{pH}=5 ; \mathrm{T}=25^{\circ} \mathrm{C} \pm 2^{\circ} \mathrm{C}\right)$

FIGURA 51 - Curvas linearizadas dos modelos de Langmuir (a) e Freundlich (b) da adsorção do CV sobre ZCL

FIGURA 52 - Curvas linearizadas dos modelos de Langmuir (a) e Freundlich (b) da adsorção do CV sobre ZCP

FIGURA 53 - Curvas linearizadas dos modelos de Langmuir (a) e Freundlich (b) da adsorção do CV sobre ZBayer

FIGURA 54 - Curvas linearizadas dos modelos de Langmuir (a) e Freundlich (b) da adsorção do CV sobre ZMSL 
FIGURA 55 - Curvas linearizadas dos modelos de Langmuir (a) e Freundlich (b) da adsorção do CV sobre ZMSP

FIGURA 56 - Curvas linearizadas dos modelos de Langmuir (a) e Freundlich (b) da adsorção do AL8 sobre ZCL

FIGURA 57 - Curvas linearizadas dos modelos de Langmuir (a) e Freundlich (b) da adsorção do AL8 sobre ZMSL

FIGURA 58 - Curvas linearizadas dos modelos de Langmuir (a) e Freundlich (b) da adsorção do AL8 sobre ZMSP

FIGURA 59 - Design para o processo descontínuo de estágio simples

FIGURA 60 - Relação da massa do adsorvente com o volume da solução tratada (a) CV/ZCL; (b) CV/ZCP. (c) CV/ZMSL; (d) CV/ZMSP

FIGURA 61 - Relação da massa do adsorvente com o volume da solução tratada (a) AL8/ZCL; (b) AL8/ZMSL; (c) AL8/ZMSP 


\section{INTRODUÇÃO}

O desenvolvimento da atividade industrial nas últimas décadas proporcionou confortos e praticidades à sociedade. Contudo, os problemas ambientais cresceram. Atualmente, a poluição ambiental é considerada como um dos principais problemas em países desenvolvidos e em desenvolvimento.

Um processo industrial que se destaca mundialmente tanto pelo seu crescimento quanto pela geração de resíduos é a indústria têxtil. É um setor fragmentado e que apresenta processos complexos, dominado por pequenas e médias empresas. A indústria têxtil é considerada como uma das mais poluentes.

A cadeia têxtil brasileira possui um importante potencial de expansão. Em 2011, produziu US\$ 67,3 bilhões, o que equivale a 5,6\% do valor total da indústria brasileira de transformação. O consumo mundial de fibras e filamentos é um indicativo de produção de manufaturados têxteis. Em 2007 foram consumidos em todo o mundo 76,2 milhões de toneladas, chegando em 2010 a 80,1 milhões de toneladas. Estes dados representam um crescimento de mais de $100 \%$ sobre o consumo de 1990, que foi de 40 milhões de toneladas, equivalente a um crescimento médio de $4,1 \%$ ao ano (ABIT, 2012).

As etapas do processo produtivo da indústria têxtil envolve fiação, tecelagem e/ou malharia, beneficiamento e enobrecimento dos fios e tecidos e confecções. As etapas de beneficiamento e enobrecimento consomem uma grande quantidade de água, gerando então a maior parte dos efluentes.

Além do alto consumo de água, o processo de tingimento (beneficiamento) utiliza grandes quantidades de corantes, sendo estes de diversos tipos. Uma quantidade significativa destes corantes é perdida devido à fixação incompleta dos corantes à fibra. Atualmente, a remoção desses compostos coloridos é um dos maiores problemas enfrentados pela indústria.

Além do setor têxtil, estima-se que outras indústrias percam $20 \%$ de corantes nos efluentes durante a síntese, processamento e aplicação.

Os corantes são substâncias altamente coloridas e possuem estruturas complexas. Cabe ressaltar que, além dos corantes, os efluentes têxteis são compostos por outras substâncias, e estas variam conforme as diversas etapas 
do processo. Isto torna o efluente com características específicas, dificultando desta forma, a seleção de um tratamento adequado para atender a legislação ambiental.

A poluição gerada pelos efluentes têxteis é visualmente detectada nos rios e lagos, mesmo com concentrações baixas de corantes. As informações sobre os riscos da poluição causada pelo descarte de corantes em corpos d'água são pouco difundidas, mas sabe-se que estes compostos são tóxicos e são prejudiciais a todas as formas de vida. Algumas classes de corantes podem apresentar carcinogenicidade e mutagenicidade e podem permanecer por cerca de 50 anos nos ecossistemas terrestres e aquáticos.

Diante deste cenário, se faz necessário buscar formas de atenuar estes problemas. Pesquisadores têm estudado alternativas de tratamento com novas tecnologias para prevenção de danos aos ecossistemas naturais.

Nos últimos anos, as implementações de leis e normas ambientais cada vez mais restritivas e a criação de mercados mais competitivos vêm exigindo que as empresas sejam mais eficientes do ponto de vista produtivo e ambiental.

Segundo estudos, não existe uma simples técnica que seja uma solução considerada universal, a tendência atual é focada na integração de múltiplas técnicas no tratamento de efluentes, e estas podem ser químicas, físicas e biológicas.

Entre os processos físicos de tratamento, a adsorção tem sido bastante estudada e tem sido considerada superior a outras técnicas para reuso de água em termos de custo inicial, flexibilidade e simplicidade de projeto e facilidade de operação.

O adsorvente mais utilizado nos processos de adsorção é o carvão ativado. Este material apresenta alta eficiência na remoção de poluentes, mas apresenta alto custo.

Uma proposta sustentável é a utilização de resíduos sólidos que podem ser reciclados. Estes resíduos são conhecidos por adsorventes de baixo custo. Existem pesquisas que utilizam resíduos orgânicos e industriais como materiais adsorventes. Os resíduos industriais ou agrícolas (biomassa), cuja composição principal é de sílica e alumina em fase amorfa, podem ser usados como matéria prima na síntese de zeólita. 
As termelétricas a carvão mineral geram toneladas de cinzas, e somente uma pequena parte é comercializada para o setor de construção. A disposição inadequada deste resíduo polui o meio ambiente, contaminando o solo e as águas superficiais e subterrâneas.

As cinzas de carvão podem ser uma alternativa como matéria prima na síntese de zeólita. O material adsorvente sintetizado pode ser eficiente no tratamento de efluentes têxteis.

A utilização da zeólita sintetizada a partir das cinzas de carvão tem chamado à atenção dos pesquisadores da área ambiental. Muitos estudos abordam a aplicabilidade deste material adsorvente como uma medida de sustentabilidade e, consequentemente, são investigados os efeitos benéficos para o meio ambiente. 


\section{OBJETIVOS}

\section{Objetivo geral}

O objetivo geral deste estudo foi sintetizar zeólitas a partir de cinzas de carvão e avaliar o seu uso na remoção de corante básico e corante ácido de solução aquosa contribuindo, dessa forma, com os sistemas de gestão ambiental, tanto do setor têxtil quanto de usinas termelétricas a carvão.

\section{Objetivos específicos}

1. Sintetizar zeólitas de cinzas leves e cinzas pesadas de carvão.

2. Sintetizar zeólitas de cinzas leves e cinzas pesadas de carvão modificadas por surfactante.

3. Caracterizar físico-quimicamente as zeólitas de cinzas de carvão.

4. Estudar o processo de adsorção dos corantes Cristal Violeta e Ácido Laranja 8 sobre materiais zeolíticos: modelagem cinética e modelagem de equilíbrio.

5. Comparar as capacidades de adsorção dos materiais zeolíticos de cinzas de carvão com aquelas obtidas com zeólita comercial. 


\section{REVISÃO DA LITERATURA}

\subsection{Cinzas de carvão mineral}

O carvão é o principal combustível utilizado para a geração de eletricidade em todo o mundo. O sistema de produção de energia a carvão mineral consiste, essencialmente, da mineração, da preparação ou processamento e geração de energia.

O carvão mineral é um sedimento fóssil, formado pela decomposição da matéria orgânica (como restos de árvores e plantas) durante milhões de anos, sob determinadas condições de temperatura e pressão. É composto por átomos de carbono, oxigênio, nitrogênio, enxofre, associados a outros elementos rochosos (como arenito, siltito, folhelhos e diamictitos) e minerais, como a pirita (ANEEL, 2008).

A produção mundial de carvão aumentou consideravelmente após 2000. Seis países, os EUA, a Rússia, Índia, China, Austrália e África do Sul, produziram $81,9 \%$ do total de carvão extraído em todo o mundo em 2006 . Estes mesmos países têm cerca de $90 \%$ das reservas mundiais de carvão. A produção na China foi responsável por $38,4 \%$ do total mundial e aumentou cerca de $66 \%$ ao longo dos últimos cinco anos de 1,38 bilhões de toneladas em 2001 para 2,3 bilhões de toneladas em 2006 (EWG, 2007).

O consumo mundial de carvão mineral em 2010 foi de aproximadamente 6,5 bilhões de toneladas, sendo $55 \%$ destinadas à geração de energia elétrica (Matriz energética, 2013). Por exemplo, China e Estados Unidos que, segundo a IEA, em 2006 produziram mais da metade dos 7.775 terawattshora (TWh1) gerados no mundo. Além disso, países como Alemanha, Polônia, Austrália e África do Sul usam o carvão como base da geração de energia elétrica devido à segurança de suprimento e ao menor custo na comparação com outros combustíveis.

No Brasil, o minério representa pouco mais de 1,5\% da matriz da energia elétrica. Em 2007 foram produzidos 435,68 TWh no País, e o carvão foi responsável pela geração de 7,9 TWh, a partir da operação de usinas 
termelétricas que estão localizadas na região Sul, nas proximidades das áreas de mineração (ANEEL, 2008).

As Usinas Termelétricas que utilizam o carvão no processo de geração de energia produzem uma grande quantidade de resíduos. Nos processos de gaseificação ou combustão direta do carvão a fração orgânica gera compostos voláteis $\left(\mathrm{SO}_{x}, \mathrm{NO}_{x}, \mathrm{CO}\right.$, gases ácidos) e coque, e a matéria mineral forma um resíduo sólido, denominado cinzas de carvão. As cinzas são materiais heterogênios e complexos e podem ser classificadas, dependendo do processo de combustão, em volantes (ou leves), de fundo (ou pesadas) e escórias (Alonso-Hernández et al., 2011; Rhode et al., 2006).

As cinzas leves apresentam uma granulometria fina (tamanho das partículas menor que $0,15 \mathrm{~mm}$ ), e são conduzidas pelos gases no processo de combustão. Este material fica retido num sistema de coleta como, por exemplo, precipitador eletrostático, filtros de manga, ciclone e outros (Rhode et al., 2006). Os sistemas que proporcionam uma maior eficiência de coleta de partículas finas e que são mais utilizados pelas usinas termelétricas são os precipitadores eletrostáticos e os filtros de manga (Ortiz e Teixeira, 2002).

As cinzas pesadas são constituídas por partículas mais grossas que caem no fundo das fornalhas. São previamente desagregadas e transportadas para os tanques de decantação por meio de bombeamento hidráulico (Andrade et al., 2009; Rhode et al., 2006).

Escórias são as cinzas provenientes da queima ou gaseificação do carvão granulado em grelhas estáticas ou móveis. Este material é resfriado com água e posteriormente removido do fundo da fornalha. Apresentam frequentemente granulometria grosseira e blocos sinterizados e possui teores de carbono não queimado entre 10 e $20 \%$ (Rhode et al., 2006).

A composição das cinzas, de uma maneira global, é conhecida. Entretanto, o tipo de carvão e os processos tecnológicos utilizados nas usinas termelétricas interferem diretamente nas características físicas, químicas e mineralógicas deste material, tornando impraticável o desenvolvimento de uma padronização para as propriedades deste resíduo (Vassilev e Vassileva, 2007).

As cinzas leves e as cinzas pesadas de carvão são constituídas por uma parte orgânica e uma inorgânica. A parte inorgânica é constituída principalmente por materiais amorfos, tais como partículas vítreas e esféricas, 
angulares e irregulares, e por materiais cristalinos. A fração orgânica contém carvão não queimado (Quispe et al., 2012; Vassilev e Vassileva, 2007; Vassilev, 1996; Silva et al., 2010; Querol et al., 2002).

A constituição química principal das cinzas de carvão são $\mathrm{SiO}_{2}, \mathrm{Al}_{2} \mathrm{O}_{3} \mathrm{e}$ $\mathrm{Fe}_{2} \mathrm{O}_{3}$ e quantidades variáveis de $\mathrm{CaO}$ e $\mathrm{MgO}$ são encontradas. Além disto, alguns elementos em menor quantidade podem ser encontrados, tais como $\mathrm{Hg}$, As, Ge, Ga, Cr, Co,Cu, Pb, Mn, Ni e Zn (Kumar et al., 2007). Estes elementos traços são enriquecidos durante o processo de combustão do carvão, resultando em resíduos potencialmente perigosos (Ahmaruzzaman, 2010). Estudos realizados para avaliar a toxicidade das cinzas revelaram a presença de metais tóxicos, tais como arsênio, cromo, chumbo, vanádio, zinco e urânio (Quispe et al., 2012; Izquierdo e Querol, 2012; Alonso-Hernández et al., 2011; Lu et al., 2009; Depoi et al., 2008; Levandowski e Kalkreuth, 2009).

A disposição inadequada das cinzas gera um grande impacto no meio ambiente e na saúde humana. A principal preocupação ambiental deriva da possível lixiviação de metais e compostos orgânicos e sua migração para as águas subterrâneas ou superficiais. Além disso, as cinzas podem afetar a saúde humana da população residente próximo às Usinas termelétricas por inalação direta ou ingestão no ar da poeira silicosa que se arrasta com o vento (Kumar et al., 2007; Leandro, 2005).

É fundamental conhecer as propriedades dos carvões e das cinzas, de modo a avaliar o potencial risco de contaminação das usinas sobre o meio ambiente e a saúde humana, e também na decisão de utilização industrial (Levandowski e Kalkreuth, 2009).

A produção de cinzas no mundo ultrapassa 600 milhões de toneladas por ano. Essas estimativas são baseadas em dados dos últimos 10 anos. O consumo de carvão aumentou em 50\% neste intervalo, em grande parte devido ao crescimento econômico da China (Ahmaruzzaman, 2010). Considerando este fato, a previsão é que a geração de cinzas leves chegue a 750 milhões de toneladas em uma base global a cada ano (Blissett, 2012). As cinzas leves representam aproximadamente $80 \%$ do total desta produção.

No Brasil, as usinas a carvão localizadas no sul do País produzem cerca de 4 milhões de toneladas de cinzas por ano, dos quais $65-85 \%$ são cinzas 
leves e 15-35\% são cinzas de fundo (Rocha et al., 2012; Levandowski e Kalkreuth, 2009; Fungaro et al., 2009).

A média mundial de utilização das cinzas é $25 \%$, considerada baixa quando comparada com a quantidade gerada. Em muitos países, a produção total excede seu potencial de aplicações. Atualmente, os Estados Unidos utilizam 39\% e a Europa 47\% (Blissett e Rowson, 2012) do total de cinzas geradas. As cinzas leves de carvão são usadas como matéria prima para a fabricação de cimento, enquanto uma proporção significativa da produção anual fica disposta em aterro e também utilizada para recompor minas de carvão desativadas (Paprocki, 2008). Com relação às cinzas pesadas, não há uma utilização comercial, ficando dispostas em bacias de sedimentação (Pimraksa et al., 2010; Fansuri et al., 2010; Leandro, 2005).

Do ponto de vista da geração de energia, cinzas são resíduos, enquanto que a partir de uma perspectiva de utilização do carvão, cinzas podem ser consideradas como subprodutos, um recurso ainda a ser universalmente explorado (Ahmaruzzaman, 2010).

A aplicação das cinzas geradas nas termelétricas é investigada por pesquisadores no mundo todo, com o objetivo de diminuir o impacto ambiental e também para aprimorar e desenvolver técnicas de eliminação de resíduos economicamente viáveis. Entre as principais aplicações desenvolvidas ou que estão em desenvolvimento encontram-se: síntese de zeólita a partir de cinzas leves e pesadas de carvão (Izidoro, 2013; Fungaro e Borrely, 2012; Izidoro, 2008; Rocha et al., 2012; Jha e Singh, 2011; Pimraksa et al., 2010; Paprocki, 2009; Fungaro e Izidoro, 2006a; Ferret, 2004; Moreno et al., 2001; Querol et al., 1997; Henmi, 1987; Höller e Wirsching, 1985), aproveitamento das cinzas pesadas em bases e sub-bases de pavimentos flexíveis (Leandro, 2005), aproveitamento da cinza de carvão mineral na agricultura (Martins, 2001), fabricação de blocos e tijolos (Silva, 2011; Chies et al., 2003), possibilidade de recuperação de alumina das cinzas volantes (Zhou et al., 2009).

As cinzas de carvão, numa visão mais específica e inovadora, podem ser transformadas em coproduto (Rodhe, 2013). A proposta seria incluir as cinzas de carvão fóssil na categoria de substâncias não-metálicas produzidas no Rio Grande do Sul e Santa Catarina obtendo uma característica nova e gerando um material alternativo com várias aplicações. 


\subsection{Usina Termelétrica Jorge Lacerda}

O Brasil é o nono maior gerador de energia do mundo e o terceiro maior do hemisfério ocidental, sendo excedido somente pelos Estados Unidos e Canadá (EIA, 2009). A capacidade de geração de energia é fundamentada principalmente em usinas hidrelétricas e em menor escala em termelétricas a carvão. As usinas a carvão estão localizadas na região Sul do país, nos estados do Rio Grande do Sul, Paraná e Santa Catarina, onde estão concentradas as reservas mais abundantes de carvão do país.

Este estudo enfoca sobre as cinzas geradas na Usina termelétrica Jorge Lacerda. Esta usina está localizada no estado de Santa Catarina, no município de Capivari de Baixo, e pertence à Companhia Tractebel Energia. $\mathrm{O}$ complexo é considerado o maior da América Latina e é composto por três fases distintas (A, B e C), com capacidade total de produção instalada de 857 Megawatts (Tractebel, 2013). A usina abastece indústrias, residências e comércio (Paprocki, 2009).

Na FIG. 1 é apresentada uma vista geral do complexo.

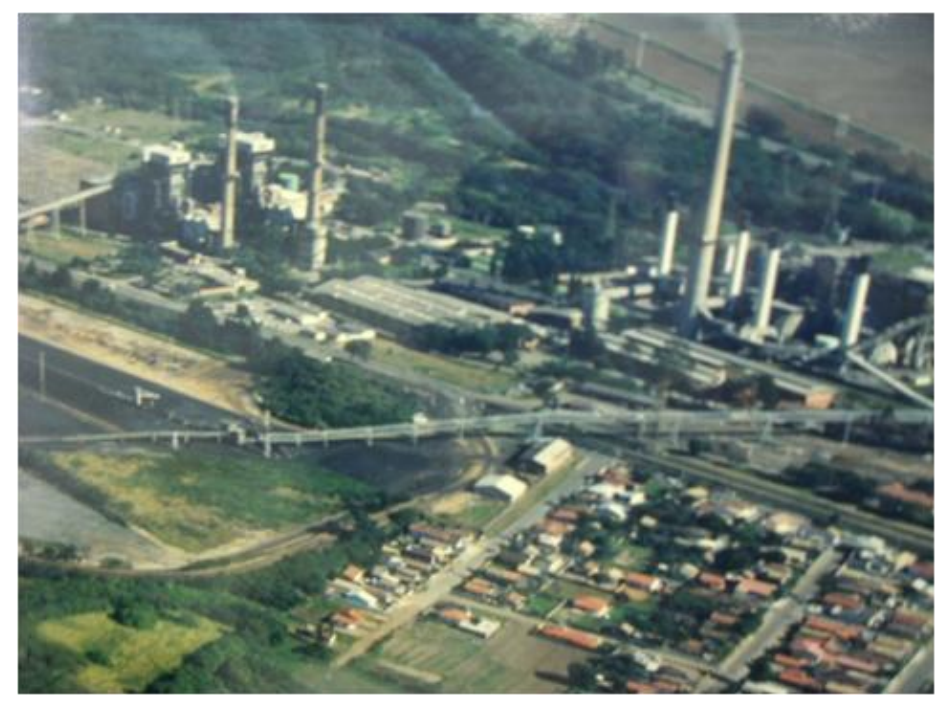

FIGURA 1 - Vista geral da Usina Termelétrica Jorge Lacerda (fonte: acervo da Usina) 
O carvão mineral usado na usina Jorge Lacerda apresenta teor médio de enxofre ( $<2 \%$ total S) e aproximadamente $40 \%$ de cinza (Silva et al., 2010). O combustível fóssil é fornecido por diferentes mineradoras de Santa Catarina e do Rio Grande do Sul (Oliveira et al., 2013). O mesmo passa pelo processo de beneficiamento, de onde é levado até a usina. No processo de geração de energia, o carvão pulverizado é queimado a uma temperatura entre $1200^{\circ} \mathrm{C}$ e $1400^{\circ} \mathrm{C}$ (Izidoro, 2013).

O carvão beneficiado em Santa Catarina apresenta dois tipos de produto, sendo o carvão grosso, que é vendido para a Usina Jorge Lacerda, com tamanho geralmente acima de $2 \mathrm{~mm}$, e o carvão menor que $2 \mathrm{~mm}$; este é destinado para a produção de coque metalúrgico ou misturado com carvão grosso e enviado para a usina (Oliveira et al., 2013).

A produção anual de cinzas é estimada em 2 milhões de toneladas, sendo cinzas leves e pesadas (Rhode, 2013).

A usina é equipada com queimadores de baixo teor de $\mathrm{NO}_{\mathrm{x}}$. Aproximadamente $98,5 \%$ das cinzas leves são retidos por precipitadores eletrostáticos (Silva et al., 2010). Toda a produção de cinzas leves da usina Jorge Lacerda é reaproveitada pela indústria cimenteira, enquanto que as cinzas pesadas são dispostas em bacias de sedimentação (FIG. 2) localizadas nos arredores da termelétrica (Silva, 2006).

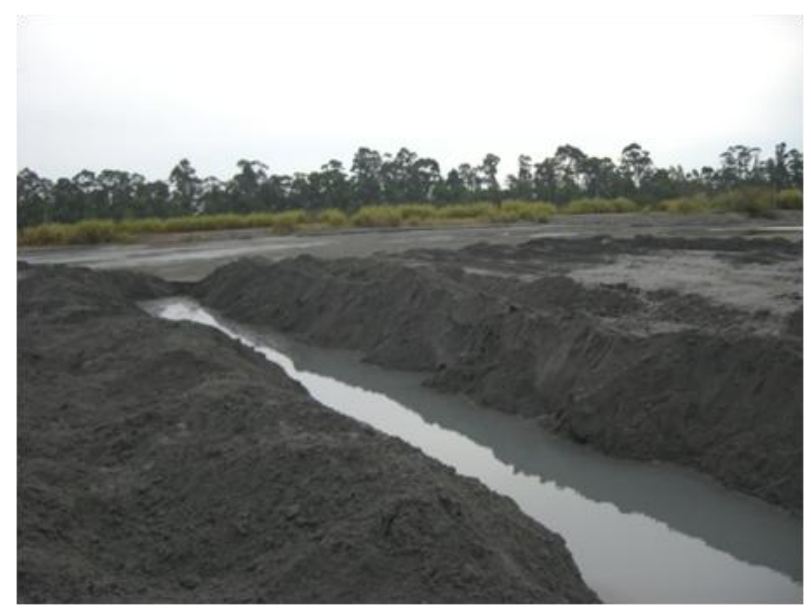

FIGURA 2 - Disposição inadequada das cinzas pesadas Fonte: Denise Alves Fungaro 
O potencial impacto para o meio ambiente e para a saúde humana por elementos perigosos das cinzas da usina Jorge Lacerda foi estudado por Quispe et al., 2012. Os poluentes derivam do armazenamento, transporte e uso dos subprodutos da combustão como materiais de construção. Os resultados indicaram que quase todos os elementos traços encontrados no carvão são transferidos para as cinzas durante a combustão e, consequentemente, a emissão dos compostos voláteis é baixa.

Estudos realizados por Silva e Boit, 2010 revelaram uma preocupação considerável com relação à inalação das nanopartículas de cinzas pesadas geradas da combustão do carvão na Usina Jorge Lacerda. Os resultados sugeriram que é necessário um monitoramento de longo prazo próximo à usina para quantificar as emissões de forma mais eficiente. É provável que a população perto da usina esteja exposta a maiores riscos de saúde ligados à toxicidade pulmonar.

\subsection{Zeólitas}

O termo "zeólita" tornou-se notável pela primeira vez quando o mineralogista sueco Alex Fredrik Cronstedt, há 250 anos, descobriu uma zeólita natural - a estilbita. Cronstedt juntou as palavras gregas, zeo - que ferve, e lithos - pedra, ou seja, pedra que ferve para generalizar a zeólita (Gianneto, 1990; Coombs et al., 1998). No entanto, o campo da química das zeólitas ficou quase estagnado por algumas décadas, até a descoberta das zeólitas sintéticas por Barrer e Milton - um dos episódios cruciais que fez das zeólitas um pilar tecnológico da nova era. A história é fascinante e ao mesmo tempo complexa. Alguns dos aspectos históricos da descoberta da zeólita estão relatados na literatura (Masters e Maschmeyer, 2011).

As zeólitas são aluminosilicatos hidratados de metais alcalinos e alcalinos terrosos (principalmente $\mathrm{Na}, \mathrm{K}, \mathrm{Mg}$, e $\mathrm{Ca}$ ), estruturados em redes cristalinas tridimensionais, compostas de tetraedros do tipo $\mathrm{TO}_{4}(\mathrm{~T}=\mathrm{Si}, \mathrm{Al}, \mathrm{Ga}$, $\mathrm{Ge}, \mathrm{Fe}, \mathrm{B}, \mathrm{P}, \mathrm{Ti}$, etc) unidos nos vértices através de átomos de oxigênio (FIG. 3) (Breck, 1984; Ghobarkar et al., 1999; Smart et al., 1992).

As zeólitas podem ser representadas pela fórmula empírica abaixo:

$\mathrm{M} x / n\left[\left(\mathrm{AlO}_{2}\right) x\left(\mathrm{SiO}_{2}\right) y\right] \cdot w \mathrm{H}_{2} \mathrm{O}$ 
onde $\mathrm{n}$ representa a valência do cátion $\mathrm{M}$, w é o número de moléculas de água, $x+y$ é o número total de tetraedros $\mathrm{SiO}_{4}$ e $\mathrm{AlO}_{4}$ por célula unitária e y/x é a razão atômica Si/Al, que pode variar de 1 até infinito (Guisnet e Ribeiro, 2004; Breck, 1984).

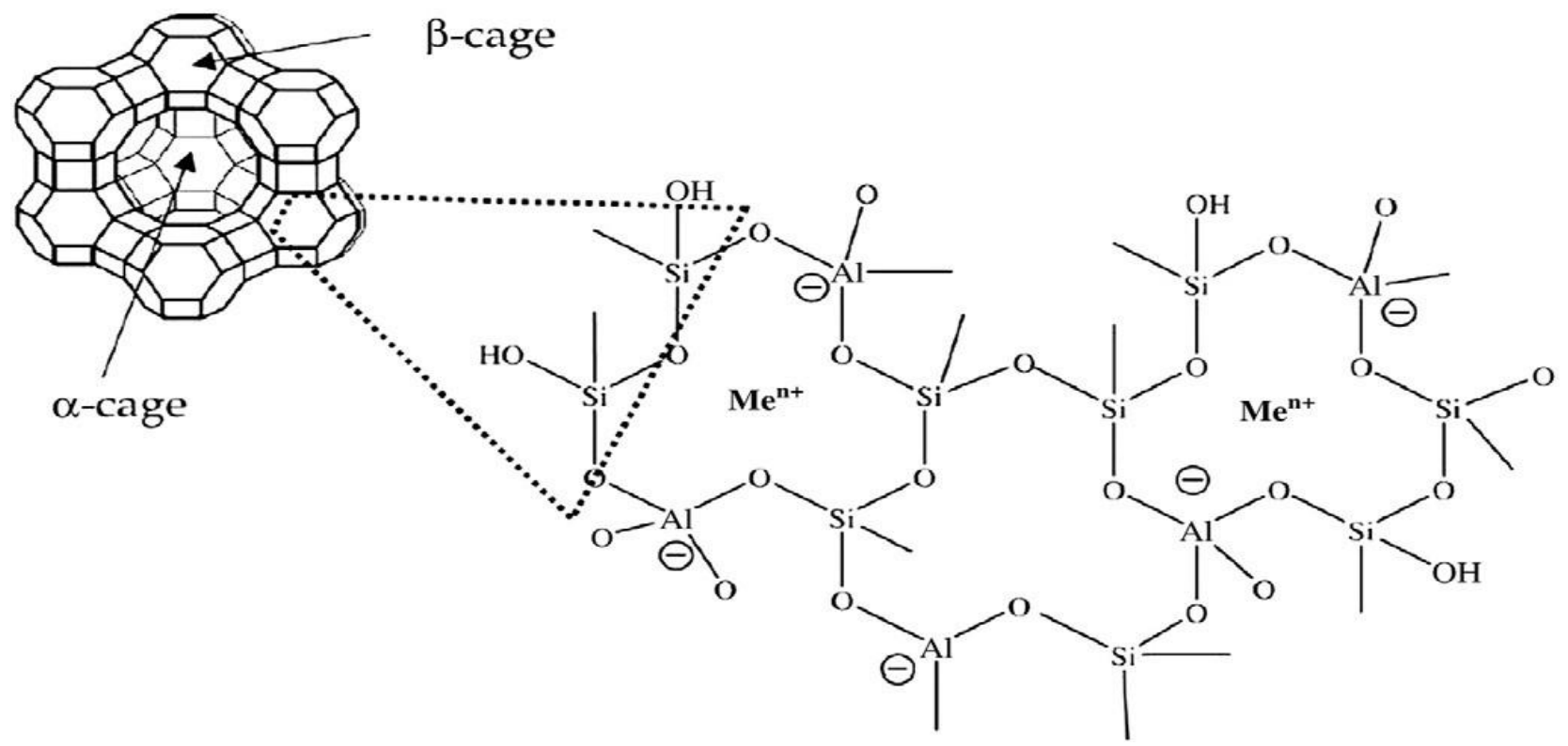

FIGURA 3 - Representações bi e tridimensionais da rede estrutural de zeólitas Fonte: Foo e Hameed, 2011

A estrutura da zeólita apresenta canais e cavidades interconectadas de dimensões moleculares, nas quais se encontram íons de compensação, moléculas de água ou outros adsorbatos e sais. Este tipo de estrutura microporosa confere à zeólita uma superfície interna muito alta, quando comparada à sua superfície externa apresentando as propriedades de adsorção, capacidade de troca iônica e catálise (Giannetto, 1990).

As zeólitas naturais são geralmente encontradas em depósitos associados com a ativação alcalina de rochas vulcânicas (Izidoro, 2008). Existem na natureza aproximadamente 40 tipos de zeólitas (International Zeolite Association, 2012). As zeólitas naturais mais comuns são analcima, chabazita, clinoptilolita, erionita, faujasita, ferrierita, heulandita, laumontita, mordenita e phillipsita (Mumpton, 1999). 
As zeólitas sintéticas são geralmente produzidas por tratamento alcalino de sílica e alumina a partir de materiais sintéticos, naturais ou residuais (Shoumkova, 2011).

A síntese convencional de zeólita envolve a cristalização hidrotérmica de soluções ou géis contendo aluminossilicatos, na presença de cátions e em condição básica (Shoumkova, 2011; Yang, 2003; Breck, 1984).

A primeira zeólita sintética, ZK-5 $\left(\mathrm{Na}_{2} \mathrm{Al}_{2} \mathrm{Si}_{4}-6 \mathrm{O}_{12^{-}}-16.6 \mathrm{H}_{2} \mathrm{O}\right)$, foi obtida no final de 1940 por Richard Barrer. O pesquisador investigou a conversão de minerais sob a ação de fortes soluções de sal em altas temperaturas (Barrer, 1982). Posteriormente, Milton desenvolveu sínteses utilizando matérias primas com maior reatividade e condições de reação mais moderadas, descobrindo a zeólita $A$ que se tornou a mais importante zeólita sintética, utilizada comercialmente como um purificador de água na indústria de detergentes, no tratamento de resíduos radioativos e no tratamento de águas residuais industriais (Shoumkova, 2011; Milton, 1959).

Atualmente, as zeólitas sintéticas são usadas mais frequentemente do que as zeólitas naturais devido à pureza dos produtos cristalinos e à uniformidade do tamanho das partículas (Ríos et al., 2012).

Devido às suas propriedades únicas, as zeólitas têm uma ampla variedade de aplicações industriais, tais como, catalisadores, adsorventes, peneiras moleculares e trocadores de íons (Breck, 1984). Nas últimas décadas, muitos artigos científicos, livros, patentes e notas técnicas, discutem a utilização da zeólita com diferentes aspectos nos processos de tratamento de água, e numerosas pesquisas de laboratório e plantas piloto estão em andamento. (Shoumkova, 2011).

A preparação de zeólitas sintéticas utilizando reagentes químicos como matéria prima apresenta um custo alto. Os custos podem ser reduzidos com a utilização de resíduos industriais, tais como as cinzas de carvão mineral geradas nas termelétricas. Estes resíduos contêm uma quantidade significativa de aluminossilicatos cristalinos e amorfos que podem ser utilizados para a produção de zeólita.

Desde o estudo de síntese da zeólita a partir de cinzas de carvão publicado em 1985 por Höller e Wirsching, muitas pesquisas foram e estão sendo desenvolvidas, com o objetivo de melhorar e otimizar os métodos de zeolitização 
utilizando cinzas leves de carvão (Izidoro, 2013; Ríos et al., 2012; Shoumkova, 2011; Ríos et al., 2009; Rayalu et al., 2006; Ríos, et al., 2006; Querol et al., 2002; Querol et al, 1997; Lin e His, 1995; Kolousek et al., 1993; Henmi, 1987).

As cinzas pesadas de carvão também podem ser utilizadas como matéria prima para a síntese de zeólitas, mas há poucos relatos na literatura.

A conversão das cinzas de carvão em zeólitas pode ser realizada de forma convencional (Ferret, 1999). O processo de síntese ocorre em três etapas, que são denominadas: dissolução, condensação e cristalização (Murayama et al., 2002).

Na FIG. 4 é mostrado um esquema da síntese de zeólita a partir do tratamento hidrotérmica das cinzas de carvão.

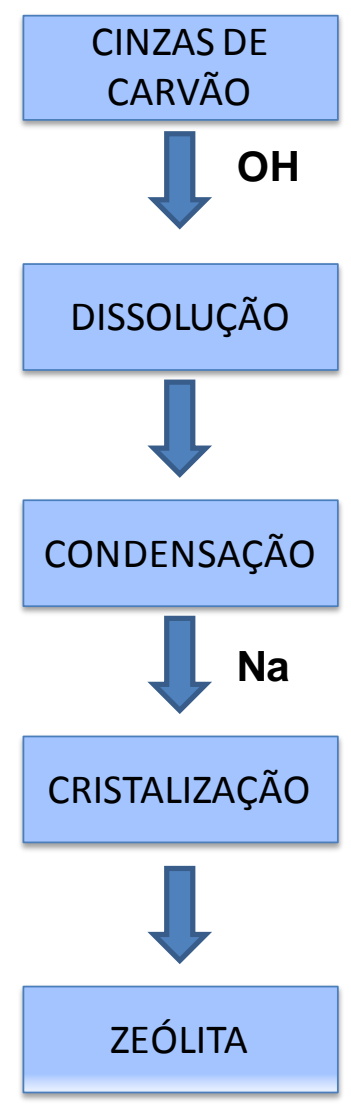

FIGURA 4 - Esquema da conversão hidrotérmica das cinzas de carvão em zeólita Fonte: Murayama et al., 2002 
A dissolução das cinzas ocorre com a elevação da temperatura (20 - $120^{\circ} \mathrm{C}$ ), e a concentração de $\mathrm{OH}^{-}$interfere significativamente na velocidade da reação. $\mathrm{Na}$ etapa de condensação ocorre a reação entre os íons aluminato e silicato com a formação de gel aluminossilicato (hidrogel). A quantidade de íons $\mathrm{Si}_{4}$ e $\mathrm{Al}_{3}$ dissolvidos diminuem rapidamente de acordo com o progresso da etapa de condensação. Em seguida, o hidrogel é transformado em cristal de zeólita. Neste estágio, a quantidade de $\mathrm{Na}^{+}$na reação alcalina controla a velocidade de cristalização. Geralmente, o processo de síntese é realizado em sistemas fechados com elevação da temperatura e durante algumas horas ou dias. $O$ rendimento e a pureza da zeólita obtida são influenciados pela composição da matéria prima e reagentes e condições de reação (Shoumkova, 2011; Murayama et al., 2002).

O tratamento hidrotérmico clássico, segundo Murayama et al., (2002), produz complexos monoméricos de sílica e alumina e a reação se processa por meio de íons complexos com cargas negativas segundo a equação:

$$
\mathrm{Si}(\mathrm{OH})_{4}+\mathrm{H}_{2} \mathrm{O}+\mathrm{OH}^{-} \leftrightarrow\left(\mathrm{H}_{2} \mathrm{O}\right) \mathrm{Si}(\mathrm{OH})^{-}
$$

Os complexos $\mathrm{Al}(\mathrm{OH})_{4}{ }^{-}$são suscetíveis à estágios de desidratação, segundo a equação:

$$
2 \mathrm{Al}(\mathrm{OH})_{4}{ }^{-} \leftrightarrow\left[(\mathrm{OH}) 3 \mathrm{Al}-\mathrm{O}-\mathrm{Al}(\mathrm{OH})_{3}\right]_{2}{ }^{-}+\mathrm{H}_{2} \mathrm{O}
$$

No processo de síntese de zeólita a partir das cinzas de carvão ocorre, portanto, uma reação de equilibrio entre a solução alcalina e a fase sólida. $\mathrm{Na}$ etapa de cristalização há a formação de várias fases de zeólita:

$$
\begin{array}{cc}
{\left[\mathrm{Na}_{\mathrm{a}}\left(\mathrm{AlO}_{2}\right)_{\mathrm{b}}\left(\mathrm{SiO}_{2}\right)_{\mathrm{e}}{ }^{*} \mathrm{HO}_{\mathrm{a}} \mathrm{N}^{*} \mathrm{H}_{2} \mathrm{O}\right] \leftrightarrow\left[\mathrm{Na}_{\times}(\mathrm{AlO} 2)_{\times}\left(\mathrm{SiO}_{2}\right)_{\mathrm{y}}\right]^{*}{ }_{\mathrm{z}} \mathrm{H}_{2} \mathrm{O}+\text { solução }} \\
\text { íon complexo } & \text { zeólita }
\end{array}
$$


Segundo estudo realizado por Umanã, 2002, os parâmetros mais importantes nos processos de zeolitização por processo hidrotérmico são a composição química da cinza, concentração e tipo do agente de ativação, a relação líquido/sólido, temperatura, tempo de reação e intensidade de agitação. Em diferentes condições experimentais é possível sintetizar, a partir de um tipo de cinzas, mais de 15 tipos de zeólita (Ríos et al., 2009; Querol et al., 2001).

Segundo Querol et al., 2002, na maioria dos estudos, a ativação das cinzas leves é realizada a temperaturas entre 100-200 C, o tempo de conversão é de 3-48 horas e a concentração de álcali é entre $0,5-5 \mathrm{~mol} \mathrm{~L}^{-1}$ e relação líquido / sólido 1-20 $\mathrm{mL} \mathrm{g}^{-1}$.

Os produtos zeolíticos do tipo A, X, Y, P, NaP1 e sodalita obtidos a partir das cinzas leves são bem conhecidos e são aplicados amplamente em indústrias (Jha e Singh, 2011). Outros tipos de zeólitas originárias das cinzas leves de carvão e suas propriedades podem ser encontrados no artigo de revisão Shoumkova, 2011.

Fansuri et al., (2010) estudaram a síntese de zeólita A a partir de cinzas pesadas de carvão. Primeiramente, as cinzas foram obtidas por tratamento hidrotérmico alcalino. Os autores estudaram o efeito do carbono não queimado na qualidade do produto.

A zeólita NaP1 foi sintetizada a partir de cinzas pesadas de carvão mineral no estudo realizado por Böer, 2013. O processo de síntese utilizado foi o hidrotérmico alcalino. O autor avaliou a eficiência da zeólita sintetizada para remoção de nitrogênio amoniacal presente nos efluentes do processo industrial de curtumes e de um aterro.

Um estudo de viabilidade econômica da conversão de cinzas de carvão em zeólita do tipo $X$ foi realizado por Ruen-ngam et al., 2009. Os resultados estimaram que o custo total por cada lote $(68 \mathrm{~g})$ de produto sintetizado foi de aproximadamente 6,50 dólares ou 96 dólares por quilograma de material zeolítico. Este valor é consideravelmente baixo quando comparado com o valor atual da zeólita X, por exemplo (243,42 dólares por $10 \mathrm{~g}$ da Sigma- Aldrich). No entanto, os custos das zeólitas de classe comercial podem variar de 25 a 80 dólares, que é menor do que o custo real de produção. Mas, apesar destes valores, o estudo foi baseado unicamente no laboratório, onde os produtos químicos eram de alta qualidade e, portanto, os valores eram mais altos. O autor sugere que, no cenário 
industrial, é provável que os resíduos das termelétricas e os produtos químicos utilizados reduzam significativamente o custo da produção.

Muitas pesquisas estão direcionadas na aplicação das zeólitas sintetizadas a partir das cinzas de carvão mineral, já que este processo apresenta baixo custo e também é ambientalmente viável. Algumas aplicações são: remoção de íons metálicos em água e em efluentes de galvanoplastia (Fungaro e Silva, 2002; Fungaro e Izidoro, 2004b; Fungaro, 2004), adsorção de íons metálicos tóxicos de águas residuárias poluídas (Pimraksa et al., 2010; Querol et al., 2002; Singer \& Bergaut, 1996; Srinivasan \& Grutzeck, 1999; Kolousek et al., 1993; Endres, 2001; Gobbi et al., 2004; Querol et al., 2001; Fungaro e Izidoro, 2006a; Izidoro e Fungaro, 2007; Fungaro e Izidoro, 2008; Izidoro, 2008; Böer, 2013), tratamento de solos (Ferret, 2004), tratamento de drenagem ácida de mina (Moreno et al., 2001; Fungaro e Izidoro, 2006b; Paprocki, 2009), como peneiras moleculares para purificação de gás (Querol et al., 2001), remoção de corantes em solução aquosa (Bruno, 2008; Fungaro e Bruno, 2009a; Fungaro e Bruno 2009b; Fungaro et al., 2009a; Fungaro et al., 2009b; Carvalho, 2010; Carvalho et al., 2010; Fungaro et al., 2010; Magdalena, 2010; Ferreira, 2011; Carvalho et al., 2011; Cunico et al., 2011; Fungaro et al., 2011; Magdalena et al., 2012; Bertolini et al., 2013).

Embora existam muitas pesquisas sobre a aplicação de zeólitas de cinzas leves na remoção de corantes, há poucos relatos na literatura sobre a utilização de zeólitas de cinzas pesadas para tal propósito.

\subsection{Zeólitas modificadas por surfactante}

Os surfactantes (do inglês surface active) são compostos que, como o nome indica, possuem atividade na superfície da interface entre duas fases, tais como a água, óleo-água, e na superfície de sólidos. Também são conhecidos como agentes tenso-ativos. Tais compostos caracterizam-se por possuir duas regiões distintas na mesma molécula: uma região polar (hidrofílica) e outra região não-polar (hidrofóbica).

O dodecil sulfato de sódio (SDS), cuja estrutura química está ilustrada na FIG. 5, é um bom exemplo desta natureza ambígua dos compostos tensoativos. Este apresenta uma longa cadeia alquílica, praticamente insolúvel em 
água, ligada covalentemente a um grupo iônico, o sulfato de sódio. Esta particularidade na estrutura química dos surfactantes é responsável pelos fenômenos de atividade na tensão superficial de interfaces, pela micelização e solubilização.

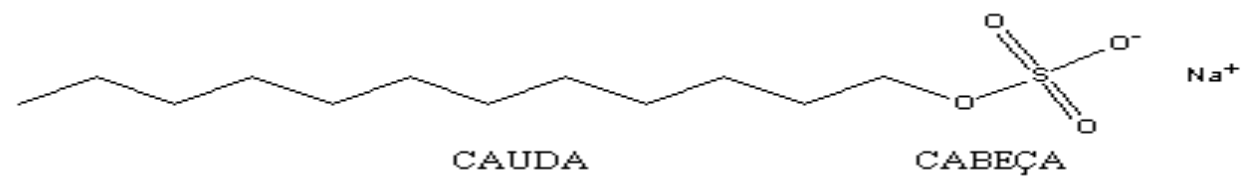

FIGURA 5 - Estrutura do surfactante dodecil sulfato de sódio (SDS): "cauda" hidrofóbica e "cabeça" hidrofílica

Uma das características comum a todos os surfactantes é a capacidade de formar agregados em solução aquosa a partir de uma determinada concentração. Estes agregados são denominados micelas. A concentração onde inicia o processo de formação das micelas (micelização) é chamada de concentração crítica micelar, CMC, que é uma propriedade intrínseca e característica do surfactante (FIG. 6).

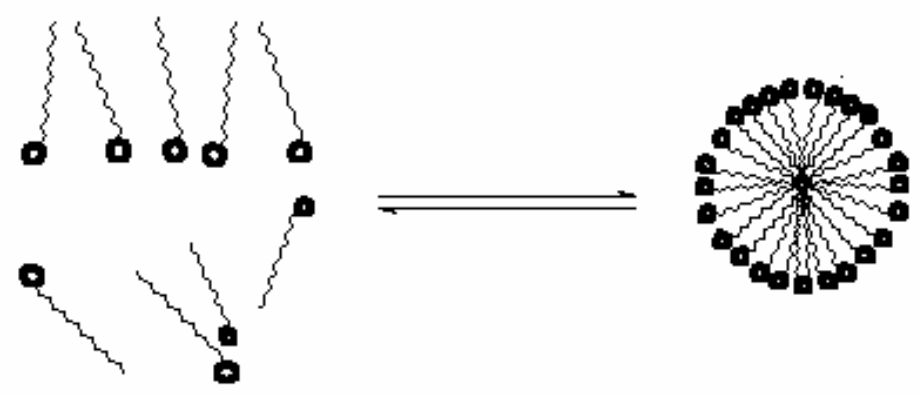

FIGURA 6 - llustração do processo de micelização do surfactante em solução aquosa. Na CMC, os monômeros livres estão em equilibrio com o surfactante micelizado 
A adsorção de surfactantes catiônicos de solução sobre superfícies sólidas foi extensivamente estudada primeiramente sob a perspectiva da flotação em processos de separação de mineral usando-se materiais que apresentavam baixa densidade de carga superficial, por ex. quartzo, silica coloidal (Bijsterbosch, 1974; Ralston e Kitchener, 1975).

Posteriormente, foram realizados estudos sobre a preparação de materiais argilosos modificados com surfactantes catiônicos e sua aplicação potencial na remediação ambiental (Boyd et al., 1988a, b e c).

A adsorção de corantes orgânicos (cristal violeta, laranja II e vermelho fenol) sobre montimorilonita modificada foi investigada. $O$ adsorvente foi modificado pelo surfactante catiônico cetilpiridínio. Os autores estudaram o efeito do $\mathrm{pH}$ e do solvente sobre a afinidade de adsorção dos corantes orgânicos sobre a montimorilonita modificada. As capacidades de adsorção dos corantes sobre o adsorvente modificado foram mais altas do que as capacidades obtidas sobre a montimorilonita não modificada (Lee et al., 2001).

Wang e Wang, (2008) avaliaram a adsorção do corante aniônico vermelho do congo (CR) de solução aquosa sobre montimorilonitas (MMT) modificadas por surfactante. Os adsorventes foram preparados usando brometo de octiltrimetilamônio (OTAB), brometo de dodeciltrimetilamônio (DTAB), brometo de cetiltrimetilamônio (CTAB) e brometo de esteariltrimetilamônio (STAB). Os resultados indicaram que as capacidades de adsorção das amostras de MMT modificadas por surfactante para CR aumentaram muito em relação aos adsorventes não modificados, e a amostra modificada com CTAB foi mais eficiente.

As zeólitas apresentam muitas das propriedades superficiais das argilas e apresentam pouca ou nenhuma afinidade por espécies aniônicas e compostos orgânicos. Sendo assim, a superfície das zeólitas pode ser modificada usando-se surfactantes catiônicos.

Segundo a literatura, as primeiras zeólitas modificadas por surfactantes catiônicos foram usadas como adsorventes para a remoção de contaminantes orgânicos como PCPE, TCE e BTX e de ânions como cromato, sulfato e selenato de solução aquosa (Haggerly e Bowman, 1994; Bowman et al., 1995).

Os surfactantes catiônicos mais usados para modificar as zeólitas são as aminas quaternárias de cadeia alquílica longa, principalmente o brometo de 
hexadeciltrimetilamônio (HDTMA-Br) devido a sua disponibilidade e baixo custo (FIG. 7). Estes compostos possuem carga permanente positiva de nitrogênios pentavalentes e alto grau de hidrofobicidade (Haggerly e Bowman, 1994; Bowman, 2003).

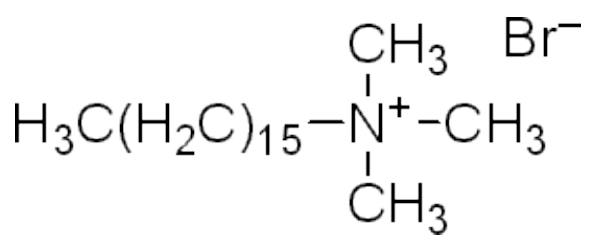

FIGURA 7- Estrutura química do brometo hexadeciltrimetilamônio

O processo de adsorção do surfactante catiônico sobre a superfície da zeólita é governado principalmente por mecanismo de troca catiônica e interações hidrofóbicas (Xu e Boyd, 1995).

Quando uma zeólita é misturada com a solução do surfactante em concentração menor do que a concentração micelar crítica (CMC), as moléculas catiônicas do surfactante formam uma monocamada na superfície externa da zeólita carregada negativamente via troca iônica. Quando a concentração do surfactante aumenta excedendo a CMC, forma-se uma bicamada via interação hidrofóbica entre as caudas do surfactante devido às forças coercivas fracas de Van der Waals. Quando ocorre a formação da bicamada completa, a carga da superfície da zeólita inverte, proporcionando locais onde os ânions serão adsorvidos e espécies neutras poderão se dividir em núcleos hidrofóbicos (Wingenfelder, 2006). A FIG. 8 apresenta a adsorção de surfactante na superfície da zeólita. 


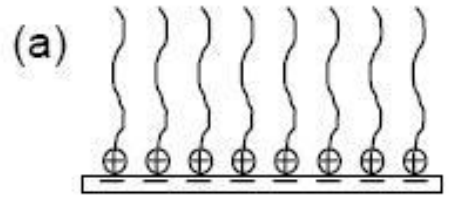

(b)

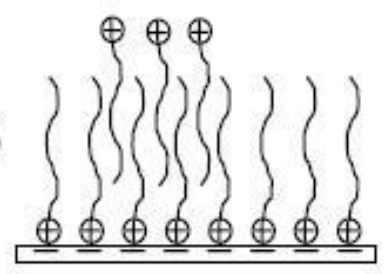

(c)

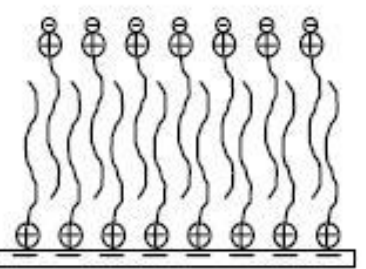

FIGURA 8 - Adsorção de surfactante na superfície da zeólita como: (a) monocamada; (b) bicamada incompleta; (c) bicamada completa onde os anions monovalentes (brometo) contrabalanceiam a carga positiva dos grupos "cabeça" que apontam para fora

Os surfactantes possuem moléculas muito largas para entrar na estrutura porosa da zeólita e, portanto, os sítios zeolíticos de troca internos permanecem disponíveis para adsorver íons catiônicos. Sendo assim, a zeólita modificada por surfactante é capaz de adsorver as principais classes de contaminantes encontrados em água: ânions, cátions, substâncias orgânicas e disruptores endócrinos simultaneamente, melhorando o custo-efetividade do produto.

Pesquisas sobre a modificação de zeólitas naturais e sintéticas por surfactantes estão em desenvolvimento com o objetivo de melhorar a qualidade da água contaminada. Os contaminantes alvos incluem metais (Chutia et al., 2009; Li et al., 2009; Matijasevic et al., 2006), poluentes orgânicos (Kuleyin, 2007; Sprynskyy et al., 2009; Zhang et al., 2007; Ranck et al., 2005), corantes orgânicos em águas residuais e soluções aquosas (Ozdemir et al., 2009; Jin et al., 2008) e organismos patogênicos (Schulze-Makuch et al., 2003). 
A adsorção de um surfactante catiônico (hexadeciltrimetilamônio) sobre amostras de zeólita natural clinoptilolita foi investigada por Guan et al., 2010. Os materiais adsorventes foram utilizados para avaliar a remoção de nitrato.

Taffarel et al. (2010) estudaram a modificação da superfície de uma zeólita natural chilena com brometo de trimetilamônio cetílico (CTAB), para investigar a eficiência de adsorção para a remoção de um surfactante aniônico em solução aquosa - dodecil benzeno sulfonato de sódio (SDBS), em escala de laboratório. A modificação da zeólita com CTAB foi baseada na capacidade de troca catiônica externa. Sugeriu-se que a adsorção do SDBS na superfície do adsorvente ocorreu devido à interação hidrofóbica entre as moléculas do CTAB e as frações de surfactante.

Pesquisadores realizaram um estudo utilizando zeólita natural chinesa modificada por surfactante. Os resultados apresentaram uma alta eficiência na remoção de ácido tânico a partir de solução aquosa em relação à zeólita não modificada. O principal mecanismo suposto é o de interação hidrofóbica (Lin et al., 2011).

Apesar dos estudos encontrados na literatura sobre a modificação e posterior utilização das zeólitas naturais, um enfoque especial é dado para as pesquisas que utilizam zeólitas de cinzas de carvão modificadas por surfactante. Existem poucos estudos desses materiais zeolíticos sintetizados, principalmente aqueles obtidos a partir das cinzas pesadas de carvão.

Li et al., (2011) sintetizaram duas zeólitas a partir de cinzas leves de carvão e, em seguida, as mesmas foram modificadas utilizando o surfactante hexadeciltrimetilamônio (HDTMA). Ambas as zeólitas foram investigadas quanto à sua capacidade em adsorver ácido húmico em água. Os resultados indicaram que, após a modificação das zeólitas, a capacidade de adsorção aumentou.

Fungaro e Borrely, (2012) estudaram zeólitas sintetizadas a partir de cinzas leves de carvão modificadas com diferentes concentrações (2 e $20 \mathrm{mmol}^{-1} \mathrm{~L}^{-1}$ ) de brometo de hexadeciltrimetilamônio (HDTMA-Br). A zeólita não modificada (ZNM) e as zeólitas modificadas por surfactante (ZMS) foram caracterizadas por fluorescência de raios $X$, difração de raios $X$, espectroscopia no infravermelho com transformada de Fourier (FTIV), microscopia eletrônica de varredura, análise termogravimétrica e métodos físico-químicos. De acordo com os resultados de $\mathrm{pH}$ de ponto de carga zero, as cargas negativas observadas 
para as zeólitas em água indicaram a formação de bicamada incompleta no processo de adsorção do surfactante na superfície dos adsorventes. Desta forma, terão sítios ativos de troca carregados negativamente disponíveis. As caracterizações mineralógica e estrutural das zeólitas de cinzas de carvão modificadas mostraram que ocorreu o processo de adsorção sem que houvesse alteração da natureza cristalina e estrutural da zeólita que serviu como matéria prima.

Estudos foram realizados por Xie et al., (2012) utilizando zeólita modificada por surfactante (hexadeciltrimetilamônio) a partir de cinzas leves de carvão. A remoção de compostos fenólicos ionizáveis (fenol, p-clorofenol e bisfenol A) e compostos orgânicos não-ionizáveis (anilina, nitrobenzeno e naftaleno) foi avaliada. A capacidade de adsorção do adsorvente modificado foi alta para todos os compostos fenólicos. A adsorção de compostos ionizáveis dependeu fortemente do $\mathrm{pH}$, aumentando em condições de $\mathrm{pH}$ alcalino. Contudo, a adsorção de compostos não ionizáveis foi essencialmente a mesma em todos os níveis de $\mathrm{pH}$ estudados. Os contaminantes orgânicos com maior hidrofobicidade são mais facilmente adsorvidos pela zeólita modificada.

A remoção de diferentes tipos de poluentes em água, tais como amônio, fosfato e ácido húmico foi investigada utilizando zeólita modificada. 0 material adsorvente foi sintetizado a partir de cinzas leves de carvão e posteriormente foi modificado por quitosana. Os resultados mostraram uma melhor adsorção de fosfato sobre a zeólita modificada, quando comparado com a zeólita não modificada, e uma remoção alta de amônio foi observada. Apesar da zeólita de cinzas leves apresentar pouca afinidade por ácidos orgânicos, a modificação por quitosana melhorou em grande parte o desempenho da adsorção (Xie et al., 2013).

Fungaro et al., (2013) investigaram as capacidades de adsorção de zeólita modificada para remover Laranja Reativo 16, um corante azo, a partir de solução aquosa. A zeólita foi sintetizada a partir de cinzas leves de carvão e em seguida foi modificada com a utilização do surfactante brometo de hexadeciltrimetilamônio. Uma série de experiências foi realizada para examinar os efeitos do tempo de contato, o pH da solução, e a massa do adsorvente na remoção de corante. Os resultados indicaram que a zeólita modificada foi mais eficiente na adsorção do corante em relação à zeólita não modificada. 


\subsection{Corantes}

Os corantes são usados desde o princípio das civilizações. Sua presença foi detectada no Egito (2500 a.C.), em amostras de tecidos de tumbas. Registros históricos indicam que os corantes eram extraídos de vegetais, frutas, flores, insetos e moluscos (Zanoni e Carneiro, 2001; Kant, 2012). O primeiro corante orgânico sintético, mauve, foi descoberto em 1856 pelo químico William H. Perkin. A partir deste fato, as pesquisas aumentaram e, consequentemente, a produção e aplicação de corantes também (Gupta e Suhas, 2009; Mathur et al., 2012).

Os corantes têxteis são compostos orgânicos que possuem a capacidade de conferir uma determinada cor a uma fibra (substrato). A molécula de corante é constituída por duas partes principais: o grupo cromóforo, que dá a cor ao composto, e grupos auxiliares (auxocromos), que facilitam a sua afinidade para o substrato e que são responsáveis pela fixação à fibra (ABIQUIM, 2013).

Os corantes são compostos complexos, que apresentam considerável diversidade estrutural e são raramente identificados por uma fórmula química. Geralmente são utilizados nomes comerciais utilizando o Colour Index (CI), publicação da American Association of Textile Chemists and Colorists e da British Society of Dyers and Colorists, que contém uma lista organizada de nomes e números para designar os diversos tipos. Colour Index $(\mathrm{Cl})$ determina as propriedades do corante, tais como adequação para o tingimento de um substrato específico e as propriedades de solidez dos produtos tingidos. Os números de Colour Index são atribuídos quando a estrutura química é definida e conhecida (Mathur et al., 2012; ABIQUIM, 2013; Gupta e Suhas, 2009).

A classificação dos corantes pode ser realizada de acordo com sua estrutura química ou de acordo com o modo de fixação da molécula na fibra (Gupta e Suhas, 2009; Guaratini e Zanoni, 2000).

Com base na estrutura química do grupo cromóforo, os corantes são classificados como azo, antraquinona, trifenilmetano, heterocíclico e corantes poliméricos (ABIQUIM, 2013; Zanoni e Carneiro, 2001). Cabe ressaltar que os corantes azos são mais utilizados e representam $65-70 \%$ do total de corantes produzidos (Gupta e Suhas, 2009).

Os principais grupos de corantes classificados pelo modo de fixação à fibra são: reativos, diretos, azóicos, ácidos, básicos, a cuba, dispersivos, de 
enxofre, pré-metalizados, branqueadores (Gupta e Suhas, 2009; Robinson et al., 2001; Zanoni e Carneiro, 2001).

De acordo com o índice de cor (IC), que é gerido pela sociedade de tintureiros e coloristas, atualmente mais de 10.000 tipos de corantes são sintetizados e disponíveis em todo o mundo (Elkady et al., 2011).

Entre todos os setores industriais, a indústria têxtil é classificada como uma das maiores fontes poluidoras do meio ambiente no mundo, considerando o volume descarregado e a composição do efluente (Gümüs e Akbal, 2010). Segundo uma pesquisa realizada na década de 80, estimou-se que 280.000 toneladas de corantes têxteis foram descartadas anualmente nos efluentes industriais do mundo todo (Saratale et al., 2011; Jin et al., 2007).

O processo têxtil requer uma grande quantidade de água. O consumo diário de água de uma fábrica de tamanho médio com uma produção de cerca de $8000 \mathrm{~kg}$ de tecido por dia é de cerca de 1,6 milhões de litros, e a consequência é a descarga de grandes quantidades de efluentes. A quantidade anual de efluente têxtil gerado está estimada em 200 bilhões de litros (Kant, 2012).

Os efluentes têxteis são considerados um resíduo tóxico perigoso, são coloridos e contêm produtos químicos orgânicos, apresentando efeito adverso sobre todas as formas de vida. A FIG.9 mostra o descarte de corante em corpo d'água.

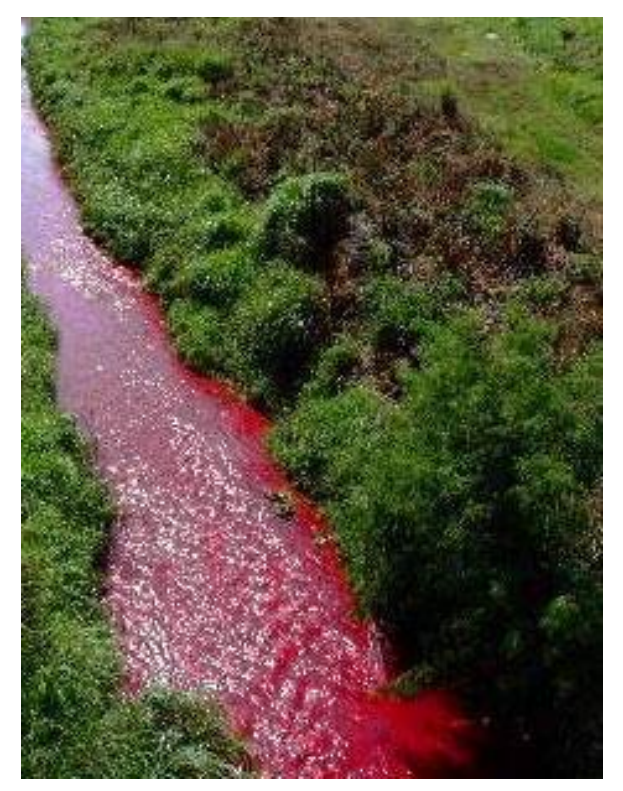

FIGURA 9 - Descarte de corante em rio Fonte: http://www.rc.unesp. br/biosferas 
Os corantes podem causar irritação na pele e nos olhos, e aproximadamente $40 \%$ dos corantes utilizados mundialmente contêm agentes cancerígenos (Kant, 2012). Além disto, podem prejudicar os processos de metabolismo biológicos, destruindo as comunidades aquáticas presentes no ecossistema (Gupta e Suhas, 2009).

A descarga de efluentes a partir de indústrias têxteis e de corantes tem causado atualmente grandes preocupações de saúde para as agências reguladoras ambientais. A remoção da cor, especificamente, tornou-se interesse científico, como indicado por uma multiplicidade de relatórios de investigação sobre este tema (Mathur et al., 2012). Vários países têm adotado legislações ambientais na produção de têxteis (Ventura-Camargo e Marin-Morales, 2013).

No Brasil, o Conselho Nacional do Meio Ambiente (CONAMA) estabelece na Resolução no 357 de 17 de março de 2005 (artigos 14, 15 e 16) que não é permitida a presença, em corpos de água das classes 1, 2 e 3, de corantes provenientes de fontes antrópicas que não sejam removíveis por processos de coagulação, sedimentação e filtração convencionais.

\subsubsection{Corantes Cristal Violeta e Ácido Laranja 8}

Para avaliar o uso dos materiais zeolíticos de cinzas de carvão na remoção de corantes básico e ácido de efluente aquoso, os corantes cristal violeta e ácido laranja 8 foram escolhidos como modelo. As características gerais e as estruturas moleculares de ambos corantes encontram-se na (TAB. 1) e nas (FIG. 10 e 11).

TABELA 1- Características Gerais do Cristal Violeta e Ácido Laranja 8

\begin{tabular}{ccc}
\hline & Cristal Violeta & Ácido Laranja 8 \\
\hline Nome genérico & $\mathrm{Cl} 42555$ & $\mathrm{Cl} 15575$ \\
Grupos Cromóforos & $-\mathrm{C}=\mathrm{C}-;-\mathrm{C}=\mathrm{N}-;$ Anel & $-\mathrm{N}=\mathrm{N}-$ \\
Absorbância Amax. $(\mathrm{nm})$ & quinóide & \\
Massa Molecular & 590 & 488 \\
Fórmula Química & $408 \mathrm{~g} / \mathrm{mol}$ & $364 \mathrm{~g} / \mathrm{mol}$ \\
Classe & $\mathrm{C}_{25} \mathrm{H}_{30} \mathrm{~N}_{3} \mathrm{Cl}$ & $\mathrm{C}_{17} \mathrm{H}_{13} \mathrm{~N}_{2} \mathrm{NaO}_{4} \mathrm{~S}$ \\
Tipo & básico & ácido \\
& catiônico & aniônico \\
\hline
\end{tabular}




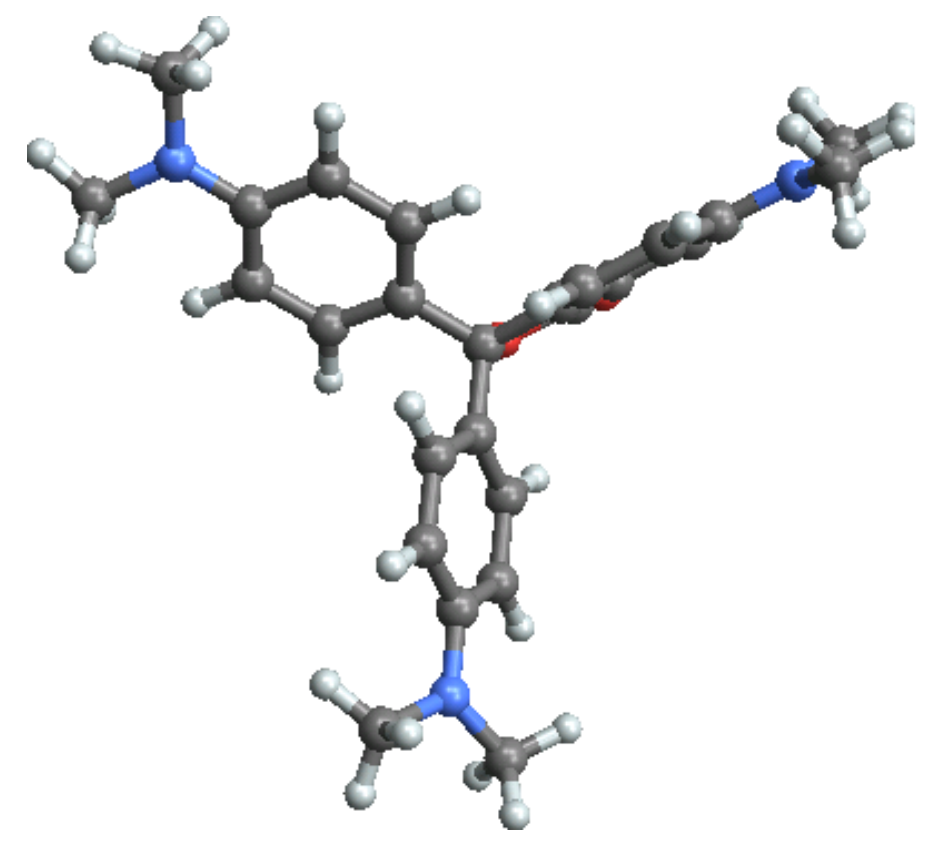

FIGURA 10 - Estrutura molecular tridimensional (3D) do CV (cinza = átomos de carbono; branco = átomos de hidrogênio; azul = átomos de nitrogênio; vermelho = dupla ligação carbono-carbono)

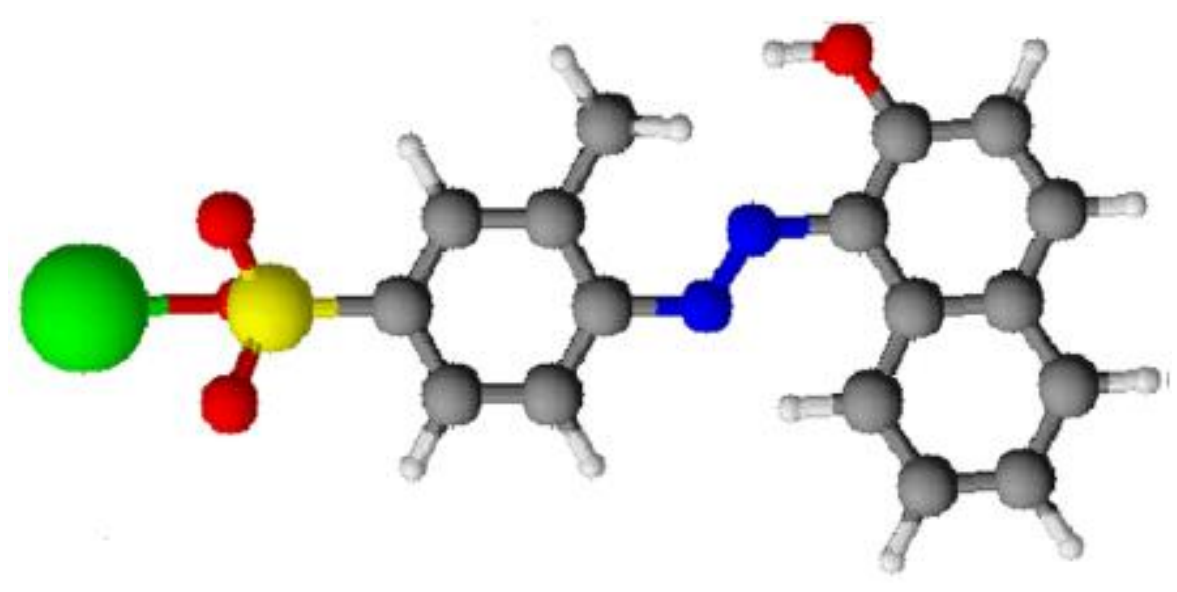

FIGURA 11 - Estrutura molecular tridimensional (3D) do AL8 (cinza = átomos de carbono; branco = átomos de hidrogênio; vermelho = átomos de oxigênio; azul = átomos de nitrogênio; amarelo = átomos de enxofre e verde = átomos de sódio 
O corante Cristal Violeta (CV) é também conhecido como Violeta básico 3, Violeta genciana e Violeta de Metila 10B, pertencendo ao grupo dos triarilmetanos. O seu nome IUPAC é N-[4-[bis-[4-dimetilamino)-fenil]-metileno] 2,5-ciclohexadieno-1-ilidino]-N- cloreto de metilmetanamínico (Mittal et al., 2010). Essa substância é amplamente utilizada desde 1890 na medicina e como corante em processos industriais (BALANOVA, 2003).

As aplicações do CV são muitas. O mesmo pode ser utilizado como um indicador de $\mathrm{pH}$, é ingrediente ativo na coloração de GRAM na comunidade médica e é empregado como um agente bacteriostático. O corante é usado externamente como desinfetante da pele em seres humanos. O CV é usado na criação de animais e na prática veterinária e como um aditivo para rações de aves para inibir a propagação de fungos e parasitas intestinais (Kumar et al., 2010; Kumar e Ahmad, 2011). É amplamente usado como corante roxo para têxteis tais como algodão e seda, e em tintas de impressão (Kumar et al., 2010; Chakraborty et al., 2011).

Assim como todos os corantes comerciais, o corante cristal violeta não é completamente absorvido nos processos industriais e seus resíduos são descartados nos rios e lagos.

O cristal violeta é pouco metabolizado pelos microorganismos, não é biodegradável e pode persistir em diversos ambientes, sendo considerada como uma molécula recalcitrante (Chakraborty et al. , 2011).

Segundo estudo realizado por Chakraborty et al., 2011, o corante é altamente citotóxico e carcinogênico para células de mamíferos. A exposição aguda ao CV pode causar irritação na pele, no trato digestivo e pode também, em casos extremos, levar à insuficiência respiratória e renal e cegueira permanente (Saeed et al.; 2010).

De acordo com um estudo realizado por Malachová et al., 2006, o corante cristal violeta foi considerado mutagênico.

Existem muitos estudos na literatura que relatam a remoção do cristal violeta de meio aquoso utilizando métodos químicos e físicos, incluindo adsorção, precipitação química e floculação, oxidação por cloro, peróxidos de hidrogênio e ozônio, eletrólise e outros. Alguns estudos sobre a remoção do corante utilizando o método de adsorção serão relatados. 
A remoção do cristal violeta em efluente foi avaliada por Mohan et al., (2002). As cinzas leves de carvão foram utilizadas como adsorvente de baixo custo. Os estudos de adsorção foram realizados para diferentes temperaturas, tamanhos de partícula, $\mathrm{pH}$ e quantidade de adsorvente. A remoção foi inversamente proporcional ao tamanho das partículas das cinzas leves. As formas lineares e não lineares dos modelos de Langmuir e Freundlich ajustaram-se aos dados de adsorção. As análises indicaram que a isoterma de Freundlich ajustouse melhor aos dados do que a isoterma de Langmuir. Além disso, os dados correlacionaram-se melhor com a forma não linear do que com a forma linear. Parâmetros termodinâmicos tais como energia livre, entalpia e entropia de adsorção do sistema corante/adsorvente também foram avaliados. Os valores negativos de energia livre indicaram que o processo foi espontâneo, e os valores positivos de entalpia indicaram processo endotérmico. O processo de adsorção do cristal violeta seguiu o modelo cinético de pseudo-primeira-ordem. A capacidade de adsorção do material investigado foi comparável com a de outros adsorventes comercialmente disponíveis usados para a remoção de corantes catiônicos de efluente.

Özdemir et al., (2006) realizaram testes em batelada para remover o cristal vileta de solução aquosa usando sepiolita como um adsorvente. As variáveis operacionais estudadas foram $\mathrm{pH}$, força iônica e temperatura. $\mathrm{O}$ equilíbrio do processo de adsorção foi alcançado dentro de $3 \mathrm{~h}$. A quantidade do corante adsorvida aumentou com o aumento do $\mathrm{pH}$, força iônica e temperatura. Os dados experimentais foram analisados pelas isotermas de Langmuir e Freundlich. O modelo que melhor se ajustou foi o de Langmuir. Além disso, para a remoção do cristal violeta, um reator em batelada foi projetado. Os dados de adsorção mostraram que o processo foi eficiente e de natureza física.

A remoção do corante cristal violeta sobre cinzas pesadas de carvão e óleo de bagaço de soja foi investigada por Mittal et al., (2010). Experimentos em batelada foram realizados para descrever o impacto de parâmetros tais como $\mathrm{pH}$, quantidade de adsorvente, concentração do corante, temperatura e tempo de contato sobre a remoção do corante. Os dados experimentais foram modelados pelas isotermas de Langmuir, Freundlich, Tempkin e Dubinin-Radushkevich (D-R). Os parâmetros termodinâmicos (energia livre, entalpia e entropia) foram avaliados para os sistemas corante/adsorvente, os quais revelaram que o processo de 
adsorção é endotérmico. Os modelos cinéticos de pseudo-primeira e segundaordem foram aplicados aos dados experimentais e a cinética de pseudo-segundaordem descreveu a adsorção do corante cristal violeta sobre os adsorventes. Para alcançar uma maior remoção do corante, operações utilizando coluna foram realizadas.

Gandhimathi et al., (2012) avaliaram a remoção do cristal violeta em solução aquosa em sistemas simples e terciário. As cinzas pesadas provenientes da usina termelétrica Neyveli Lignite Corporation Limited, localizada em Neyveli (Índia) foram utilizadas como material adsorvente. As características superficiais das cinzas pesadas foram investigadas por meio da análise de Infravermelho com Transformada de Fourier. A eficiência de remoção das cinzas pesadas aumentou com o aumento da massa do adsorvente até atingir o equilíbrio. No estudo cinético, o modelo de pseudo-segunda-ordem ajustou-se melhor aos dados experimentais. Os autores observaram que a capacidade de adsorção das cinzas pesadas diminuiu no sistema terciário em comparação com o sistema simples. Os modelos das isotermas de Langmuir e Freundlich foram utilizados e o modelo que melhor se ajustou foi o de Freundlich.

O Ácido Laranja 8 (AL8) pertence à família dos corantes azo, os quais representam mais de $50 \%$ da produção mundial de um milhão de toneladas por ano. Os corantes azo são constituídos de um ou mais grupos azo (-N=N-), ligados aos radicais fenil e naftol, os quais são substituídos com algumas combinações de grupos funcionais incluindo: aminoácidos $\left(-\mathrm{NH}_{2}\right)$, cloro $(-\mathrm{Cl})$, hidroxila $(-\mathrm{OH})$, metila $\left(-\mathrm{CH}_{3}\right)$, nitro $\left(-\mathrm{NO}_{2}\right)$, o ácido sulfônico e sais de sódio $\left(-\mathrm{SO}_{3} \mathrm{Na}\right)$ (Ventura-Camargo e Marin-Morales, 2013).

O AL8 é um importante corante no mercado têxtil. Como um eletrólito forte, é completamente dissociado sob condições ácidas utilizadas no processo de tingimento. Este corante é aplicado principalmente no tingimento de couro e lã e na coloração de papel, o que torna seus resíduos uma importante questão econômica (Elizalde-González e García-Díaz, 2010).

O AL8 não possui excelentes propriedades colorísticas entre os corantes ácidos monoazos, mas distingue-se pelo brilho de seu tom e particularmente baixo custo de produção.

O AL8 existe como uma mistura nas formas tautoméricas (FIG. 12) azo e hidrazona em solução aquosa. O equilíbrio favorece a última forma, devido à 
boa estabilidade (Ball e Nicholls, 1982; Leiw et al., 2013). Na forma azo o corante é denominado como 3-metil-4-(2-hidroxi-1-naftilazo) ácido benzeno sulfônico de sódio e na forma hidrazona como 3-metil-4-[N'-(2-oxo-2H-naftaleno-1-ilideno)hidrazino] - ácido benzeno sulfônico de sódio (Elizalde-González e García-Díaz, 2010).

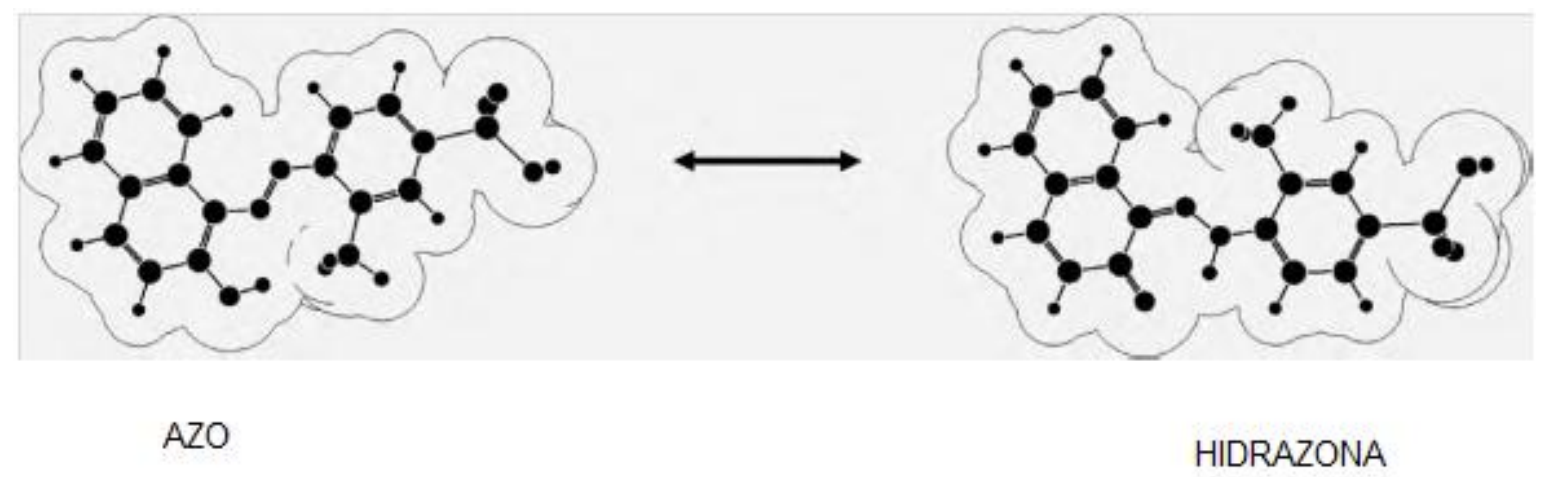

FIGURA 12 - Equilíbrio entre os tautômeros azo-hidrazona em solução aquosa de AL8

A forma hidrazona do AL8 é resistente à oxidação e à foto-oxidação química. O AL8 é facilmente reduzido para aminas primárias, e estes compostos são potencialmente mutagênicos e carcinogênicos (Guaratini e Zanoni, 2000; Elizalde-González e García-Díaz, 2010). No entanto, a toxicidade do AL8 não tem sido relatada.

$\mathrm{Na}$ indústria têxtil, os problemas ambientais predominantes estão relacionados com o uso de corantes do tipo azo (Mathur et al., 2012). A maioria dos corantes pertencentes a este grupo é altamente resistente à degradação natural e apresentam potencial tóxico em diferentes organismos (Guaratini e Zanoni, 2000; Chequer et al., 2011). Além dos problemas relacionados com compostos tóxicos, os efluentes provenientes dos processos contendo estes corantes têm coloração forte, causando desta forma, problemas para toda a biota aquática, já que os processos de fotossíntese são prejudicados.

Existem discussões sobre o impacto ambiental e a toxicidade dos azocorantes em artigos de revisão (Mathur et al., 2012;). No Brasil, por exemplo, estudos têm demonstrado a presença de corantes azo em diferentes amostras de 
água e sedimentos. Os resultados de um estudo realizado por Umbuzeiro et al., 2004 indicaram uma atividade mutagênica baixa a moderada no Ribeirão dos Cristais em Cajamar, no estado de São Paulo, devido à presença de corantes azo, compostos nitroaromáticos e aminas aromáticas. Um estudo utilizando amostras do efluente de uma indústria de tinturaria, da água bruta e da água da estação de tratamento foi realizado por Umbuzeiro et al., 2005. Os resultados indicaram a presença de corantes em todas as amostras, apresentando mutagenicidade, principalmente a água bruta, que além de corantes, apresentava compostos nitroaromáticos policíclicos incolores, possivelmente gerados durante o tratamento do efluente.

A mutagenicidade e a carcinogenicidade do efluente gerado por uma indústria têxtil contendo diversos corantes incluindo três corantes da família azo foram avaliadas por Lima et al., 2007. Os resultados confirmaram que o efluente era potencialmente carcinogênico e apresentava risco para os seres humanos expostos de forma crônica à ingestão de água. $O$ autor discutiu que o método de tratamento do efluente utilizado pela fábrica em questão não foi eficiente para remover completamente os compostos perigosos.

Vários países, como Alemanha, Suécia, França, Portugal e Dinamarca, têm adotado legislação ambiental no uso dos corantes do tipo azo (VenturaCamargo e Marin-Morales, 2013).

Existem poucos estudos na literatura sobre a remoção do AL8 em meios aquosos.

Aleboyeh et al., (2003) investigaram a descoloração fotoquímica oxidativa do corante ácido laranja 8 por meio de processo UV/ peróxido de hidrogênio. A descoloração foi completa em tempo relativamente curto e o processo seguiu uma cinética de pseudo-primeira-ordem. Verificou-se que a taxa de descoloração aumenta com o aumento do volume inicial de $\mathrm{H}_{2} \mathrm{O}_{2}$ até um valor crítico.

A adsorção do Ácido Laranja 8 sobre clinoptilolita modificada por surfactante foi estudada em sistema de batelada por Karadag (2007). O brometo de hexadeciltrimetilamônio foi usado para modificação da superfície da clinoptilolita. Os efeitos do pH, concentração inicial e tempo de contato sobre a adsorção foram avaliados. O tempo de equilíbrio foi atingido aos $20 \mathrm{~min}$. Os dados de equilíbrio de adsorção foram analisados pelas equações das isotermas 
de Langmuir, Freundlich e Redlich-Peterson, Koble-Corrigan usando análise por regressão não linear. As análises mostraram que os dados se ajustaram melhor ao modelo de Koble-Corrigan. A adsorção foi analisada com a utilização de modelos de pseudo-primeira-ordem e pseudo-segunda-ordem e o modelo de pseudo-segunda-ordem ajustou-se melhor aos dados experimentais. O processo de adsorção foi controlado pela transferência de massa externa e por difusão intrapartícula.

Dávila-Jiménez et al., (2009) estudaram a remoção do corante ácido laranja 8 utilizando o processo de adsorção. Dois adsorventes carbonáceos utilizados foram preparados a partir da casca da semente de manga. A eficiência de adsorção foi determinada não só pelas características químicas e texturais dos adsorventes, mas também pelas propriedades do corante: tamanho, espécies iônicas e polaridade. O carbono com maior superfície específica foi o mais eficiente na adsorção do corante em concentração baixa.

Um estudo de adsorção do corante ácido laranja 8 sobre carvão ativado foi realizado por Elizalde-González e Garcia-Diaz, (2010). As condições para a adsorção do corante ácido laranja 8 sobre o carvão com uma baixa área superficial foram otimizadas usando o método de Taguchi. Quatro amostras de carvão ativado foram obtidas a partir de sementes de goiaba, e as mesmas foram caracterizadas pelas isotermas de adsorção de nitrogênio. Para alcançar máxima remoção do corante, os efeitos de temperatura $\left(10-40^{\circ} \mathrm{C}\right)$, área específica (67-143 $\left.\mathrm{m}^{2} \mathrm{~g}^{-1}\right)$, concentração inicial (250-1500 $\left.\mathrm{mgL}^{-1}\right), \mathrm{pH}(2-13)$ e a relação massa/volume (10-150 $\left.\mathrm{gL}^{-1}\right)$ foram estudados. $\mathrm{O} \mathrm{pH}$ foi o fator mais eficaz para remoção do corante, seguido da relação massa/volume. Uma temperatura de $10^{\circ} \mathrm{C}$, uma área específica de $114 \mathrm{~m}^{2} \mathrm{~g}^{-1}$, uma concentração inicial de $500 \mathrm{mg} \mathrm{L}^{-1}$, pH 2 e uma relação massa/volume de $150 \mathrm{~g} \mathrm{~L}^{-1}$ foram as melhores condições determinadas pelo método Taguchi. O material adsorvente foi testado usando amostras de soluções de efluente real e sintético e as eficiências de remoção de cor foram de $60 \%$ e $40 \%$, respectivamente.

Konicki et al., (2013) avaliaram o processo de adsorção para remoção do corante ácido laranja 8 de solução aquosa. Neste estudo, o adsorvente foi preparado a partir de núcleo de concha mesoporosa estruturada em esfera de sílica. O adsorvente obtido foi denominado nanoesferas ocas de carbono mesoporoso. $\mathrm{O}$ adsorvente foi caracterizado por difração de raios $\mathrm{X}$, microscopia 
eletrônica de transmissão, espectroscopia de Raman, espectroscopia de infravermelho com transformada de Fourie, área superficial específica e potencial zeta. Os efeitos da concentração inicial do corante, temperatura e pH sobre a capacidade máxima de adsorção foram estudados. Observou-se um tempo de equilíbrio de 90 minutos. Os dados experimentais foram analisados pelos modelos de Langmuir e Freundlich. O modelo de Langmuir ajustou-se melhor aos dados experimentais. Os dados do estudo cinético foram analisados utilizando-se os modelos de pseudo- primeira ordem pseudo- segunda ordem e do modelo de difusão intrapartícula. O processo seguiu o modelo de pseudo-segunda ordem. Os parâmetros termodinâmicos (energia livre, entalpia e entropia) foram calculadas e indicaram que o processo de adsorção foi espontâneo e de natureza exotérmica.

A remoção do corante ácido laranja 8 em solução aquosa foi investigada por Leiw et al., (2013). Os autores investigaram a degradação do poluente orgânico utilizando o óxido de metal estrôncio ferrita por meio do método de oxidação avançada em ambiente escuro sem qualquer estimulante externo. As partículas de óxido foram sintetizadas a partir de uma reação convencional a alta temperatura e alta energia e processo de moagem. $O$ material foi caracterizado usando difração de raios $X$, microscopia eletrônica de varredura, área superficial específica e potencial zeta. Observou-se uma rápida descoloração do ácido laranja 8 (60 min) e desarranjo completo. Análises cromatográficas confirmaram a degradação do corante em ácidos carboxílicos alifáticos simples.

\subsection{Tratamentos de efluentes têx teis}

A seleção de um método de tratamento de efluente têxtil é uma tarefa complexa que envolve muitos fatores que incluem o espaço disponível para a construção de instalações, confiabilidade dos equipamentos, restrições de eliminação de resíduos, qualidade desejável da água e custos operacionais (Bhatnagar e Sillanpää, 2010).

Ainda não existe um método padrão para a descoloração de efluentes aquosos da indústria têxtil. Os métodos mais utilizados podem ser agrupados nas três categorias: químicos, físicos e biológicos. Algumas das metodologias são: sedimentação (Gupta e Suhas, 2009), filtração (Gupta e Suhas, 2009; 
He et al., 2013), tratamento químico (Gupta e Suhas, 2009; Khandegar e Saroha, 2013; Lee et al., 2012), oxidação, eletroquímica, processos avançados de oxidação (PAOs) e tratamento biológico (Gupta e Suhas, 2009). O tratamento realizado exclusivamente por uma destas três categorias provou ser ineficiente para remover a cor e outros poluentes de águas residuais têxteis. A combinação de vários métodos de tratamento de efluentes pode remover mais de $85 \%$ de elementos poluentes (Kant, 2012), mas não é muito viável devido à variação das características dos efluentes, sendo necessários pré-tratamentos físicos ou físicoquímicos dispendiosos (Körbahti e Tanyolac, 2008). A presença de coloração e de possíveis impurezas excedentes no final do tratamento torna necessário um método complementar no processo (Kant, 2012).

No Brasil, especificamente no Estado de São Paulo, a maioria das indústrias de tingimento utiliza lodo ativado para tratar seus efluentes. No entanto, alguns estudos mostraram que este tipo de tratamento não é eficiente para remover todos os corantes e as aminas aromáticas presentes em efluentes industriais (Ventura-Camargo e Marin-Morales, 2013).

Pesquisas desenvolvidas no mundo todo estão em busca de processos eficientes e economicamente viáveis para diminuir o impacto da poluição gerada pela indústria têxtil. Além dos métodos já mencionados, o processo de adsorção está se tornando uma alternativa superior, por razões de custo, eficiência, praticidade e facilidade de operação (Gupta e Suhas, 2009; Ahmaruzzaman, 2011).

Um exemplo típico de tratamento de efluente pode apresentar várias etapas: preliminar e estágios primário, secundário e terciário. A fase preliminar inclui equalização e neutralização. O estágio primário envolve triagem, sedimentação, flotação, e floculação. O secundário reduz a carga orgânica e facilita a separação física / química (oxidação biológica). A última fase é centralizada na remoção da cor (Allegre et al., 2006; Hessel et al., 2007), e geralmente é empregado o método de adsorção em carvão ativado (Al-Degs et al., 2009).

O processo de adsorção tem sido aplicado para tratamento como um único estágio, principalmente para a remoção de corantes em efluentes simulados, ou em um modo combinado para a descoloração total de efluentes reais (Kyzas et al., 2011). 


\subsection{Adsorção}

A adsorção é um processo de transferência de massa que envolve a concentração de substâncias na interface das duas fases, como por exemplo, uma superfície sólida num ambiente líquido ou gasoso. O material sobre o qual a adsorção ocorre é conhecido como adsorvente, e a espécie química que é adsorvida é denominada adsorbato. Os constituintes dos adsorventes são diretamente responsáveis pela remoção dos poluentes, principalmente aqueles provenientes de águas residuárias. As propriedades de cada material do processo são específicas e dependem da sua composição (Khattri e Singh, 2009, Gupta et al., 2009, Chiou, 2002).

Segundo a literatura, o fenômeno da adsorção foi observado primeiramente por Scheele em 1773, e por Lowitz em 1785. Larvitz em 1792. No entanto, foi Kayser que introduziu pela primeira vez em 1881, o termo adsorção para diferenciar a concentração na superfície de penetração intermolecular. (Masschelein, 1992; Mantell, 1951;).

O processo de adsorção pode ter interações físicas e químicas. Se a interação for de natureza física, as interações existentes são as forças de van der Waals (dispersão-repulsão) e interações eletrostáticas incluindo polarização, dipolo e interação quadrupolo, e o mesmo é classificado como fisiossorção, apresentando reversibilidade, uma vez que as atrações são fracas. Ao contrário, se as interações forem decorrentes de ligações químicas (iônicas, covalentes) entre a superfície do adsorvente e o composto adsorvido, o processo é chamado de quimissorção (McCash, 2004). A quimissorção ocorre apenas como monocamada e, além disso, as substâncias ligadas quimicamente à superfície sólida são dificilmente removidas. Ambas as interações podem ocorrer simultaneamente, isto depende das condições do processo (Zuim, 2010; Grassi, 2012).

Os fatores que influenciam o processo de adsorção são os seguintes: a área de superfície, a natureza e concentração inicial de adsorbato, o pH da solução, a temperatura, substâncias interferentes e a natureza e massa do adsorvente (Grassi, 2012).

O processo de adsorção pode ser considerado superior a outros, devido à sua alta eficiência na remoção de poluentes quando comparado com métodos convencionais e também pela viabilidade econômica. Outras vantagens 
são o baixo consumo de energia, praticidade de projeto, facilidade de operação, ausência de substâncias tóxicas e maior remoção de resíduos orgânicos (Robinson et al., 2001; Noroozi e Sorial, 2013).

O processo de adsorção de corantes pode ser representado por quatro etapas consecutivas (Al-Godah, 2000; Baup et al, 2000; Sanghi e Bhattacharya, 2002): difusão das moléculas do corante na solução, difusão das moléculas do corante por meio de um camada limite, migração das moléculas do corante para a superfície externa do material adsorvente e, por fim, a adsorção das moléculas do corante sobre o superfície do adsorvente.

A segunda etapa pode ser afetada pela concentração do corante e agitação, a terceira é fase que determina a taxa de adsorção sobre o adsorvente e a última depende da natureza da molécula do corante, por exemplo, estruturas aniônicas e catiônicas. Cabe ressaltar que a fase que determina a taxa de adsorção pode envolver dois fenômenos: difusão porosa e difusão de superfície (Noroozi e Sorial, 2013).

A seleção de um adsorvente deve ser feita considerando a sua estrutura porosa. Materiais adsorventes que apresentam porosidade possuem elevada área superficial. Outro fator relevante é a cinética, esta deve apresentar uma velocidade alta, de modo que a remoção de contaminantes ocorre rapidamente (Gupta et al., 2009).

Os adsorventes que geralmente são utilizados para o tratamento de efluentes têxteis são: alumina, sílica gel, zeólitas e carvão ativado (Gupta e Suhas, 2009). O carvão ativado é o adsorvente mais estudado, e tem sido utilizado na remoção de diferentes tipos de compostos emergentes em geral (Gupta et al., 2009). O processo de adsorção é favorável, mas o material apresenta um custo alto e dificuldades associadas à regeneração. Pesquisadores têm estudado adsorventes alternativos economicamente viáveis que podem substituir carvões ativados no controle da poluição por meio do processo de adsorção (Grassi et al., 2012).

Os materiais que têm sido investigados para esta finalidade podem ser classificados de acordo com a disponibilidade, tais como, naturais (madeira, turfa, carvão, linhita), os resíduos industriais, agrícolas e domésticos e subprodutos (escórias, lama e cinzas das termelétricas, bagaço, lama vermelha, etc) e 
produtos sintetizados e também conforme a natureza, sendo eles inorgânicos ou orgânicos (Gupta et al, 2009).

Alguns materiais naturais disponíveis em grandes quantidades a partir de operações agrícolas, tais como, serragem de amargoseira (Melia azedarach); cascas de avelã, de amendoim e azeitona e bambu, estão sendo usados como adsorventes de baixo custo para remover corantes de águas residuais (Khattri e Singh, 2009, Gupta et al., 2009). Mas a utilização destes materiais está se tornando uma preocupação vital, porque eles representam recursos não utilizados e podem causar graves problemas de eliminação (Bhatnagar e Jain, 2005; Bhatnagar e Sillanpää, 2010; Wanngah e Hanafiah, 2008).

Resíduos industriais, como por exemplo, escórias de alto forno e lamas, bagaço de cana, cinzas leves (resíduos das termelétricas) e lama vermelha, estão sendo investigados como potenciais adsorventes para a remoção dos contaminantes emergentes de água residual (Gupta et al, 2009).

A zeólita obtida a partir de resíduos como adsorvente de baixo custo tem chamado à atenção dos pesquisadores da área ambiental.

\subsection{Isotermas de adsorção}

O processo de adsorção pode ser avaliado quantitativamente através das isotermas. As isotermas fornecem os dados de equilíbrio, e os mesmos são utilizados para avaliar a capacidade de diferentes adsorventes para adsorver uma determinada molécula.

As isotermas relacionam a quantidade do material adsorvido e a concentração na fase fluida em temperatura constante (Dabrowski, 2001).

As isotermas são classificadas de acordo com as formas de suas curvas McCabe et al. (1993) (FIG. 13). A isoterma linear que sai da origem indica que a quantidade adsorvida é proporcional à concentração do fluido. As isotermas côncavas são consideradas favoráveis, pois grandes quantidades adsorvidas podem ser obtidas com concentrações baixas de soluto no fluido. As isotermas convexas são classificadas como desfavoráveis ou não favoráveis devido à sua baixa eficiência de remoção em baixas concentrações. 


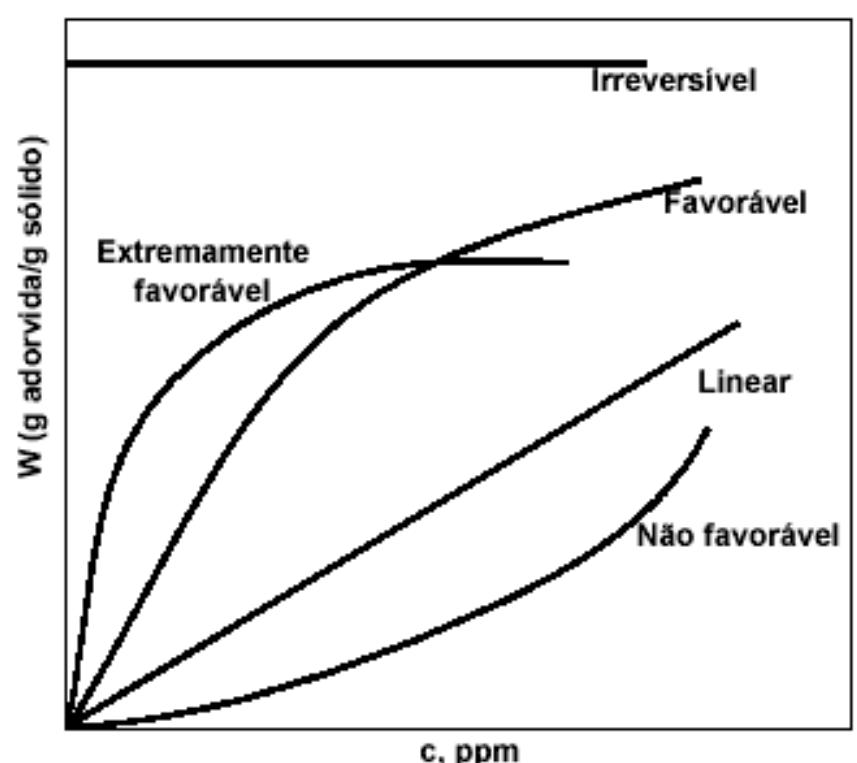

FIGURA 13 - Isotermas de adsorção Fonte - McCabe et al., 1993

O mecanismo e o tipo de adsorção que ocorrem entre o adsorvente e 0 adsorbato podem ser determinados pela forma da curva da isoterma (Giles et al., 1960).

Giles et al. (1974) classificaram a isoterma de adsorção para solução em quatro classes principais, relacionadas de acordo com suas formas como $S, L$, H e C, de subgrupos 1, 2, 3, 4 ou máximo, de acordo com a presença de patamares, aclives, pontos de inflexão, pontos de máximo ou mínimo. A isoterma do tipo S sugere uma associação entre as moléculas adsorvidas, conhecida como "adsorção cooperativa", que ocorre se a interação adsorbato-adsorbato é mais forte que a interação adsorbato-adsorvente; a do tipo $L$ (Langmuir) indica uma afinidade relativamente alta entre o adsorbato e o adsorvente e normalmente é evidencia um processo de quimissorção. A isoterma do tipo $\mathrm{H}$ trata-se de um caso especial de curva do tipo $L$ e é observada quando a superfície do adsorvente interage fortemente com o soluto no processo de adsorção. Este fato pode ser um indicativo de quimissorção). A isoterma do tipo C (constante de partição) sugere uma afinidade relativa constante das moléculas do adsorbato com o adsorvente, sugerindo um aspecto linear da curva (Giles et al., 1974).

Existem muitos estudos na literatura que relatam vários modelos para descrever os dados experimentais das isotermas de adsorção. Os mais utilizados 
para descrever os processos de adsorção para tratamento de águas e efluentes são os modelos de Langmuir e Freundlich (Perrich, 1981; Faust e Aly, 1987), e suas equações podem ser linearizadas, possibilitando que as constantes sejam determinadas por regressão linear (Fungaro et al., 2004).

\subsubsection{Iso terma de Langmuir}

O modelo da isoterma de Langmuir é fundamentado na possível adsorção de moléculas sobre a superfície do adsorvente em sítios definidos e finitos. A adsorção máxima ocorre em monocamada e a mesma torna-se saturada de moléculas de adsorbato na superfície do adsorvente. Para este modelo é suposto que não há interação entre as moléculas adsorvidas e que a energia de adosrção é igual em todos os sítios (Carvalho, 2010).

A expressão linear de Langmuir é:

$$
\frac{C_{e}}{q_{e}}=\frac{1}{Q_{o} b}+\frac{C_{e}}{Q_{o}}
$$

onde $\mathrm{C}_{\mathrm{e}}$ é a concentração do metal no equilíbrio $\left(\mathrm{mg} \mathrm{L}^{-1}\right)$, $\mathrm{q}_{e}$ é a quantidade adsorvida no equilíbrio ( $\left.\mathrm{mg} \mathrm{g}^{-1}\right), Q_{0}\left(\mathrm{mg} \mathrm{g}^{-1}\right)$ e b $\left(\mathrm{L} \mathrm{mg}^{-1}\right)$ são constantes relacionadas com a capacidade de adsorção máxima e a energia de adsorção, respectivamente.

O gráfico linear de $\mathrm{C}_{\mathrm{e}} / \mathrm{q}_{\mathrm{e}}$ vs $\mathrm{C}_{\mathrm{e}}$ confirma a validade do modelo de Langmuir para o processo. A equação de reta obtida apresentará coeficiente angular correspondente a 1/Qo e coeficiente linear correspondente a 1/Q $b$.

\subsubsection{Isoterma de Freundlich}

O modelo da isoterma de Freundlich é usado para energias de superfície heterogêneas. Para os sistemas que seguem esse modelo, ocorre a formação de multicamadas. Neste modelo, não há previsão da saturação do material adsorvente e, desta forma, ocorre a cobertura superficial incompleta (Reed e Matsumoto, 1993). 
A forma linear da equação de Freundlich é dada pela equação:

$\log \mathrm{qe}=\log \mathrm{Kf}+\frac{1}{n} \log C_{e}$

onde $\mathrm{k}_{\mathrm{f}}\left[\left(\mathrm{mg} \mathrm{g}^{-1}\right)\left(\mathrm{L} \mathrm{mg}^{-1}\right)^{1 / \mathrm{n}}\right]$ e $\mathrm{n}$ são constantes relacionadas com a capacidade de adsorção e a intensidade de adsorção, respectivamente. Os valores de $k_{f}$ e $n$ podem ser obtidos pela intersecção e inclinação do gráfico linear de $\log _{\mathrm{qe}}$ versus $\log C_{e}$.

Em um estudo de isoterma de um simples componente, a otimização do procedimento requer que uma análise de erro seja definida, de tal forma que esta seja capaz de avaliar o ajuste da isoterma aos dados experimentais de equilibrio. Podem-se empregar para tal fim, os coeficientes de correlação $(R)$ ou de determinação $\left(R_{2}\right)$ dos gráficos lineares dos modelos ou um teste não-linear Qui-quadrado.

$\mathrm{Na}$ avaliação do ajuste usando a análise linear, os coeficientes de correlação ou de determinação dos modelos são comparados. O modelo que melhor se ajusta aos dados experimentais apresentará valor de $R$ ou $R_{2}$ mais alto e mais próximo de um.

O teste não linear do Qui-quadrado $\left(x^{2}\right)$ é empregado como um critério para encontrar o modelo de isoterma de adsorção que melhor se ajusta aos dados experimentais de equilibrio devido à inerente tendenciosidade resultante da linearização dos modelos de isotermas. A análise estatística é baseada na soma das raízes quadradas das diferenças entre o dado experimental e o dado calculado pelo modelo, sendo que a diferença é dividida pelo correspondente dado calculado pelos modelos. O teste do Qui-quadrado pode ser representado pela seguinte equação $7(\mathrm{Ho}, 2004)$ :

$$
\mathrm{X}^{2}=\Sigma \frac{\left(q_{e} \exp -q_{e} \text { calc }\right)^{2}}{q_{e} \text { calc }}
$$

onde $\mathrm{qe}_{\exp }$ é a capacidade de equilibrio do adsorvente obtida dos dados experimentais ( $\left.\mathrm{mg} \mathrm{g}^{-1}\right)$ e qe $\mathrm{q}_{\text {calc }}$ é a capacidade de equilibrio calculada a partir do 
modelo $\left(\mathrm{mg} \mathrm{g}^{-1}\right)$. Quanto mais baixo é o valor de $\mathrm{x}^{2}$, mais o dado experimental se ajusta ao valor obtido pelo modelo.

\subsection{Modelos cinéticos}

Há vários modelos cinéticos para testar os dados experimentais com a finalidade de orientar a escolha de mecanismos de controle do processo de adsorção, tais como transferência de massa, controle de difusão e reação química (Dogăn e Alkan, 2003). Neste estudo, utilizaram-se os modelos cinéticos de pseudo-primeira-ordem e de pseudo-segunda-ordem e o modelo de difusão intrapartícula.

\subsubsection{Modelo cinético de pseudo-primeira-ordem}

A velocidade de adsorção pode ser determinada por uma expressão de velocidade de pseudo-primeira-ordem dada por Lagergren para a adsorção em sistema líquido/sólido baseada na capacidade do sólido (Lagergren, 1898). Ele assumiu que a velocidade de remoção do adsorbato com o tempo é diretamente proporcional à diferença na concentração de saturação e ao número de sítios ativos do sólido.

A equação geral é expressa como:

$$
\log _{10}\left(q_{e}-q\right)=\log _{10} q_{e}-k_{1} t / 2,303
$$

onde $q_{e}$ e q são as quantidades de corante adsorvida $\left(\mathrm{mg} \mathrm{g}^{-1}\right)$ no equilíbrio e no tempo $\mathrm{t}(\mathrm{min})$, respectivamente; $\mathrm{k}_{1}$ é a constante de velocidade de adsorção $\left(\min ^{-1}\right)$. A constante $k_{1}$ pode ser calculada a partir da inclinação da reta do gráfico $\log _{10}\left(q_{e}-q\right)$ versus $t$.

\subsubsection{Modelo cinético de pseudo-segunda-ordem}

Os dados cinéticos foram também analisados usando as cinéticas de pseudo-segunda-ordem desenvolvidas por Ho et al, 1996, onde a velocidade da reação é dependente da quantidade do soluto adsorvido na superfície do adsorvente e da quantidade adsorvida no equilíbrio. O modelo linear de pseudosegunda-ordem pode ser representado por: 


$$
\frac{t}{q}=\frac{1}{K_{2} q_{e}{ }^{2}}+\frac{1}{q_{e}} t
$$

onde $\mathrm{k}_{2}$ é a constante de velocidade de pseudo-segunda-ordem $\left(\mathrm{g} \mathrm{mg}^{-1} \mathrm{~min}^{-1}\right)$, qe e q são as quantidades de corante adsorvida $\left(\mathrm{mg} \mathrm{g}^{-1}\right)$ no equilíbrio e no tempo $\mathrm{t}$ (min), respectivamente.

A partir das retas do gráfico de t/q versus $t$, os valores das constantes $\mathrm{k}_{2}\left(\mathrm{~g} \mathrm{mg}^{-1} \mathrm{~min}^{-1}\right)$ e qe $\left(\mathrm{mg} \mathrm{g}^{-1}\right)$ podem ser calculados. Ao contrário do modelo cinético de primeira-ordem, não há necessidade do conhecimento de algum parâmetro prévio. Este modelo prevê o comportamento sobre o período completo da adsorção e está de acordo com um mecanismo de adsorção responsável pela etapa controladora da velocidade (Ho e McKay, 1999).

A constante $k_{2}$ é usada para calcular a velocidade de adsorção inicial $\mathrm{h}\left(\mathrm{mg} \mathrm{g}^{-1} \mathrm{~min}^{-1}\right)$, para $\mathrm{t} \rightarrow 0$, como segue:

$$
h=k_{2} q e^{2}
$$

\subsubsection{Modelo cinético de difusão in trapartícula}

O mecanismo do processo de adsorção definitivo pode não ser obtido pelos modelos cinéticos descritos acima e, portanto, o modelo da difusão intrapartícula pode ser empregado. De acordo com Weber e Morris, 1963, se a difusão intrapartícula é o fator determinante da velocidade, a remoção do adsorbato varia com a raiz quadrada do tempo. Assim, o coeficiente de difusão intrapartícula $(k)$ pode ser definido como:

$$
k_{i}=q / t^{0,5}+C
$$

onde q ( $\left.\mathrm{mg} \mathrm{g}^{-1}\right)$ é a quantidade de corante adsorvida e $\mathrm{t}$ ( $\mathrm{min}$ ) é o tempo de agitação.

O valor de $\mathrm{k}_{\mathrm{i}}\left(\mathrm{mg} \mathrm{g}^{-1} \min ^{-0,5}\right)$ pode ser obtido da inclinação da curva do gráfico $\mathrm{q}\left(\mathrm{mg} \mathrm{g}^{-1}\right)$ versus $\mathrm{t}^{0,5}\left(\mathrm{~min}^{0,5}\right)$. 
Se o gráfico q vs $t^{1 / 2}$ for linear e passar pela origem, o único mecanismo de adsorção é a difusão intrapartícula (Ho, 2003). Os valores de C dão uma idéia da espessura da camada limite, isto é, quanto maior for o valor de $\mathrm{C}$, maior será o efeito da camada limite (Dizge et al., 2008) .

Estudos prévios mostraram que o gráfico pode apresentar uma multilinearidade, a qual caracteriza os diferentes estágios na adsorção: transferência de massa externa seguida por difusão intrapartícula no macro, meso e microporo (Allen et al., 1989). Quando o gráfico apresentar multilinearidade, o valor de $\mathrm{C}$ é calculado pela primeira porção linear. 


\section{MATERIAIS E MÉTODOS}

\section{1. Área de estudo}

As cinzas leves e pesadas de carvão utilizadas neste estudo foram coletadas na Usina Termelétrica de Jorge Lacerda (UTJL), localizada no município de Capivari de Baixo, no estado de Santa Catarina.

\subsection{Amostras de cinzas leves e pesadas de carvão}

As cinzas leves foram coletadas dos precipitadores eletrostáticos (FIG. 14) e as cinzas pesadas das bacias de sedimentação (FIG. 15) da usina em estudo, respectivamente.

Neste estudo, as cinzas leves foram denominadas CLC e pesadas CPC, e ambas foram utilizadas como matéria prima para a síntese das zeólitas.

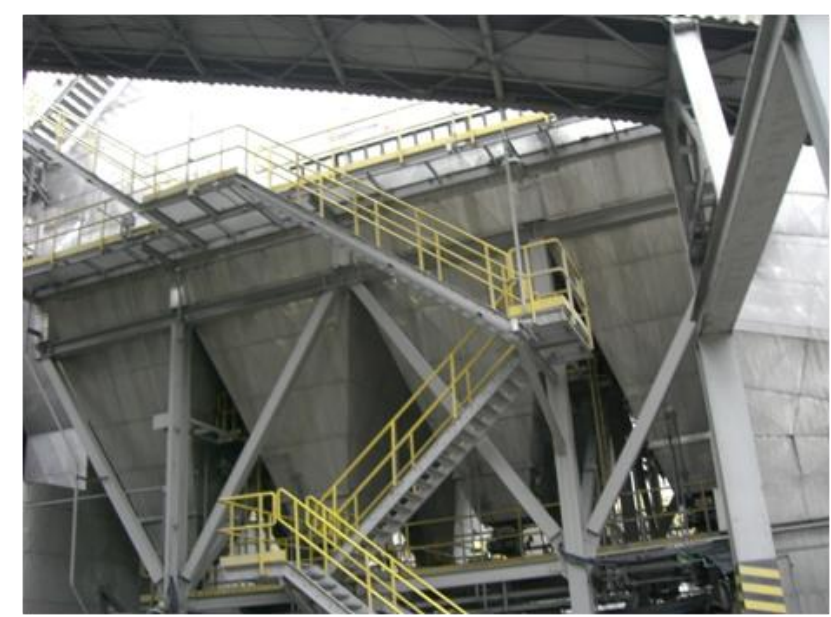

FIGURA 14 - Precipitadores eletrostáticos da Usina Jorge Lacerda Fonte: Denise Alves Fungaro 


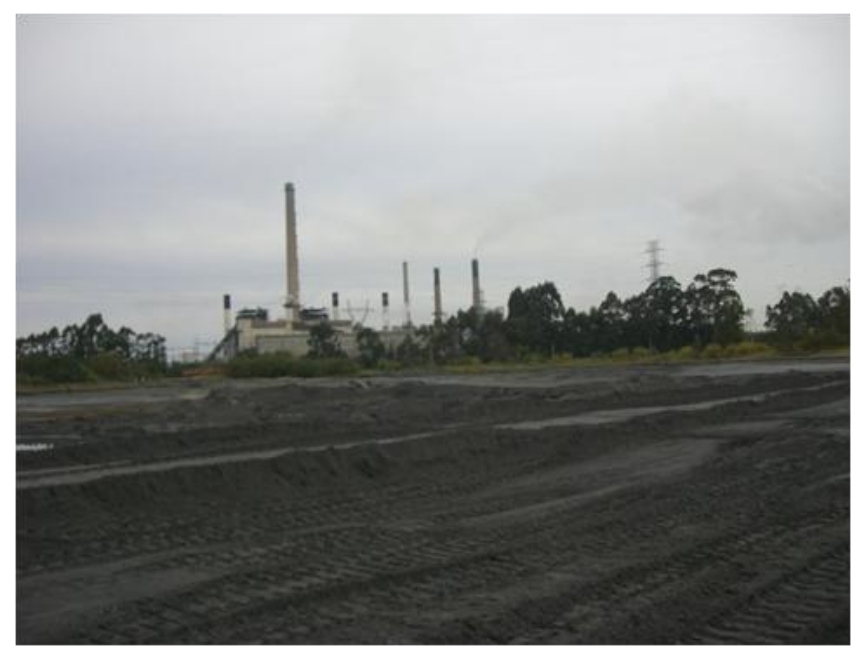

FIGURA 15 - Bacia de sedimentação da Usina Jorge Lacerda Fonte: Denise Alves Fungaro

\subsection{Materiais}

Todos os reagentes usados foram de grau analítico. Os corantes utilizados neste estudo foram Cristal Violeta (CV), pureza considerada 100\%, adquirido da empresa Proton-Research e o corante ácido Laranja 8 (AL8), pureza considerada $65 \%$, fornecido pela empresa Aldrich. As características gerais e as estruturas químicas de ambos corantes foram apresentadas no item 3.7.1. As soluções dos corantes foram preparadas a partir da diluição do reagente p.a com água bidestilada. O brometo de hexadeciltrimetilamônio (HDTMA-Br) da Merck foi usado na modificação das zeólitas. A zeólita sintética 4A na forma de esferas da empresa Bayer (ZBayer) foi utilizada no estudo para comparação. Mesa agitadora Quimis - modelo Q-225M, estufa Fanen Orion 515, centrífuga Quimis e espectrofotômetro Cary $\mathbb{E}$ - Varian foram utilizados.

\subsection{Síntese das zeólitas a partir das cinzas leves e pesadas de carvão}

O procedimento para a preparação das zeólitas foi feito pelo tratamento hidrotérmico alcalino descrito a seguir: a amostra contendo $20 \mathrm{~g}$ das cinzas de carvão foi aquecida em estufa à $100^{\circ} \mathrm{C}$, por $24 \mathrm{~h}$ com $160 \mathrm{~mL}$ de $\mathrm{NaOH}$ $3,5 \mathrm{~mol} \mathrm{~L}^{-1}$. A suspensão foi filtrada em papel de filtro, o sólido repetidamente lavado com água bidestilada até obter o $\mathrm{pH} \sim 10$ e seco em estufa a $50^{\circ} \mathrm{C}$ por $12 \mathrm{~h}$ 
(Henmi, 1987). Os materiais obtidos foram denominados ZCL para a zeólita preparada com as cinzas leves e ZCP para a zeólita preparada com as cinzas pesadas.

\subsection{Síntese das zeólitas de cinzas de carvão modificadas por surfactante}

O procedimento para a preparação das zeólitas modificadas com surfactante foi feito pela mistura de $10 \mathrm{~g}$ de zeólita de cinzas de carvão com $0,2 \mathrm{~L}$ de brometo de hexadeciltrimetilamônio (HDTMA-Br) 1,8 $\mathrm{mmol} \mathrm{L}^{-1}$. A mistura foi agitada por 7 horas a $120 \mathrm{rpm}$ em temperatura ambiente com agitador mecânico. A suspensão foi filtrada e o sólido foi seco em estufa a $50^{\circ} \mathrm{C}$. Os materiais obtidos foram denominados ZMSL para a zeólita modificada preparada com as cinzas leves e ZMSP para a zeólita modificada preparada com as cinzas pesadas.

\subsection{Caracterização dos adsorventes}

Os materais adsorventes sintetizados neste trabalho foram caracterizados físico-quimicamente. As técnicas utilizadas, tais como fluorescência de raios-X, difração de raios-X e microscopia eletrônica de varredura, estão descritas com detalhe na literatura (Izidoro, 2008) e a técnica de espectroscopia na região do infravermelho está apresentada no trabalho de (Carvalho, 2010).

\subsubsection{Determinação do pH e condutividade}

Para os ensaios de $\mathrm{pH}$ e condutividade, $0,25 \mathrm{~g}$ das amostras de zeólita foram colocadas em contato com $25 \mathrm{~mL}$ de água bidestilada. As misturas foram agitadas por 24 h em agitador mecânico (Ética - Mod. 430) a 120 rpm. Em seguida, as amostras foram filtradas e o pH (MS Tecnopon - Mod. MPA 210) e a condutividade (BEL Engineering - Mod. W12D) foram determinados.

\subsubsection{Determinação do Ponto de Carga Zero $\left(\mathrm{pH}_{\mathrm{PZC}}\right)$}

A metodologia de batelada foi empregada neste estudo para a determinação do PZC. O procedimento consistiu em misturar $0,1 \mathrm{~g}$ do adsorvente com $50 \mathrm{~mL}$ de solução aquosa de $\mathrm{NaNO}_{3} 0,1 \mathrm{~mol} \mathrm{~L}^{-1}$ sob diferentes condições de pH inicial $(2,0 ; 4,0 ; 10,0 ; 11,0 ; 12,0 ; 13,0)$ e determinar o pH final após $24 \mathrm{~h}$ de agitação no agitador mecânico à 120 rpm e temperatura ambiente. Os valores de 
$\mathrm{pH}$ inicial foram ajustados pela adição de $\mathrm{HNO}_{3} 0,1$, 1 e $3 \mathrm{~mol} \mathrm{~L}^{-1}$ ou $\mathrm{NaOH} 3$ mol $L^{-1}$, e os mesmos estão apresentados na TAB. 2. Os valores da diferença entre o $\mathrm{pH}$ inicial e final $(\Delta \mathrm{pH})$ foram colocados em gráfico em função do $\mathrm{pH}$ inicial. O ponto $\mathrm{x}$ onde a curva intercepta o eixo $\mathrm{y}=0$ é o valor do $\mathrm{pH}$ do $\mathrm{PCZ}$.

TABELA 2- Valores medidos de $\mathrm{pH}$ inicial dos adsorventes sintetizados

\begin{tabular}{ccccccc}
\hline \multirow{2}{*}{ ADSORVENTES } & $\mathbf{7}$ & $\mathbf{p H}$ inicial \\
& $\mathbf{2 , 0}$ & $\mathbf{4 , 0}$ & $\mathbf{1 0 , 0}$ & $\mathbf{1 1 , 0}$ & $\mathbf{1 2 , 0}$ & $\mathbf{1 3 , 0}$ \\
\hline ZCL & 2,2 & 4,2 & 9,9 & 10,9 & 11,9 & 12,9 \\
ZCP & 2,1 & 4,0 & 10,1 & 11,1 & 12,0 & 12,9 \\
ZMSL & 2,3 & 3,9 & 10,1 & 11,1 & 11,8 & 12,8 \\
ZMSP & 2,1 & 4,1 & 9,9 & 11,0 & 11,9 & 12,9 \\
\hline
\end{tabular}

\subsubsection{Capacidade de troca catiônica e capacidade de Troca catiônica externa}

A capacidade de troca catiônica (CTC) foi determinada por processo de duas etapas.

Na primeira etapa, a amostra contendo $100 \mathrm{~mL}$ de solução de acetato de sódio $1 \mathrm{~mol} \mathrm{~L}^{-1}$ e $1 \mathrm{~g}$ de zeólita foi agitada por $24 \mathrm{~h}$. A suspensão foi filtrada, o sólido foi lavado com água destilada, recolhido e seco em estufa a $80{ }^{\circ} \mathrm{C}$. $\mathrm{Na}$ segunda etapa, o sólido seco foi pesado e submetido à saturação com de acetato de amônio $1 \mathrm{~mol} \mathrm{~L}^{-1}$, por agitação durante $24 \mathrm{~h}$. A suspensão foi filtrada e no filtrado foi determinada a quantidade de sódio por absorção atômica (AA).

Na determinação da Capacidade de Troca Catiônica Externa (CTCE), o mesmo procedimento da CTC foi usado, porém na segunda etapa foi usada solução de HDTMA-Br 0,9 mmol L-1 no lugar de acetato de amônio $1 \mathrm{~mol} \mathrm{~L}^{-1}$.

\subsubsection{Grau de hidrofobicidade}

O procedimento consistiu em misturar $1 \mathrm{~g}$ do adsorvente com $100 \mathrm{~mL}$ de água em um funil de separação. A mistura foi agitada manualmente por 3 min. Adicionou-se $100 \mathrm{~mL}$ de hexano no funil e agitou-se manualmente por $3 \mathrm{~min}$. 
Após 5 min de repouso em suporte, a fase aquosa foi recolhida em um béquer e filtrada. O sólido retido no papel de filtro foi seco ao ar e pesado.

Calculou-se a massa do sólido transferido para a fase orgânica ( $m_{\text {org }}$ ) usando-se a equação:

$\mathrm{m}_{\mathrm{org}}=\mathrm{m}_{\mathrm{o}}-\mathrm{m}_{\text {aquo }}$

onde $m_{\circ}(g)$ é a massa inicial do adsorvente e $m_{\text {aquo }}(g)$ é a massa do sólido que ficou retido no papel de filtro.

O grau de hidrofobicidade (\% em massa) foi calculado usando-se a equação:

Grau de hidrofobicidade $=\frac{m_{\text {org }}}{m_{0}}$

\subsubsection{Massa específica}

A massa específica das zeólitas, ou densidade real, foi determinada em picnômetro de hélio. Foi utilizado cilindro de gás hélio 4.5 (99,995\% de pureza). O equipamento utilizado era da marca Micromeritcs Instrument Corporation, modelo Accupyc 1330, de acordo com as seguintes condições de análise: número de purgas: 30; pressão de purga: 19,5 psig; número de repetições (corridas): 30; pressão de preenchimento: 19,5 psig; taxa de equilíbrio: 0,005 psig/min; porcentagem de variação: 0,05\%; temperatura de análise: 26,0 ํ․ Essa análise foi realizada no Centro do Combustível Nuclear (CCN) do Instituto de Pesquisas Energéticas e Nucleares (IPEN).

\subsection{6 Área específica superficial}

A área específica BET foi determinada pelo equipamento BET Surface Area Analyser, versão 3.11, Quanta-Chrome Corporation, Nova 1200. Primeiramente, a amostra foi degaseificada por 12 horas no banho de areia a $150^{\circ} \mathrm{C}$ para retirada de voláteis e gases interferentes, em seguida, houve 
adsorção de nitrogênio para garantir a atmosfera inerte, finalmente, a determinação foi feita por meio da adsorção e dessorção de nitrogênio nas amostras em condições de vácuo de $0,1 \mathrm{mmHg}$. Essa análise foi realizada no Centro de Ciência e Tecnologia dos Materiais (CCTM) do Instituto de Pesquisas Energéticas e Nucleares (IPEN).

\subsubsection{Difração de Raios-X}

A composição mineralógica foi obtida por Difração de Raios-X. A amostra compactada de zeólita em pó colocada em um porta amostra de aço inoxidável foi analisada em difratômetro de raios $X$ Rigaku modelo Multiflex com monocromador e com radiação Cu K- $\alpha$, gerada a $40 \mathrm{kV}$ e $20 \mathrm{~mA}$. A velocidade de varredura era de $0,5 \% \mathrm{~min}$ e variou de 5 a $80^{\circ} 2 \theta$. A identificação das fases cristalinas se fez com auxílio dos padrões disponíveis no sistema International Centre for Diffraction Data / Joint Committee on Power Diffraction Standards (ICDD/JCPDS). Essa análise foi realizada no Centro de Ciência e Tecnologia dos Materiais (CCTM) do Instituto de Pesquisas Energéticas e Nucleares (IPEN).

\subsubsection{Fluorescência de Raios-X}

A composição química das zeólitas foi determinada por fluorescência de raios $X(F R-X)$. O procedimento de preparação de amostra de zeólita utilizado para determinação dos elementos inorgânicos foi o de pastilha prensada de dupla camada, utilizando-se como aglutinante 8 gotas de uma solução de álcool polivinílico (PVA) $5 \% \mathrm{~m} / \mathrm{v}$ (Scapin, 2003). A amostra foi submetida em espectrômetro de fluorescência de raios X modelo RIX 3000, da marca Rigaku Company com sistema de dispersão de comprimento de onda (WDXRF). $O$ método utilizado para determinação quantitativa foi de parâmetros fundamentais (FP) (Lanchance \& Claisse, 1995; Buhrke et al., 1998; Scapin, 2003). Essa análise foi realizada no Centro de Química e Meio Ambiente (CQMA) do Instituto de Pesquisas Energéticas e Nucleares (IPEN).

\subsubsection{Microscopia Eletrônica de Varredura}

Para verificação da morfologia, a zeólita foi colocada em suporte metálico e pulverizada com uma fina camada de Au para torná-la condutora e 
gerar uma imagem de melhor resolução. $O$ equipamento utilizado foi o microscópio eletrônico de varredura (MEV), modelo XL30, marca PHILIPS, com aumentos de 100, 500, 1000, 2000, 5000 e 10000 vezes a $10 \mathrm{kV}$. Essa análise foi realizada no Centro de Ciência e Tecnologia dos Materiais (CCTM) do Instituto de Pesquisas Energéticas e Nucleares (IPEN).

\subsubsection{Espectroscopia no Infravermelho}

A técnica de espectroscopia de infravermelho com transformada de Fourier (FTIR) foi usada para examinar as características estruturais principais das zeólitas antes e após a adsorção do corante e também a modificação por surfactante. Os espectros em $\mathrm{KBr}$ foram feitos no espectrofotômetro Nexus 670 FTIR da Thermo Nicolet usando a técnica de disco prensado.

\subsection{Estudos de adsorção}

As concentrações dos corantes CV e AL8 foram determinadas por meio da técnica de espectroscopia UV-Visível (espectrofotômetro UV/Vis Cary 1E, Varian). Uma curva de calibração de absorbância vs concentração foi construída para cada um dos corantes em solução aquosa e as medidas de absorbância foram realizadas no comprimento de onda $(\lambda)$ de maior intensidade para o CV $(590 \mathrm{~nm})$ e o AL8 $(491 \mathrm{~nm})$. A concentração do corante remanescente na fase fluida após o processo de adsorção foi obtida por meio da respectiva curva de calibração.

A cinética de adsorção para os adsorventes ZCL, ZCP, ZMSL, ZMSP e ZBayer foi realizada, em sistema de batelada (processo descontínuo), com soluções aquosas de CV e de AL8 nas concentrações, conforme mostram as (TAB. 3 e 4): 
TABELA 3 - Concentração do corante CV e tempo de agitação no estudo da cinética de adsorção

\begin{tabular}{ccc}
\hline Adsorvente & $\begin{array}{c}\text { Concentração } \\
\left(\mathbf{m g ~ L}^{-1}\right)\end{array}$ & $\begin{array}{c}\text { Tempo de agitação } \\
(\text { min })\end{array}$ \\
\hline ZCL & 185 & 1 a 12 \\
\hline \multirow{2}{*}{$Z C P$} & 359 & 0,5 a 14 \\
& 52 & a 12 \\
\hline$Z$ Bayer & 185 & 1 a 20 \\
\hline ZMSL & 63 & 1 a 12 \\
ZMSP & 185 & 1 a 20 \\
\hline & 227 & 2 a 20 \\
\hline
\end{tabular}

TABELA 4 - Concentração do corante AL8 e tempo de agitação no estudo da cinética de adsorção

\begin{tabular}{ccc}
\hline Adsorvente & $\begin{array}{c}\text { Concentração } \\
\left(\mathbf{m g ~ L}^{-1}\right)\end{array}$ & $\begin{array}{c}\text { Tempo de agitação } \\
\text { ( } \text { min) }\end{array}$ \\
\hline ZCL & 2,0 & 10 a 360 \\
\hline ZCP & 2,0 & 60 a 1440 \\
\hline ZBayer & 2,0 & 10 a 1440 \\
\hline ZMSL & 10 & 5 a 120 \\
\hline ZMSP & 53,0 & 10 a 300 \\
& 2,0 & 5 a 300 \\
\hline
\end{tabular}

Alíquotas das soluções dos corantes foram colocadas em béqueres com os adsorventes (com relação massa /volume de $0,01 \mathrm{~g} \mathrm{~mL}^{-1}$ ). As suspensões foram agitadas a $120 \mathrm{rpm}$ pelos diferentes intervalos de tempo, conforme mostram as TAB. 3 e 4.

Ao final de cada período de tempo, o sobrenadante de uma amostra foi separado por centrifugação a 3000 rpm. Uma porção do sobrenadante foi analisada por espectroscopia, após ajuste para pH 5 (pH da solução aquosa dos corantes) com $\mathrm{HNO}_{3} \quad 0,05 \mathrm{~mol} \mathrm{~L}$. Todos os ensaios foram realizados em temperatura ambiente de $25^{\circ} \mathrm{C} \pm 2^{\circ} \mathrm{C}$. 
A capacidade de adsorção do corante sobre os adsorventes ( $q$ em $\mathrm{mg} \mathrm{g}^{-1}$ ) foi calculada conforme a equação:

$$
q=\frac{V\left(C_{o}-C_{f}\right)}{M}
$$

onde $V(L)$ é o volume da solução de corante, $C_{0}\left(m g ~ L^{-1}\right)$ é a concentração inicial da solução de corante, $C_{f}\left(m g ~ L^{-1}\right)$ é a concentração final da solução de corante obtida após um tempo t e $\mathrm{M}(\mathrm{g})$ é a massa de zeólita.

A eficiência de adsorção (ou remoção) foi calculada usando-se a equação:

$$
R=100 \frac{\left(C_{o}-C_{f}\right)}{C_{o}}
$$

As isotermas de adsorção foram determinadas para as faixas de concentração de 23 a $560 \mathrm{mg} \mathrm{L}^{-1}$ para o CV e de 1 a $253 \mathrm{mg} \mathrm{L}^{-1}$ para o AL8.

Alíquotas das soluções dos corantes foram colocadas em béqueres com os adsorventes (com relação massa /volume de $0,01 \mathrm{~g} \mathrm{~mL}^{-1}$ ). As suspensões foram agitadas a 120 rpm até alcançar o tempo de equilibrio, que foi determinado no estudo cinético.

Ao final de cada período de tempo, o sobrenadante de uma amostra foi separada do adsorvente por centrifugação a $3000 \mathrm{rpm}$ e as capacidades de adsorção foram medidas conforme a Equação 10. 


\section{RESULTADOS E DISCUSSÃO}

\subsection{Caracterização dos adsorventes}

\subsubsection{Propriedades Físico-químicas}

A TAB. 5 apresenta algumas propriedades físico-químicas das cinzas leves de carvão (CLC) e das cinzas pesadas de carvão (CPC) e suas respectivas zeólitas (ZCL e ZCP) e das zeólitas modificadas (ZMSL e ZMSP). Na mesma tabela constam resultados encontrados na literatura (Izidoro, 2013; Bertolini et al., 2013).

TABELA 5 - Propriedades físico-químicas dos adsorventes

\begin{tabular}{|c|c|c|c|c|c|c|}
\hline \multirow[b]{2}{*}{$\begin{array}{l}\text { PROPRIEDADES } \\
\text { FÍSICO-QUÍMICAS }\end{array}$} & \multicolumn{6}{|c|}{ ADSORVENTES } \\
\hline & CLC & CPC & ZCL & ZCP & ZMSL & ZMSP \\
\hline Massa específica $\left(\mathrm{g} \mathrm{cm}^{-3}\right)$ & 2,26 & 1,79 & 2,01 & 2,43 & 2,38 & 2,49 \\
\hline Area superficial BET $\left(\mathrm{m}^{2} \mathrm{~g}^{-1}\right)$ & 9,6 & 5,33 & 134 & 85 & 64 & 62 \\
\hline Perda por calcinação (\%) & 15,1 & 9,33 & - & - & - & - \\
\hline pH em água & 8,0 & 7,6 & 8,4 & 8,4 & 8,3 & 8,5 \\
\hline $\mathrm{pH}_{\mathrm{PCZ}}{ }^{\mathrm{a}}$ & - & - & 6,5 & 7,3 & 6,3 & 6,1 \\
\hline Grau de hidrofobicidade (\%) & - & - & zero & zero & 86 & 98 \\
\hline Condutividade $\left(\mu \mathrm{S} \mathrm{cm}^{-1}\right)$ & 259 & 110 & 389 & 367 & 220 & 281 \\
\hline CTC $\left.(\text { meq g })^{-1}\right)^{b}$ & 0,026 & 0,109 & 1,27 & 1,19 & 1,61 & 1,49 \\
\hline CTCE $\left(\text { meq g }{ }^{-1}\right)^{\mathrm{C}}$ & - & - & 0,163 & 0,137 & - & - \\
\hline
\end{tabular}

(a) ponto de carga zero; (b) capacidade de troca catiônica; (c) capacidade de troca catiônica externa.

Os valores de massa específica foram próximos e variaram entre $1,79-2,49 \mathrm{~g} \mathrm{~cm}^{-3}$ para todos os adsorventes (TAB. 5). Os resultados encontrados para as cinzas são compatíveis com os de medições encontradas na literatura. Sabedota et al encontraram um valor de $2,17 \mathrm{~g} \mathrm{~cm}^{-3}$ para as cinzas leves e Kreuz, 2002 encontrou um valor $1,81 \mathrm{~g} \mathrm{~cm}^{-3}$ para as cinzas pesadas da usina amostrada no presente trabalho. 
Observou-se que o valor da área superficial específica das zeólitas foi maior do que o das cinzas precursoras. Este aumento é devido ao estágio de cristalização sobre as partículas esféricas lisas das cinzas depois do tratamento hidrotérmico. Os valores da área superficial específica da ZCL e da ZCP foram 2 e 1,4 vezes maiores do que aqueles da ZMSL e ZMSP, respectivamente, indicando a cobertura da superfície pelas moléculas do HDTMA (Fungaro e Borrely, 2012).

As cinzas leves e pesadas apresentaram valores baixos de CTC, e são semelhantes aos valores relatados na literatura (Paprocki, 2009). Os valores de CTC obtidos para as zeólitas não modificadas e modificadas foram muito próximos e variaram entre 1,19 e 1,61 meq $\mathrm{g}^{-1}$. Para a ZCL e a ZCP, os valores da capacidade de troca cationica externa (CTCE) corresponderam a 13\% e 12\% dos valores da CTC, respectivamente. A adsorção do HDTMA sobre a zeólita envolve somente a CTCE deixando a CTC inalterada. As dimensões do cátion do HDTMA são muito grandes e ele não consegue penetrar nos canais das estruturas das zeólitas. Assim, os sítios internos da zeólita estão ainda acessíveis a pequenos íons (Xie et al, 2012).

$\mathrm{O} \mathrm{pH}$ das cinzas de carvão está diretamente relacionado com a disponibilidade de macro e micro nutrientes e indica se as cinzas de carvão são ácidas ou alcalinas na natureza. Baseado no $\mathrm{pH}$, as cinzas de carvão foram classificadas em três categorias, a saber: ligeiramente alcalinas 6,5-7,5; moderadamente alcalinas 7,5-8,5 e altamente alcalinas > 8,5 (Sijakova-Ivanova et al., 2011). Os valores de pH das $\operatorname{CLC}(8,0)$ e CPC $(7,6)$ indicam que as cinzas foram moderadamente alcalinas na natureza. Esta alcalinidade é justificada pela presença de compostos formados pelos cátions de $\mathrm{K}^{+}, \mathrm{Na}^{+}, \mathrm{Ca}^{2+}$ e $\mathrm{Mg}^{2+}$ combinados com carbonatos, óxidos ou hidróxidos de (Paprocki, 2009). O pH dos materiais zeolíticos aumentou devido ao tratamento hidrotérmico com solução de $\mathrm{NaOH}$.

O valor de condutividade elétrica encontrado para as cinzas leves foi superior ao das cinzas pesadas. Isto ocorre porque as cinzas leves apresentam níveis mais elevados de solubilidade e, consequentemente, uma maior quantidade de íons na solução. Os níveis totais elevados de solubilidade dos elementos nas cinzas leves podem ser originados pelas maiores áreas de 
superfície e pelas maiores abundâncias de espécies condensadas que as mesmas apresentam (Silva et al., 2010).

Depoi et al., 2008 estudaram as cinzas de Jorge Lacerda e encontraram valores de condutividade de $458 \pm 129 \mu \mathrm{S} \mathrm{cm}^{-1}$ e $119 \pm 9 \mu \mathrm{sm}^{-1}$ para as cinzas leves e pesadas, respectivamente.

As zeólitas sintetizadas neste estudo apresentaram valores de condutividade próximos ou maiores que os valores encontrados para as cinzas precursoras. Isto pode ser explicado pela presença de cátions trocáveis nas estruturas dos adsorventes sintetizados por tratamento hidrotérmico alcalino.

O ponto de carga zero (PCZ) é definido como o pH em que a superfície do adsorvente possui carga neutra. $\mathrm{O} \mathrm{pH}_{\mathrm{PCZ}}$ de adsorventes depende de vários fatores como natureza da cristalinidade, razão Si/Al, conteúdo de impurezas, temperatura, eficiência de adsorção de eletrólitos, grau de adsorção de íons $\mathrm{H}^{+} \mathrm{e}$ $\mathrm{OH}^{-}$, etc. e, portanto, ele deve variar de adsorvente para adsorvente (Fungaro e Borrely, 2012)

Os valores de $\mathrm{pH}_{\mathrm{PZC}}$ das zeólitas ZCL e ZCP (TAB. 5) foram inferiores ao $\mathrm{pH}$ em água indicando que a superfície apresenta carga negativa em solução aquosa $(\mathrm{pH}>\mathrm{pH}$ PCZ) para ambos os adsorventes. O mesmo ocorreu para ZMSL e ZMSP.

No caso de adsorvente modificado, entre os fatores que influenciam o pH PCZ está também a concentração do surfactante usado na modificação da superfície. A mudança do $\mathrm{pH}_{\mathrm{PCZ}}$ em relação à concentração está relacionada com a transição da configuração do surfactante de monocamada para bicamada na superfície do adsorvente ( $\mathrm{Li}$ e Bowman, 1998). No presente estudo, a carga negativa das ZMSL e ZMSP indicou que ocorreu a formação de uma bicamada incompleta do surfactante sobre a superfície das zeólitas, enquanto ainda há sítios ativos de troca carregados negativamente disponíveis.

O grau de hidrofobicidade da zeólita antes e após a modificação foi estimado de acordo com sua partição entre uma fase polar (água) e uma fase orgânica (hexano). A avaliação dessa propriedade é importante, uma vez que as interações existentes entre o corante, água e o adsorvente são determinantes nas taxas de adsorção. Entretanto, vale a pena ressaltar que o teste de hidrofobicidade é um teste rápido e prático para verificar a mudança de polaridade dos materiais, e não teve por objetivo a quantificação do grau de modificação. 
De acordo com a TAB. 5 as zeólitas não modificadas não apresentaram hidrofobicidade, ou seja, após o término do teste, 100\% da massa utilizada de zeólita encontrava-se na fase aquosa. Por outro lado, foi possível verificar 0 alto grau de hidrofobicidade para as zeólitas modificadas. Esses resultados confirmam que o surfactante tornou os materiais hidrofóbicos e que os mesmos terão, preferencialmente, uma interação maior pelo composto orgânico do que pela água. Esse fato pode ser comprovado posteriormente nos ensaios de adsorção, nos quais a remoção de corante é superior sobre as zeólitas modificadas. Este fenômeno foi semelhante aos relatados em Sidik et al., 2012, no estudo da interação hidrofóbica entre óleo de folhas de palmeira modificado e óleo bruto, e em Taffarel e Rubio, 2010, que avaliaram a eficiência de adsorção de um surfactante aniônico (dodecil benzeno sulfonato de sódio) sobre uma zeólita natural modificada.

Os dados de perda por calcinação das cinzas de carvão podem indicar a eficiência de combustão de uma usina termelétrica. Os elevados níveis desta propriedade torna difícil a síntese de zeólitas, tal como a fase não reativa pode ser uma quantidade menor durante a conversão. A perda por calcinação é geralmente um indicativo da presença de carvão não queimado e fases minerais estáveis a altas temperaturas (Umaña-Peña, 2002). Os valores encontrados (TAB. 5) para CLC e CPC foram de $15,1 \%$ e $9,33 \%$, respectivamente. De acordo com os valores obtidos de perda por calcinação das cinzas leves brasileiras foi sugerido que a Usina Termelétrica Jorge Lacerda tem uma baixa eficiência (Izidoro et al, 2012).

\subsubsection{Composição Química}

$\mathrm{Na}$ TAB. 6 é apresentada a composição química, obtida por fluorescência de raios $X$ (em \% em massa), das cinzas leves (CLC) e pesadas (CPL) de carvão e suas respectivas zeólitas (ZCL e ZCP), e das zeólitas modificadas por surfactante (ZMSL e ZMSP). Alguns valores da TAB. 6 estão na literatura (Izidoro, 2013; Bertolini et al., 2013). 
TABELA 6 - Composição química dos adsorventes

\begin{tabular}{ccccccc}
\hline ELEMENTOS & CLC & CPC & ZCL & ZCP & ZMSL & ZMSP \\
\hline $\mathrm{Fe}_{2} \mathrm{O}_{3}$ & 6,7 & 10,9 & 8,3 & 16,1 & 8,5 & 13 \\
$\mathrm{SiO}_{2}$ & 50,3 & 49,6 & 36,6 & 35,1 & 36 & 33 \\
$\mathrm{Al}_{2} \mathrm{O}_{3}$ & 29,8 & 27 & 38 & 32,9 & 37 & 38 \\
$\mathrm{CaO}$ & 2,7 & 1,8 & 3,6 & 3,2 & 3,4 & 2,7 \\
$\mathrm{Br}$ & - & - & - & - & 0,06 & 0,05 \\
$\mathrm{TiO}_{2}$ & 2,2 & 1,9 & 2,7 & 2,4 & 2,7 & 2,0 \\
$\mathrm{SO}_{3}$ & 1,4 & 0,7 & 1,4 & 0,3 & 1,0 & 0,24 \\
$\mathrm{Na}_{2} \mathrm{O}$ & - & 1,9 & 6,9 & 7,7 & 8,7 & 8,0 \\
$\mathrm{~K}_{2} \mathrm{O}$ & 5,3 & 4,4 & 0,8 & 0,7 & 0,8 & 0,7 \\
$\mathrm{ZnO}$ & 0,10 & 0,03 & 0,09 & 0,03 & 0,09 & 0,02 \\
$\mathrm{MgO}^{\mathrm{ZrO}}$ & 1,1 & 1,3 & 1,4 & 1,3 & 1,6 & 1,4 \\
$\mathrm{SiO}_{2} / \mathrm{Al}_{2} \mathrm{O}_{3}$ & 0,05 & 0,03 & 0,05 & 0,04 & 0,06 & 0,04 \\
& 1,69 & 1,84 & 0,96 & 1,06 & 0,97 & 0,87 \\
\hline
\end{tabular}

Os constituintes principais observados para as CLC e CPC foram a sílica $\left(\mathrm{SiO}_{2}\right)$, alumina $\left(\mathrm{Al}_{2} \mathrm{O}_{3}\right)$, e óxido férrico $\left(\mathrm{Fe}_{2} \mathrm{O}_{3}\right)$. Quantidades inferiores a 5 wt.\% de $\mathrm{K} 2 \mathrm{O}, \mathrm{CaO}, \mathrm{TiO}_{2}, \mathrm{SO}_{3}$ e $\mathrm{MgO}$ também foram observados. A relação $\mathrm{SiO}_{2} / \mathrm{Al}_{2} \mathrm{O}_{3}$ foi de 1,69 e 1,84 para CLC e CPC, respectivamente, indicando uma boa fonte para sintetizar zeólitas (Shigemoto et al., 1993).

O carvão e as respectivas cinzas geradas na usina termelétrica Jorge Lacerda foram analisados por Silva et al 2010. Os resultados indicaram que o carvão é do tipo betuminoso, altamente volátil (C/A). As amostras de cinzas leves coletadas nos precipitadores eletrostáticos apresentaram as seguintes faixas de teores dos elementos principais de maior concentração (\% em massa): 57,98 - 60,10 de $\mathrm{SiO}_{2}, 22,98$ - 26,97 de $\mathrm{Al}_{2} \mathrm{O}_{3}$ e 4,67 - 8,01 de $\mathrm{Fe}_{2} \mathrm{O}_{3}$. Para as amostras de cinzas pesadas as faixas foram: 46,14 - 61,95 de $\mathrm{SiO}_{2}, 19,20-23,88$ de $\mathrm{Al}_{2} \mathrm{O}_{3}$ e $5,38-7,81$ de $\mathrm{Fe}_{2} \mathrm{O}_{3}$.

A composição química encontrada para os materiais zeolíticos foram principalmente sílica $\left(\mathrm{SiO}_{2}\right)$, alumina $\left(\mathrm{Al}_{2} \mathrm{O}_{3}\right)$ e óxido férrico $\left(\mathrm{Fe}_{2} \mathrm{O}_{3}\right)$. Encontraramse os óxidos de cálcio, titânio, enxofre e outros compostos em quantidades $\leq 5,1 \%$. Uma quantidade significativa do elemento $\mathrm{Na}$ é incorporada nos produtos finais devido ao tratamento hidrotérmico com solução de $\mathrm{NaOH}$. A presença do brometo na ZMSL e ZMSP foi detectada, já que a carga positiva do cátion HDTMA adsorvido na superfície da zeólita é contrabalanceada pelos ânions brometo. 
A razão $\mathrm{SiO}_{2} / \mathrm{Al}_{2} \mathrm{O}_{3}$ das zeólitas está associada à capacidade de troca catiônica. Os materiais zeolíticos que apresentam valor menor desta relação apresentam uma alta capacidade das partículas de trocarem íons positivamente carregados. De acordo com a TAB. 6, os valores para ZCL, ZCP, ZMSL e ZMSP são inferiores àqueles encontrados para as cinzas de origem, indicando que o tratamento hidrotérmico alcalino contribuiu para o aumento do potencial de utilização dos materiais zeolíticos como trocadores iônicos.

\subsubsection{Composição Mineralógica}

Os difratogramas de raios $X$ da ZCL e ZCP estão apresentados nas FIG. 16 e 17, respectivamente.

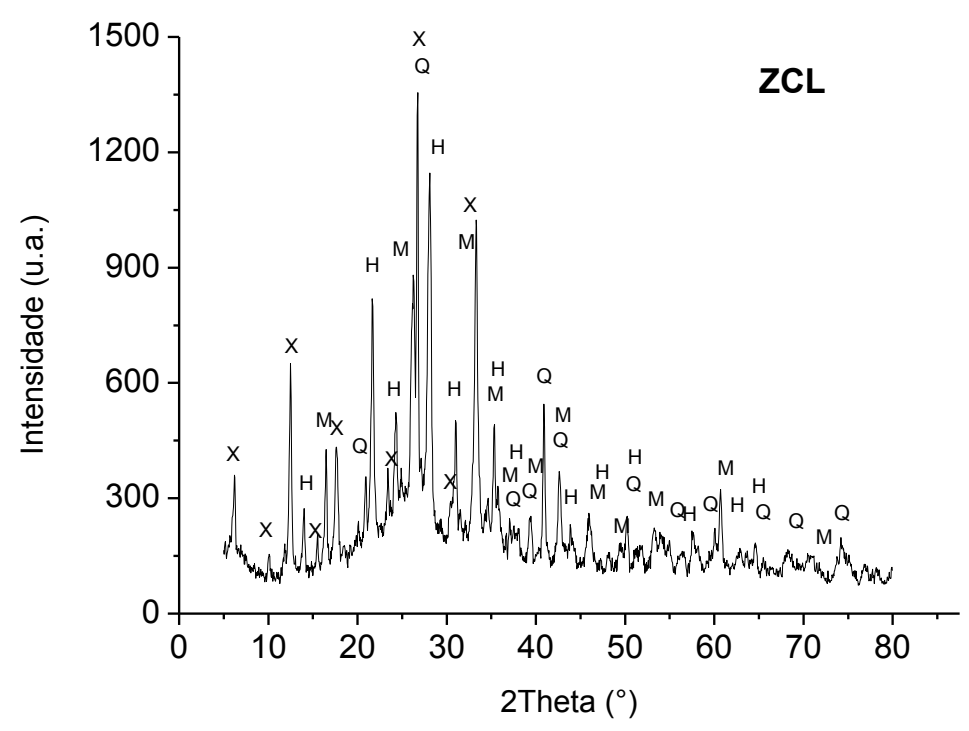

FIGURA 16 - Difratograma de raios X da ZCL (Q=Quartzo, M=Mulita, H=zeólita hidroxisodalita, $\mathrm{X}=$ zeólita $\mathrm{NaX}$ ) 


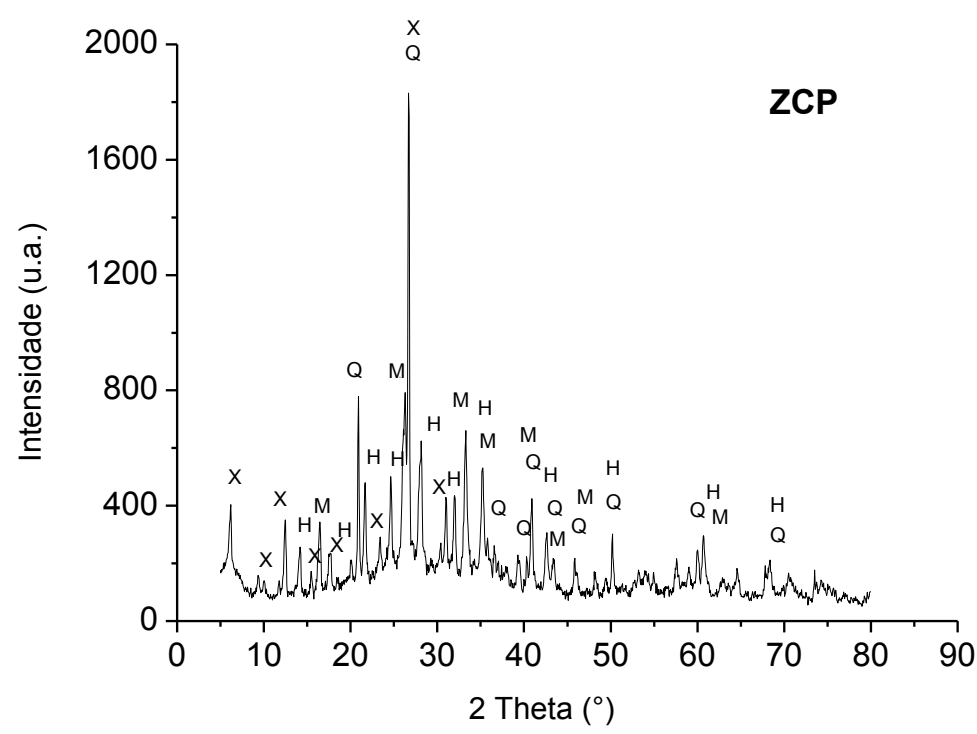

FIGURA 17 - Difratograma de raios X da ZCP (Q=Quartzo, M=Mulita, H=zeólita hidroxisodalita, $\mathrm{X}=$ zeólita $\mathrm{NaX}$ )

A identificação e interpretação dos padrões PXRD dos materiais são preparados por comparar o banco de dados de difração fornecido pelo "Centro Internacional para a difração de Dados / Comité Misto no poder Padrões de difração" (ICDD / JCPDS). As espécies cristalinas identificadas nos materiais zeolíticos foram hidroxisodalita (JCPDS 31-1271) e NaX (JCPDS 38-0237), com picos de quartzo (JCPDS 85-0796) e mulita (JCPDS 74-4143) de cinzas que permaneceram após o tratamento hidrotérmico alcalino. A composição mineralógica das cinzas utilizadas como matéria prima para a síntese de zeólitas depende dos fatores geológicos relacionados com a formação e deposição de carvão e as suas condições de combustão.

As análises de DRX das zeólitas modificadas e das zeólitas saturadas dos corantes foram realizadas para confirmar se ocorria uma modificação da estrutura cristalina e da identidade dos materiais após a modificação com surfactante e a adsorção dos corantes.

As FIG. 18 e 19 mostram os difratogramas das zeólitas modificadas por surfactante (ZMSL e ZMSP) com sobreposição dos difratogramas das zeólitas não modificadas (ZCL e ZCP). 


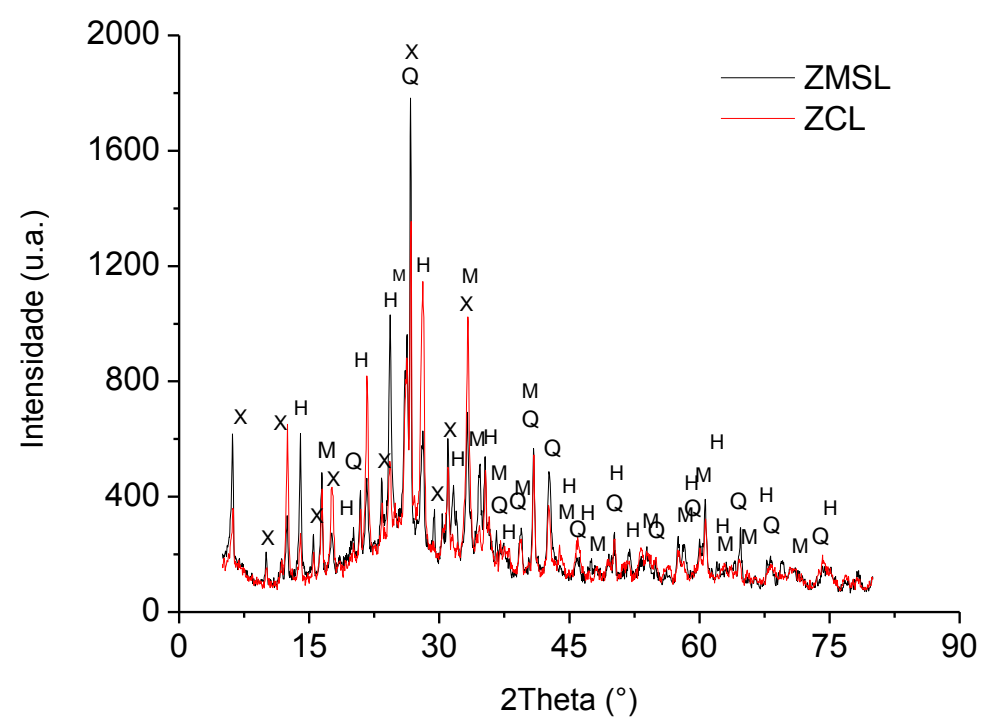

FIGURA 18 - Difratogramas da zeólita (ZCL) e da zeólita modificada por surfactante (ZMSL)

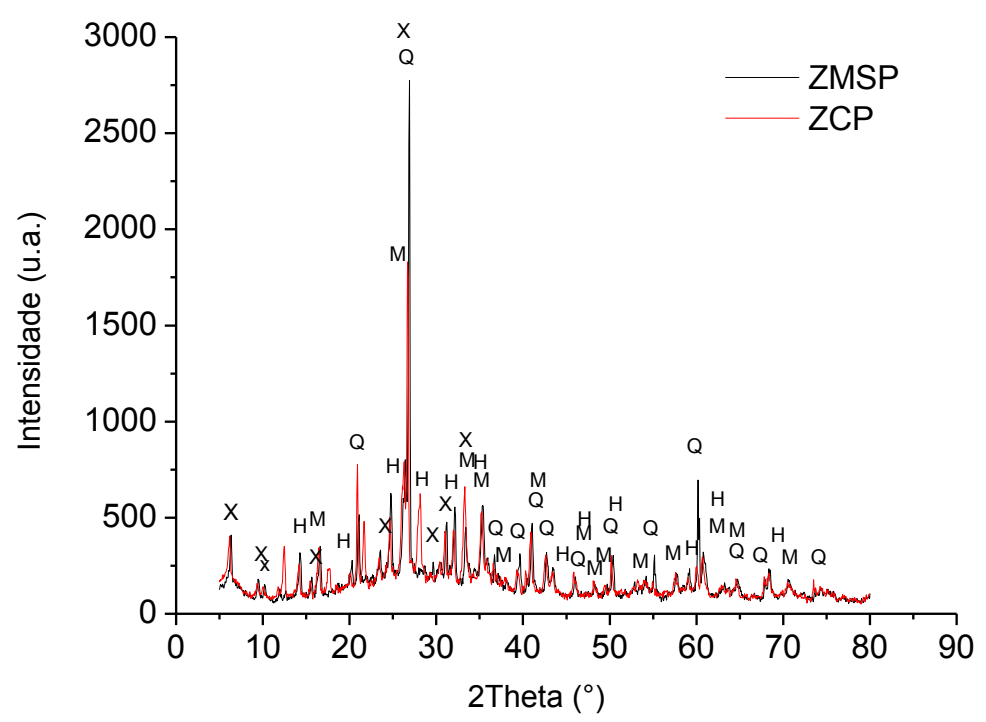

FIGURA 19 - Difratogramas da zeólita (ZCP) e da zeólita modificada por surfactante (ZMSP)

Os parâmetros estruturais das zeólitas modificadas por surfactante eram muito próximos daqueles da correspondente zeólita não modificada, indicando que a natureza cristalina da zeólita permaneceu intacta após a adsorção das moléculas do HDTMA-Br e o aquecimento para secagem do material adsorvente. 
De acordo com os parâmetros estruturais apresentados nas FIG. 20 e 21, as zeólitas modificadas saturadas dos corantes apresentaram um perfil semelhante ao das zeólitas modificadas por surfactante. Após a adsorção do CV e do AL8, a natureza cristalina dos sistemas corante/zeólita e corante/zeólita modificada permaneceu intacta (Lin et al., 2011).
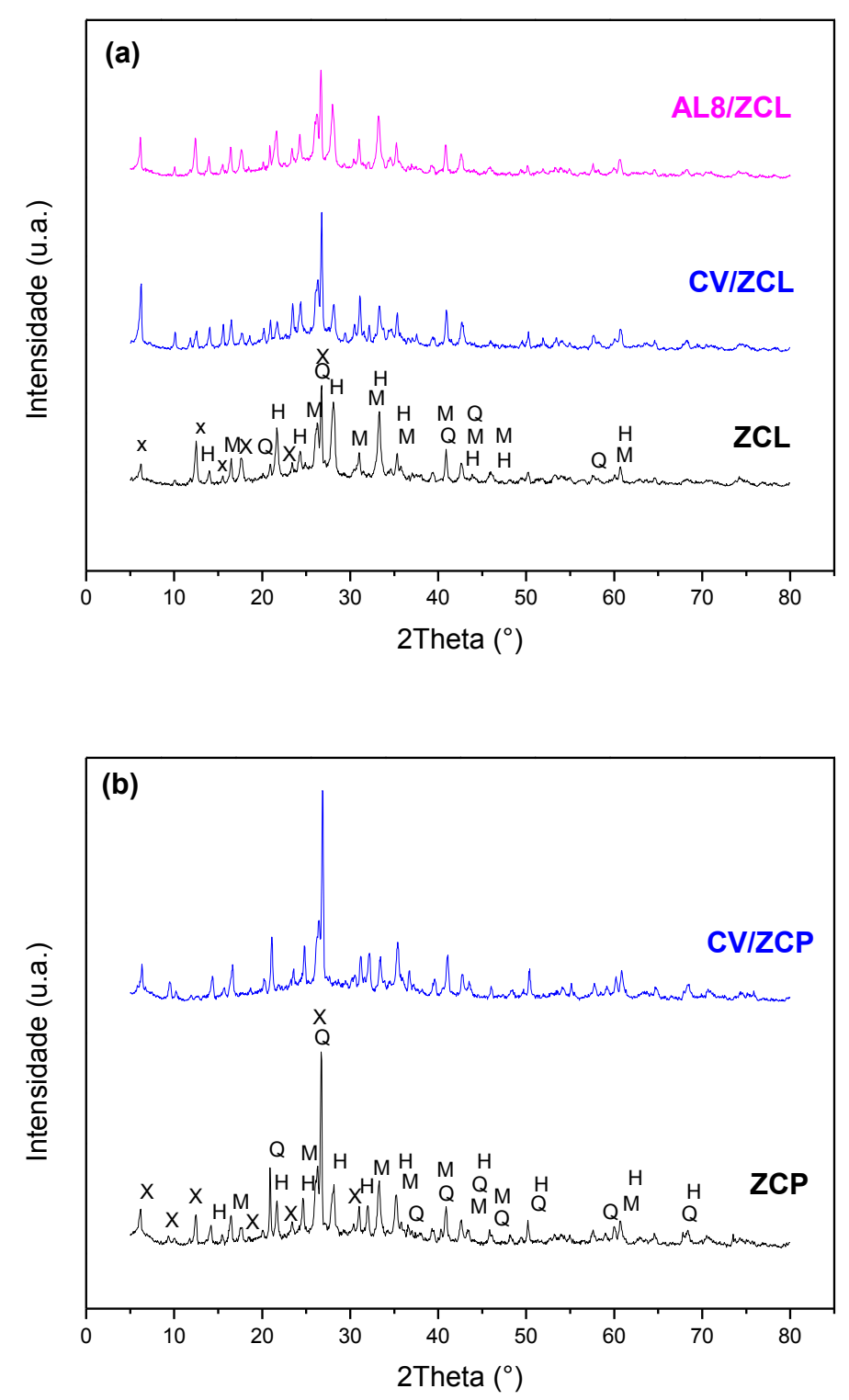

FIGURA 20 - Difratogramas de raios $X$ das zeólitas não modificadas antes e após adsorção com os corantes (a) ZCL; (b) ZCP (Q=Quartzo, M=Mulita, H=zeólita hidroxisodalita, $\mathrm{X}=$ zeólita $\mathrm{NaX}$ ) 

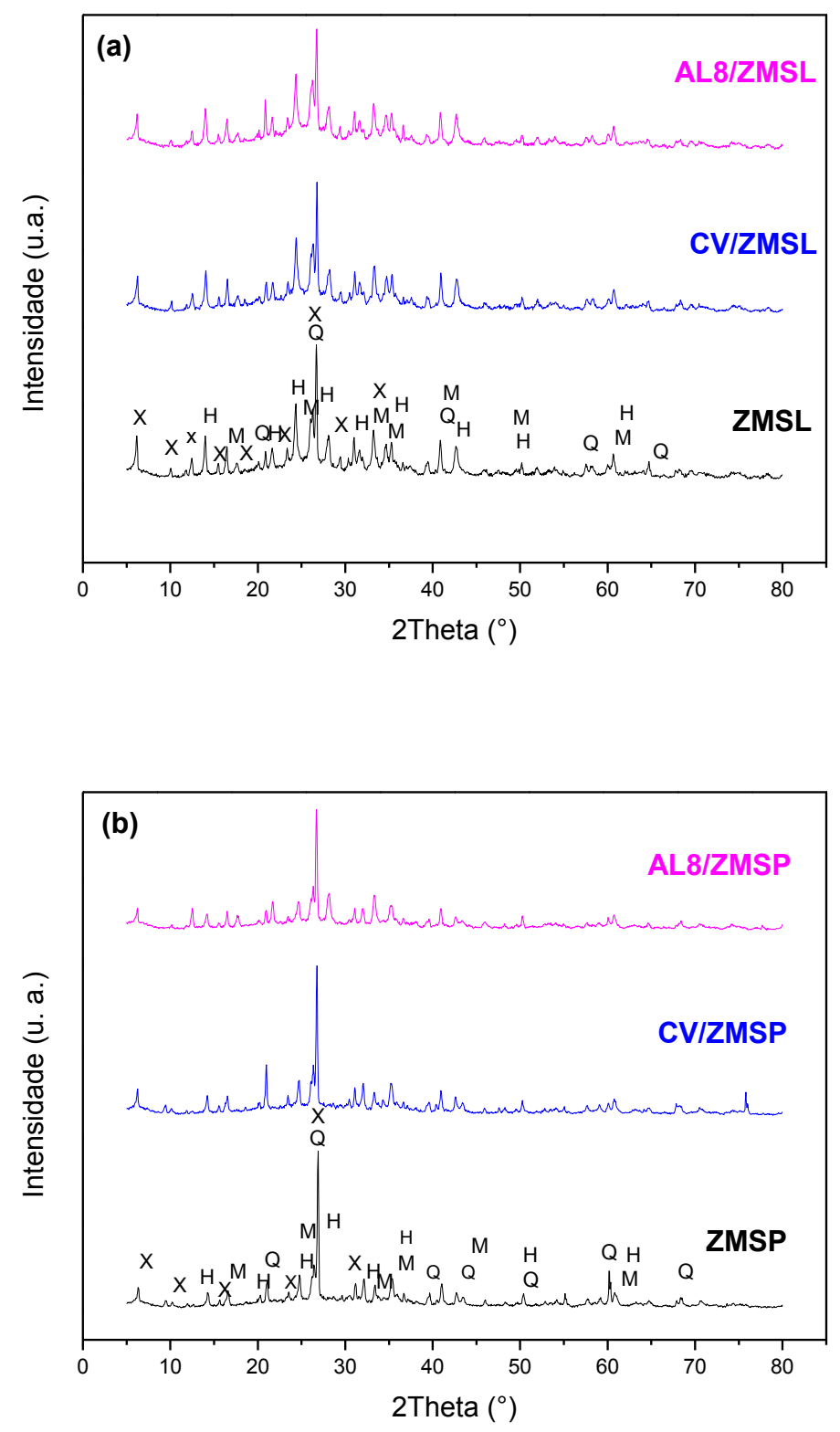

FIGURA 21 - Difratogramas de raios $X$ das zeólitas modificadas antes e após adsorção com os corantes (a) ZMSL; (b) ZMSP (Q=Quartzo, M=Mulita, H=zeólita hidroxisodalita, $\mathrm{X}=$ zeólita $\mathrm{NaX}$ )

\subsubsection{Identificação de grupos funcionais}

A técnica de espectroscopia de infravermelho com transformada de Fourier (FTIR) é relevante para estudar a interação entre os grupos ativos do adsorbato e o adsorvente.

As amostras das zeólitas modificadas e das zeólitas saturadas dos corantes foram submetidas à análise por espectroscopia de infravermelho para 
confirmar se ocorria uma mudança estrutural após a modificação com surfactante e a adsorção dos corantes.

Os espectros das zeólitas antes e após a modificação com HDTMA-Br são mostrados nas FIG. 22 e 23.
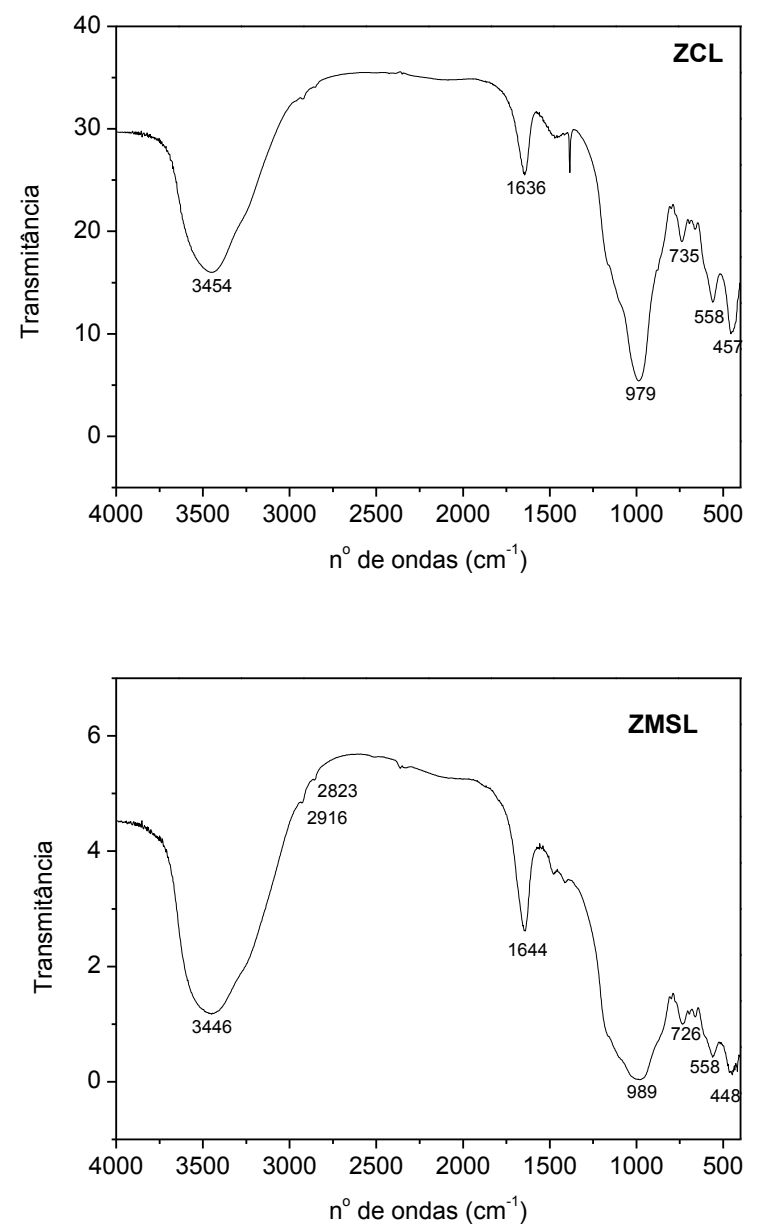

FIGURA 22 - Espectros de infravermelho da ZCL e da ZMSL 


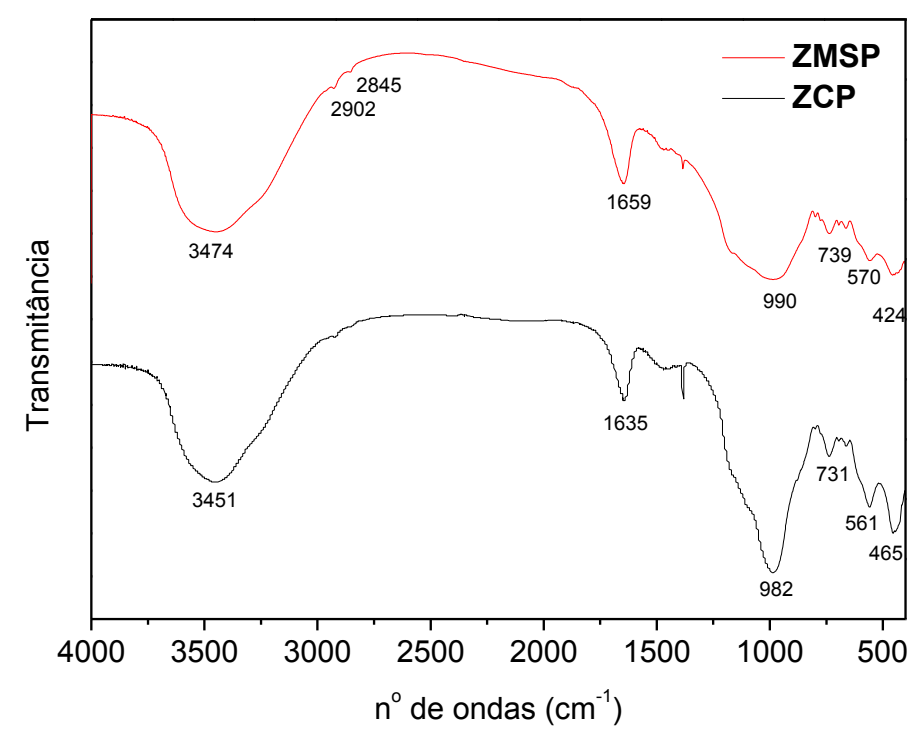

FIGURA 23 - Espectros de infravermelho da ZCP e da ZMSP

A TAB. 7 apresenta as atribuições das bandas do espectro de IV dos adsorventes sintetizados neste estudo. 
TABELA 7 - Atribuições das bandas do espectro IV das zeólitas não modificadas e modificadas por surfactante

\begin{tabular}{|c|c|c|c|c|}
\hline \multirow{2}{*}{ ATRIBUIÇÃO } & \multicolumn{4}{|c|}{ NÚMERO DE ONDA $\left(\mathrm{cm}^{-1}\right)$} \\
\hline & ZCL & ZCP & ZMSL & ZMSP \\
\hline$\checkmark(\mathrm{O}-\mathrm{H})_{\text {sim e assim }}$ & 3454 & 3451 & 3446 & 3474 \\
\hline Estiramento & & & & \\
\hline $\begin{array}{c}\mathrm{CH}_{2} \text { assimétrico do } \\
\text { HDTMA-Br } \\
\text { Estiramento }\end{array}$ & - & - & 2916 & 2902 \\
\hline $\begin{array}{c}\mathrm{CH}_{2} \text { simétrico do } \\
\text { HDTMA-Br }\end{array}$ & - & - & 2823 & 2845 \\
\hline $\mathrm{H}_{2} \mathrm{O}$ & 1636 & 1635 & 1644 & 1659 \\
\hline $\begin{array}{l}\text { Estiramento } \\
\text { assimétrico da } \\
\text { Hidroxisodalita }\end{array}$ & 979 & 982 & 989 & 990 \\
\hline Anel duplo ( $\mathrm{NaX})$ & 558 & 561 & 558 & 570 \\
\hline Quartzo & 735 & 731 & 726 & 739 \\
\hline $\begin{array}{l}\text { Flexão } \\
\text { T-O }\end{array}$ & 457 & 465 & 448 & 424 \\
\hline
\end{tabular}

As bandas dos espectros da ZCL e da ZCP entre 982 a $424 \mathrm{~cm}^{-1}$ correspondem à formação da zeólita hidroxisodalita (Covarrubias et al., 2006) e da zeólita NaX (Menzi et al., 2011).

A identificação de bandas em 2823 e $2916 \mathrm{~cm}^{-1}$ e em 2845 e $2902 \mathrm{~cm}^{-1}$ nos espectros da ZMSL e da ZMSP, respectivamente, correspondem aos modos de vibração do estiramento $\mathrm{C}-\mathrm{H}$, dos grupos metileno, assimétrico $\left(\right.$ vs $\left.\mathrm{CH}_{2}\right)$ e simétrico (vs $\mathrm{CH}_{2}$ ), respectivamente, devido às moléculas do surfactante (Covarrubias et al., 2006). O aparecimento destas bandas principais do 
HDTMA-Br e a similaridade dos espectros da zeólitas não modificadas e das modificadas evidenciam que ocorreu a adsorção do surfactante na superfície dos adsorventes sem comprometer a estabilidade estrutural dos mesmos.

Os espectros de infravermelho dos corantes CV e AL8 encontram-se no ANEXO A e as respectivas atribuições das bandas encontradas na literatura são apresentadas nas (TAB. 8 e 9).

TABELA 8 - Atribuições das bandas do espectro IV do CV

\begin{tabular}{|c|c|c|}
\hline Atribuição & Número de onda $\left(\mathrm{cm}^{-1}\right)$ & Referência \\
\hline Estiramento do grupo $-\mathrm{N}-\mathrm{H}-$ & $3440-2918$ & \\
\hline Estiramento do grupo $\mathrm{C}=\mathrm{C}$ & 1590 & \\
\hline $\begin{array}{c}\text { Estiramento assimétrico } \\
\text { do grupo } \mathrm{CH}_{3}\end{array}$ & 1375 & Cheng et al., 2012 \\
\hline Vibração do Anel benzênico & 802 & \\
\hline
\end{tabular}

TABELA 9 - Atribuições das bandas do espectro IV do AL8

\begin{tabular}{|c|c|c|}
\hline Atribuição & Número de onda $\left(\mathrm{cm}^{-1}\right)$ & Referência \\
\hline Estiramento $-\mathrm{N}=\mathrm{N}-$ & 1509 & Elías et al., 2012 \\
\hline Grupo $-\mathrm{N}-\mathrm{H}$ (forma hidrazona) & 1500 & Elías et al., 2012 \\
\hline $\begin{array}{l}\text { Vibração do esqueleto } \\
\text { aromático }\end{array}$ & 1623 & Elías et al., 2012 \\
\hline Flexão O-H & 1420 & Lucarelli et al., 2000 \\
\hline $\begin{array}{l}\text { Estiramento simétrico do } \\
\text { grupo } \mathrm{SO}_{3}^{-}\end{array}$ & 1124 & Elías et al., 2012 \\
\hline $\begin{array}{l}\text { Estiramento assimétrico do } \\
\text { grupo } \mathrm{SO}_{3}^{-}\end{array}$ & 1212 & Wang et al., 2012 \\
\hline Vibração -N-N- & 1216 & Stylidi et al., 2003 \\
\hline
\end{tabular}


Nas FIG. 24 e 25 são mostrados os espectros de infravermelho obtidos para os adsorventes saturados dos corantes CV e AL8.

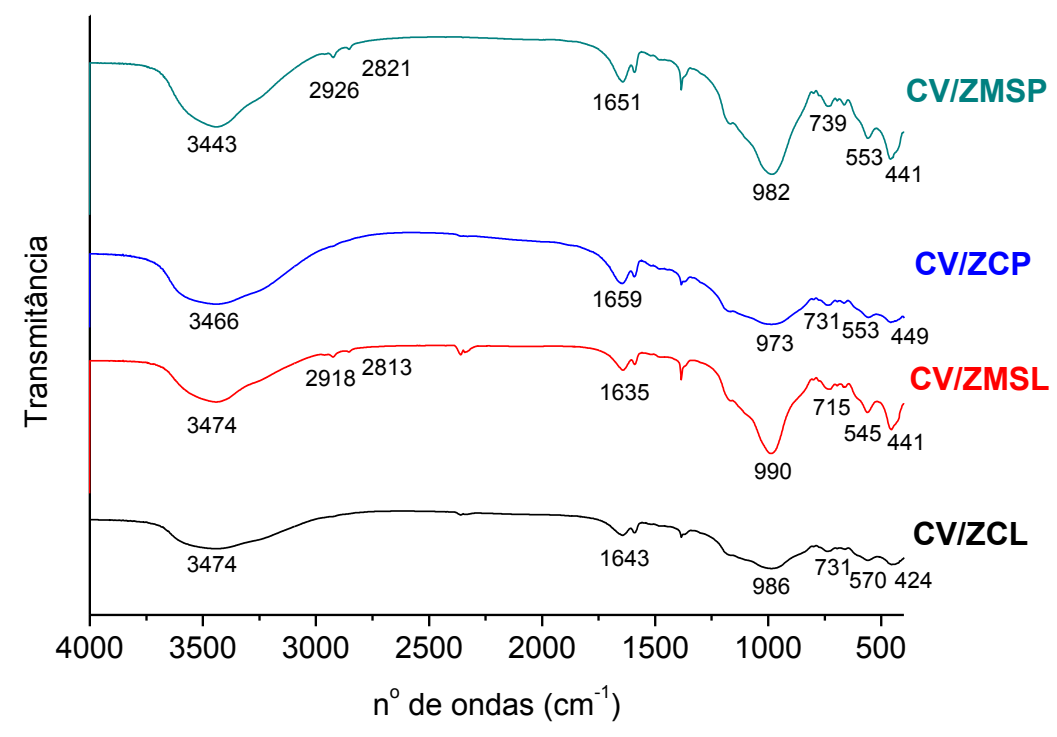

FIGURA 24 - Espectros de infravermelho dos adsorventes saturados do CV

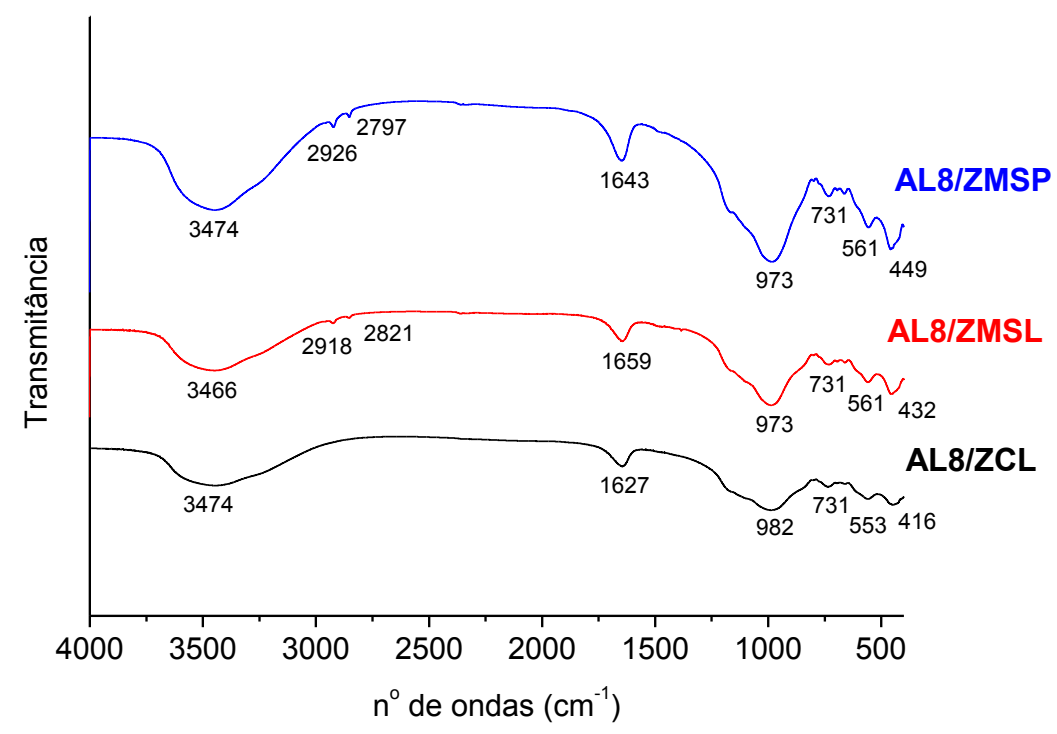

FIGURA 25 - Espectros de infravermelho dos adsorventes saturados do AL8

As bandas correspondentes à estrutura cristalina da zeólita podem ser observadas nos espectros de todos os sistemas corante/adsorvente. No caso das zeólitas modificadas, as bandas do HDTMA-Br podem ser identificadas. As 
bandas entre 2818 e 3440 correspondentes ao grupo -N-H- (TAB. 8), e as bandas entre 1124 a $1509 \mathrm{~cm}^{-1}$ características dos grupos $\mathrm{SO}_{3}^{-}$e $-\mathrm{N}=\mathrm{N}-(\mathrm{TAB} .9$ ), não são identificadas nos espectros dos adsorventes saturados dos corantes. Toda esta análise sugere que os grupos funcionais presentes na superfície dos adsorventes estejam envolvidos no processo de adsorção dos corantes.

\subsubsection{Composição Morfológica}

A técnica de Microscopia Eletrônica de Varredura (MEV) foi utilizada no presente estudo para avaliar a morfologia das partículas presentes nas amostras de cinzas e das zeólitas sintetizadas.

As micrografias das cinzas leves e pesadas utilizadas neste estudo como matéria prima para a síntese das zeólitas são mostradas no ANEXO B e na FIG. 26, respectivamente.

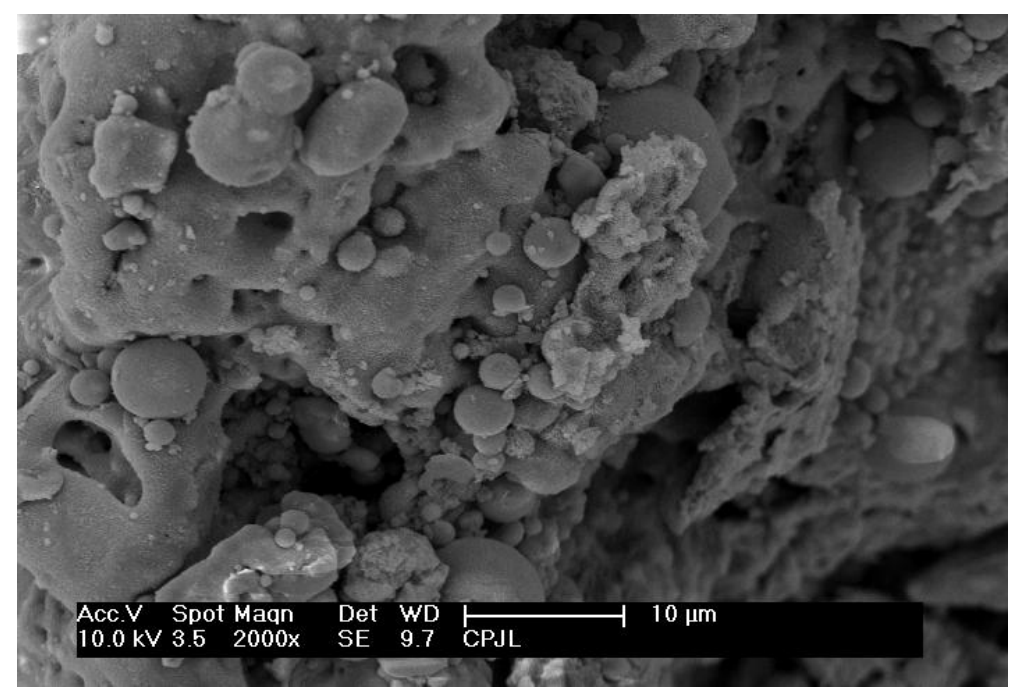

FIGURA 26 - Micrografia das cinzas pesadas de carvão

Observou-se que as partículas da CLC e da CPC são esféricas de superfícies lisas com diâmetros diferentes. Além das partículas esféricas, há também partículas de tamanhos irregulares que podem ser atribuídos a diferentes estados físicos de sílica (Sarbak et al., 2004). 
No ANEXO C e na FIG. 27 são mostradas as micrografias das amostras da ZCL e da ZCP, respectivamente.

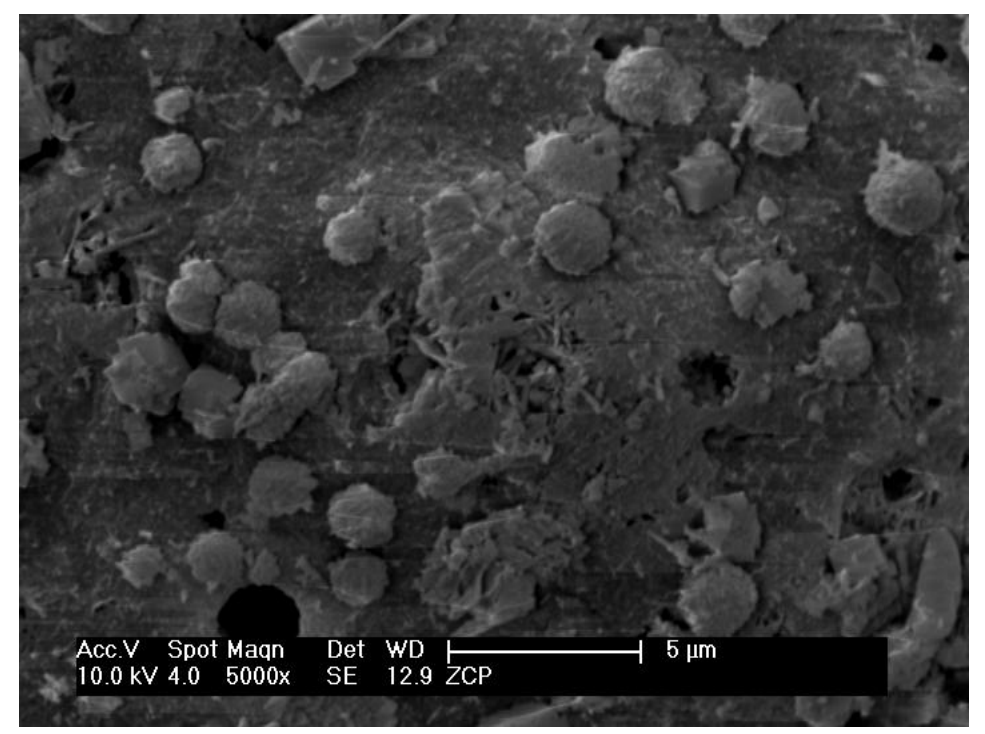

FIGURA 27- Micrografia da zeólita de cinzas pesadas

As micrografias da ZCL e da ZCP ilustram uma mudança na morfologia da superfície das partículas das cinzas após o tratamento hidrotérmico alcalino. Isto ocorre devido à dissolução da fase amorfa aluminosilicato das cinzas e posterior cristalização sobre a superfície das partículas de cinzas. Os cristais zeolíticos que precipitam durante a síntese aparecem normalmente como cristalitos de hastes orientados aleatoriamente, formando aglomerados de partículas esféricas rugosas e irregulares com forma esponjosa e de tamanhos variados (Shoumkova e Stoyanova, 2013).

As micrografias das zeólitas modificadas com surfactante são apresentadas na (FIG. 28). 
(a)

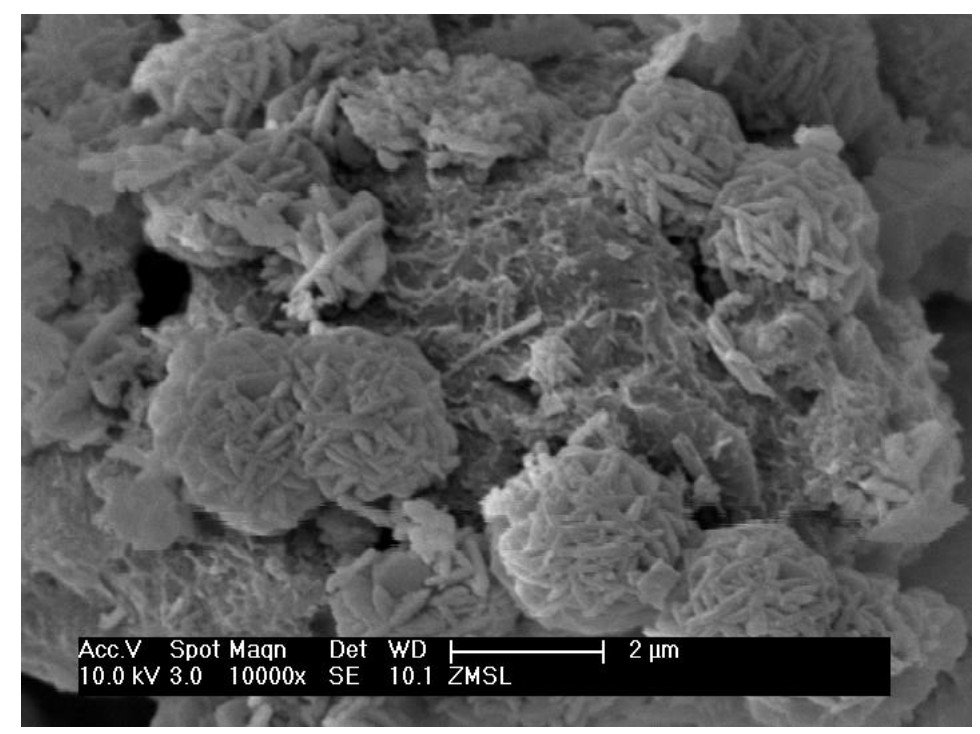

(b)

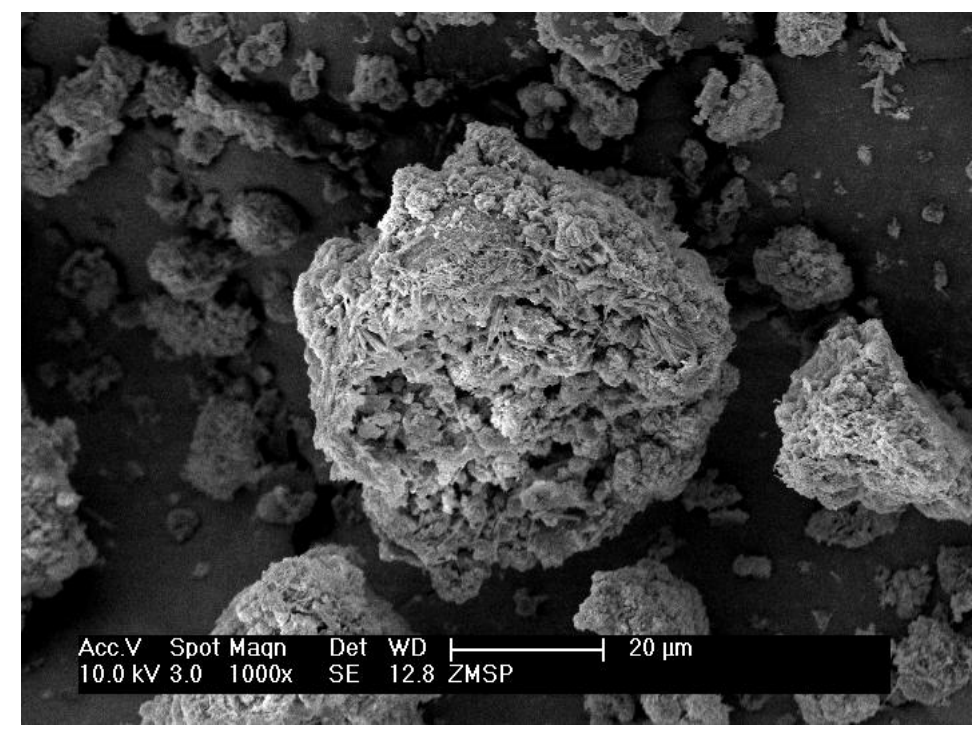

FIGURA 28 - Micrografias das zeólitas modificadas (a) ZMSL; (b) ZMSP

A diferença morfológica entre as zeólitas modificadas e as zeólitas não modificadas foi observada, porém não foi muito significativa. Depois da modificação com o surfactante, a superfície das zeólitas foi coberta com uma camada orgânica. Desta maneira, os poros tornaram-se mais densamente 
empacotados, mas sem o total desaparecimento das extremidades dos cristais da zeólita (Lin et al., 2011).

\subsection{Espectro de varredura para determinar o comprimento de onda máximo}

A varredura do espectro de absorção na região do visível da solução aquosa de Cristal Violeta $\left(10 \mathrm{mg} \mathrm{L}^{-1}\right)$ e Ácido Laranja $8\left(5 \mathrm{mg} \mathrm{L}^{-1}\right)$ apresentou um comprimento de onda de absorção máxima ( $\lambda \max$ ) em 590 nm e 491 nm, respectivamente.

Os espectros são mostrados nas FIG. 29 e 30.

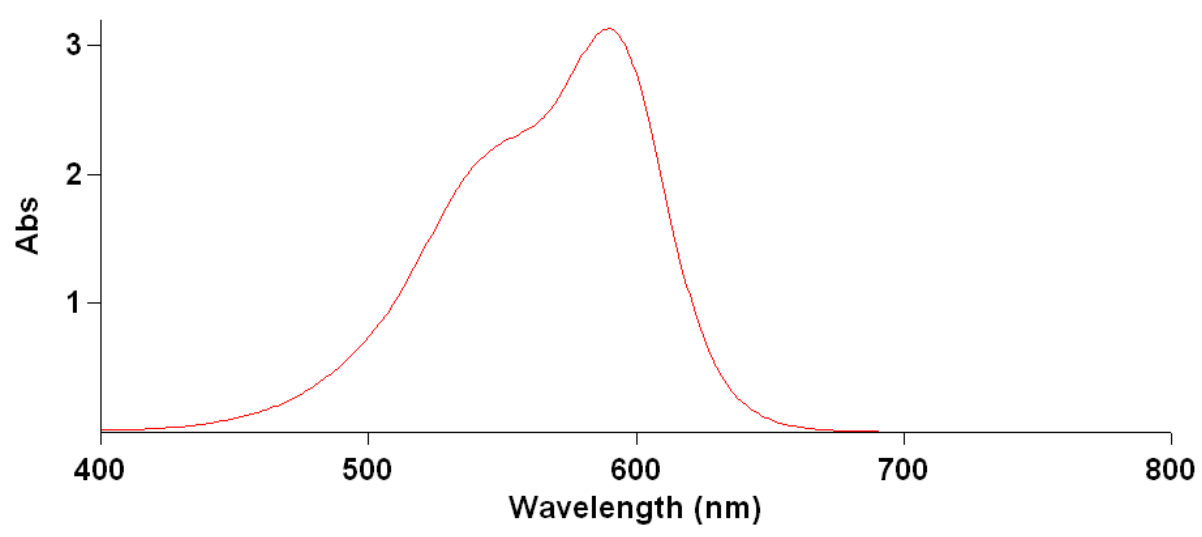

FIGURA 29 - Espectro de absorção na região do visível do Cristal Violeta

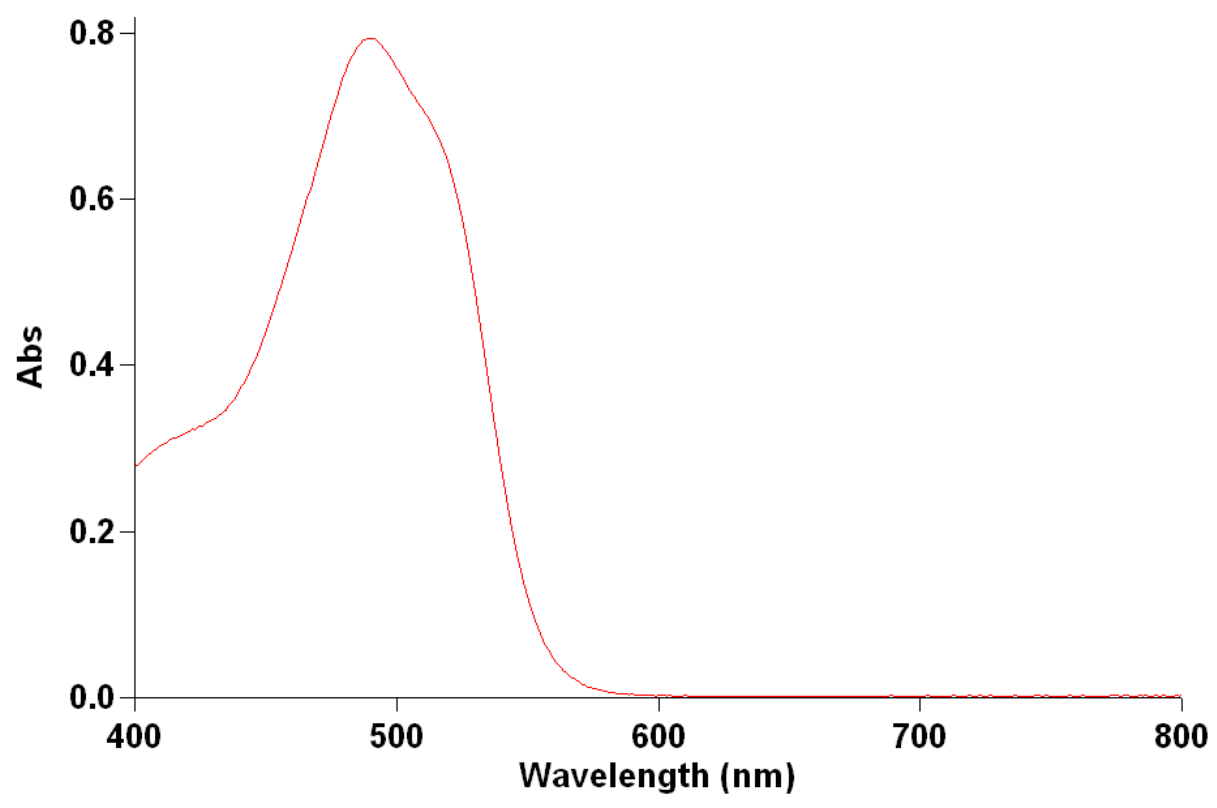

FIGURA 30- Espectro de absorção na região do visível do Ácido Laranja 8 


\subsection{Estudos cinéticos}

\subsubsection{Efeito do tempo de contato}

O efeito do tempo de agitação na adsorção do CV e do AL8 pelas zeólitas ZCL, ZCP, ZBayer, ZMSL e ZMSP foi investigado. As FIG. 31 e 32 mostram as curvas da quantidade adsorvida de corante $\left(\mathrm{mg} \mathrm{g}^{-1}\right)$ em função do tempo de contato ( $\min$ ), em diferentes concentrações iniciais do CV e do AL8. A remoção do corante em solução aumentou com o tempo de contato até atingir um equilíbrio.
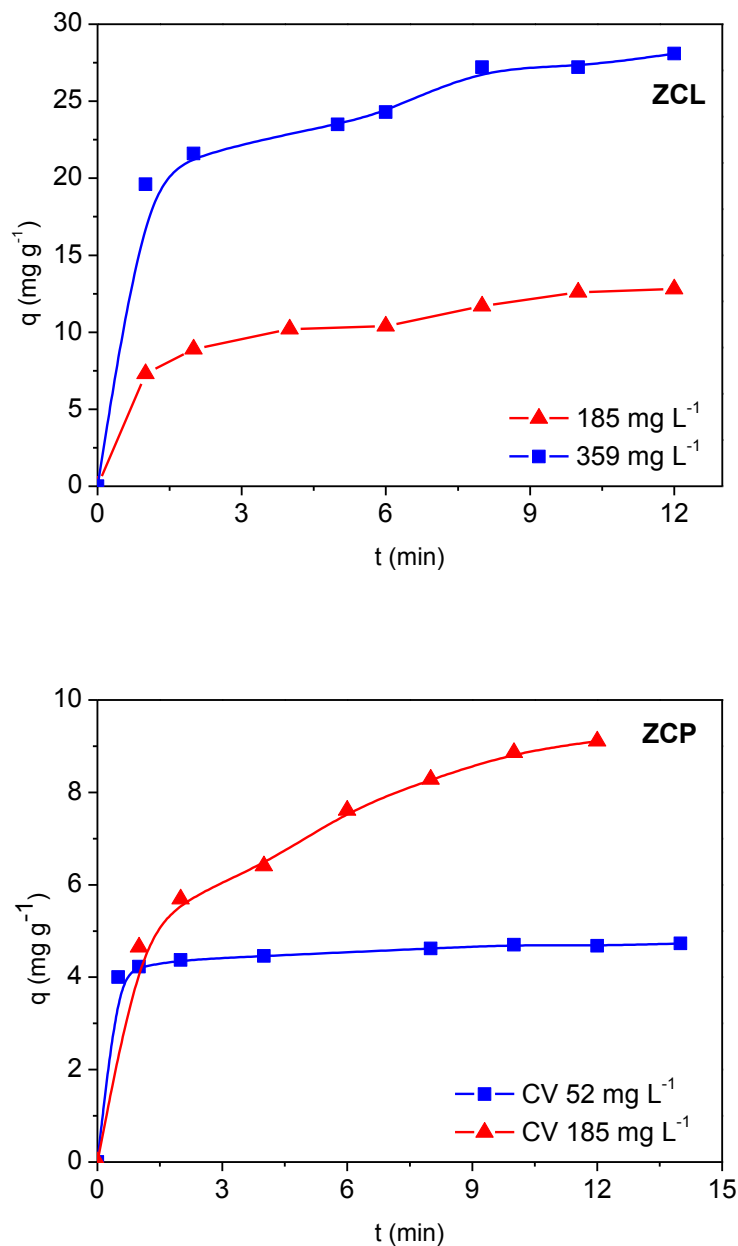

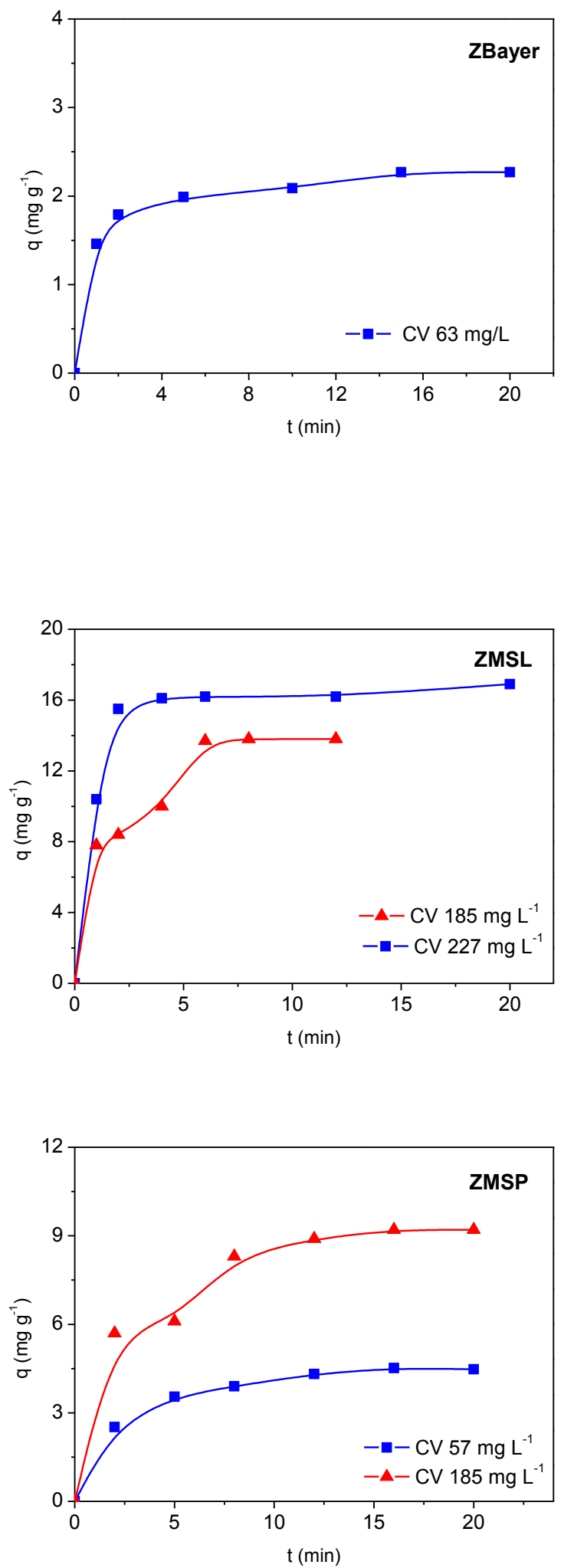

FIGURA 31 - Efeito do tempo de contato na remoção do corante CV 

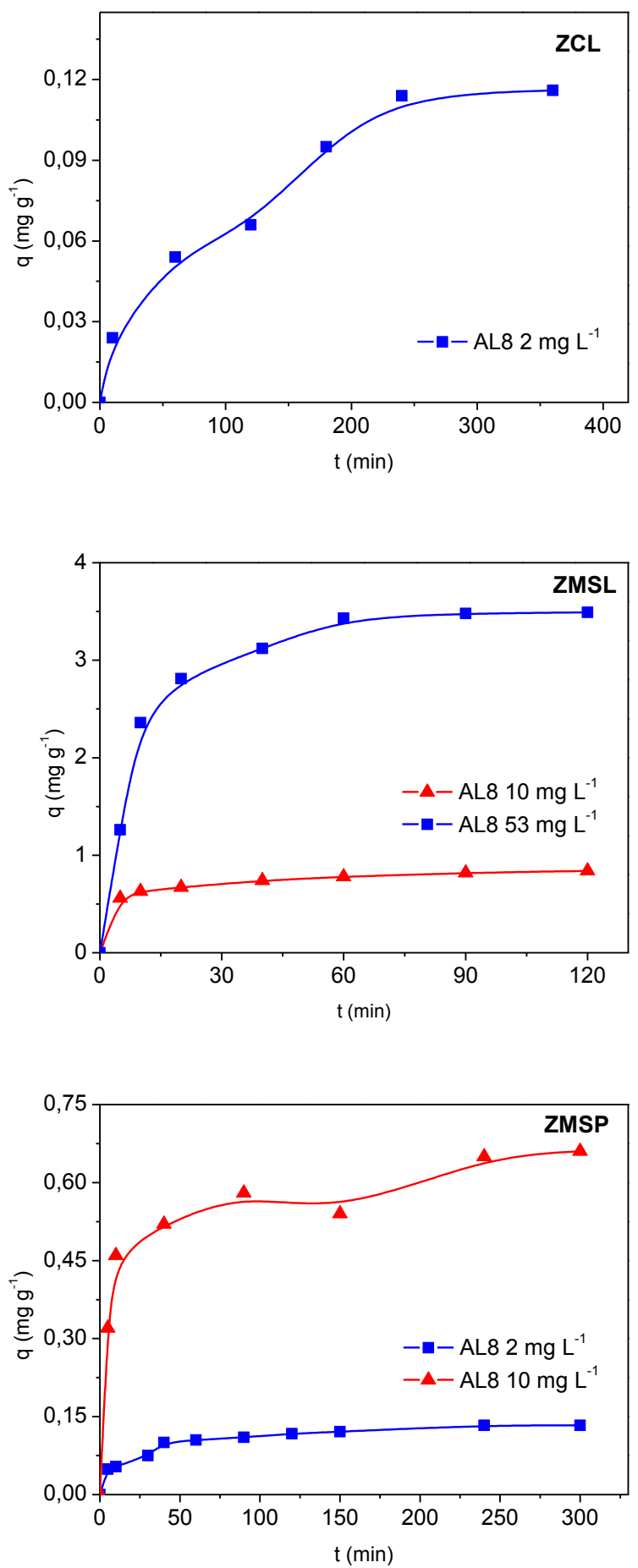

FIGURA 32 - Efeito do tempo de contato na remoção do corante AL8

Os resultados obtidos no estudo de cinética do CV e do AL8 estão apresentados nas TAB. 10 e 11, respectivamente. 
TABELA 10 - Comparação dos resultados obtidos no estudo de cinética do CV

\begin{tabular}{cccc}
\hline Adsorvente & $\begin{array}{c}\text { Concentração } \\
\text { inicial do CV } \\
\left(\mathbf{m g ~ L}^{-1}\right)\end{array}$ & $\begin{array}{c}\text { Tempo de } \\
\text { equilíbrio (min) }\end{array}$ & Remoção (\%) \\
\hline \multirow{2}{*}{ ZCL } & 185 & 10 & 71 \\
& 359 & 10 & 77 \\
\hline \multirow{2}{*}{ ZCP } & 52 & 15 & 91 \\
& 185 & 60 \\
\hline ZBayer & 63 & 6 & 37 \\
\multirow{2}{*}{ ZMSL } & 185 & 16 & 77 \\
\hline \multirow{2}{*}{ ZMSP } & 227 & 16 & 82 \\
& 57 & & 52 \\
\hline
\end{tabular}

TABELA 11 - Comparação dos resultados obtidos no estudo de cinética do AL8

\begin{tabular}{cccc}
\hline Adsorvente & $\begin{array}{c}\text { Concentração } \\
\text { inicial do CV } \\
\left(\mathbf{m g ~ L}^{-1}\right)\end{array}$ & $\begin{array}{c}\text { Tempo de } \\
\text { equilíbrio (min) }\end{array}$ & Remoção (\%) \\
\hline ZCL & 2,00 & 360 & 76 \\
\hline ZCP & 2,00 & -- & zero \\
\hline ZBayer & 2,00 & -- & zero \\
\hline \multirow{2}{*}{ ZMSL } & 10,0 & 90 & 84 \\
& 53,0 & & 67 \\
\hline \multirow{2}{*}{ ZMSP } & 2,00 & 240 & 63 \\
& 10,0 & & 68 \\
\hline
\end{tabular}

Para a ZCP e ZBayer não houve remoção do AL8, evidenciando que a utilização desses adsorventes não é viável para este corante nas condições experimentais do presente estudo.

A remoção rápida do adsorbato e o alcance de equilíbrio em um período curto de tempo são uma das indicações que o adsorvente é eficiente e também possibilita que o tratamento de efluentes seja mais econômico.

A remoção da cor das soluções aquosas de CV e AL8 por meio do processo de adsorção estão ilustradas nas FIG. 33 e 34 . Foram selecionados para esta ilustração os sistemas CV/ZCL e AL8/ZMSL. 


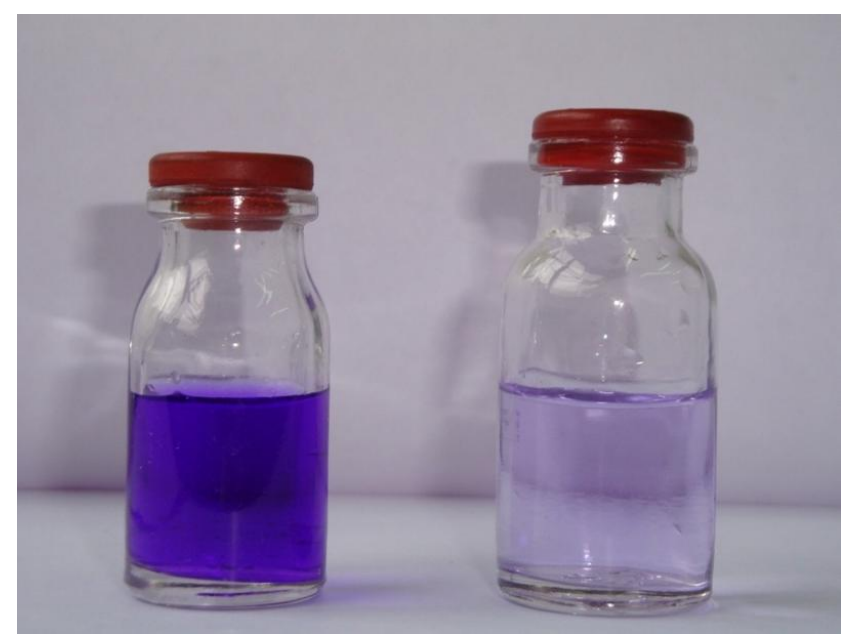

FIGURA 33 - Soluções aquosas do CV antes e após adsorção sobre ZCL em $\mathrm{t}=0$ e $\mathrm{t}$ de equilíbrio

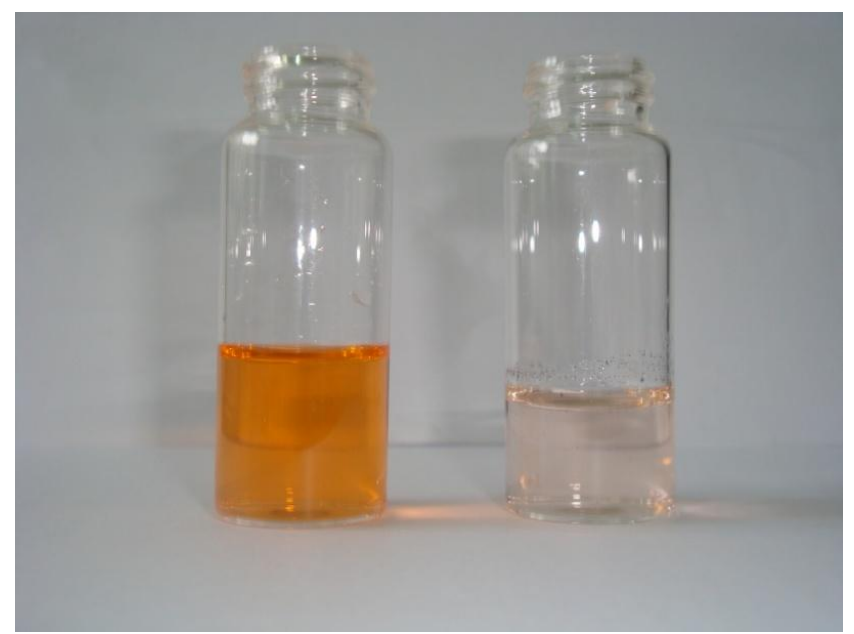

FIGURA 34 - Soluções aquosas do AL8 antes e após adsorção sobre ZMSL em $\mathrm{t}=0$ e $\mathrm{t}$ de equilíbrio

Observou-se neste estudo que após o tempo de equilíbrio ser atingido no processo de adsorção dos corantes de solução aquosa pela zeólita modificada por surfactante, uma porção do material adsorvente ficava suspensa no líquido (FIG. 35). Este fato ocorreu porque a modificação da zeólita com surfactante catiônico tornou o ambiente superficial hidrofóbico propiciando que o material apresentasse flotabilidade. Sendo assim, será possível realizar a remoção dos corantes de soluções aquosas sobre zeólita modificada e a posterior separação sólido/líquido pela técnica de flotação a ar dissolvido das partículas adsorventes. Desse modo, o tratamento poderá ser realizado em um único estágio tornando-se 
mais rápido e prático do que com o uso de centrifugação, filtração ou sedimentação.
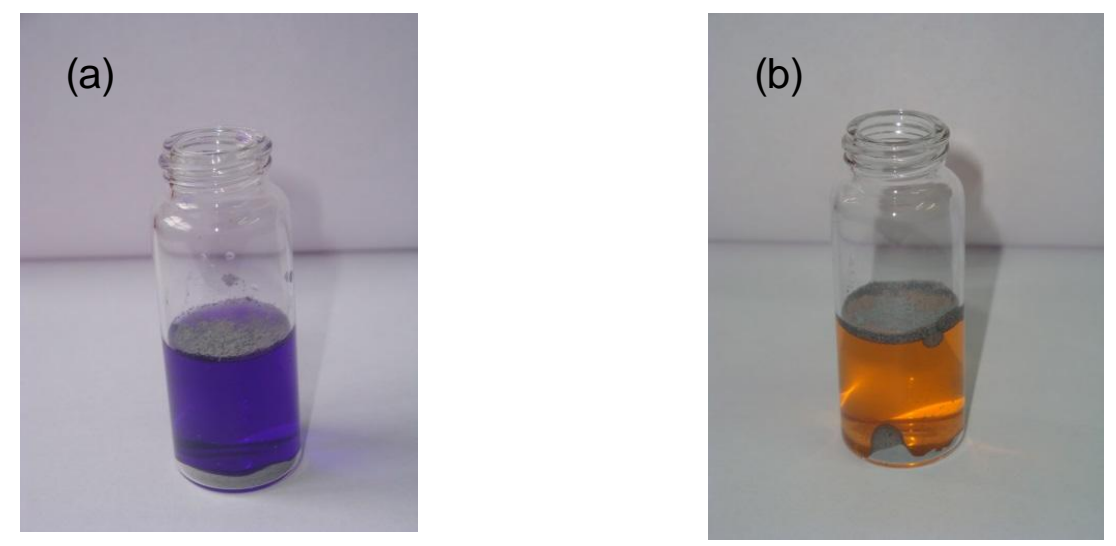

FIGURA 35 - Solução aquosa dos corantes CV (a) e AL8 (b) após adsorção com flotação do material zeólitico modificado por surfactante

O processo de flotação a ar dissolvido baseia-se na adsorção do poluente em algum material adsorvente e a posterior separação do conjunto poluente/adsorvente pela adesão em bolhas de ar (Oliveira e Rúbio, 2007; Rúbio et al., 2002).

Industrialmente, o processo de adsorção pode ser utilizado em um reator de mistura perfeita seguido de um processo de separação do adsorvente, no caso a flotação a ar dissolvido. As melhores condições de adsorção-flotação poderão ser otimizadas aumentando o valor agregado do material zeolítico modificado. Na FIG. 36 é apresentado um fluxograma do tratamento de água contendo os corantes CV e o AL8 pelo processo de adsorção sobre as zeólitas modificadas com subsequente separação por flotação. 


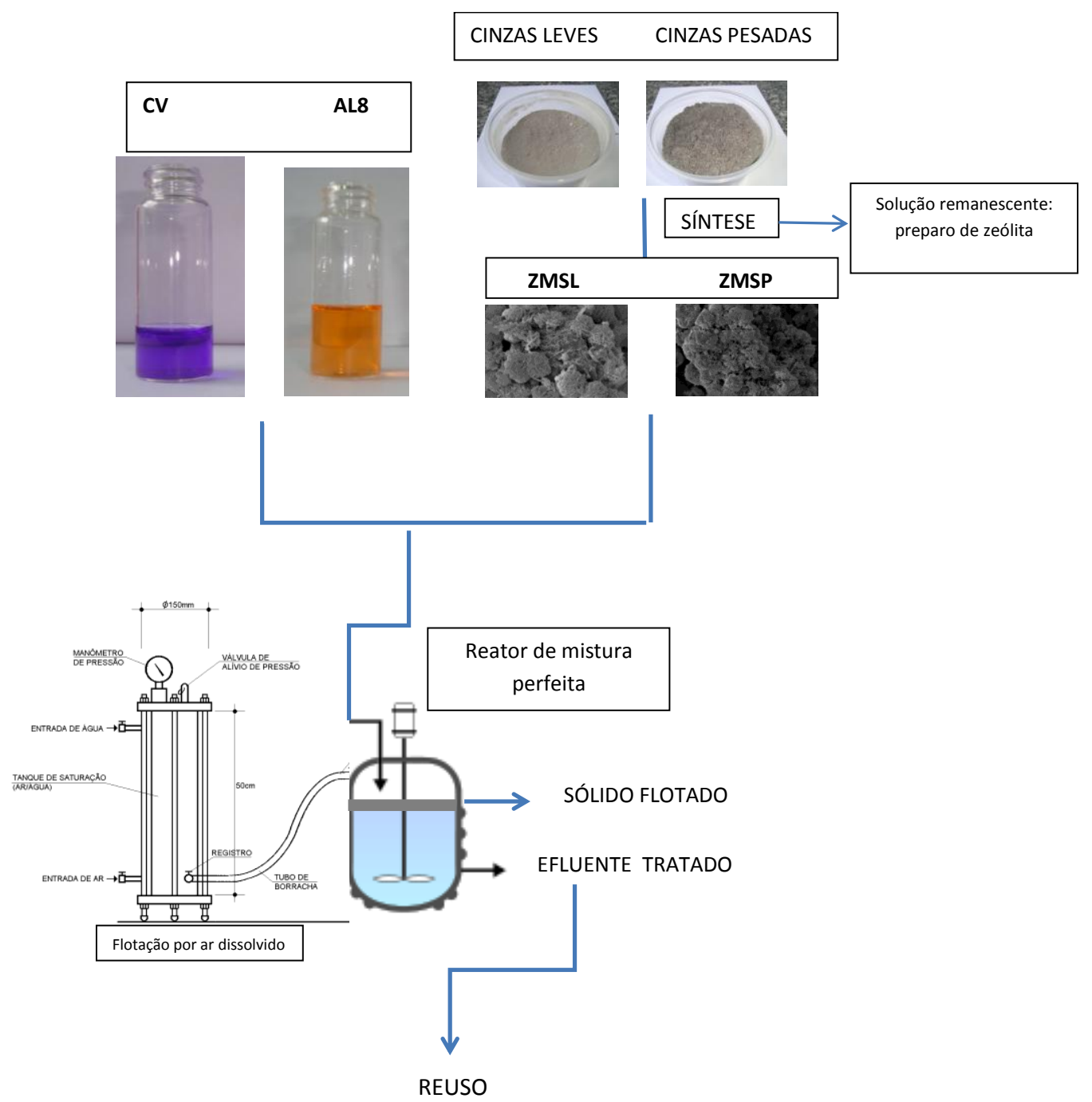

FIGURA 36 - Fluxograma do processo de adsorção-flotação para o tratamento de solução aquosa de CV e AL8 sobre zeólitas modificadas

\subsubsection{Estabilidade dos corantes}

Os estudos de estabilidade dos corantes CV e AL8 foram realizados com o objetivo de avaliar possíveis mudanças nas suas estruturas durante 0 processo de adsorção. As FIG. 37 e 38 apresentam os gráficos da variação da absorbância e do pH com o tempo de agitação para CV e AL8. O tempo máximo estudado foi de 10 min para CV e 360 min para AL8 que são os respectivos tempos de equilibrio obtidos nos estudos de cinética de adsorção de cada corante com a zeólita de cinzas leves ZCL. 


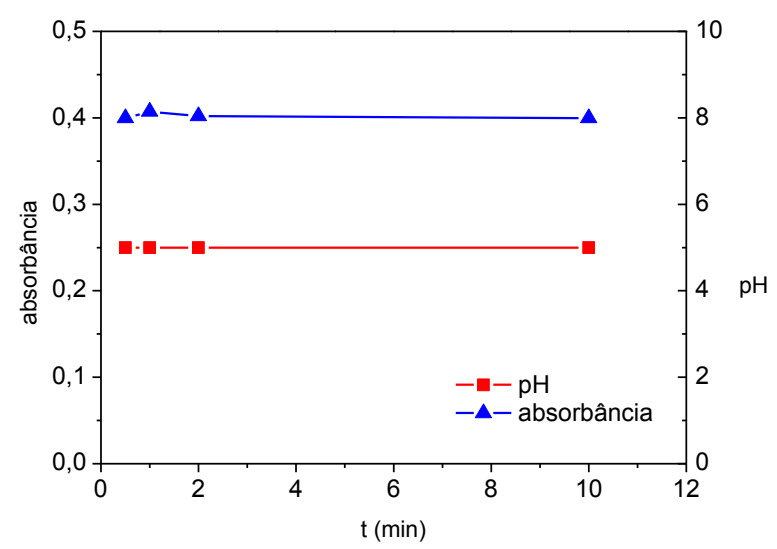

FIGURA 37 - Variação da absorbância e do pH do corante CV em função do tempo de agitação

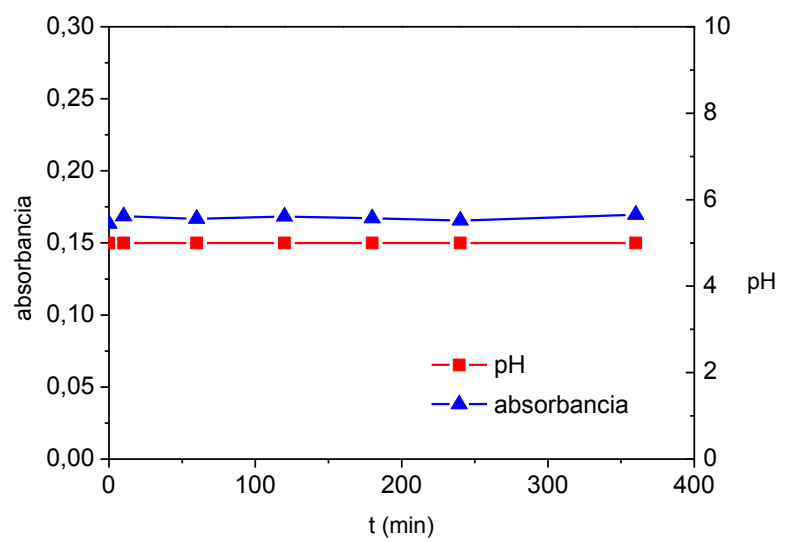

FIGURA 38 - Variação da absorbância e do pH do corante AL8 em função do tempo de agitação

Os dados mostraram que não houve variações significativas na absorbância e no pH da solução aquosa dos corantes nas condições empregadas demonstrando que as soluções aquosas dos corantes não se degradam com o tempo e sob agitação.

\subsubsection{Modelagem cinética}

As cinéticas de adsorção foram descritas pelos modelos de pseudoprimeira-ordem, de pseudo-segunda-ordem e de difusão intrapartícula utilizandose as equações de Lagergren (equação 4), de Ho (equação 5) e de Weber e Morris (equação 7), respectivamente. 
Os ajustes dos resultados do processo de adsorção do cristal violeta sobre os adsorventes, aos vários modelos cinéticos, são mostrados nas FIG. 39, 40, 41, 42 e 43 e do Ácido Laranja 8 nas FIG. 44, 45 e 46. Os parâmetros cinéticos foram obtidos pelas regressões lineares dos gráficos de cada modelo e estão apresentados nas (TAB. 12 e 13). 

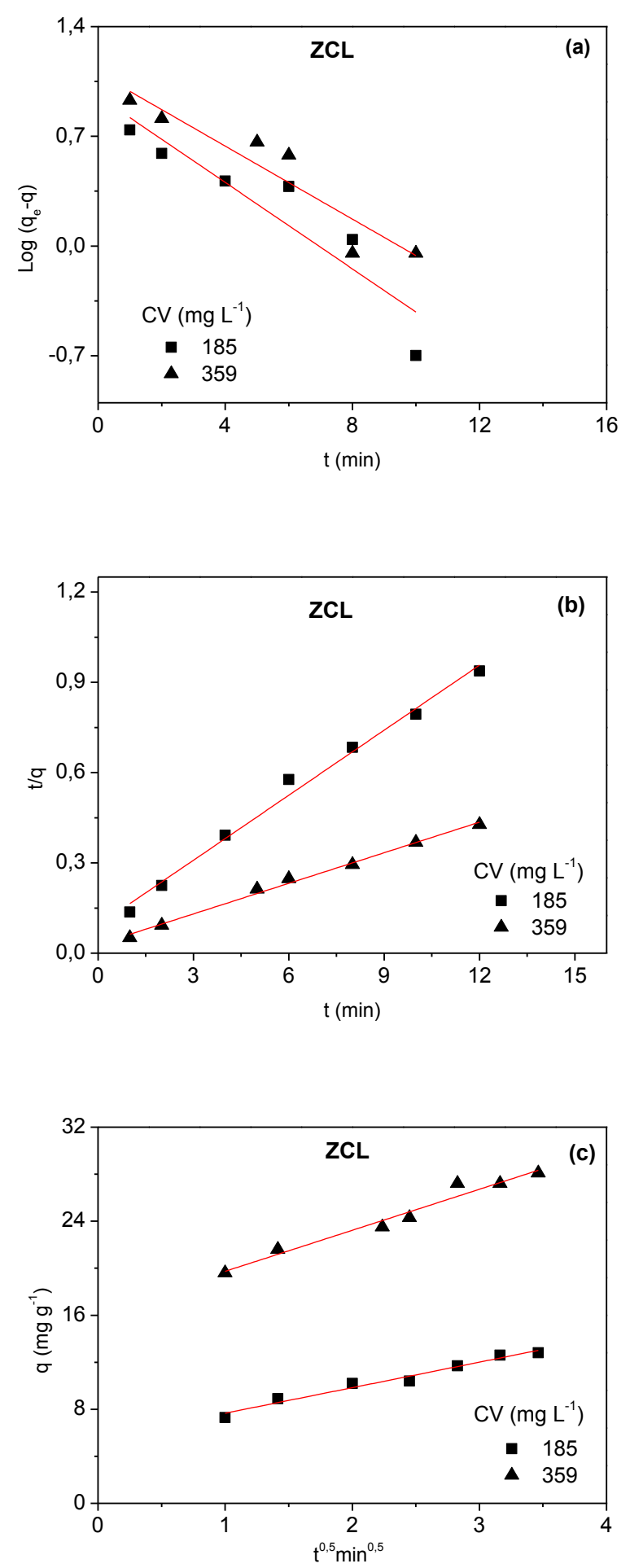

FIGURA 39 - Comparação dos modelos cinéticos da adsorção do CV sobre a ZCL (a) pseudo-primeira-ordem; (b) pseudo-segunda-ordem; (c) modelo de difusão intrapartícula 

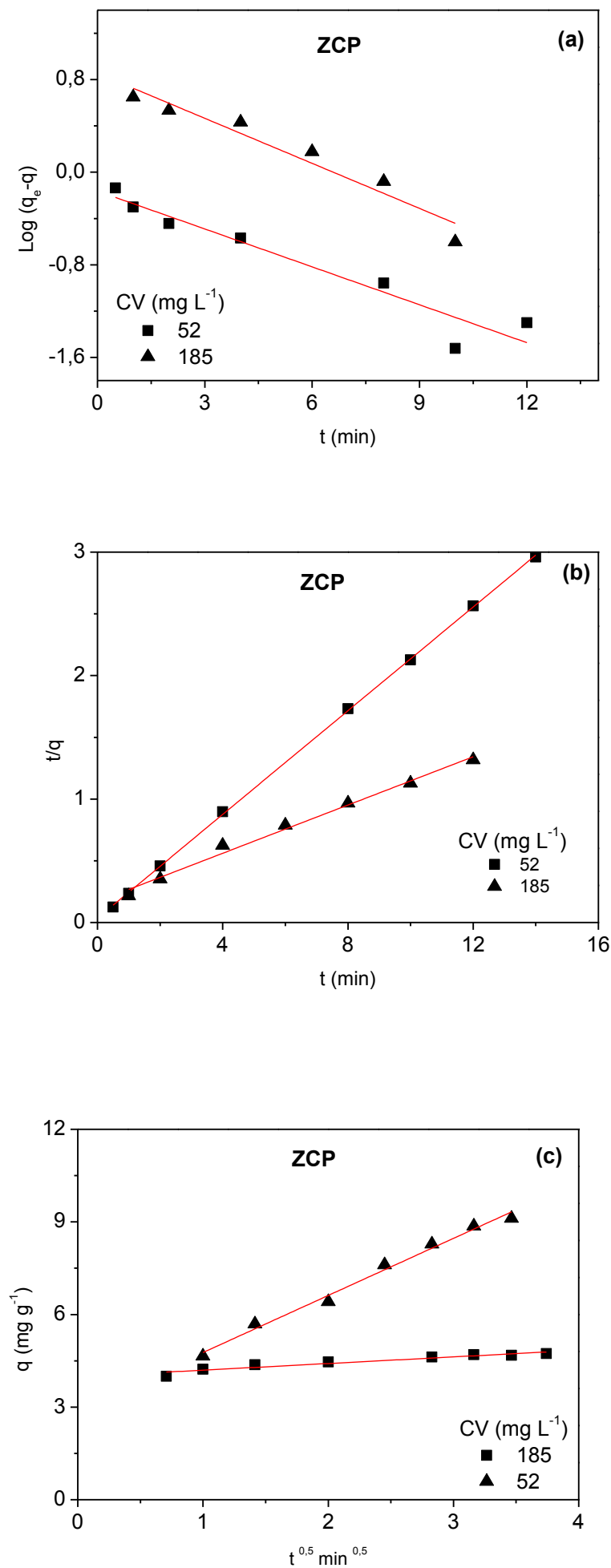

FIGURA 40 - Comparação dos modelos cinéticos da adsorção do CV sobre a ZCP (a) pseudo-primeira-ordem; (b) pseudo-segunda-ordem; (c) modelo de difusão intrapartícula 

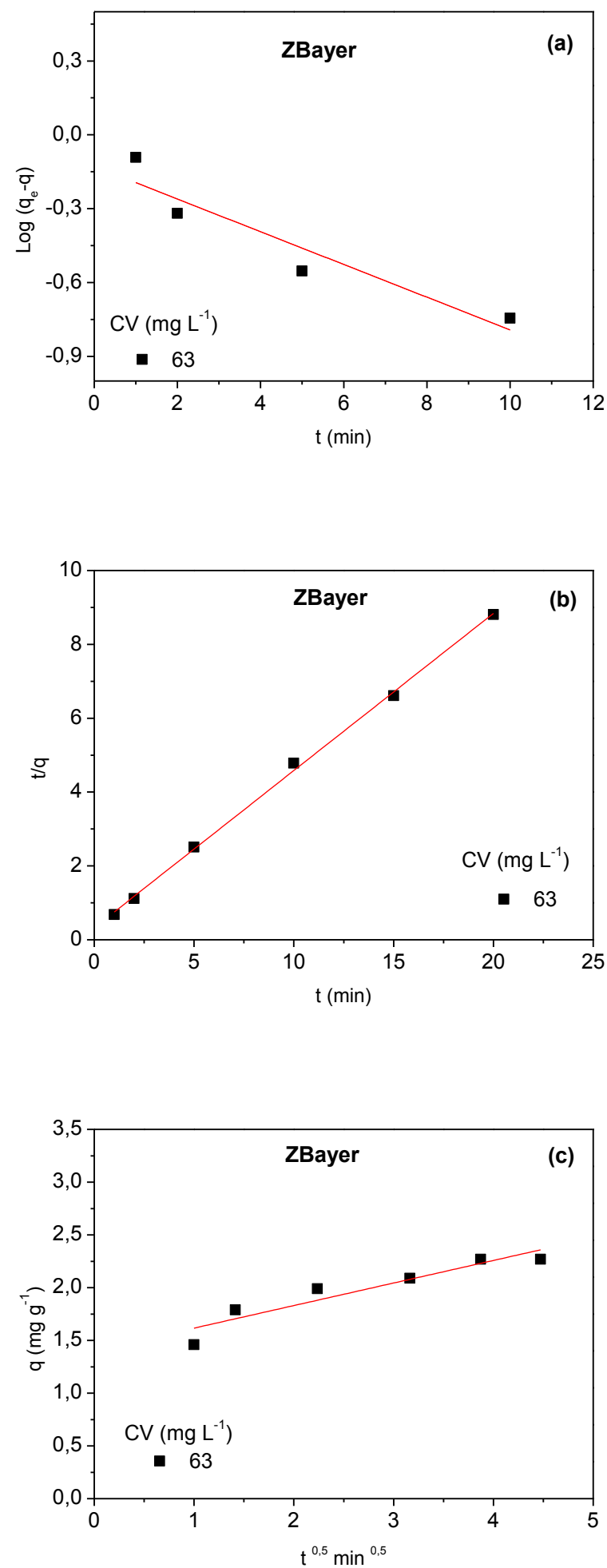

FIGURA 41 - Comparação dos modelos cinéticos da adsorção do CV sobre a ZBayer (a) pseudo-primeira-ordem; (b) pseudo-segunda-ordem; (c) modelo de difusão intrapartícula 

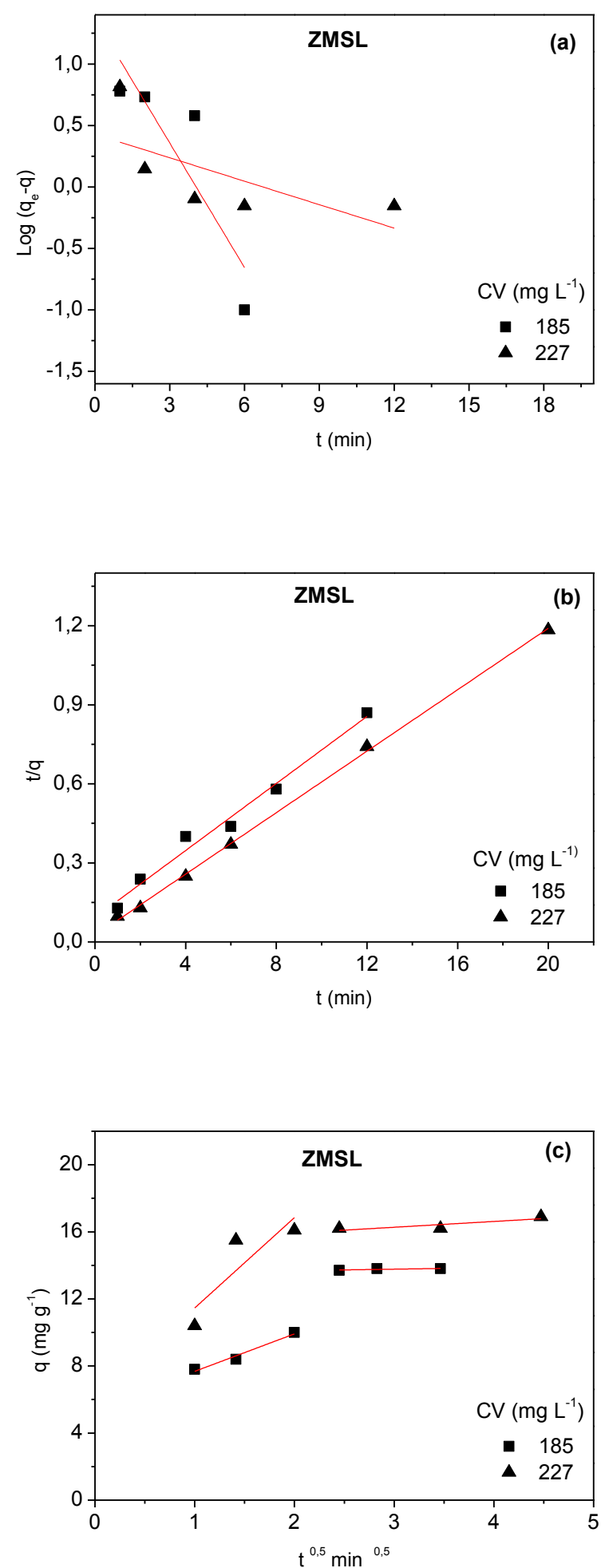

FIGURA 42 - Comparação dos modelos cinéticos da adsorção do CV sobre a ZMSL (a) pseudo-primeira-ordem; (b) pseudo-segunda-ordem; (c) modelo de difusão intrapartícula 

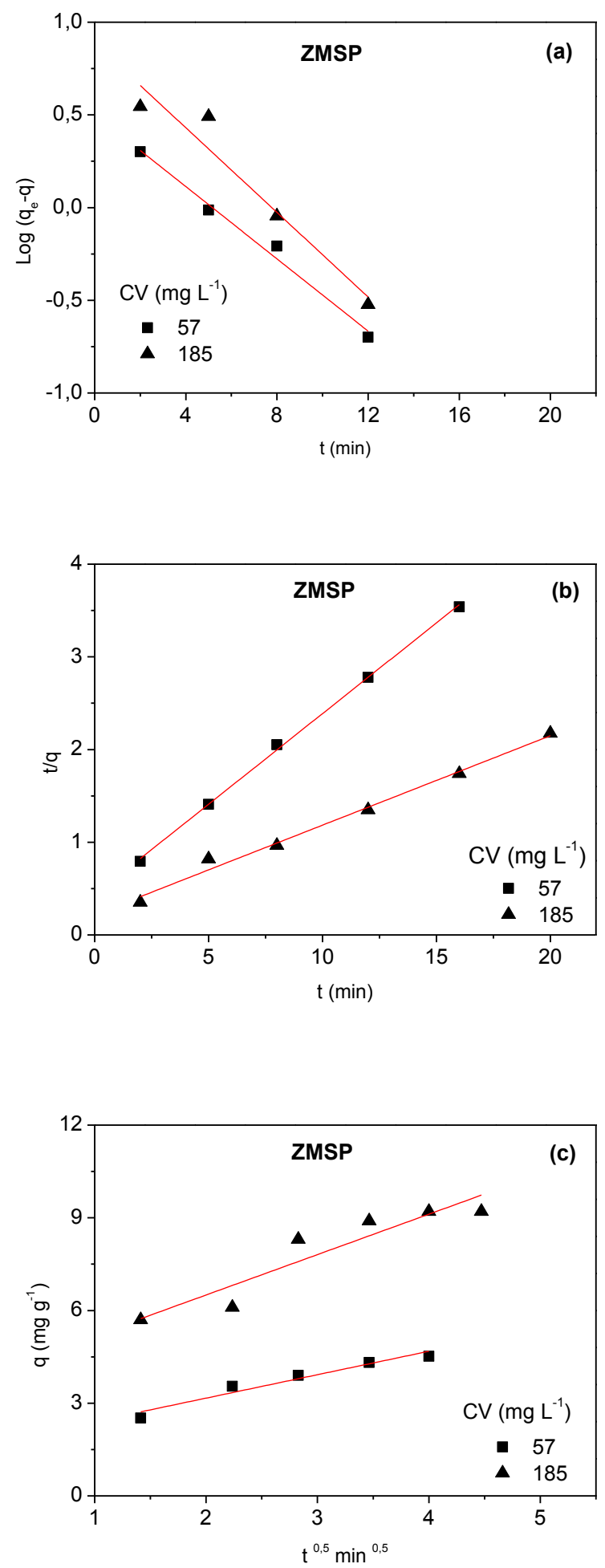

FIGURA 43 - Comparação dos modelos cinéticos da adsorção do CV sobre a ZMSP (a) pseudo-primeira-ordem; (b) pseudo-segunda-ordem; (c) modelo de difusão intrapartícula 

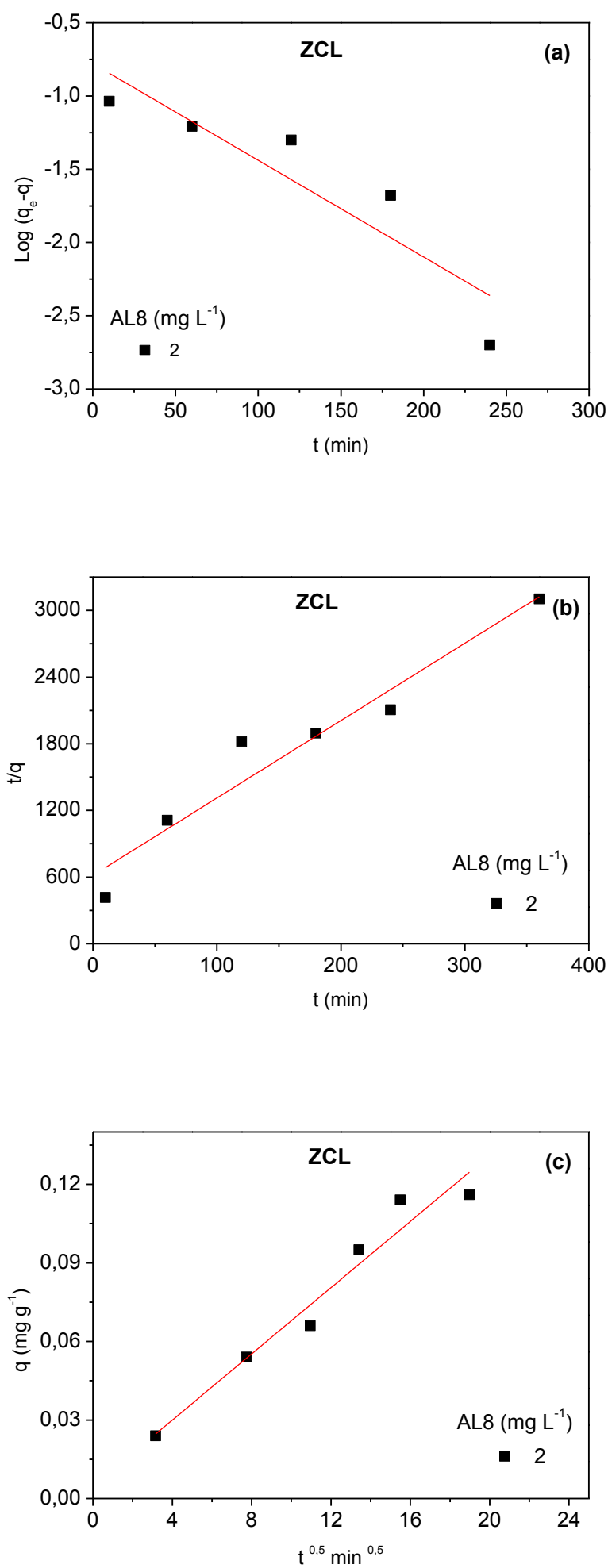

FIGURA 44 - Comparação dos modelos cinéticos da adsorção do AL8 sobre a ZCL (a) pseudo-primeira-ordem; (b) pseudo-segunda-ordem; (c) modelo de difusão intrapartícula 

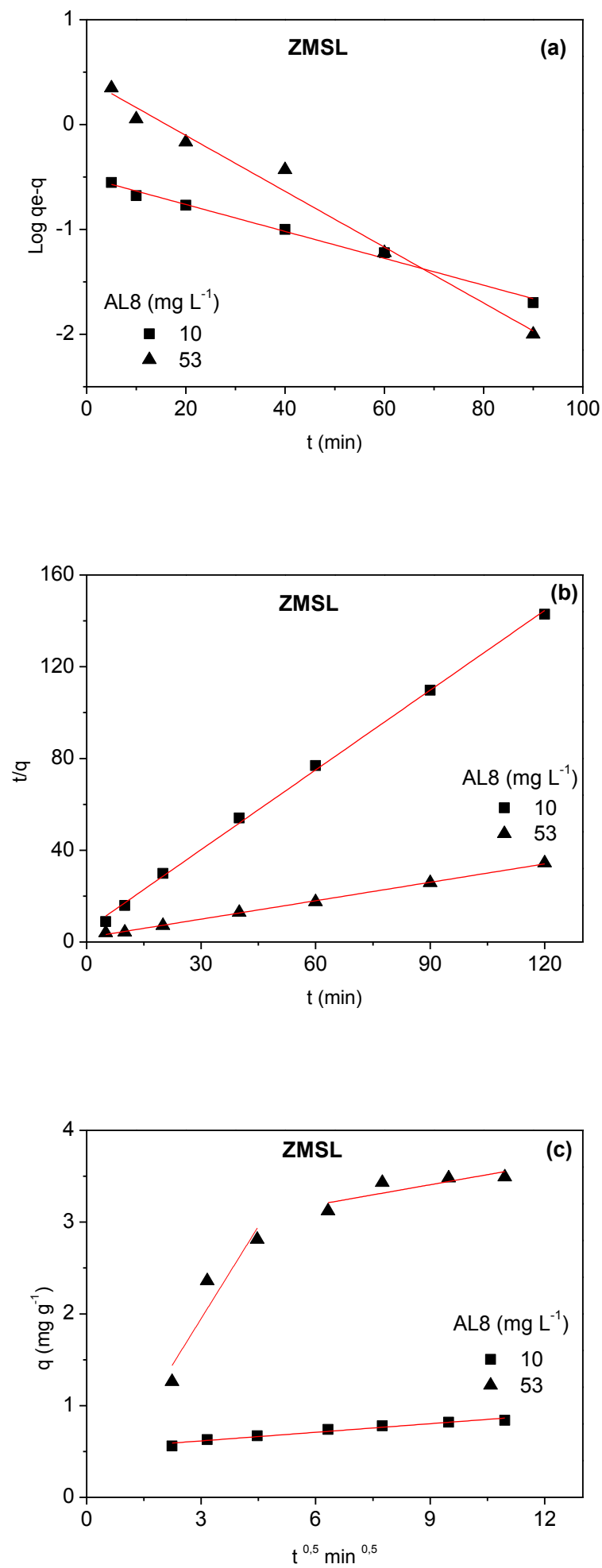

FIGURA 45 - Comparação dos modelos cinéticos da adsorção do AL8 sobre a ZMSL (a) pseudo-primeira-ordem; (b) pseudo-segunda-ordem; (c) modelo de difusão intrapartícula 

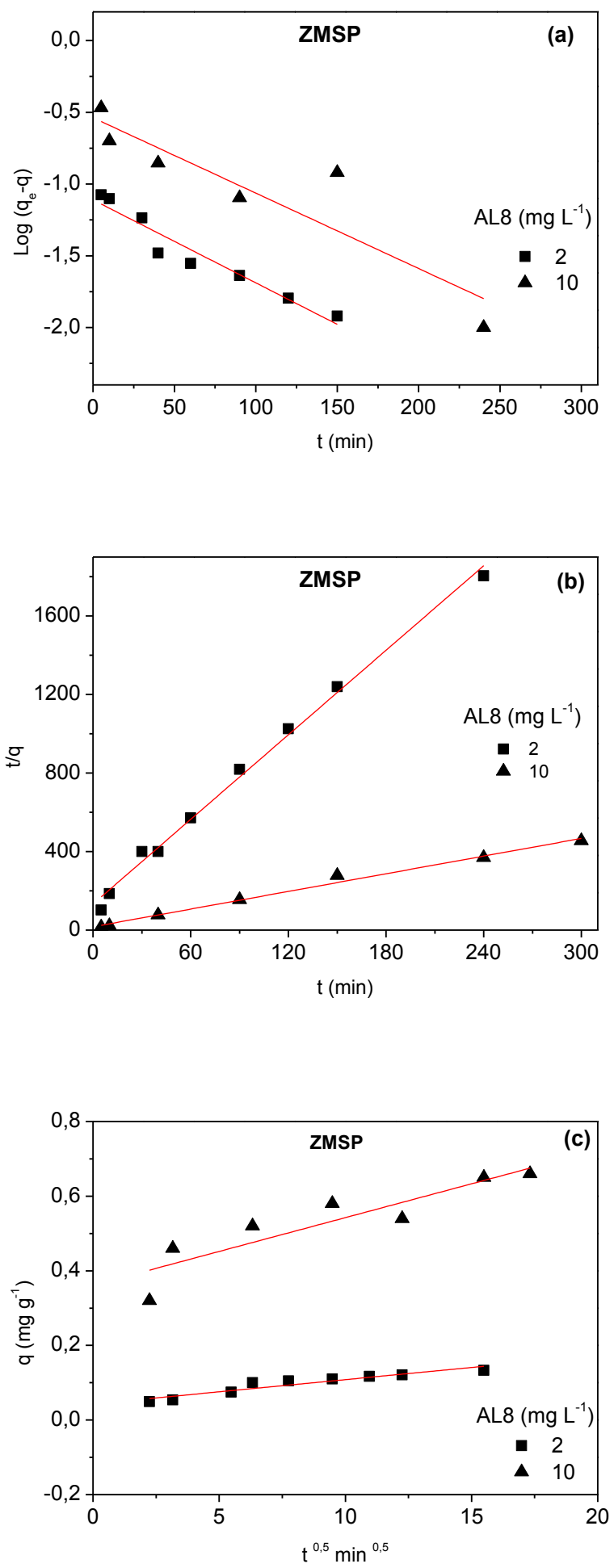

FIGURA 46 - Comparação dos modelos cinéticos da adsorção do AL8 sobre a ZMSP (a) pseudo-primeira-ordem; (b) pseudo-segunda-ordem; (c) modelo de difusão intrapartícula 
TABELA 12 - Parâmetros cinéticos para a remoção do CV sobre os adsorventes.

\begin{tabular}{|c|c|c|c|c|c|c|}
\hline \multirow[b]{2}{*}{ ADSORVENTES } & \multirow{2}{*}{$\underset{\left(\mathrm{mg} \mathrm{L}^{-1}\right)}{\mathrm{CV}}$} & \multicolumn{5}{|c|}{ Pseudo-primeira-ordem } \\
\hline & & $\begin{array}{c}\mathbf{k}_{1} \\
(\mathrm{~m} \mathrm{in})^{-1} \\
\end{array}$ & $\begin{array}{c}\mathrm{qe}_{\text {calc }} \\
\left(\mathrm{mg} \mathrm{g}^{-1}\right)\end{array}$ & $\begin{array}{c}\mathrm{qe}_{\text {exp }} \\
\left(\mathrm{mg} \mathrm{g}^{-1}\right)\end{array}$ & $\mathbf{R}_{\mathbf{1}}$ & \\
\hline \multirow{2}{*}{$\mathrm{ZCL}$} & 185 & 0,317 & 9,1 & 12,8 & 0,927 & \\
\hline & 359 & 0,267 & 12,7 & 28,1 & 0,940 & \\
\hline \multirow{2}{*}{ ZCP } & 52,0 & 0,251 & 0,687 & 4,73 & 0,963 & \\
\hline & 185 & 0,299 & 7,16 & 9,11 & 0,970 & \\
\hline ZBayer & 63,0 & 0,153 & 0,745 & 2,27 & 0,947 & \\
\hline \multirow{2}{*}{ ZMSL } & 185 & 0,778 & 23,5 & 13,8 & 0,878 & \\
\hline & 227 & 0,146 & 2,68 & 16,9 & 0,673 & \\
\hline \multirow{4}{*}{ ZMSP } & 57,0 & 0,224 & 3,19 & 4,52 & 0,994 & \\
\hline & 185 & 0,263 & 7,71 & 9,2 & 0,969 & \\
\hline & & \multicolumn{5}{|c|}{ Pseudo-segunda-ordem } \\
\hline & & $\begin{array}{c}\mathbf{k}_{2} \\
\left(\mathrm{~g} \mathrm{mg}^{-1} \mathrm{~min}^{-1}\right)\end{array}$ & $\begin{array}{c}\mathbf{h} \\
\left(\mathrm{mgg}^{-1} \mathrm{~min}^{-1}\right)\end{array}$ & $\begin{array}{c}\mathrm{qe}_{\text {calc }} \\
\left(\mathrm{mg} \mathrm{g}^{-1}\right)\end{array}$ & $\begin{array}{c}\mathrm{qe}_{\text {exp }} \\
\left(\mathrm{mg} \mathrm{g}^{-1}\right)\end{array}$ & $\mathbf{R}_{\mathbf{2}}$ \\
\hline \multirow{2}{*}{$\mathrm{ZCL}$} & 185 & $5,59 \times 10^{-2}$ & 10,8 & 13,9 & 12,8 & 0,996 \\
\hline & 359 & $3,97 \times 10^{-2}$ & 34,8 & 29,6 & 28,1 & 0,997 \\
\hline \multirow{2}{*}{ ZCP } & 52,0 & 1,25 & 28,3 & 4,76 & 4,73 & 0,999 \\
\hline & 185 & $5,60 \times 10^{-2}$ & 5,88 & 10,2 & 9,11 & 0,995 \\
\hline ZBayer & 63,0 & $5,77 \times 10^{-1}$ & 3,19 & 2,35 & 2,27 & 0,999 \\
\hline \multirow{2}{*}{ ZMSL } & 185 & $4,37 \times 10^{-2}$ & 10,8 & 15,7 & 13,8 & 0,991 \\
\hline & 227 & $1,42 \times 10^{-1}$ & 41,7 & 17,1 & 16,9 & 0,999 \\
\hline \multirow{4}{*}{ ZMSP } & 57,0 & $8,87 \times 10^{-2}$ & 2,31 & 5,11 & 4,52 & 0,999 \\
\hline & 185 & $4,25 \times 10^{-2}$ & 4,56 & 10,4 & 9,20 & 0,995 \\
\hline & & \multicolumn{5}{|c|}{ Difu são intrapartícula } \\
\hline & & $\begin{array}{c}\mathbf{C} \\
\left(\mathbf{m ~ g ~ g}^{-1}\right)\end{array}$ & $\begin{array}{c}\mathbf{K}_{\text {dif }} \\
\left(\mathrm{mg} \mathrm{g}^{-1} \mathrm{~min}^{-0,5}\right)\end{array}$ & $\mathbf{R}_{\mathbf{i}}$ & & \\
\hline \multirow{2}{*}{ ZCL } & 185 & 5,49 & 2,17 & 0,986 & & \\
\hline & 359 & 16,3 & 3,49 & 0,984 & & \\
\hline \multirow{2}{*}{ ZCP } & 52,0 & 3,98 & 1,66 & 0,961 & & \\
\hline & 185 & 2,92 & 1,85 & 0,995 & & \\
\hline ZBayer & 63,0 & 1,40 & 0,214 & 0,944 & & \\
\hline \multirow{2}{*}{ ZMSL } & 185 & 5,44 & $8,84 \times 10^{-2}$ & 0,988 & & \\
\hline & 227 & 6,07 & $3,46 \times 10^{-1}$ & 0,865 & & \\
\hline \multirow{2}{*}{ ZMSP } & 57,0 & 1,65 & $7,59 \times 10^{-1}$ & 0,975 & & \\
\hline & 185 & 3,89 & 1,31 & 0,937 & & \\
\hline
\end{tabular}

(1) $R_{1}=$ Fator de correlação do modelo de pseudo-primeira-ordem; (2) $R_{2}=$ Fator de correlação do modelo de pseudo-segunda-ordem; (3) $R_{i}=$ Fator de correlação do modelo de difusão intrapartícula. 
TABELA 13 - Parâmetros cinéticos para a remoção do AL8 sobre os adsorventes.

\begin{tabular}{|c|c|c|c|c|c|c|}
\hline \multirow[b]{2}{*}{ ADSORVENTES } & \multirow[b]{2}{*}{$\underset{\left(\mathrm{mg} \mathrm{L}^{-1}\right)}{\mathrm{AL8}}$} & \multicolumn{5}{|c|}{ Pseudo-primeira-ordem } \\
\hline & & $\begin{array}{c}\mathbf{k}_{1} \\
(\mathrm{~m} \mathrm{in})^{-1} \\
\end{array}$ & $\begin{array}{c}\mathrm{qe}_{\text {calc }} \\
\left(\mathrm{mg} \mathrm{g}^{-1}\right)\end{array}$ & $\begin{array}{c}q e_{\text {exp }} \\
\left(\mathbf{m g ~ g}^{-1}\right)\end{array}$ & $\mathbf{R}_{\mathbf{1}}$ & \\
\hline $\mathrm{ZCL}$ & 2,00 & $1,52 \times 10^{-2}$ & 0,166 & 0,116 & 0,909 & \\
\hline \multirow{2}{*}{ ZMSL } & 10,0 & $2,95 \times 10^{-2}$ & 0,310 & 0,840 & 0,996 & \\
\hline & 53,0 & $6,13 \times 10^{-2}$ & 2,68 & 3,49 & 0,992 & \\
\hline \multirow{4}{*}{ ZMSP } & 2,00 & $1,33 \times 10^{-2}$ & 0,0775 & 0,133 & 0,967 & \\
\hline & 10,0 & $1,21 \times 10^{-2}$ & 0,288 & 0,663 & 0,909 & \\
\hline & & \multicolumn{5}{|c|}{ Pseudo-segunda-ordem } \\
\hline & & $\begin{array}{c}\mathbf{k}_{2} \\
\left(\mathrm{~g} \mathrm{mg}^{-1} \min ^{-1}\right)\end{array}$ & $\begin{array}{c}\mathbf{h} \\
\left(\mathrm{mgg}^{-1} \min ^{-1}\right)\end{array}$ & $\begin{array}{l}\mathrm{qe}_{\text {calc }} \\
\left(\mathrm{mg} \mathrm{g}^{-1}\right)\end{array}$ & $\begin{array}{c}\mathrm{qe}_{\text {exp }} \\
\left(\mathrm{mg} \mathrm{g}^{-1}\right)\end{array}$ & $\mathbf{R}_{\mathbf{2}}$ \\
\hline $\mathrm{ZCL}$ & 2,00 & $7,83 \times 10^{-2}$ & $1,62 \times 10^{-3}$ & 0,144 & 0,116 & 0,970 \\
\hline \multirow{2}{*}{ ZMSL } & 10,0 & $2,45 \times 10^{-1}$ & $1,81 \times 10^{-1}$ & 0,860 & 0,840 & 0,999 \\
\hline & 53,0 & $3,69 \times 10^{-2}$ & 41,7 & 3,74 & 3,49 & 0,999 \\
\hline \multirow{4}{*}{ ZMSP } & 2,00 & $3,87 \times 10^{-1}$ & $5,16 \times 10^{-1}$ & 0,139 & 0,133 & 0,997 \\
\hline & 10,0 & $1,31 \times 10^{-1}$ & $5,88 \times 10^{-2}$ & 0,666 & 0,663 & 0,995 \\
\hline & & \multicolumn{5}{|c|}{ Difu são intrapartícula } \\
\hline & & $\underset{\left(\mathbf{m g ~ g}^{-1}\right)}{\mathbf{C}}$ & 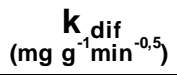 & $\mathbf{R}_{\mathbf{i}}$ & & \\
\hline $\mathrm{ZCL}$ & 2,00 & $4,67 \times 10^{-3}$ & $6,32 \times 10^{-3}$ & 0,975 & & \\
\hline \multirow{2}{*}{ ZMSL } & 10,0 & 0,522 & $3,13 \times 10^{-2}$ & 0,932 & & \\
\hline & 53,0 & 0,0610 & $7,33 \times 10^{-2}$ & 0,844 & & \\
\hline \multirow{2}{*}{ ZMSP } & 2,00 & 0,0430 & $6,53 \times 10^{-2}$ & 0,948 & & \\
\hline & 10,0 & 0,361 & $1,81 \times 10^{-2}$ & 0,907 & & \\
\hline
\end{tabular}

(1) $R_{1}=$ Fator de correlação do modelo de pseudo-primeira-ordem; (2) $R_{2}=$ Fator de correlação do modelo de pseudo-segunda-ordem; (3) $R_{i}=$ Fator de correlação do modelo de difusão intrapartícula.

A avaliação quantitativa dos modelos foi realizada pela comparação dos coeficientes de correlação (R). Verifica-se pelos dados das TAB. 12 e 13 que os coeficientes de determinação $R_{2}$ foram maiores que aqueles de $R_{1}$ para todos os sistemas corante/adsorvente, confirmando que o mecanismo de pseudosegunda-ordem se ajusta melhor ao processo de adsorção.

O mecanismo de pseudo-segunda-ordem foi também confirmado pela comparação dos valores de qe determinados experimentalmente (qe exp) com os valores de qe calculados (qe calc$_{\text {) }}$ pelos modelos (TAB. 12 e 13). Há proximidade entre os valores de $\mathrm{qe}_{\mathrm{exp}}$ e $\mathrm{qe}_{\text {calc. }}$

Os valores de $\mathrm{C}$ do modelo da difusão intrapartícula (TAB. 12 e 13) obtidos eram diferentes de zero indicando que as retas dos gráficos $q$ vs $t^{1 / 2}$ não 
passaram pela origem para os sistemas corante/adsorvente. Portanto, 0 mecanismo de difusão intrapartícula não é a etapa determinante da velocidade e no processo de transferência de massa outros mecanismos devem atuar simultaneamente no controle do processo de adsorção (Weber e Morris, 1963).

Uma comparação dos resultados calculados e experimentais da cinética de adsorção do corantes CV e AL8 sobre os adsorventes sintetizados neste trabalho são mostrados nas FIG. 47 e 48, respectivamente. Como pode ser observado, o modelo de pseudo-primeira-ordem subestima a adsorção e o modelo cinético de pseudo-segunda-ordem fornece a melhor correlação para os processos de adsorção.
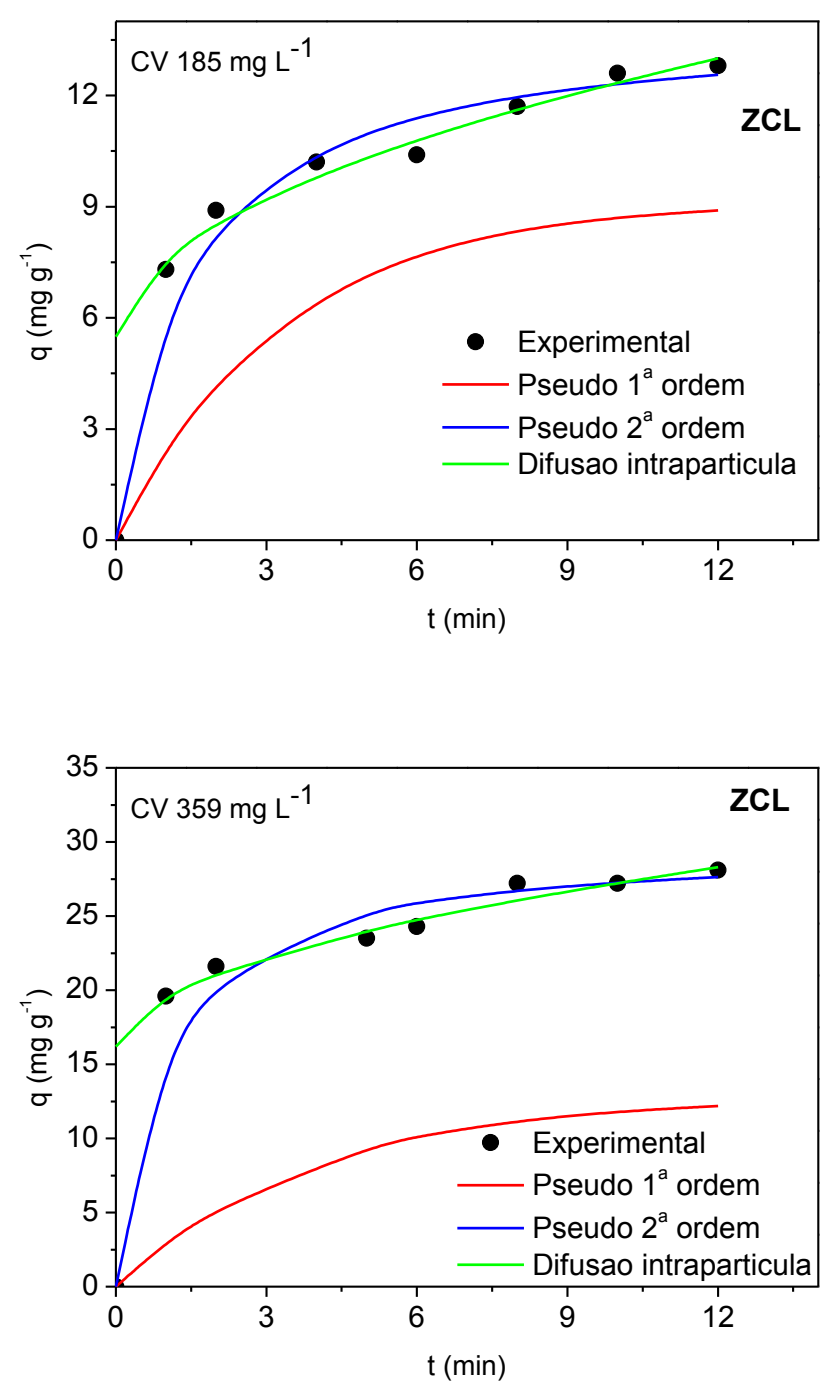

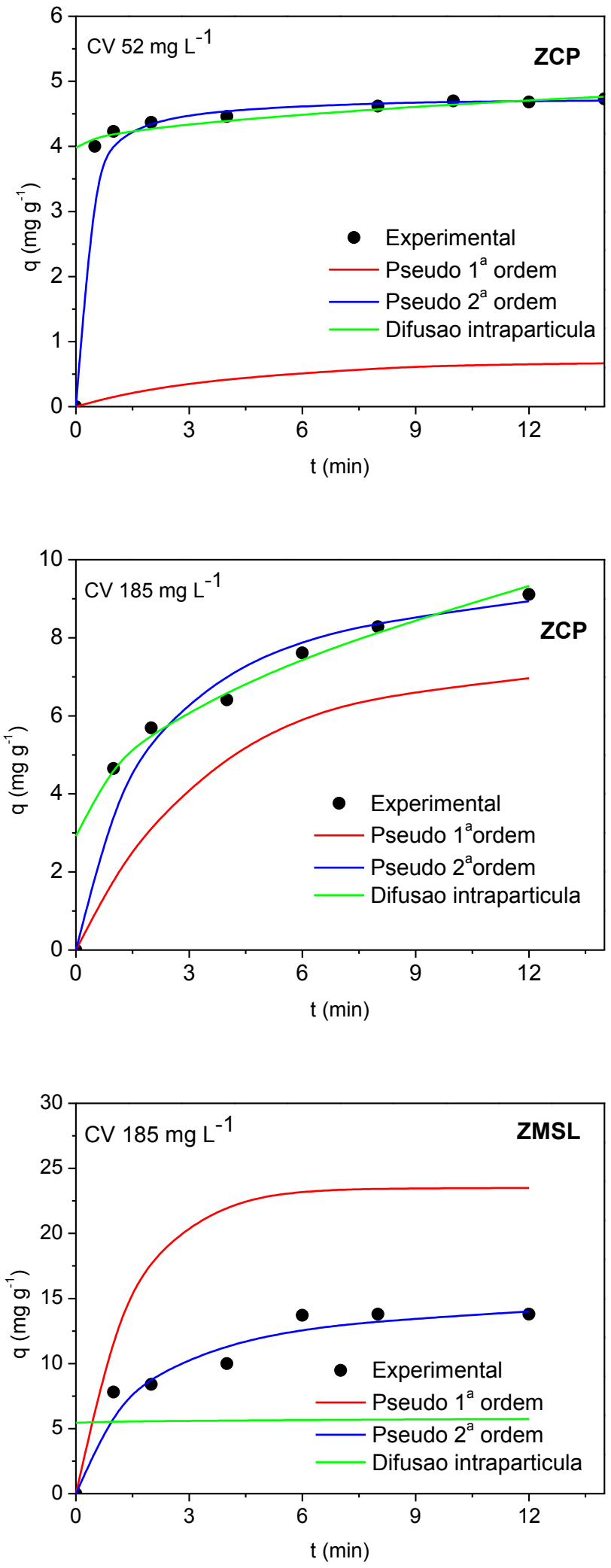

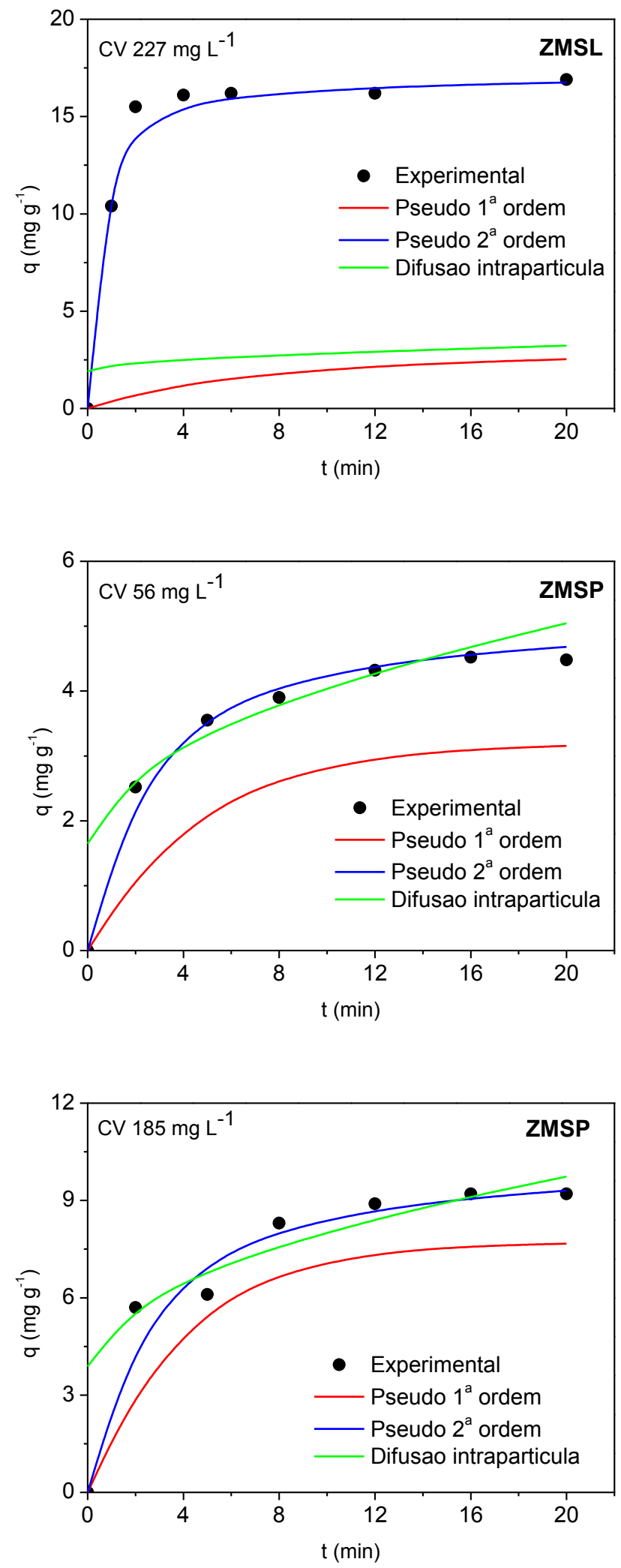

FIGURA 47 - Comparação dos resultados calculados e experimentais da cinética de adsorção do CV sobre os adsorventes 

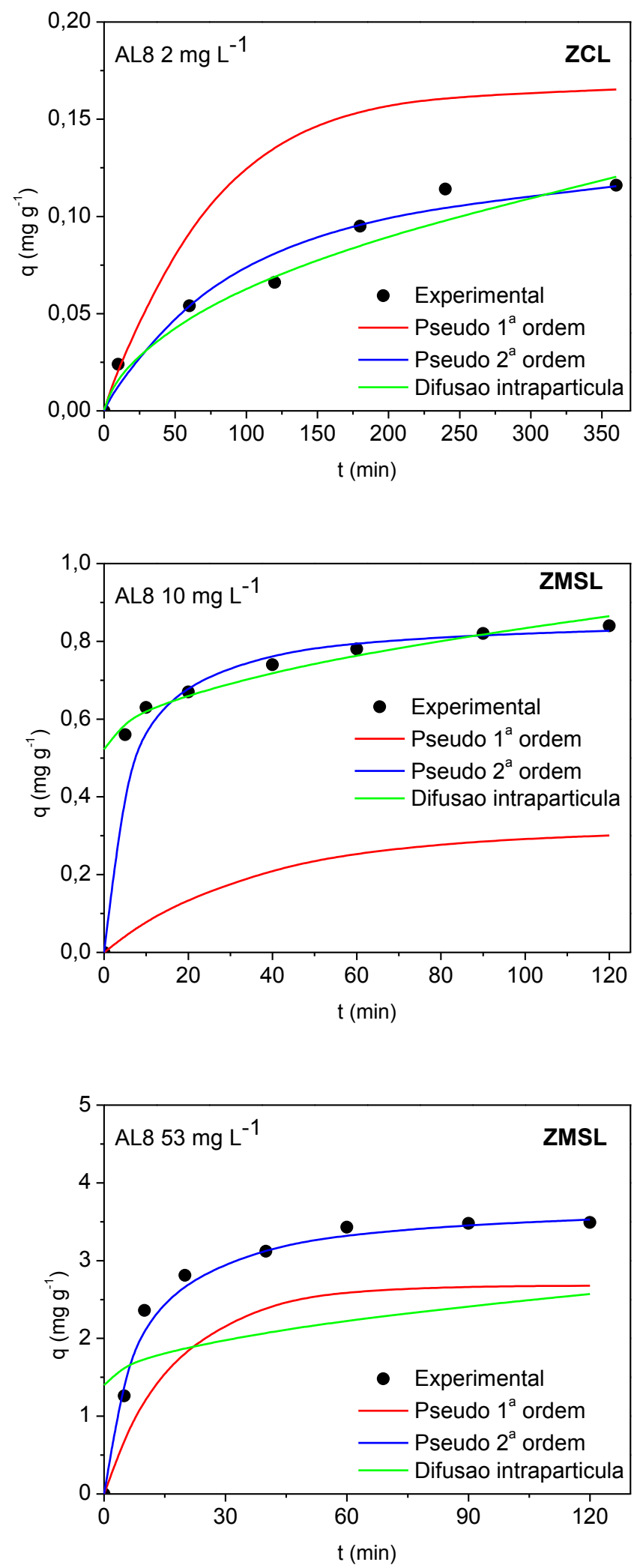

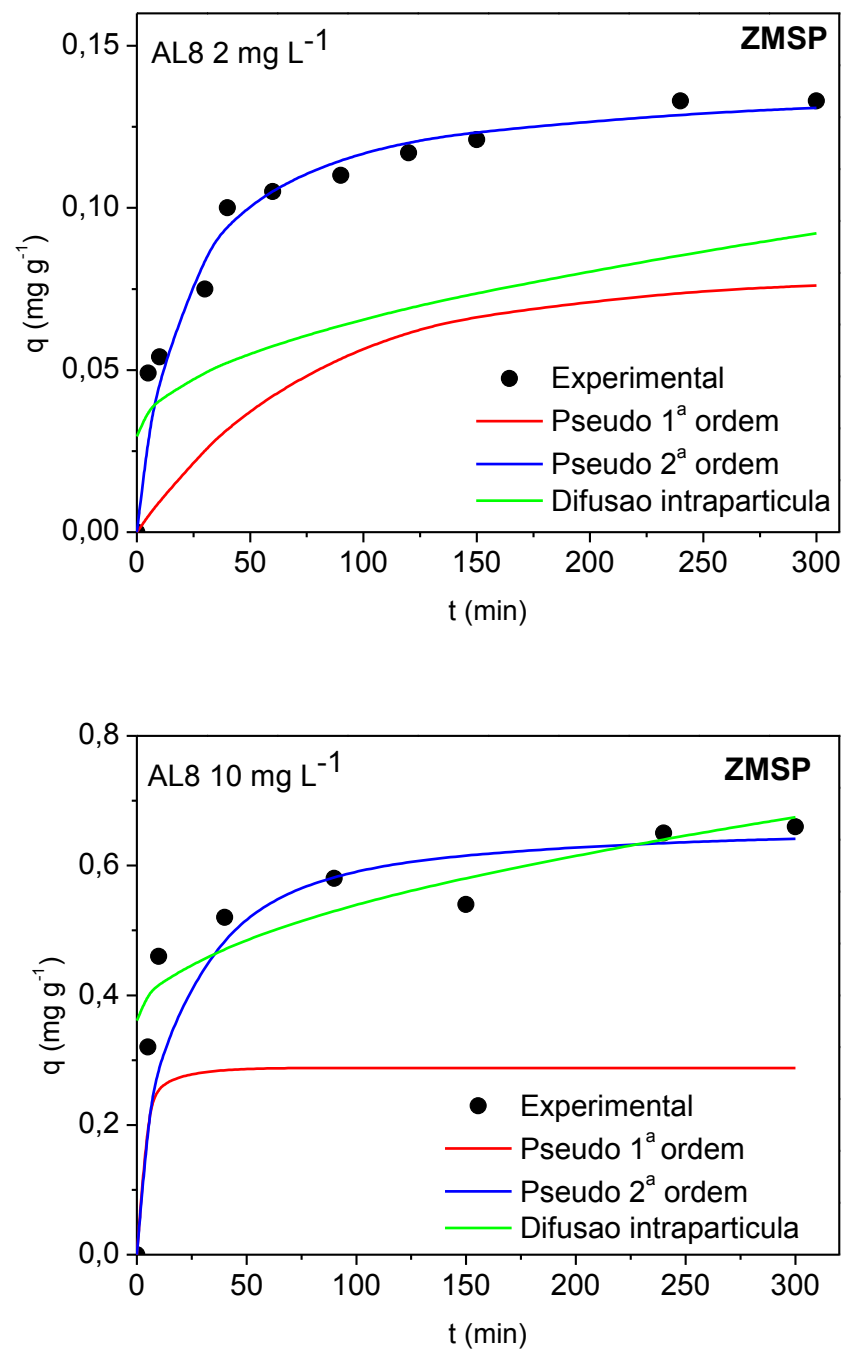

FIGURA 48 - Comparação dos resultados calculados e experimentais da cinética de adsorção do AL8 sobre os adsorventes

\subsection{Isotermas de adsorção}

As FIG. 49 e 50 mostram as isotermas de adsorção dos corantes CV e AL8 nos adsorventes, nas quais são apresentados os valores obtidos experimentalmente e as curvas alcançadas a partir dos valores estimados pelos modelos de Langmuir e Freundlich. 

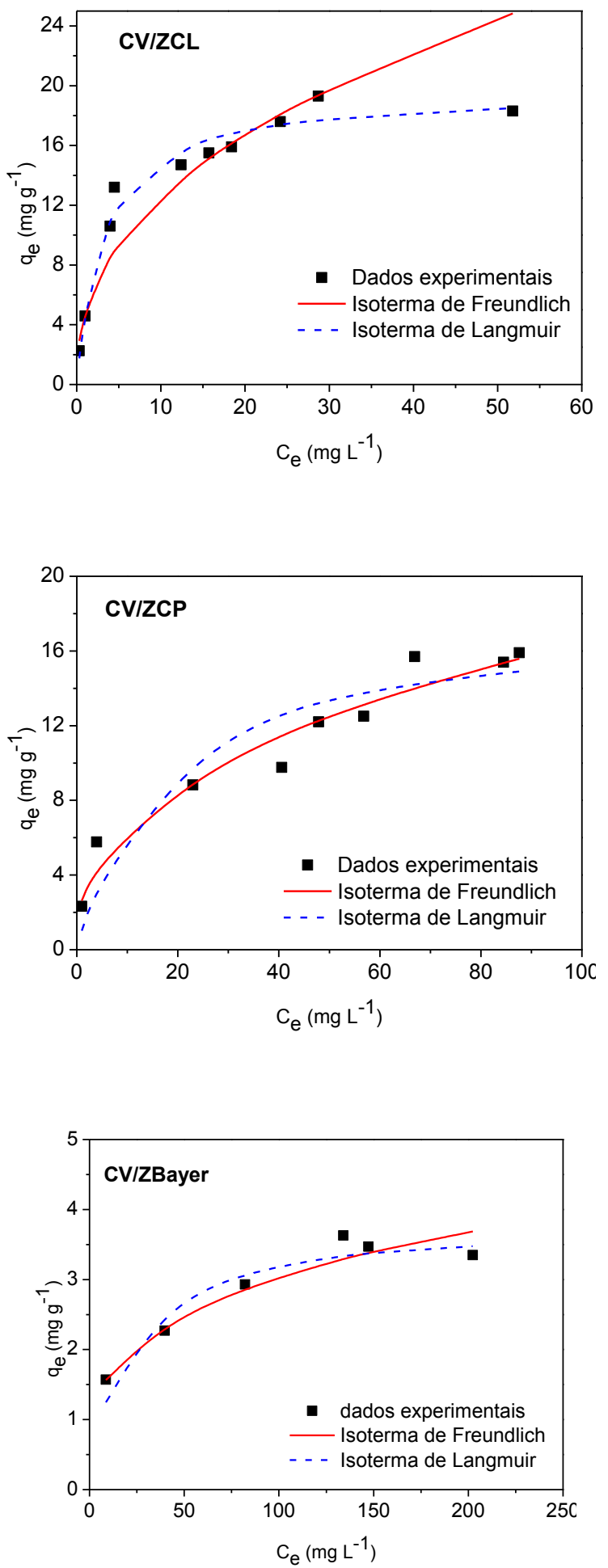

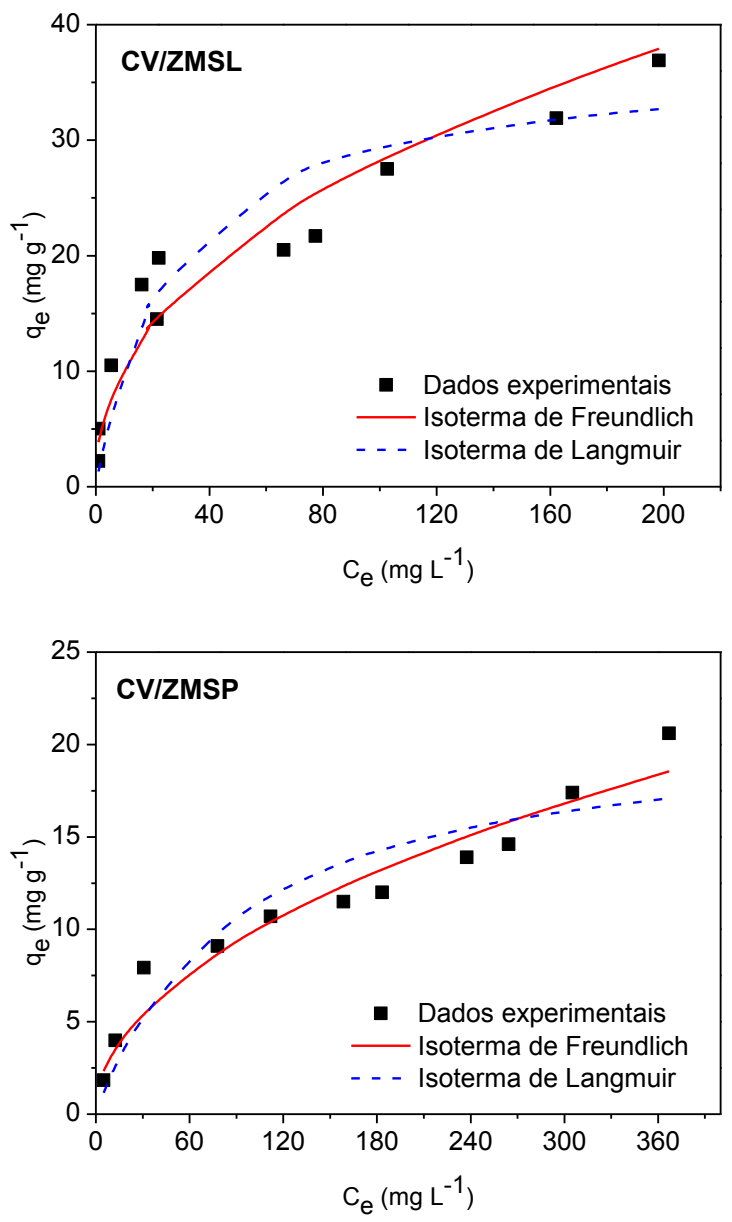

FIGURA 49 - Isotermas de adsorção do CV sobre os adsorventes $(\mathrm{pH}=5$; $\mathrm{T}=25^{\circ} \mathrm{C} \pm 2^{\circ} \mathrm{C}$ ). 

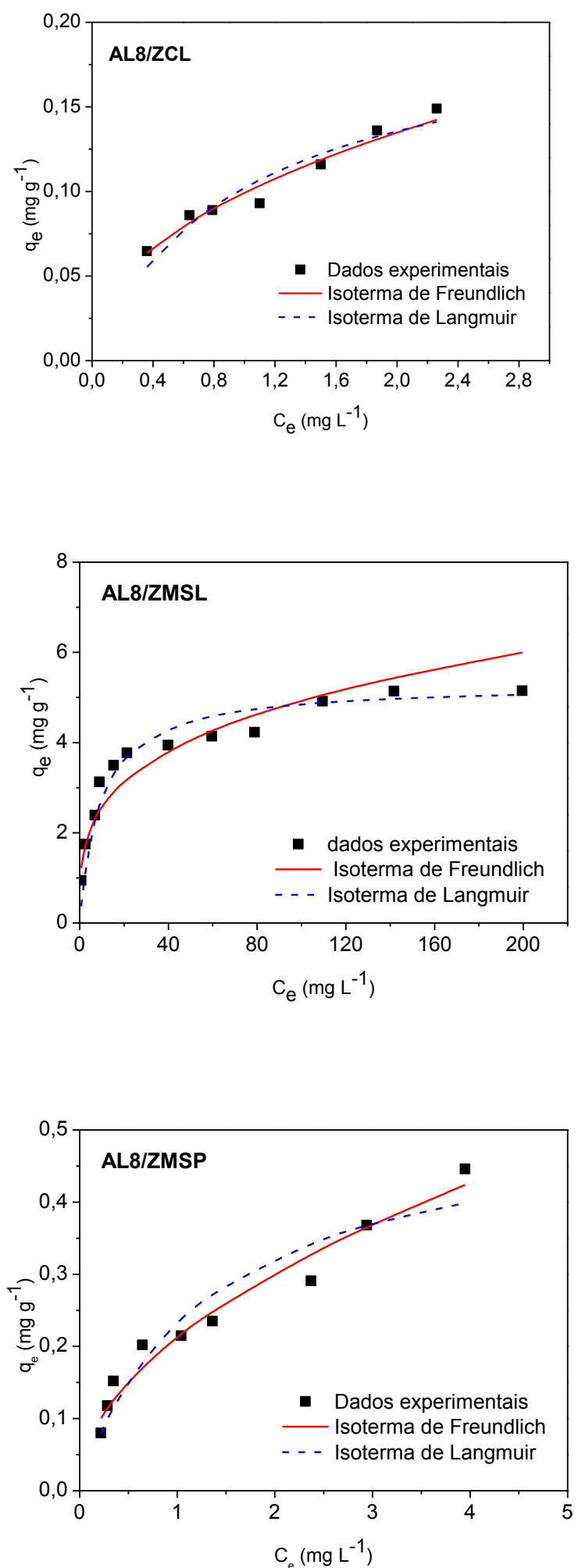

FIGURA 50 - Isotermas de adsorção do AL8 sobre os adsorventes $(\mathrm{pH}=5$; $\mathrm{T}=25^{\circ} \mathrm{C} \pm 2^{\circ} \mathrm{C}$ ). 
As isotermas de equilibrio dos sistemas CV/ZCL e CV/ZBayer apresentaram curvas com comportamento correspondente à classe do Tipo L2 indicando a formação de uma monocamada saturada de moléculas do soluto sobre a superfície do adsorvente e que a afinidade de adsorção aumenta com o aumento da concentração do adsorbato até a saturação. Para os sistemas CV/ZMSL, CV/ZMSP, AL8/ZCL e AL8/ZMSP, as curvas apresentadas foram correspondentes à classe do Tipo L3 indicando a formação rápida de uma segunda camada de adsorção. As curvas apresentadas nos sistemas CV/ZCP e AL8/ZMSL adequaram-se à classe do Tipo L4, indicando a formação de duas camadas, uma no primeiro grau de saturação da superfície e outra na adsorção posterior na nova superfície (Giles et al., 1960).

As curvas linearizadas de Langmuir e Freundlich encontram-se nas FIG. $51,52,53,54,55,56,57$ e 58 e os respectivos parâmetros das isotermas foram determinados por regressão linear usando-se as equações 1 e 2 e estão apresentados nas (TAB. 14 e 15).
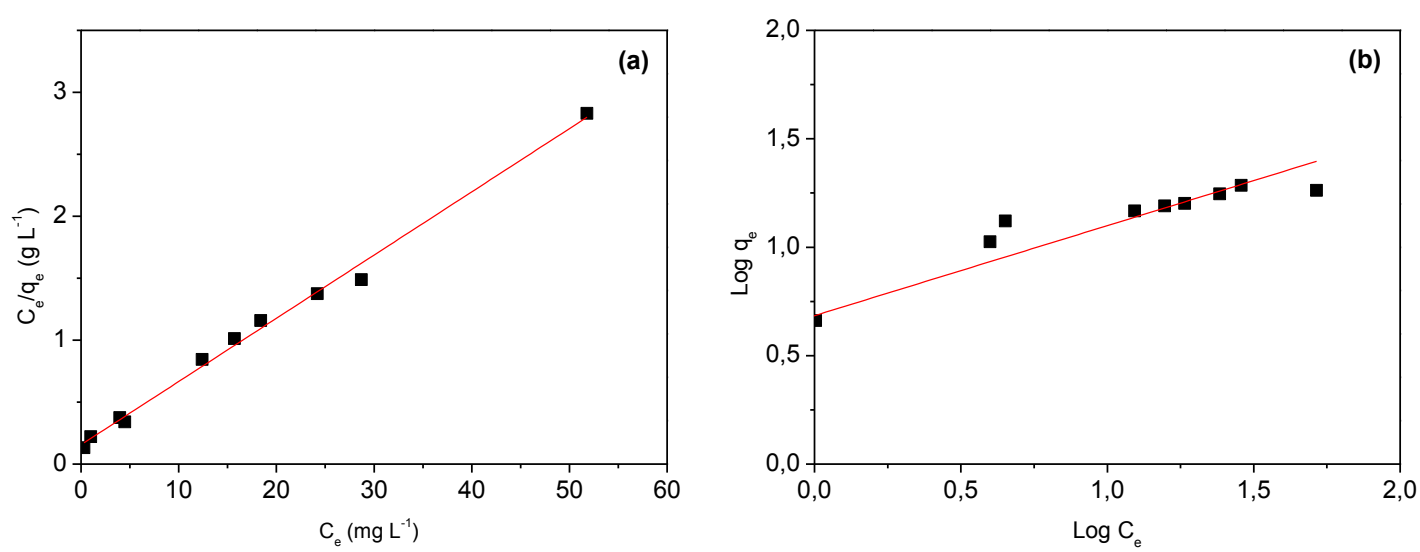

FIGURA 51 - Curvas linearizadas dos modelos de Langmuir (a) e Freundlich (b) da adsorção do CV sobre ZCL 

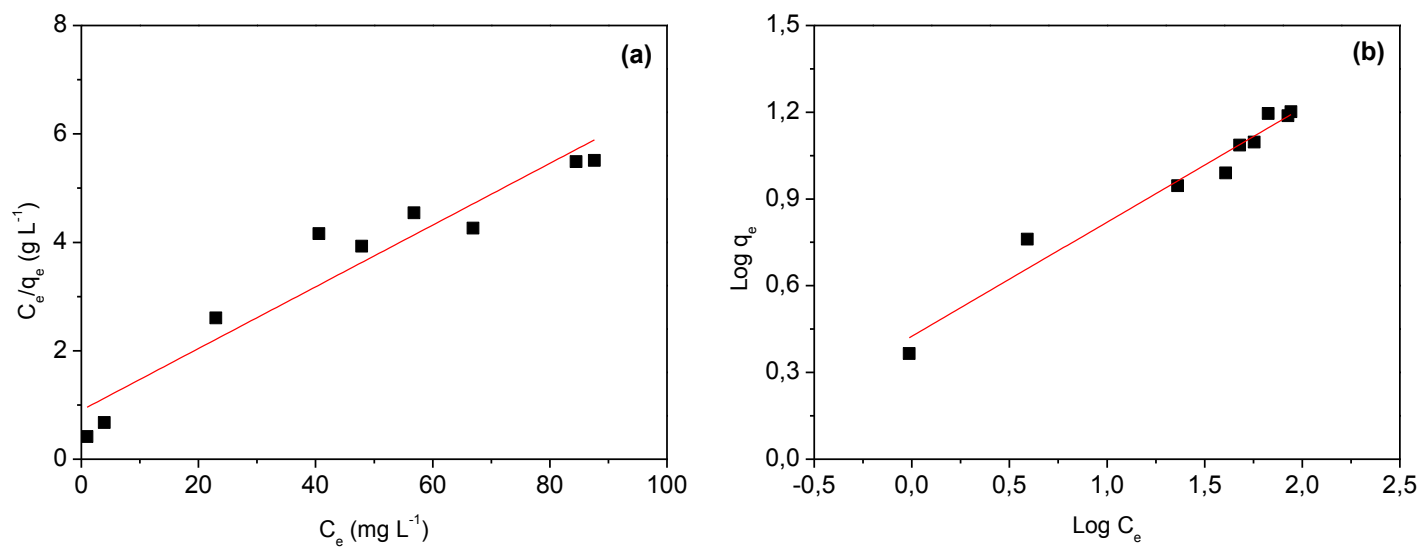

FIGURA 52 - Curvas linearizadas dos modelos de Langmuir (a) e Freundlich (b) da adsorção do CV sobre ZCP
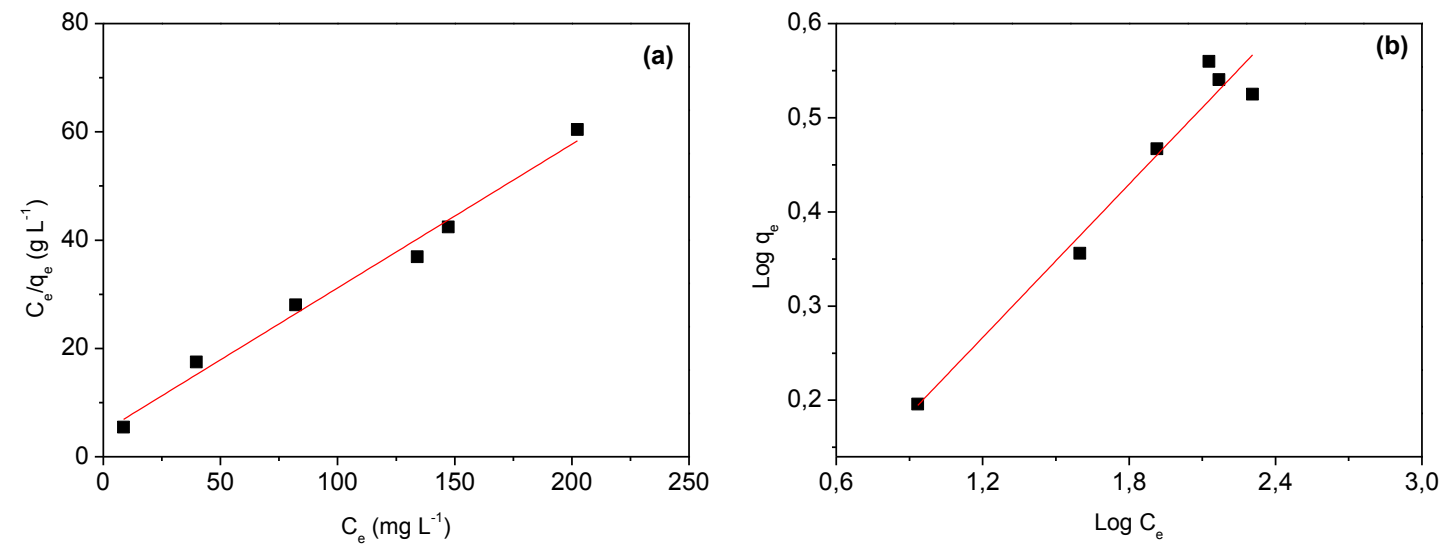

FIGURA 53 - Curvas linearizadas dos modelos de Langmuir (a) e Freundlich (b) da adsorção do CV sobre ZBayer
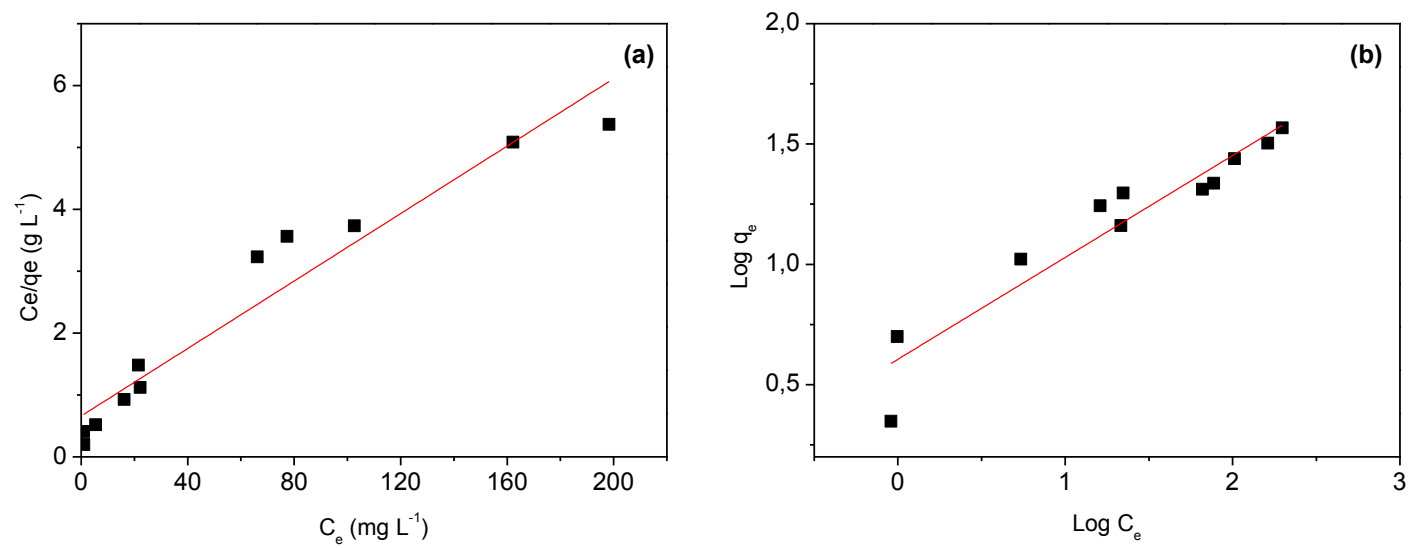

FIGURA 54 - Curvas linearizadas dos modelos de Langmuir (a) e Freundlich (b) da adsorção do CV sobre ZMSL 

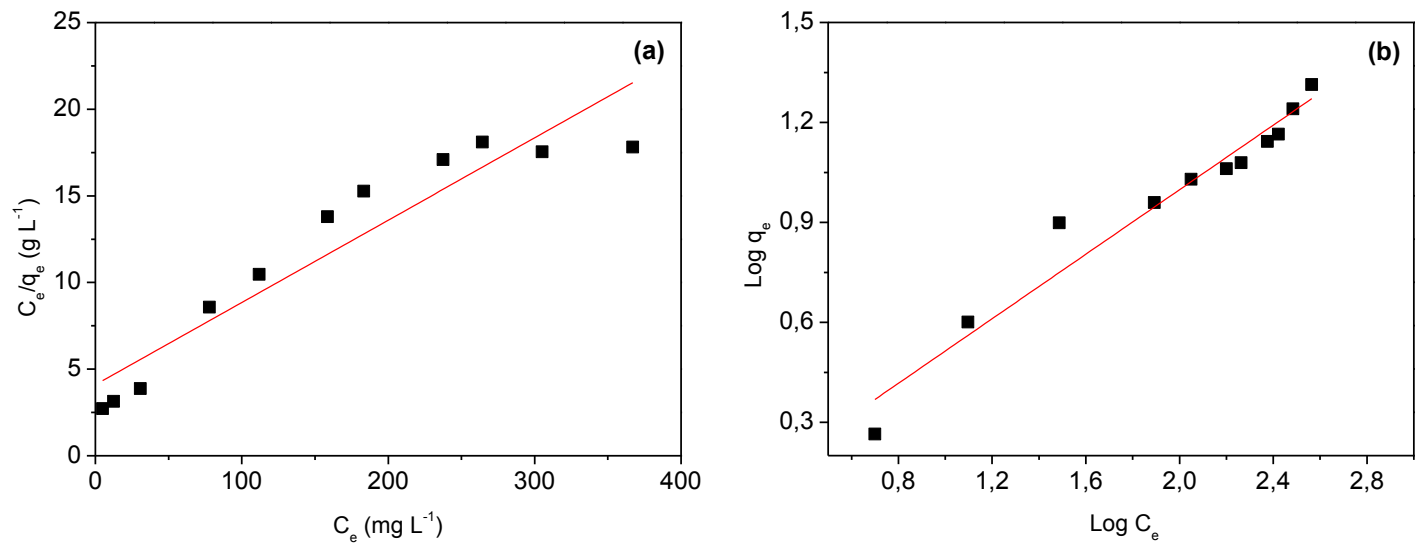

FIGURA 55 - Curvas linearizadas dos modelos de Langmuir (a) e Freundlich (b) da adsorção do CV sobre ZMSP
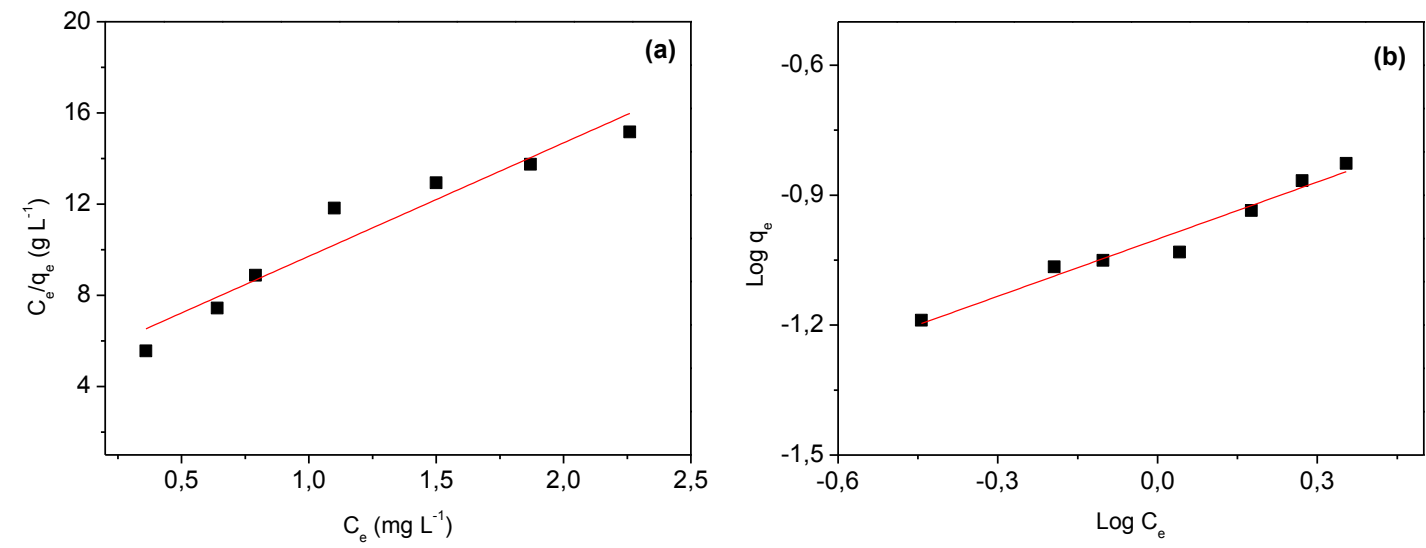

FIGURA 56 - Curvas linearizadas dos modelos de Langmuir (a) e Freundlich (b) da adsorção do AL8 sobre ZCL
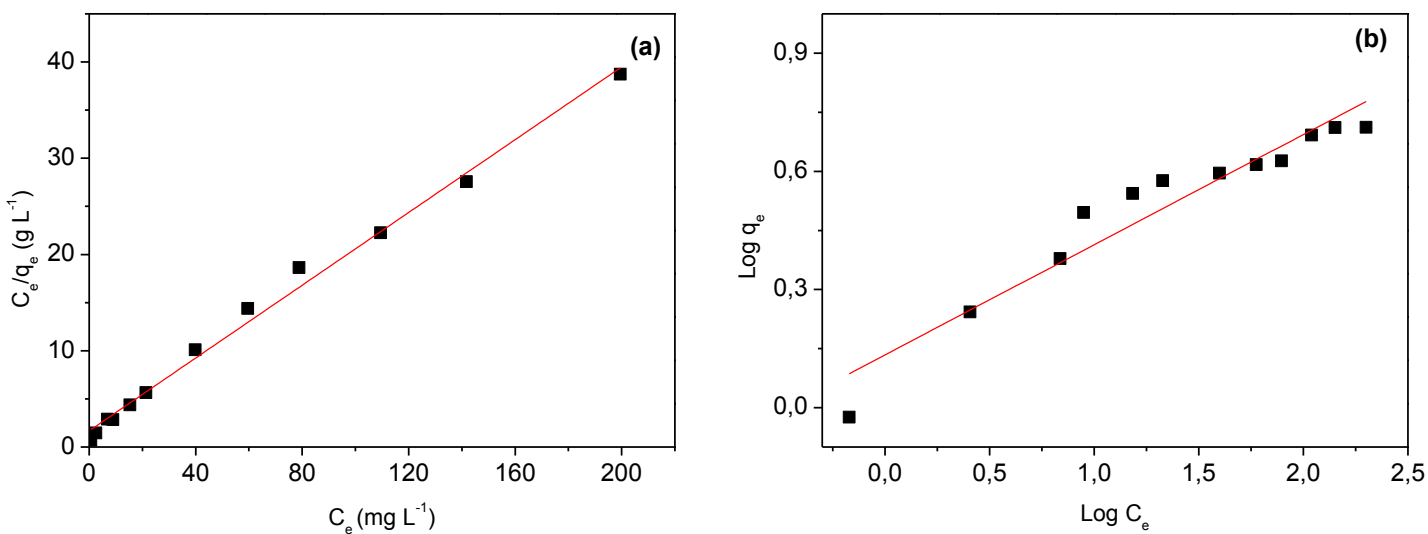

FIGURA 57 - Curvas linearizadas dos modelos de Langmuir (a) e Freundlich (b) da adsorção do AL8 sobre ZMSL 

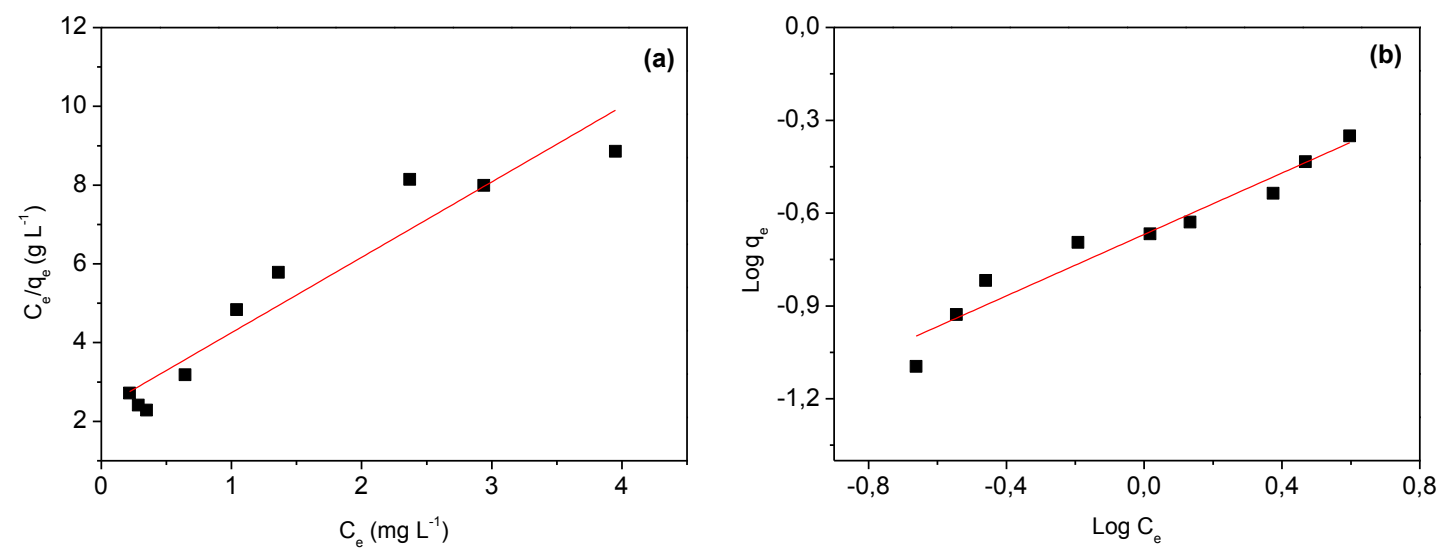

FIGURA 58 - Curvas linearizadas dos modelos de Langmuir (a) e Freundlich (b) da adsorção do AL8 sobre ZMSP

TABELA 14 - Parâmetros dos modelos de isoterma de Langmuir e Freundlich para o corante CV sobre os adsorventes e valores de Qui-quadrado $\left(\mathrm{X}^{2}\right)$

\begin{tabular}{ccccc} 
ADSORVENTES & \multicolumn{3}{c}{ LANGMUIR } & $\mathrm{X}^{2}$ \\
& $\mathrm{Q}_{\mathrm{o}}\left(\mathrm{mg} \mathrm{g}^{-1}\right)$ & $\mathrm{b}\left(\mathrm{L} \mathrm{mg}^{-1}\right)$ & $\mathrm{R}$ & 0,706 \\
ZCL & 19,6 & 0,329 & 0,997 & 4,53 \\
ZCP & 17,6 & 0,0630 & 0,961 & 0,174 \\
Z Bayer & 3,77 & 0,0574 & 0,982 & 16,9 \\
ZMSL & 36,7 & 0,0413 & 0,969 & 4,06 \\
ZMSP & 21,1 & 0,0116 & 0,946 & $\mathrm{X}^{2}$ \\
\hline & & FREUNDLICH & & 4,42 \\
ZCL & 4,83 & $\mathrm{n}$ & $\mathrm{R}$ & 0,869 \\
ZCP & 2,66 & 2,41 & 0,959 & 0,0716 \\
Z Bayer & 0,873 & 2,53 & 0,981 & 5,89 \\
ZMSL & 4,03 & 3,69 & 0,950 & 1,72 \\
ZMSP & 1,07 & 2,36 & 0,954 & \\
\hline
\end{tabular}

$\left({ }^{*}\right)\left(\mathrm{mg} \mathrm{g}^{-1}\right)\left(\mathrm{L} \mathrm{mg}^{-1}\right)^{1 / n}$ 
TABELA 15 - Parâmetros dos modelos de isoterma de Langmuir e Freundlich para o corante AL8 sobre os adsorventes e valores de Qui-quadrado $\left(X^{2}\right)$.

\begin{tabular}{|c|c|c|c|c|}
\hline \multirow{2}{*}{ ADSORVENTES } & \multicolumn{3}{|c|}{ LANGMUIR } & \multirow{2}{*}{$x^{2}$} \\
\hline & $Q_{0}\left(m g g^{-1}\right)$ & $\mathrm{b}\left(\mathrm{L} \mathrm{mg}^{-1}\right)$ & $\mathrm{R}$ & \\
\hline$\overline{Z C L}$ & 0,200 & 1,06 & 0,966 & 0,00489 \\
\hline ZMSL & 5,29 & 0,112 & 0,997 & 1,41 \\
\hline \multirow[t]{3}{*}{ ZMSP } & 0,522 & 0,820 & 0,959 & 0,0400 \\
\hline & \multicolumn{3}{|c|}{ FREUNDLICH } & \\
\hline & $\mathrm{K}_{\mathrm{f}}{ }^{*}$ & $n$ & $\mathrm{R}$ & $x$ \\
\hline$\overline{Z C L}$ & $9,96 \times 10^{-2}$ & 2,28 & 0,981 & 0,00193 \\
\hline ZMSL & 1,36 & 3,57 & 0,962 & 0,614 \\
\hline ZMSP & 0,214 & 2,01 & 0,972 & 0,0210 \\
\hline
\end{tabular}

$\left({ }^{*}\right)\left(\mathrm{mg} \mathrm{g}^{-1}\right)\left(\mathrm{L} \mathrm{mg}^{-1}\right)^{1 / n}$

A comparação dos coeficientes de correlação $(R)$ e do teste não linear do Qui-quadrado $\left(x^{2}\right)$ mostrados nas TAB. 14 e 15 foram usados na avaliação do modelo que melhor descreve o processo de adsorção dos sistemas corante/adsorvente. Quanto mais baixo é o valor de $x^{2}$, mais o dado experimental se ajusta ao valor obtido pelo modelo da isoterma (Ho, 2004).

O modelo da isoterma de Freundlich ajustou-se melhor aos dados experimentais (TAB. 14 e 15) para os sistemas corante/adsorvente estudados, com exceção do sistema CV/ZCL, que seguiu o modelo de Langmuir, conforme evidenciado pelos valores mais baixos de $x^{2}$.

Uma maneira de comparar a eficiência de diferentes adsorventes é analisar a capacidade de adsorção máxima determinada pelo modelo de Langmuir $\left(Q_{0}\right)$, a qual expressa a quantidade removida de corante pela quantidade utilizada de adsorvente $\left(\mathrm{mg} \mathrm{g}^{-1}\right)$. A TAB. 16 ilustra as capacidades de adsorção do CV e do AL8 em adsorventes sintetizados neste estudo. 
TABELA 16 - Comparação das capacidades máximas $\left(Q_{0}\right)$ de adsorção do CV e AL8 sobre os adsorventes

\begin{tabular}{ccccc}
\hline \multirow{2}{*}{ CORANTES } & \multicolumn{4}{c}{$\mathbf{Q}_{\mathrm{o}}\left(\mathrm{mg} \mathrm{g}^{-1}\right)$} \\
& ZCL & ZMSL & ZCP & ZMSP \\
\hline CV & 19,6 & 36,7 & 17,6 & 21,1 \\
AL8 & 0,200 & 5,29 & -- & 0,520 \\
\hline
\end{tabular}

Analisando os resultados da TAB. 16, observou-se que $\circ Q_{0}$ dos sistemas $\mathrm{CV} /$ adsorventes foi maior do que o $Q_{0}$ dos sistemas AL8/adsorventes. A diferença entre os dois corantes pode estar relacionada com as respectivas cargas. Os valores baixos de $Q_{0}$ do AL8 sobre os adsorventes sintetizados provavelmente são devidos à repulsão eletrostática. Os sítios carregados negativamente na superfície do adsorvente desfavorecem a adsorção do corante aniônico (Mall et al., 2006).

Comparando-se os adsorventes originários das cinzas leves com os adsorventes das cinzas pesadas observa-se que as capacidades máximas de adsorção da ZCL e da ZMSL são maiores em relação àquelas obtidas para a ZCP e ZMSP, respectivamente. Cabe ressaltar que não foi possível realizar o estudo de equilibrio do AL8 sobre a ZCP e ZBayer, pois não houve remoção no estudo cinético descrito anteriormente (item 5.3.1). Esses resultados de melhor desempenho do CV e do AL8 sobre os materiais adsorventes de cinzas leves já eram esperados e são devido às características granulométricas da amostra de cinzas que serviu de matéria prima. Quando o tamanho de partícula de um material decresce, aumenta a área superficial externa, o que significa um aumento do número de sítios ativos disponíveis para a adsorção do adsorbato e assim, aumenta a eficiência (Ali et al., 1997).

A capacidade de adsorção decresceu na seguinte ordem: ZMSL > ZMSP > ZCL > ZCP. A eficiência de remoção dos corantes foi maior sobre as zeólitas modificadas por surfactante do que sobre as zeólitas não modificadas devido ao mecanismo de partição descrito posteriormente (item 5.7.2.).

O fato da zeólita de cinzas leves apresentar uma granulometria menor sugere uma maior eficiência na adsorção das moléculas do surfactante. 
As zeólitas sintetizadas com cinzas de carvão apresentaram melhor eficiência de remoção do CV do que a zeólita comercial.

Para uma melhoria da capacidade de adsorção do AL8 pelas zeólitas modificadas é possível realizar um planejamento fatorial usando técnicas estatísticas a partir dos resultados obtidos.

As TAB. 17 e 18 comparam as capacidades máximas de adsorção do CV e do AL8, respectivamente, sobre vários adsorventes encontradas na literatura com os adsorventes sintetizados neste estudo.

TABELA 17 - Comparação da capacidade de adsorção máxima do CV em vários adsorventes

\begin{tabular}{|c|c|c|c|}
\hline ADSORVENTE & CONDIÇÃO & $Q_{0}\left(\mathrm{mg} \mathrm{g}^{-1}\right)$ & REFERÊNCIA \\
\hline Cinzas leves & $\begin{array}{c}12,5-200 \mathrm{mg} \mathrm{L}^{-1} \\
\text { Tagit }=60 \mathrm{~min} \\
\left(25^{\circ} \mathrm{C}\right)\end{array}$ & 74,62 & Çoruh et al.,2012 \\
\hline Cinzas pesadas & $\begin{array}{c}10-1600 \mathrm{mg} \mathrm{L}^{-1} \\
\text { Tagit }=180 \mathrm{~min} \\
\left(30^{\circ} \mathrm{C}\right)\end{array}$ & 12,10 & $\begin{array}{l}\text { Gandhimathi } \\
\text { et al.,2012 }\end{array}$ \\
\hline Carvão ativado & $\begin{array}{l}20-100 \mathrm{mg} \mathrm{L}^{-1} \\
\text { Tagit }=120 \mathrm{~min} \\
\left(25^{\circ} \mathrm{C}\right)\end{array}$ & 19,8 & $\begin{array}{c}\text { Malarvizhi and Ho, } \\
2010\end{array}$ \\
\hline $\mathrm{ZCL}$ & $\begin{array}{c}24 \text { a } 236 \mathrm{mg} \mathrm{L}^{-1} \\
\text { Tagit }=10 \mathrm{~min} \\
\left(25^{\circ} \mathrm{C}\right)\end{array}$ & 19,6 & Este estudo \\
\hline ZCP & $\begin{array}{c}24 \text { a } 248 \mathrm{mg} \mathrm{L}^{-1} \\
\text { Tagit }=10 \mathrm{~min} \\
\left(25^{\circ} \mathrm{C}\right)\end{array}$ & 17,6 & Este estudo \\
\hline ZMSL & $\begin{array}{c}23 \text { a } 579 \mathrm{mg} \mathrm{L}^{-1} \\
\text { Tagit }=10 \mathrm{~min} \\
\left(25^{\circ} \mathrm{C}\right)\end{array}$ & 36,7 & Este estudo \\
\hline ZMSP & $\begin{array}{c}23 \text { a } 579 \mathrm{mg} \mathrm{L}^{-1} \\
\text { Tagit }=20 \mathrm{~min} \\
\left(25^{\circ} \mathrm{C}\right)\end{array}$ & 21,1 & Este estudo \\
\hline
\end{tabular}


TABELA 18 - Comparação da capacidade de adsorção máxima do AL8 em vários adsorventes

\begin{tabular}{|c|c|c|c|}
\hline ADSORVENTE & CONDIÇÃO & $Q_{0}\left(m g g^{-1}\right)$ & REFERÊNCIA \\
\hline $\begin{array}{c}\text { Nanoesferas ocas } \\
\text { de carvão } \\
\text { mesoporo }\end{array}$ & $\begin{array}{l}7-40 \mathrm{mg} \mathrm{L}^{-1} \\
\text { Tagit }=90 \mathrm{~min} \\
\left(30^{\circ} \mathrm{C}\right)\end{array}$ & 456,60 & Konicki et al., 2013 \\
\hline $\begin{array}{l}\text { Clinoptilolita } \\
\text { modificada }\end{array}$ & $\begin{array}{c}25-200 \mathrm{mg} \mathrm{L}^{-1} \\
\text { Tagit }=20 \mathrm{~min} \\
\left(30^{\circ} \mathrm{C}\right)\end{array}$ & 44,05 & Karadag, 2007 \\
\hline $\begin{array}{c}\text { Carvão da casca } \\
\text { de sementes de } \\
\text { manga }\end{array}$ & $\begin{array}{c}50-2000 \mathrm{mg} \mathrm{L}^{-1} \\
\text { Tagit }=24 \mathrm{~h} \\
\left(25^{\circ} \mathrm{C}\right)\end{array}$ & 15,20 & $\begin{array}{l}\text { Dávila-Jiménez et } \\
\text { al., } 2009\end{array}$ \\
\hline $\begin{array}{l}\text { Carvão ativado de } \\
\text { sementes de } \\
\text { goiaba }\end{array}$ & $\begin{array}{c}50-3000 \mathrm{mg} \mathrm{L}^{-1} \\
\text { Tagit }=24 \mathrm{~h} \\
\left(20^{\circ} \mathrm{C}\right)\end{array}$ & 1,00 & $\begin{array}{c}\text { Elizalde-González } \\
\text { e García-Díaz, } \\
2010\end{array}$ \\
\hline ZCL & $\begin{array}{c}1 \text { a } 4 \mathrm{mg} \mathrm{L}^{-1} \\
\text { Tagit }=360 \mathrm{~min} \\
\left(25^{\circ} \mathrm{C}\right)\end{array}$ & 0,20 & Este estudo \\
\hline ZMSL & $\begin{array}{c}11 \text { a } 253 \mathrm{mg} \mathrm{L}^{-1} \\
\text { Tagit }=90 \mathrm{~min} \\
\left(25^{\circ} \mathrm{C}\right)\end{array}$ & 5,29 & Este estudo \\
\hline ZMSP & $\begin{array}{c}1 \mathrm{a} 9 \mathrm{mg} \mathrm{L}^{-1} \\
\text { Tagit }=240 \mathrm{~min} \\
\left(25^{\circ} \mathrm{C}\right)\end{array}$ & 0,52 & Este estudo \\
\hline
\end{tabular}

Os valores apresentados (TAB. 17 e 18) revelam que os presentes adsorventes (ZCL, ZCP, ZMSL e ZMSP) têm valores máximos de adsorção comparáveis com os valores reportados em alguns casos. Cabe ressaltar que a capacidade máxima de adsorção depende das características particulares do adsorvente e do adsorbato e das condições experimentais. No entanto, o presente estudo é conduzido para encontrar a aplicabilidade técnica dos adsorventes de baixo custo para o tratamento do CV e do AL8.

No caso da TAB. 17, o valor de $Q_{0}(74,62)$ encontrado para as cinzas leves apresenta-se alto comparando com os outros adsorventes. Observa-se que a temperatura utilizada no experimento e a faixa de concentração do adsorbato 
foram semelhantes às utilizadas para a ZCL e ZCP. Contudo, o tempo de agitação foi maior, e provavelmente outros fatores influenciaram a eficiência do processo.

O valor mais alto de $Q_{0}(456,60)$ apresentado na $T A B$. 18 pode ser explicado devido às características do material adsorvente, tais como, o volume maior dos poros e à sua elevada área superficial específica e também ao efeito do $\mathrm{pH}$ do processo.

\subsection{Energia Livre de Adsorção}

A isoterma de adsorção é uma ferramenta útil para a avaliação e interpretação da energia livre de adsorção, $\Delta G^{\circ}$ ads, também conhecida como energia livre de Gibbs $\left(\mathrm{kJ} \mathrm{mol}^{-1}\right)$. A partir dos valores das constantes de Langmuir ( $\mathrm{K}_{\mathrm{L}}$ ) obtidas nas isotermas (Liu, 2006) é possível calcular a $\Delta \mathrm{G}^{\circ}$ ads, segundo a equação abaixo:

$$
\Delta G^{\circ} \text { ads }=-R T \ln K_{L}
$$

onde $\mathrm{R}$ é a constante universal dos gases $\left(8,314 \mathrm{~J} \mathrm{~K}^{-1} \mathrm{~mol}^{-1}\right)$; T é a temperatura em Kelvin, que neste estudo foi $298 \mathrm{~K}$, e $\mathrm{K}_{\mathrm{L}}$ é a constante de Langmuir $\left(\mathrm{L} \mathrm{mol}^{-1}\right)$.

A variação da energia livre de Gibbs $\left(\Delta G^{\circ}\right)$ indica o grau de espontaneidade de um processo de adsorção, e um valor negativo maior deste parâmetro reflete uma adsorção mais energeticamente favorável.

Na TAB. 19 são apresentados os valores de $\Delta G^{\circ}$ calculados para os sistemas de adsorção corante/adsorvente. 
TABELA 19 - Energia livre de Gibbs para os sistemas corante/adsorvente

\begin{tabular}{ccc}
\hline CORANTES & ADSORVENTES & $\mathbf{\Delta G}^{\circ}$ ads $\left(\mathbf{k J ~} \mathbf{~ o l}^{-1}\right)$ \\
\hline \multirow{2}{*}{ CV } & ZCL & $-29,25$ \\
& ZCP & $-25,16$ \\
& ZMSL & $-24,11$ \\
ZMSP & $-20,97$ \\
\hline \multirow{2}{*}{ AL8 } & ZCL & $-31,87$ \\
& ZMSL & $-26,30$ \\
& ZMSP & $-31,23$ \\
\hline
\end{tabular}

De acordo com a TAB. 19 os valores calculados de $\Delta G^{\circ}$ foram negativos, indicando que a natureza do processo de adsorção para todos os sistemas é espontânea.

Gusmão et al., 2013 avaliaram o processo de adsorção do azul de metileno e do cristal violeta sobre bagaço de cana-de-açúcar modificado. A variação da energia livre de Gibbs foi calculada utilizando os valores das constantes de Langmuir e os valores encontrados também foram negativos, semelhante ao que ocorreu com o CV nos materiais adsorventes sintetizados neste estudo.

\subsection{Design do processo de adsorção descontínuo usando os dados da isoterma}

As isotermas de adsorção podem ser usadas para prever o design de sistemas de adsorção por processo descontínuo de estágio simples (McKay et al., 1985; Thomass and Crittenden, 1998; Ozdemir et al., 2006). O diagrama esquemático é mostrado na FIG. 59. 


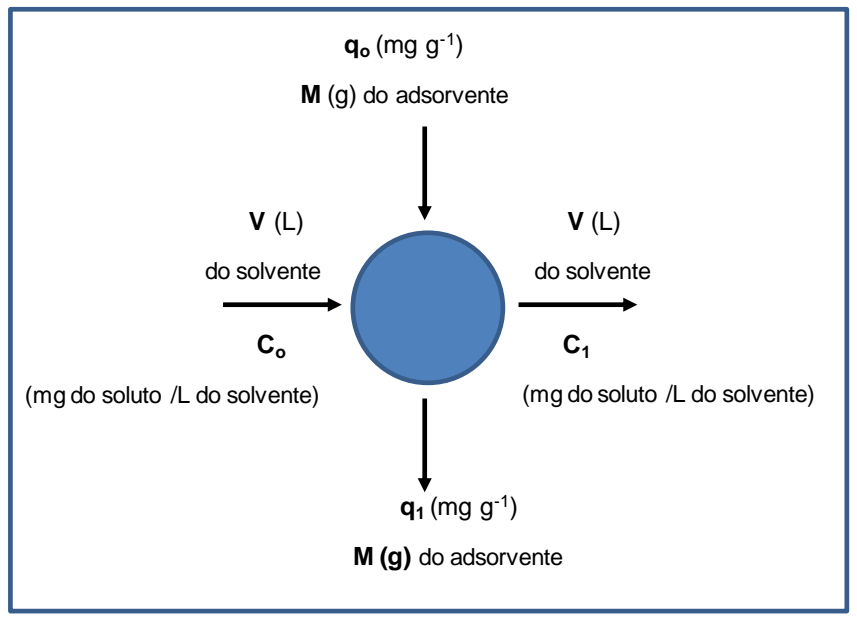

FIGURA 59 - Design para o processo descontínuo de estágio simples.

O objetivo do design é reduzir a concentração inicial $C_{0}\left(\mathrm{mg} \mathrm{L}^{-1}\right)$ da solução do corante com volume $V(L)$ para a concentração $C_{1}\left(m L^{-1}\right)$. $A$ quantidade de adsorvedor é $M(g)$ e a sua capacidade de adsorção muda de $q_{\circ}$ para $\mathrm{q}_{1}\left(\mathrm{mg} \mathrm{g}^{-1}\right)$. No tempo inicial $(\mathrm{t}=0), \mathrm{q}_{0}=0$ e a medida que o tempo passa, $\mathrm{o}$ balanço de massa iguala o corante removido do líquido com aquele adsorvido no sólido. A equação de balanço de massa do sistema de adsorção pode ser escrita como:

$V\left(C_{0}-C_{1}\right)=M\left(q_{0}-q_{1}\right)=M q_{1}$

Sob as condições de equilíbrio,

$\mathrm{C}_{1} \rightarrow \mathrm{C}_{\mathrm{e}}$ e $\mathrm{q}_{1} \rightarrow \mathrm{q}_{\mathrm{e}}$

A Equação (13) pode ser rearranjada como:

$$
\frac{M}{V}=\frac{(C o-C e)}{q_{1}}=\frac{C o-C e}{q_{e}}=\frac{C o-C e}{\frac{q_{o} K_{L} C e}{1+K_{L} C e}}
$$


onde $\mathrm{q}_{\mathrm{e}}$ pode ser obtido pela equação da isoterma que melhor se ajustar aos dados experimentais. No exemplo, está a equação de Langmuir.

No presente estudo, o modelo da isoterma de Freundlich ajustou-se melhor aos dados experimentais para todos os sistemas, com exceção do sistema CV/ZCL, como foi discutido anteriormente no item 5.3. Sendo assim, as equações (1) e (2) podem ser aplicadas para o cálculo de qe.

As FIG. 60 e 61 mostram uma série de gráficos para a adsorção de CV e AL8, respectivamente, sobre os adsorventes sintetizados neste trabalho. As concentrações iniciais de CV de $100 \mathrm{mg} \mathrm{L}^{-1}$ e de AL8 de 2 e $10 \mathrm{mg} \mathrm{L}^{-1}$ foram arbitrariamente escolhidas para a realização dos cálculos das quantidades necessárias de zeólitas organomodificadas para reduzir a cor (remoções de 80, 85, 90 e 95\%) em vários volumes de efluentes. No caso AL8, a concentração de $10 \mathrm{mg} \mathrm{L}^{-1}$ é relatada como a concentração encontrada em efluente real (Elizalde-González e García-Díaz, 2010).
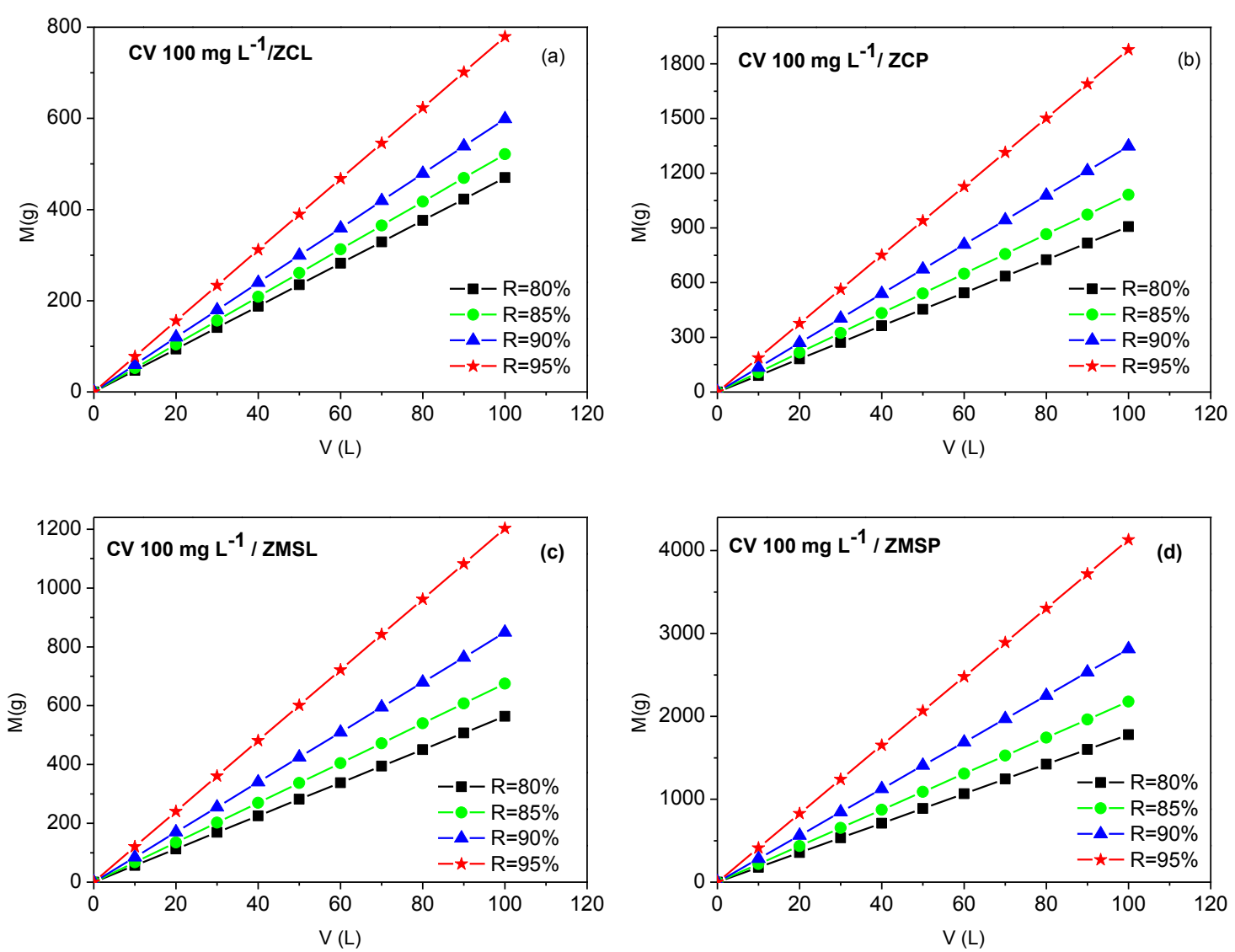

FIGURA 60 - Relação da massa do adsorvente com o volume da solução tratada; (a) CV/ZCL; (b) CV/ZCP. (c) CV/ZMSL; (d) CV/ZMSP. 

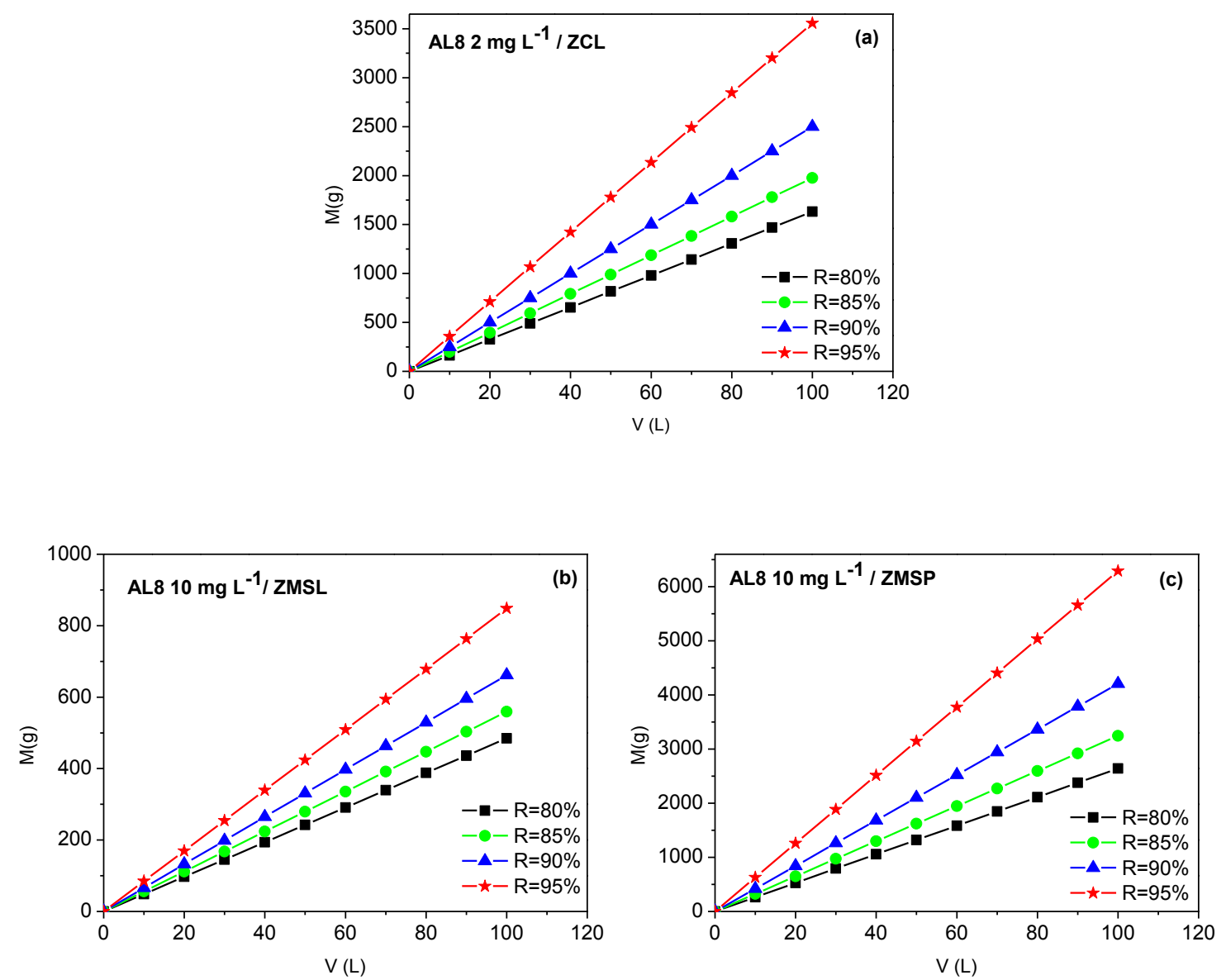

FIGURA 61 - Relação da massa do adsorvente com o volume da solução tratada; (a) AL8/ZCL; (b) AL8/ZMSL; (c) AL8/ZMSP.

Segundo ilustra a FIG. 60 (c), pode-se chegar à conclusão que a quantidade de ZMSL requerida para remover $90 \%$ do CV será 425, 509, 594, 679 g para os volumes de 50,60, 70 e 80 litros, respectivamente, por exemplo.

O procedimento está esboçado para o sistema de adsorção por processo descontínuo de um estágio simples e poderá ser modelado para outras concentrações iniciais dos corantes, taxas de remoção e volumes do efluente.

\subsection{Mecanismo de Adsorção}

A retenção dos corantes pelos materiais adsorventes envolve várias forças atrativas como interação iônica, forças de van der Waals, ligações de hidrogênio, ligações covalentes e efeitos hidrofóbicos (Gu et al.,1994; Arnarson e Keil, 2000). 


\subsubsection{Zeólitas de cinzas leves e Pesadas}

Os adsorventes do tipo zeólitas são formados predominantemente por óxidos de silício e alumínio, cujas superfícies hidroxiladas desenvolvem cargas negativas em solução aquosa. O mecanismo de adsorção do CV sobre a zeólita de cinzas de carvão ocorrerá por atração eletrostática entre os sítios negativamente carregados do adsorvente $\mathrm{e}$ as moléculas positivamente carregadas do corante $\left(=\mathrm{N}^{+}\left(\mathrm{CH}_{3}\right)_{2}\right)$ e também por troca cationica. Por outro lado, o corante AL8 contém grupo sulfonato $\left(-\mathrm{SO}_{3}{ }^{-}\right)$em sua molécula e, portanto, é um corante aniônico em solução aquosa. Assim, a interação eletrostática não ocorrerá no sistema AL8/ZCL. Provavelmente, as interações que ocorrem são por ponte de hidrogênio entre os grupos hidroxilas do adsorvente e os grupos $-\mathrm{SO}_{3}{ }^{-}$, $\mathrm{N}=\mathrm{N}$ e grupos aromáticos do corante (Acemioğlu, 2004).

\subsubsection{Zeólitas de cinzas leves e Pesadas modificadas}

Propõe-se que múltiplos mecanismos estejam envolvidos na adsorção dos corantes CV e AL8 sobre ZMSL e ZMSP devido à grande variedade de grupos funcionais que as suas moléculas possuem e às propriedades superficiais dos materiais adsorventes.

Os materiais zeolíticos modificados possuem carga negativa em água,

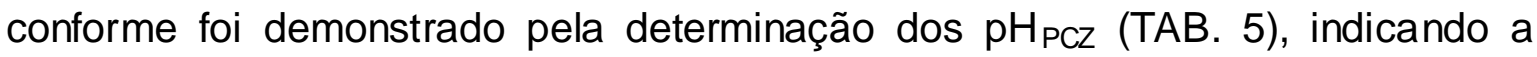
formação de uma bicamada incompleta do HTDMA na superfície.

No caso do corante aniônico AL8, a partição de sua molécula dentro do grupo "cauda" hidrofóbico da molécula do surfactante adsorvido sobre a superfície das zeólitas modificadas ZMSL e ZMSP deve ser o principal mecanismo envolvido na adsorção.

No caso do corante catiônico CV, além da interação hidrofóbica, a atração eletrostática do $-\mathrm{N}^{+}$- sobre a superfície negativa, a troca catiônica e a complexação com espécies de $\mathrm{Si}$ e $\mathrm{Al}$ da zeólita também estão atuando no mecanismo de adsorção sobre ZMSL e ZMSP (Nidheesh et al., 2012). O CV pode interagir com os sítios não ocupados pelo surfactante existentes na zeólita e, portanto, a sua remoção é muito mais eficiente do que do AL8.

Para os dois corantes, os grupos aromáticos e sulfônicos que possuem forma planar e ligações $\pi$ deslocalizadas podem interagir fortemente com $o$ íon 
amônio da molécula do HTDMA, sendo outro possível mecanismo de adsorção. (Custelcean e Jackson, 2001; Stefov et al., 2003). 


\section{CONCLUSÕES}

No presente trabalho foram sintetizados e caracterizados materiais zeolíticos e zeolíticos modificados usando cinzas leves e cinzas pesadas de carvão da Usina Termelétrica Jorge Lacerda como matéria prima. A aplicação da ZCL, ZCP, ZMSL e ZMSP como materiais adsorventes no tratamento de efluente aquoso contendo os corantes cristal violeta (CV) e ácido laranja 8 (AL8) foi avaliada. As características dos processos de adsorção foram determinadas experimentalmente. As principais conclusões a partir dos resultados obtidos foram as seguintes:

$\checkmark$ A análise química das zeólitas e das zeólitas modificadas mostrou a predominância dos compostos sílica $\left(\mathrm{SiO}_{2}\right)$, alumina $\left(\mathrm{Al}_{2} \mathrm{O}_{3}\right)$ e óxido férrico $\left(\mathrm{Fe}_{2} \mathrm{O}_{3}\right)$ em sua composição. A presença do brometo nos adsorventes modificados foi detectada.

$\checkmark$ Após o tratamento hidrotérmico alcalino das cinzas leves e pesadas de carvão formaram-se duas fases zeóliticas, a hidroxisodalita e a NaX.

$\checkmark$ As caracterizações mineralógica e estrutural indicaram que ocorreu o processo de adsorção do surfactante e dos corantes sobre a superfície dos adsorventes sem alteração da natureza cristalina e estrutural.

$\checkmark$ A formação de uma bicamada incompleta do surfactante sobre a superfície dos materiais modificados provenientes das duas cinzas foi confirmada por meio da propriedade ponto de carga zero.

$\checkmark$ Estudos cinéticos mostraram que o tempo de equilibrio de adsorção do Cristal Violeta sobre as zeólitas ZCL, ZCP, ZMSL e ZMSP foi de 10, 10, 6 e 16 min, respectivamente.

$\checkmark$ Para 0 ácido laranja 8, os estudos do tempo de contato mostraram que 0 equilibrio sobre as zeólitas ZCL, ZMSL e ZMSP foi alcançado em 360, 90 e 240 min, respectivamente. Para a ZCP não houve remoção, evidenciando que nas condições experimentais estudadas este adsorvente não é eficiente para remover o corante aniônico ácido laranja 8. 
$\checkmark$ O mecanismo de pseudo-segunda-ordem ajustou-se melhor aos dados experimentais da cinética do processo de adsorção para todos os sistemas estudados.

$\checkmark$ As zeólitas modificadas apresentaram flotabilidade.

$\checkmark$ As isotermas de equilíbrio para os sistemas CV/ZCL e CV/ZBayer apresentaram curvas com comportamento correspondente à classe do tipo L2, indicando a formação de uma monocamada saturada de moléculas do soluto sobre a superfície do adsorvente e que a afinidade de adsorção aumenta com o aumento da concentração do adsorbato até a saturação.

$\checkmark$ Para os sistemas CV/ZMSL, CV/ZMSP, AL8/ZCL e AL8/ZMSP as isotermas de equilíbrio foram classificadas com tipo $L 3$, revelando a formação rápida de uma segunda camada de adsorção.

$\checkmark$ A classificação das curvas para os sistemas CV/ZCP e AL8/ZMSL foi tipo L4. Neste comportamento há a formação de duas camadas, uma no primeiro grau de saturação da superfície e outra na adsorção posterior na nova superfície.

$\checkmark$ O modelo de isoterma de adsorção de Freundlich foi o mais compatível com os dados experimentais para todos os sistemas estudados, com exceção do sistema CV/ZCL, que seguiu o modelo de Langmuir.

$\checkmark$ As capacidades máximas dos sistemas de adsorção CV/ZCL, CV/ZCP, CV/ZMSL e CV/ZMSP foram 19,6; 17,6; 36,7 e 21,1 $\mathrm{mg} \mathrm{g}^{-1}$, respectivamenete. Para os sistemas AL8/ ZCL, AL8/ZMSL e AL8/ZMSP foram 0,200; 5,29 e 0,520 $\mathrm{mg} \mathrm{g}^{-1}$, respectivamente.

$\checkmark$ A capacidade de adsorção decresceu na seguinte ordem: ZMSL > ZMSP > ZCL > ZCP.

$\checkmark$ A adsorção do CV sobre todos os adsorventes foi mais eficaz do que a do AL8 devido às respectivas cargas.

$\checkmark$ Os adsorventes originários das cinzas leves apresentaram maiores remoções dos corantes porque têm uma granulometria mais fina.

$\checkmark$ As zeólitas modificadas foram mais eficientes do que as zeólitas não modificadas devido ao mecanismo de partição. É importante ressaltar que para o corante cristal violeta a diferença entre as capacidades máximas de adsorção não foi tão relevante. Desta maneira, não há necessidade da 
modificação da superfície das zeólitas para a adsorção deste corante catiônico.

$\checkmark$ Os valores obtidos para a energia de Gibbs foram negativos, evidenciando que a natureza do processo é espontânea.

$\checkmark$ O estudo de design mostrou que é possível prever a massa necessária de adsorvente para a remoção de cor dos efluentes.

Pode-se concluir, com base nos resultados apresentados que os materiais baseados em zeólitas e zeólitas modificadas de cinzas de carvão desenvolvidos nesse trabalho mostraram ser adsorventes eficientes para a remoção dos corantes Cristal Violeta e Ácido Laranja 8 em água. Dessa forma, estes adsorventes de baixo custo poderão ser aplicados em uma etapa terciária no processo de tratamento de efluentes contendo esses corantes. Cabe ressaltar que o material zeolítico também exibe a capacidade de remoção de metais tóxicos, contaminantes emergentes e nutrientes (fosfato e amônio) do efluente simultaneamente com os corantes. 


\section{CONSIDERAÇÕES}

Os efluentes contaminados com corantes após o tratamento com materiais zeolíticos não deverão ser descartados diretamente em corpos d'água, mas poderão ser usados como água de reúso não potável. No Brasil, a resolução 54 de 2005 do CNRH (Conselho Nacional de Recursos Hídricos) estabelece modalidades, diretrizes e critérios para a prática de reúso de água para fins não potáveis. Esse reúso e/ou reaproveitamento reduz a demanda sobre os mananciais de água devido à substituição da água potável por uma água de qualidade menos nobre. O reúso não potável com fins industriais pode ser aplicado em: processos, atividades e operações industriais, abatimento de poeiras e limpezas no geral.

O descarte de resíduos perigosos em aterros está se tornando cada vez mais inaceitável devido à crescente preocupação com o efeito dos poluentes no meio ambiente. No caso das zeólitas saturadas dos corantes, faz-se necessário realizar testes de solubilização e lixiviação antes da disposição para avaliar os possíveis riscos de uma poluição secundária. Uma alternativa para evitar o descarte das zeólitas saturadas dos corantes é a regeneração, permitindo desta forma, uma aplicação mais ampla e uma maior contribuição para a preservação do meio ambiente. Segundo alguns relatos na literatura, os adsorventes saturados dos corantes e outros poluentes orgânicos podem ser regenerados e reutilizadas por meio da implementação de tecnologias alternativas e que são economicamente acessíveis e ambientalmente amigáveis (Han et al., 2002; Yen e Hameed, 2009; Ania et al., 2005; Jones et al., 2002).

É importante ressaltar que os resultados de remoção da cor podem variar se o processo de adsorção utilizado neste trabalho for aplicado numa indústria têxtil. Isto ocorre porque os efluentes reais podem apresentar uma infinidade de substâncias diferentes entre si, e em diferentes concentrações. Por esta razão seria válido realizar estudos de adsorção utilizando estes efluentes com o propósito avaliar a capacidade de adsorção da zeólita de cinzas de carvão numa situação real. Os processos de adsorção que não forem totalmente 
eficientes para a remoção da cor, poderão ser aplicados em conjunto com outros tipos de tratamento.

Conforme foi mencionado no presente trabalho, vários fatores podem influenciar a eficiência do processo de adsorção. Uma alternativa para melhoria da capacidade de adsorção dos adsorventes sintetizados pode ser a utilização de um método estatístico - o planejamento fatorial. Por meio deste estudo é possível determinar se as variáveis escolhidas em um sistema exercem ou não efeito sobre a resposta. O objetivo é obter o máximo de dados úteis, realizando um número mínimo de experimentos. 
APÊNDICES 
APÊND ICE A - Teste de reprodutibilidade

\begin{tabular}{|c|c|c|c|c|c|}
\hline \multirow{2}{*}{ CORANTES } & \multicolumn{5}{|c|}{ DPR (\%) } \\
\cline { 2 - 6 } & ZCL & ZCP & ZBAYER & ZMSL & ZMSP \\
\hline CRISTAL VIOLETA & 2,3 & 5,9 & 1,6 & 5,6 & 4,8 \\
\hline ÁCIDO LARANJA 8 & 6,3 & - & - & 5,3 & 4,2 \\
\hline
\end{tabular}


ANEXOS 
ANEXO A - Espectros de infravermelho dos corantes CV e AL8

CV

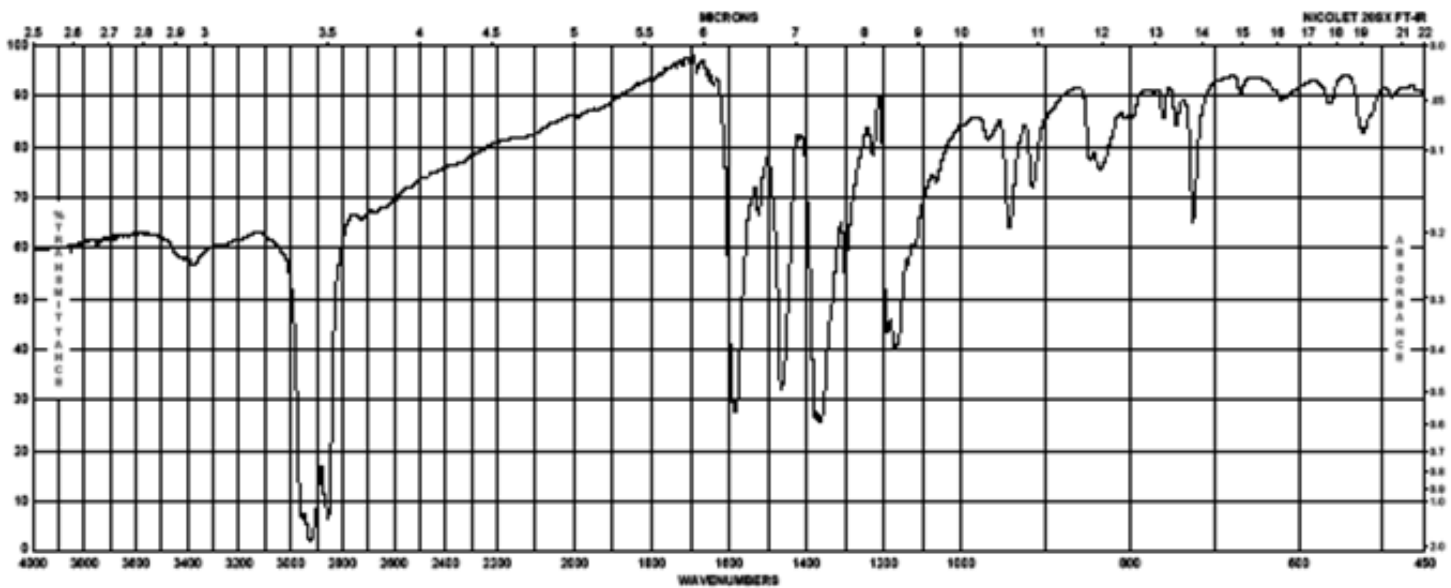

AL8

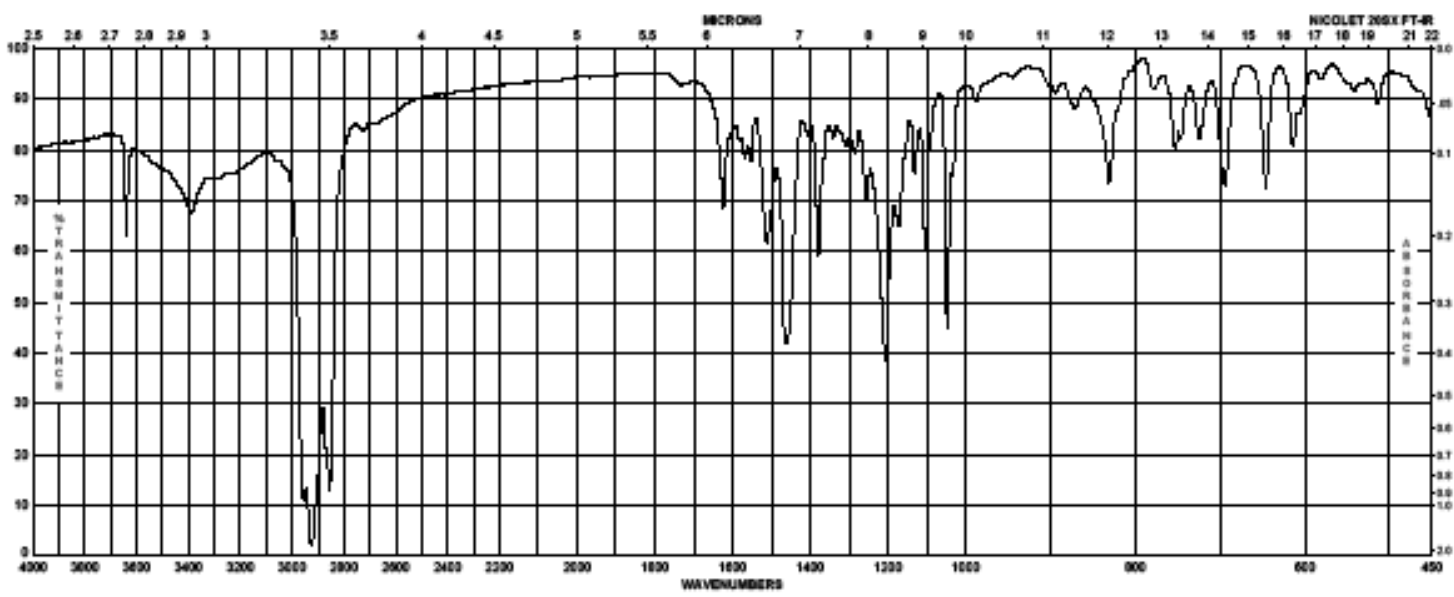


ANEXO B - Micrografia das cinzas leves (CLC)

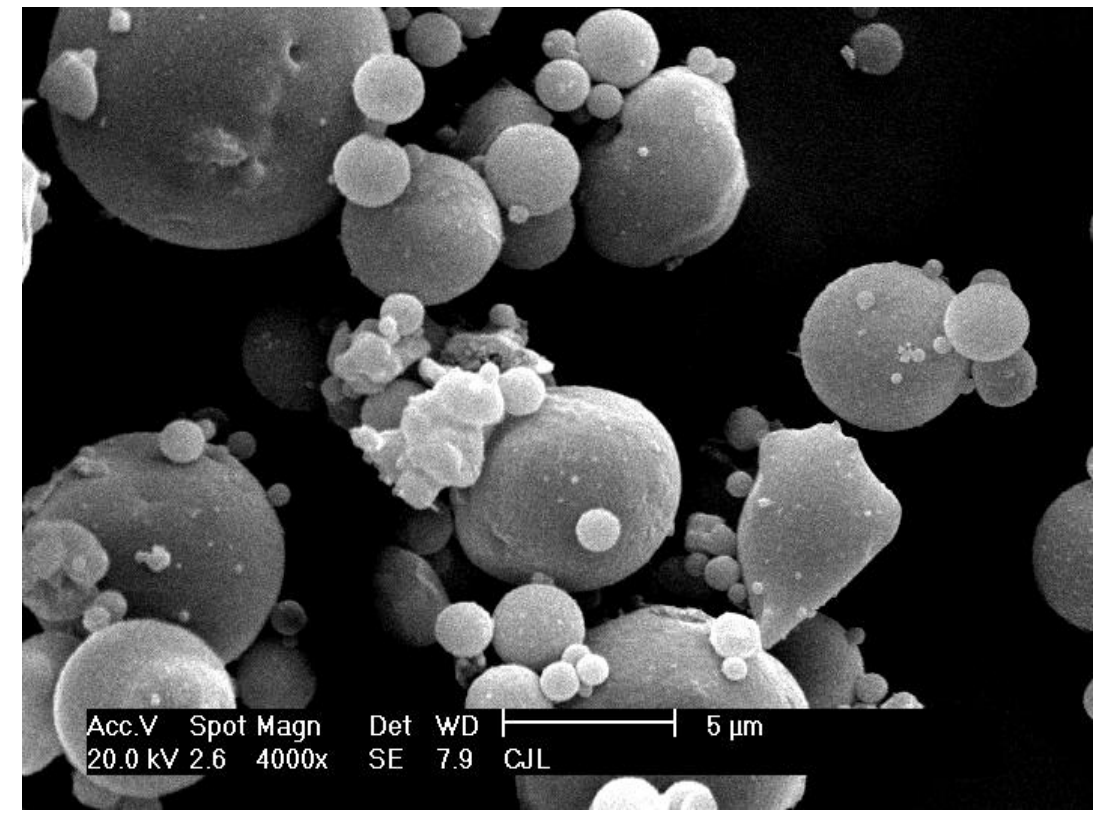

ANEXO C - Micrografia da zeólita de cinzas leves (ZCL)

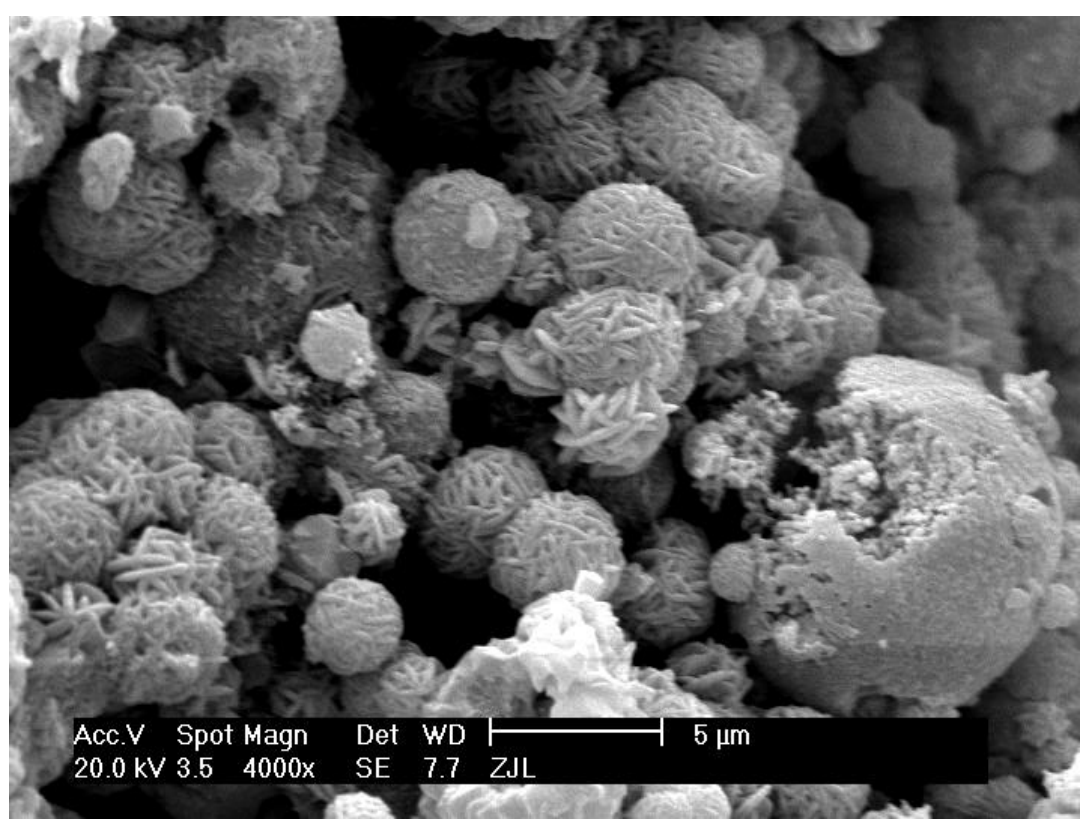




\section{REFERÊNCIAS BIBLIOGRÁFICAS}

ABIQUIM- associação Brasileira de Indústria Química. Corantes e pigmentos. Disponível em http://www.abiquim.org.br/corantes/cor_aplicacoes.asp. Acessado em 30/03/2013.

ABIT. Associação Brasileira da Indústria têxtil e de Confecção. CNI. Confederação Nacional da Indústria. Têxtil e confecção: inovar, desenvolver e sustentar. Brasília: Fascículo CNI/Abit, 2012.

ACEMIOĞLU, B. Adsorption of Congo red from aqueous solution onto calcium-rich fly ash, J. Colloid Interface Sci., v. 274, p. 371-379, 2004.

AGÊNCIA NACIONAL DE ENERGIA ELÉTRICA -- Atlas de energia elétrica do Brasil, Parte III - Fontes não-renováveis - Capítulo 9: Carvão mineral. ANEEL, 2008. Disponível em: < http://www.aneel.gov.br/visualizar_texto.cfm?idtxt=1689>. Acesso em: 03 setembro 2013.

AHMARUZZAMAN, M. A review on the utilization of fly ash. Prog Energy Combust Sci., v. 36, p. 327-363, 2010.

AHMARUZZAMAN, M. Industrial wastes as low-cost potential adsorbents for the treatment of wastewater laden with heavy metals. Adv. Colloid and Interface Sci., v.166, p.36-59, 2011.

AL-DEGS, Y.S.; KHRAISHEH, M.A.M.; ALLEN, S.J.; AHMAD, M.N. Adsorption characteristics of reactive dyes in columns of activated carbon, J. Hazard. Mater., v. 165, 944-949, 2009.

ALEBOYEH, A.; ALEBOYEH, H.; MOUSSA, Y. "Critical" effect of hydrogen peroxide in photochemical oxidative decolorization of dyes: Acid Orange 8, Acid Blue 74 and Methyl Orange. Dyes and Pigments. v. 57, p. 67-75, 2003.

ALI, A. A.-H.; El-BISHTAWI, R. Removal of lead ions using zeolite tuff. J. Chem. Technol. Biotechnol., v.69, p.27-34, 1997. 
ALLEGRE, C.; MOULIN, P.; MAISSEU, M.; CHRABIT, F. Treatment and reuse of reactive dyeing efluennts, J. Membr. Sci., v. 269, p. 15-34, 2006.

ALLEN, S.J.; MCKAY, G.; KHADER, K.Y.H. Intraparticle diffusion of a basic dye during adsorption onto sphagnum peat. Environ. Pollut., v.56, p. 39-50, 1989.

AL-GODAH, Z. Adsorption of dyes using shale oil ash. Water Research, v. 34, p. 4295-4303, 2000.

ALONSO-HERNÁNDEZ, C.M.; BERNAL-CASTILLO, J.; BOLANOS-ALVAREZ, Y.; GÓMEZ-BATISTA, M.; DIAZ-ASENCIO, M. Heavy metal content of bottom ashes from a fuel oil power plant and oil refinery in Cuba. Fuel, v. 90, p. 2820-2823, 2011.

ANDRADE, L.B.; ROCHA, J.C.; CHERIAF, M. Influence of coal bottom ash as fine aggregate on fresh properties of concrete. Constr. Build. Mater., v. 23, p. 609-614, 2009.

ARNARSON, T.S.; KEIL, R.G. Mechanisms of pore water organic matter adsorption to montmorillonite. Marine Chem., v. 71, p. 309-320, 2000.

ANIA, C.O.; PARRA, J.B.; MENENDEZ, J.A.; PIS, J.J. Effect of microwave and conventional regeneration on the microporous and mesoporous network and on the adsorptive capacity of activated carbons. Micropor. Mesopor. Mater., v. 85, p. 7-15, 2005.

BALANOVA, M.; POPOVA, L.; TCHIPEVA, R.; Clinics in Dermatology, v. 21, 2003.

BALL, P.; NICHOLLS, C. H. Azo-hidrazone tautomerism of hidroxiazo compounds - A review. Dyes and Pigments, v. 3, p. 5-26, 1982.

BARRER, R.M. Hydrotermal Chemistry of Zeolites. London: Academic Press, p. 260, 1982.

BAUP, S.; JAFFRE, C.; WOLBERT, D.; LAPLANCHE, A. Adsorption of pesticides onto granular activated carbon: Determination of surface diffusivities using simple batch experiments. Adsorption, v. 6, p. 219-228, 2000. 
BERTOLINI, T.C.R.; IZIDORO, J.C.; MAGDALENA, C.P.; FUNGARO, D.A. Adsorption of crystal violet dye from aqueous solution onto zeolites from coal fly and bottom ashes. Orbital Elec. J. Chem. v. 5, p. 179-191, 2013.

BHATNAGAR, A.; JAIN A.K. A comparative adsorption study with different industrial waste as adsorbents for the removal of cationic dyes from water. J. Colloid Interf. Sci., v. 281, p. 5-49, 2005.

BHATNAGAR, A.; SILLANPAA, M. Utilization of agro-industrial and municipal waste as potential adsorbents for water treatment - A review. Chem. Eng. J., v. 157, p. 277-296, 2010.

BIJSTERBOSCH, B.H. Characterization of Silica Surfaces by Adsorption from Solution. Investigations into the Mechanism of Adsorption of Cationic Surfactants. J. of Colloidal Interface Sci., vol. 47, p. 186-198, 1974.

BLISSETT, R.S.; ROWSON, N.A. A review of the multi-component utilisation of coal fly ash. Fuel, v. 97, p. 1-23, 2012.

BÖER, S.C. ADSORÇÃO DE NITROGÊNIO AMONIACAL DE EFLUENTES INDUSTRIAIS, A PARTIR DA SÍNTESE DA ZEÓLITA Na-P1 DE CINZAS PESADAS DE CARVÃO. 2013. Dissertação (Mestrado). Centro Universitário La Salle, Canoas.

BOYD, S.A.; LEE, J.F.; MORTLAND, M.M. Attenuating organic contaminant mobility by soil modification. Nature 333, p. 345-347, 1988a.

BOYD, S.A.; MORTLAND, M.M.; AND CHIOU, C.T. Sorption characteristics of organic compounds on hexadecyltri-methylammonium-smectites. Soil Sci. Soc. Am. J., v. 52, p. 652-657, 1988b.

BOYD, S.A.; SHAOBAI, S.; LEE, J.F; MORTLAND, M.M. Pentachlorophenol adsorption by organo-clays. Clays Clay Miner., v. 36, p. 125-130, 1988c.

BOWMAN, R.S. Applications of surfactant-modified zeolites to environmental remediation. Microp. Mesop. Mat., v. 61, p. 43-56, 2003.

BRECK, D.W. Zeolite molecular sieves: structure, chemistry, and use. Malabar: Robert E. Krieger Publishing Company, 1984. 
BRUNO, M. Utilização de zeólitas sintetizadas a partir de cinzas de carvão na remoção de corante em água. [Dissertação]. São Paulo: Centro de Química e Meio ambiente, Instituto de Pesquisas Energéticas e Nucleares, 2008.

BUHRKE, V.E., JENKINS, R., SMITH, D.K. Preparation of specimens for X-ray fluorescence and X-ray diffraction analysis. London: Wiley-VCH, 1998.

CARVALHO, T.E.M. Adsorção de corantes em água usando zeólita sintética . 2010. Dissertação (Mestrado) - Instituto de Pesquisas Energéticas e Nucleares, São Paulo.

CARVALHO, T.E.M.; FUNGARO, D.A.; IZIDORO, J.C. Adsorção do corante reativo laranja 16 de soluções aquosas por zeólita sintética. Quim. Nova, vol. 33, $n^{\circ} .2$, p. 358-363, 2010.

CARVALHO, T.E.M.; FUNGARO, D.A..; MAGDALENA, C.P.; CUNICO, P. Adsorption of indigo carmine from aqueous solution using coal fly ash and zeolite from fly ash. J. Radioanal. Nucl. Chem. v. 289, p. 617-626, 2011.

CHAKRABORTY, S.; CHOWDHURY, S.; SAHA, P.D. Adsorption of Crystal violet from aqueous solution onto NaOH-modified rice husk. Carbohydr Polym., v. 86, p.1533-1541, 2011.

CHENG, Y.; LIN, H.Y.; CHEN, Z.; MEGHARAJ, M.; NAIDU, R. Biodegradation of crystal violet using Burkholderiavietnamiensis C09V immobilized on PVAsodiumalginate-kaolingelbeads. Ecotoxicol. Environ. Saf., v. 83, p. 108-114, 2012.

CHEQUER, F.M.D.; LIZIER, T.M.; FELÍCIO, R.; ZANONI, M.V.B.; DEBONSI, H.M.; LOPES, N.P.; MARCOS, R.; OLIVEIRA, D.P. Analyses of the genotoxic and mutagenic potential of the products formed after the biotransformation of the azo dye Disperse Red 1. Toxicol. in Vitro., v. 25, p. 2054-2063, 2011.

CHIES, F., SILVA, N.I.W., ZWONOK, O. Desenvolvimento de blocos e tijolos a partir de cinzas de fundo de carvão - CIPECAL. In: ROCHA, J.C., JONH, U.M. (Eds). Utilização de resíduos na construção habitacional. (Coleção HABITARE, v.4). Porto Alegre, p. 218 - 239, 2003.

CHIOU, C.T. Partition and adsorption of organic contaminants in environmental systems. New Jersey: John Wiley \& Sons, 2002. 
CHUTIA, P.; KATO, S.; KOJIMA, T.; SATOKAWA, S. Adsorption of As(V) on surfactant modified natural zeolites. J. Hazard. Mater., v. 162, p. 204-211, 2009.

CONSELHO NACIONAL DO MEIO AMBIENTE. Resolução n‥ 357, de 17 de março de 2005. CONAMA. Disponível em:

<http://www.mma.gov.br/port/conama/res/res05/res35705.pdf>. Acesso em: 23 jun. 2009.

COOMBS, D.S.; ALBERTI, A.; ARMBRUSTER, T.; ARTIOLI, G.; COLELLA, C.; GALLI, E.; GRICE, J.D.; LIEBAU, F.; MANDARINO, J.A.; MINATO, H.; NICKEL, E.H.; PASSAGLIA, E.; PEACOR, D.R.; QUARTIERI, S.; RINALDI, R.; ROSS, M.I.; SHEPPARD, R.A.; TILLMANNS, E.; VEZZALINI, G. Recommended nomenclature for zeolite minerals; Report of the Subcommittee on Zeolites of the International Mineralogical Association, Commission on New Minerals and Mineral Names. Eur. J. Mineral., v. 10, p. 1037-1081, 1998.

COVARRUBIAS, C.; GARCÍA, R.; ARRIA GADA, R.; YÁNEZ, J.; GARLAND, M.T. $\mathrm{Cr}$ (III) exchange on zeolites obtained from kaolin and natural mordenite. Microp. Mesop. Mat., v. 88, p. 220-231, 2006.

CUSTELCEAN, R.; JACKSON, J.E. Dihydrogen Bonding: Structures, Energetics, and Dynamics. Chem. Reviews, v. 101, p.1963-1980, 2001.

ÇORUH, S.; GEYIKÇI, F.; NURI, O. N. Dye Removal from Aqueous Solution by Adsorption onto Fly Ash. In: ATINER'S Conference Paper Series, Athens, Greece, 2012.

CUNICO, P.; FUNGARO, D.A; MAGDALENA, C.P. Adsorção do reativo preto 5 de solução aquosa por zeólita de cinzas de carvão: estudos cinéticos e de equilíbrio.

Periodico Tche Quimica. v. 8, p. 17-24, 2011.

DABROWSKI, A. Adsorption - from theory to practice. Adv. Colloid Interface Sci., v. 93, p. 135-224, 2001.

DÁVILA-JIMÉNEZ, M. M.; ELIZALDE-GONZÁLEZ, M. P.; HERNÁNDEZ MONTOYA, V. Performance of mango seed adsorbents in the adsorption of anthraqui none and azo acid dyes in single and binary aqueous solutions. Bioresource Technology., v. 100, p. 6199-6206, 2009.

DEPOI, F.S.; POZEBON, D.; KALKREUTH, W.D. Chemical characterization of feed coals and combustion-by-products from Brazilian power plants. Int. J. Coal Geol., v. 76, p. 227-236, 2008. 
DIZGE, N.; AYDINER, C.; DEMIRBAS, E.; KOBYA, M.; KARA, S. Adsorption of reactive dyes from aqueous solutions by fly ash: kinetic and equilibrium studies. $\boldsymbol{J}$. Hazard. Mater., v. 150, p. 737-747, 2008.

DOGĂN, M.; ALKAN, M. Adsorption kinetics of methyl violet onto perlite.

Chemosphere, v. 50, p. 517-528, 2003.

ELÍAS, V.R.; SABRE, E.V.; WINKLER, E.L.; SATUF, M.L.; RODRIGUEZCASTELLÓN, E.; CASUSCELLI, S.G.; EIMER, G.A. Chromium and titani um/chromium-containing MCM-41 mesoporous silicates as promising catalysts for the photobleaching of azo dyes in aqueous suspensions. A multitechnique investigation. Micropor. Mesopor. Mater., v. 163, p. 85-95, 2012.

ELIZALDE-GONZÁLEZ, M.P., GARC IA-DIAZ, L.E. Application of a Taguchi L16 orthogonal array for optimizing the removal of Acid Orange 8 using carbon with a low specific surface area. Chem. Eng. J., v. 163, p. 55-61, 2010.

ELKADY, M.F.; IBRAHIM A.M.; EL-LATIF M.M.A. Assessment of the adsorption kinetics, equilibrium and thermodynamic for the potential removal of reactive dye using eggshell bio-composite beads. Desalination, v. 278, p. 412-423, 2011.

ENDRES, J.C.T., FERRET, L. S., FERNANDES, I. D., HOFMEISTER, L. C. The removal of $\mathrm{Fe}, \mathrm{Zn}, \mathrm{Cu}$ and $\mathrm{Pb}$ from wastewaters using chabazite zeolites produced from southern brazilian coal ashes. In: INTERNATIONAL ASH UTILIZATION SYMPOSIUM, 4., 2001, Lexington, Kentucky, USA. Proceedings... Lexing ton:University of Kentucky, p. 478-484, 2001.

ENERGY WATCH GROUP. Coal: Resources and Future Production. EWG: The German Member of Parliament Hans-Josef Fell, 2007.

ENERGY INFORMATION ADMINISTRATION (EIA), 2009. Country Analysis Briefs: Brazil (September 2009).

<http://www.eia.doe.gov/cabs/Brazil/Eletricity. html> Acesso em: 3 de setembro 2013.

FAUST, S.D., ALY, O.M., Adsorption Process for Water Treatment, Butterworths, London, Wellington, p.16-18, 1987.

FANSURI, H.; YANTI, Y.; LONDAR, E.; WIDIASTUTI, N. Synthesis of zeolite - $\boldsymbol{A}$ from coal bottom ash: the influence of unburned carbon to the zeolite quality. In: $13^{\text {th }}$ ASIA PACIFIC CONFEDERATION OF CHEMICAL ENGINEER CONGRESS, October 5-8, 2010, Taipei. 
FERREIRA, C.P. Estudos sobre a adsorção do corante Reativo Preto 5 de solução aquosa usando zeólita de cinzas de carvão. 2011. Dissertação (Mestrado) - Instituto de Pesquisas Energéticas e Nucleares, São Paulo.

FERRET, L.S. Zeólitas de cinzas de carvão: síntese e uso. 2004. Tese (Doutorado) - Universidade Federal do Rio Grande do Sul, Porto Alegre.

FERRET, L.S.; FERNANDES, I.D.; KHAHL, C. A.; ENDRES, J.C.T.; MAEGAWA, A. Zeolification of ashes obtained from the combustion of southern's Brazil Candiota coal. In: INTERNATIONAL ASH UTILIZATION SYMPOSIUM, 3., 1999, Lexington, Kentucky, USA. Proceedings...Lexington: University of Kentucky, p. 247-252, 1999.

FOO, K.Y.; HAMEED; B.H. The environmental applications of activated carbon/zeolite composite materials. Adv. Colloid Interface Sci.; v. 162, p. 22-28, 2011.

FORSS, J.; WELANDER, U. Biodegradation of azo and anthraquinone dyes in continuous systems. Int. Biodeterior. Biodegrad., v. 65, p. 227-237, 2011.

FUNGARO, D. A. Aplicação de material zeolítico preparado com cinzas de carvão no tratamento de águas contaminadas. Revista Meio Filtrante, n.9, 2004.

FUNGARO, D.A.; BORRELY, S.I.; CARVALHO, T.E.M. Surfactant Modified Zeolite from Cyclone Ash as Adsorbent for Removal of Reactive Orange 16 from Aqueous Solution. American Journal of Environmental Protection, 2013, vol. 1, p. 1-9, 2013.

FUNGARO, D.A.; BORRELY. S.I. Síntese e caracterização de zeólita de cinzas de carvão modificada por surfactante catiônico. Cerâmica, v. 58, p. 77-83, 2012.

FUNGARO, D.A.; BRUNO, M. Remoção do azul de metileno de solução aquosa usando zeólitas sintetizadas com amostras de cinzas de carvão diferentes.Quim. Nova., v. 32, p. 955-959, 2009b.

FUNGARO, D.A.; BRUNO, M. Utilização de zeólitas sintetizadas a partir de cinzas de carvão para remoção de azul de metileno em água. Orbital Elec. J. Chem., v.1, p.49-63, 2009a. 
FUNGARO, D.A.; BRUNO, M.; GROSCHE, L.C. Adsorption and kinetic studies of methylene blue on zeolite synthesized from fly ash. Desalin. Water. Treat., v.2, p. 231-239, 2009a.

FUNGARO, D.A., FLUES, M.S.M., CELEBRONI, A.P. Estabilização de solo contaminado com zinco usando zeólitas sintetizadas a partir de cinzas de carvão. Quím. Nova., v. 27, p. 582-585, 2004a.

FUNGARO, D.A.; GROSCHE, L.C.; PINHEIRO, A.S.; IZIDORO, J.C; BORRELY S.I. Adsorption of methylene blue from aqueous solution on zeolitic material and the improvement as toxicity removal to living organisms. Orbital Elec. J. Chem., vol. 2, p. 235-247, 2010.

FUNGARO, D.A., IZIDORO, J. C., Tratamento de efluentes industriais usando material zeolítico preparado com cinzas de carvão. In: XIX Prêmio Jovem Cientista, Porto Alegre: Gráfica e Editora Comunicação Impressa, 2004b.

FUNGARO, D.A., IZIDORO, J.C. Estudo da remoção de íons metálicos em água utilizando zeólitas sintetizadas com cinzas de carvão. Tchê Quím., v.3, p. 21-30, 2006a.

FUNGARO, D. A.; IZIDORO, J. C. Modelagem cinética da remoção de $\mathrm{Cd}^{2+}$ por zeólitas de cinzas de carvão. Revista Brasileira de Ciências Ambientais, v.25, n. 16, p. 9-13, 2008.

FUNGARO, D.A, IZIDORO, J.C. Remediação de drenagem ácida de mina usando zeólitas sintetizadas a partir de cinzas leves de carvão. Quím. Nova, v.29, n. 4, p. 735-740, 2006b.

FUNGARO, D.A.; REVA, J.; IZIDORO, J.C. Remoção de vermelho do congo de solução aquosa por zeólitas de cinzas de carvão: estudo cinético e análise deisotermas de equilîbrio. Tchê Quím., v.6, p. 25-32, $2009 \mathrm{~b}$.

FUNGARO, D.A.; SILVA, M.G. Utilização de zeólita preparada a partir de cinza residuária de carvão como adsorvedor de metais em água. Quím. Nova., v. 25, p. 1081 - 1085, 2002.

FUNGARO, D.A.; YAMAURA, M.; CARVALHO, T.E.M. Adsorption of anionic dyes from aqueous solution on zeolite from fly ash-iron oxide magnetic nanocomposite. J. At. Mol. Sci., v. 2, p. 305-316, 2011. 
GANDHIMATHI, R.; RAMESH S.T.; SINDHU, V.; NIDHEESH, P.V. Single and Tertiary System Dye Removal from Aqueous Solution Using Bottom Ash: Kinetic and Isotherm Studies. Iran J.of Energy \& Environ., v. 3, p. 52-62, 2012.

GHOBARKAR, H.; SCHAF, O.; GUTH, U. Prog. Solid State. Chem., v. 27, p. 29-73, 1999.

GIANNETTO, G. Zeolitas - caracteristicas, propiedades y aplicaciones industriales. Caracas: EdiT Editorial Innovación Tecnológica, 1990.

GILES, C.H.; MACEWAN, T.H.; NAKHUA, S.N.; SMITH, D. Studies in adsorption. A system of classification of solution adsorption isotherms, and its use in diagnosis of adsorption mechanisms and in measumrement of specific surface areas of solids. J. Chem. Soc. London, p. 3973-3993, 1960.

GILES, C. H.; SMITH, D.; HUITSON, A. A general treatment and classification of the solute adsorption isotherm. I. Theoretical. J. Colloid Interface Sci., v. 47, n. 3 , p. 755-765, 1974.

GOBBI, S.A., ENGERT, A.H., RUBIO, J. Avaliação do uso de zeólita sintética para a remoção de nitrogênio amoniacal de águas e efluentes. Porto Alegre: LTM/UFRGS, 2004.

GRASSI, M., KAYKIOGLU, G., BELGIORNO, V., LOFRANO, G. Removal of Emerging Contaminants from Water and Wastewater by Adsorption Process. In: G. Lofrano (ed.), Emerging Compounds Removal from Wastewater, 2012.

GU, B., SCHMITT, J.; CHEN, Z.; LIANG, L.; McCARTHY, J.F.; Adsorption and desorption of natural organic matter on iron oxide: mechanisms and models. Environ. Sci. Technol., v. 28, p. 38-46, 1994.

GUAN, H.; BESTLAND, E.; ZHU, C.; ZHU, H.; ALBERTSDOTTIR, D.; HUTSON, J.; SIMMONS, C.T.; GINIC-MARKOVIC, M.; TAO, X.; ELLIS, A.V. Variation in performance of surfactant loading and resulting nitrate removal among four selected natural zeolites, J. Hazard. Mater., v. 183, p. 616-621, 2010.

GUARATINI, C.C.I.; ZANONI, M.V. Corantes têxteis. Quím. Nova, v. 23, n. 1 , p. 71-78, 2000.

GUISNET, M.; RIBEIRO, F. R.; Zeólitos - um nanomundo ao serviço da catálise. Lisboa: Fundação Calouste Gulbenkian, 2004. 
GÜMÜŞ, D.; AKBAL, F. Photocatalytic degradation of textile dye and wastewater. Water Air Soil Pollut., v. 216, p. 117-124, 2010.

GUPTA, V.K.; CARROTT, P.J.M.; RIBEIRO CARROTT, M.M.L.; SUHAS. LOWCost Adsorbents: Growing Approach to Wastewater Treatment - A Review. Crit. Rev. Env. Sci. Technol., v. 39, p. 783-842, 2009.

GUPTA, V.K.; SUHAS. Application of low-cost adsorbents for dye removal - A review. J. Environ. Manage., v. 90, p. 2313-2342, 2009.

GUSMÃO, K.A.G.; GURGEL, L.V.A.; MELO, T.M.S.; GIL, L. F. Adsorption studies of methylene blue and gentian violet on sugarcane bagasse modified with EDTA dianhydride (EDTAD) in aqueous solutions: Kinetic and equilibrium aspects . J. Environ. Manage., v. 118, p. 135-143, 2013.

HAN, R.; WANG, Y.; SUN, Q.; WANG, L.; SONG, J.; HE, X.; DOU, C. Malachite green adsorption onto natural zeolite and reuse by microwave irradiation. J. Hazard. Mater., v. 175, p. 1056-1061, 2010.

HAGGERLY, G.M.; BOWMAN, R.S. Sorption of chromate and other inorganic anions by organo-zeolite. Environ. Sci. Technol., v. 28, p. 452-458, 1994.

HENMI, T. Synthesis of hydroxi-sodalite ("zeolite") from waste coal ash. Soil Sci. Plant Nutr., v. 33, p. 517-521, 1987.

HESSEL, C.; ALLEGRE, C.; MAISSEU, M.; CHARBI, F.; MOULIN, P. Review: guidelines and legislation for dye house effluents, J. Environ. Manage., v. 83, p. 171-180, 2007.

HE, Y.; WANG, X.; XU, J.; YAN; J.; GE, Q.; GU, X.; JIAN, L. Application of integrated ozone biological aerated filters and membrane filtration in water reuse of textile effluents. Bioresour. Technol., v. 133, p.150-157, 2013.

HÖLLER, H.; WIRSCHING, U. Zeolite formation from fly ash. Fortschr. Miner., v. 63 , n. 1 , p. $21-43,1985$

HO, Y.S. Citation review of Lagergren kinetic rate equation on adsorption reactions. Scientometrics, v. 59, n. 1, p. 171-177, 2004.

HO, Y.S. Removal of copper ions from aqueous solution by tree fern. Water Res., v. 37, p. 2323-2330, 2003. 
HO, Y.S.; MCKAY, G. Pseudo-second order model for sorption processes. Process Biochem., v. 34, p. 451-465, 1999.

HO, Y.S; WASE, D.A.J.; FORSTER, C .F. Kinetic studies of competitive heavy metal adsorption by sphagnum moss peat. Environm.Technol.,v.17, p. 7177,1996 .

International Energy Agency <http://www.iea.org>. Acessado em 08/09/2013.

International Zeolite Association - Index of Natural Zeolites Datasheets$<$ http://www.iza-online.org/natural/index.htm>. Acessado em 08/03/2012.

IZID ORO, J.C. Estudos sobre a remoção de íons metálicos em água usando zeólitas sintetizadas a partir de cinzas de carvão. 2008. Dissertação (Mestrado) - Instituto de Pesquisas Energéticas e Nucleares, São Paulo.

IZIDORO, J.C.; FUNGARO, D.A.; SANTOS, F.S.; WANG, S. Characteristics of Brazilian coal fly ashes and their synthesized zeolites. Fuel Process. Technol., v. 97, p. $38-44,2012$.

IZIDORO, J. C.; FUNGARO, D. A.; Utilização de resíduos de usinas termelétricas a carvão na síntese de zeólitas e sua aplicação na remoção de $\mathrm{Zn}^{2+} \mathrm{e} \mathrm{Cd}^{2+} \mathrm{em}$ água. Rev. Bras. Pesq. Des. v. 9, p. 101-106, 2007.

IZID ORO, J.C. Síntese e caracterização de zeólita pura obtida a partir de cinzas volantes de carvão. 2013. Tese (Doutorado) - Instituto de Pesquisas Energéticas e Nucleares, São Paulo.

IZQUIERDO, M.; QUEROL, X. Leaching behaviour of elements from coal combustion fly ash: an overview. Int J Coal Geol, v. 94, p. 54-66, 2012.

JHA, B.; SINGH, D.N. A review on synthesis, characterization and industrial applications of fly ash zeolites. Journal of Materials Education, v. 33, p. 65-132, 2011.

JIN, X.C.; LIU, G.Q.; XU, Z.H.; TAO, W.Y. Decolourisation of a Dye Industry Effluent by Aspergillus fumigatus XC6. Applied Microbiology and

Biotechnology, vol. 74, p. 239-243, 2007. 
JIN, X.; JIANG, M.; SHAN, X.; PEI, Z.; CHEN, Z. Adsorption of methylene blue and orange II onto unmodified and surfactant-modified zeolite. Journal of Colloid and Interface Science. V. 328, p. 243-247, 2008.

JONES, D.A.; LELYVELD, T.P.; MAVROF IDIS, S.D.; KINGMAN, S.W.; MILES, N.J. Microwave heating applications in environmental engineering - a review. Resour. Conserv. Recycl., v. 34, p. 75-90, 2002.

KANT, R. Textile dyeing industry an environmental hazard. Nat. Sci., v. 4, p. 22-26, 2012.

KARADAG, D. Modeling the mechanism, equilibrium and kinetics for the adsorption of Acid Orange 8 onto surfactant-modified clinoptilolite: The application of nonlinear regression analysis. Dyes Pigm., v. 74, p. 659-664, 2007.

KHANDEGAR, V.; SAROHA, A.K. Electrocoagulation for the treatment of textile industry effluent - A review. J. Environ. Manage., v. 128, p. 949-963, 2013.

KHATTRI, S.D.; SINGH, M.K. Removal of malachite green from dye wastewater using neem sawdust by adsorption. J. Hazard Mater, v. 167, p.1089-1094, 2009.

KYZAS, GEORGE Z.; VASSILIOU, MARGARITIS KOSTOGLOU; ALEXANDROS A.; LAZARIDIS, NIKOLAOS K. Treatment of real effluents from dyeing reactor: Experimental and modeling approach by adsorption onto chitosan. Chem. Eng. J. v. 168, p. 577-585, 2011.

KOLOUSEK, D.; SEIDL, V.; PROCHAZKOVA, E.; OBSASNIKOVA, J.; KUBELKOVA, L.; SVETLIK. I. Ecological utilization of power-plant fly as hes by heir alteration to phillipsite: hydrothermal alteration, application. Acta Univ. Carol. Geol., v. 37, p. 167-178, 1993.

KONICKI, W.; CENDROWSKI, K.; CHEN, X.; MUOWSKA, E. Application of hollow mesoporous carbon nanospheres as an high effective adsorbent for the fast removal of acid dyes from aqueous solutions. Chem. Eng. J., v. 228, p. 824-833, 2013.

KÖRBAHTI, B.K.; TANYOLAC, A. Electrochemical treatment of simulated textile wastewater with industrial components and Levafix Blue CA reactive dye:

Optimization through response surface methodology. J. Hazard. Mater., v. 151, p. 422-431, 2008. 
KREUZ, A.L. Utilização de cinzas pesadas de termelétricas na substituição de cimento e areia na confecção de concretos. 2002. Dissertação (Mestrado). Universidade Federal de Santa Catarina, Florianópolis.

KULEYIN, A. Removal of phenol and 4-chlorophenol by surfactant-modified natural zeolite, J. Hazard. Mater., v. 144, p. 307-315, 2007.

KUMAR, K.; KUMAR, S.; MEHROTRA, P. Review: Towards sustainable solutions for fly ash through mechanical activation. Resour. Conserv. Recycl. v. 52, p. 157-179, 2007.

KUMAR. P.S.; RAMALINGAM, S.; SENTHAMARAI. C.; NIRANJANAA, M.; VIJAYALAKSHMI, M.; SIVANESAN, M. Adsorption of dye from aqueous solution by cashew nut shell: studies on equilibrium isotherm, kinetics and thermodynamics of interactions. Desalination, v. 261, p. 52-60, 2010.

KUMAR, R.; AHMAD, R. Biosorption of hazardous crystal Violet dye from aqueous solution onto treated ginger waste (TGW). Desalination, v. 265, p.112-118, 2011.

LAGERGREN, S. Zur theorie der sogenannten adsorption geloster stoffe. Kungl. Svenska Vetenskapsakad. Handl. v. 24, p. 1-39, 1898.

LANCHANCE, G. R., CLAISSE, F. Quantitative X-ray fluorescence analysis Theory and Aplication. London: Wiley, 1995.

LEANDRO, R.P. Estudo laboratorial acerca da possibilidade de aproveitamento da cinza pesada de termelétrica em bases e sub-bases de pavimentos flexíveis. 2005. Dissertação (Mestrado) - Universidade de São Paulo, São Carlos.

LEE, K.E.; MORAD, N.; TENG, T.T.; POH, B.T. Development, characterization and the application of hybrid materials in coagulation/flocculation of wastewater: A review. Chem. Eng. J., v. 203, p. 370-386, 2012.

LEE, S.H.; SONG, D.I.; JEON, Y.W. An investigation of the adsorption of organic dyes onto organo-montmorillonite. Environmental Technology., v. 22, p. 247-254, 2001.

LEIW, M.Y.; GUAI, G.H.; WANG, X.; TSE, M.S.; NG, C.M.; TAN, O.K. Dark ambient degradation of Bisphenol $A$ and Acid Orange 8 as organic pollutants by perovskite SrFe O3- I metal oxide. J. Hazard. Mater., v. 260, p. 1-8, 2013. 
LEVANDOWSKI, J.; KALKREUTH, W. Chemical and petrographical characterization of feed coal, fly ash and bottom ash from the Figueira Power Plant, Paraná, Brazil. Int. J. Coal Geol., v. 77, p. 269-281, 2009.

LI, Z.H.; BOWMAN, R.S. Sorption of chromate and PCE by surfactant-modified clay minerals. Environ. Sci. Technol., v. 32, p. 2278-2282, 1998.

LI, C.; DONG, Y.; WU, D.; PENG, L.; KONG, H. Surfactant modified zeolite as adsorbent for removal of humic acid from water. Appl. Clay Sci., v. 52, p. 353357, 2011.

LI, Z.H.; HONG, H.L. Retardation of chromate through packed columns of surfactant-modified zeolite. J. Hazard. Mater., v. 162, p. 1487-1493, 2009.

LIMA, R.O.A.; BAZO, A.P.; SALVADORI, D.M.F.; RECH, C.M.; OLIVEIRA, D.P.; UMBUZEIRO, G.A. Mutagenic and carcinogenic potential of a textile azo dye processing plant effluent that impacts a drinking water source. Mutation Research, v. 626, p. 53-60, 2007.

LIN, C.F.; HIS, H.C. Resource recovery of waste fly ash: synthesis of zeolite-like materials. Environ. Sci. Technol., v. 29, p. 1109-1117, 1995.

LIN, J.; ZHAN, Y.; ZHU, Z.; XING, Y. Adsorption of tannic acid from aqueous solution onto surfactant-modified zeolite. J. Hazard. Mater., v. 193, p. 102-111, 2011.

LIU, Y. Some consideration on the Langmuir isotherm equation. Colloids and Surfaces A: Physicochem. Eng. Aspects, v. 274, p. 34-36, 2006.

LU, S.G.; CHEN, Y.Y.; SHAN, H.D.; BAI, S.Q. Mineralogy and heavy metal leachability of magnetic fractions separated from some Chinese coal fly ashes. J. Hazard Mater., v. 169, p. 246-55, 2009.

LUCARELLI, L.; NADTOCHENKO, V.; KIWI, J. Environmental Photochemistry: Quantitative Adsorption and FTIR Studies during the $\mathrm{TiO}_{2}$-Photocatalyzed Degradation of Orange II. Langmuir. v. 16, p. 1102-1108, 2000.

MAGDALENA, C.P. Adsorção de corante reativo Remazol Vermelho RB de solução aquosa usando zeólita de cinzas de carvão e avaliação da toxicidade aguda com Daphnia Similis. 2010. Dissertação (Mestrado) - Instituto de Pesquisas Energéticas e Nucleares, São Paulo. 
MAGDALENA, C.P.; FUNGARO, D.A.; CUNICO, P.; Adsorção de azo corante reativo utilizando material zeolítico: tempo de contato, $\mathrm{pH}$, temperatura e efeito de sais. Tchê Quím., v. 9 ( $\left.\mathrm{n}^{\circ} 17\right)$ p. 48-59, 2012.

MALACHOVA, K.; PAVLÍCKOVÁ, Z.; NOVOTNY, C.; SVOBODOVA, K.; LEDNICKA, D.; MUSÍLKOVÁ, E. Reduction in the mutagenicity of synthetic dyes by successive treatment with activated sludge and the Ligninolytic Fungus, Irpex lacteus. Environ. Mol. Mutagen., v. 47, p. 533-540, 2006.

MALARVIZHI, R.; HO, Y-S. The influence of $\mathrm{pH}$ and the structure of the dye molecules on adsorption isotherm modeling using activated carbon. Desalin., v. 264, p. $97-101,2010$.

MALL, I.D.; SRIVASTAVA, V.C.; AGARWAL, N.K. Removal of Orange-G and Methyl Violet dyes by adsorption onto bagasse fly ashdkinetic study and equilibrium isotherm analyses. Dyes Pigm., v. 69, p. 210-223, 2006.

MANTELL, C.L. Adsorption. New York: McGraw-Hill Book Company, 1951.

MARTINS, J.L. Aproveitamento de cinza de carvão mineral na agricultura. 2001. Tese (Doutorado) - Universidade Federal do Rio Grande do Sul, Porto Alegre.

MASSCHELEIN, W.J. Unit processes in drinking water treatment. New York: Marcel Dekker, p. 322, 1992.

MASTERS, A.F; MASCHMEYER, T. Zeolites - From curiosity to cornerstone, Microporous Mesoporous Mater., v. 142, p. 423-438, 2011.

MATHUR, N.; BHATNAGAR, P.; SHARMA, P. Review of the Mutagenicity of Textile Dye Products, Universal Journal of Environmental Research and Technology, v. 2, p. 1-18, 2012.

MATIJASEVIC, S.; DAKOVIC, A.; TOMASEVIC-CANOVIC, M.; STOJANOVIC, M.; ILES, D. Uranium(VI) adsorption on surfactant modified heulandite/clinoptilolite rich tuff, J. Serb. Chem. Soc., v. 71, p. 1323-1331, 2006.

Matriz energética: <http://www.brasil.gov.br/sobre/economia/energia/matrizenergetica/carvao-mineral-e-derivados/> Acesso em 03/09/13 
MCCABE, W.L.; SMITH, J.C.; HARRIOT, P. Units operations of chemical engineering. 5. ed. New York: McGraw Hill, 1993.

MCCASH, E.M. Surface chemistry. Great Britain: Oxford University Press, 2004.

MCKAY, G.; OTTERBURN, M.S.; AGA, J.A. Fuller's earth and fired clay as adsorbents for dyestuffs equilibrium and rate studies. Water, Air, Soil Pollut., v. 24, p. 307-322, 1985.

MEZNI, M.; HAMZAOUI, A.; HAMDI, N.; SRASRA, E. Synthesis of zeolites from the low-grade Tunisian natural illite by two different methods. Appl. Clay Sci., v. 52, p. 209-218, 2011.

MLTON, R. M. Molecular sieve adsorbents. US Patent 2882243, 1959.

MITTAL, A., MITTAL, J., MALVIYA, A., KAUR, D., GUPTA, V. K. Adsorption of hazardous dye crystal violet from wastewater by waste materials. J. Colloid Interface Sci., v.343, p. 463-473, 2010.

MOHAN, D., SINGH, K. P., SINGH, G., KUMAR, K. Removal of Dyes from Wastewater Using Fly ash, a Low-Cost Adsorbent. Ind. Eng. Chem. Res., v.41, p. 3688-3695, 2002.

MORENO, N.; QUEROL, X.; AYORA, C.; PEREIRA, C.F.; JURKOVICOVA, M.J. Utilization of zeolites synthesized from coal fly ash for the purification of acid mine waters. Environ. Sci. Technol., v. 35, p. 3526-3534, 2001.

MUMPTON, F.A. La roca magica: Uses of natural zeolites in agriculture and industry. Proc. Natl. Acad. Sci. USA (Colloquium Paper), v. 96, p. 3463-3470, 1999.

MURA YAMA, N.; YAMAMOTO, H.; SHIBATA, J. Mechanism of zeolite from coal fly ash by alkali hydrotermal reaction. Int. J. Miner. Process., v. 64, p. 1-17, 2002.

MURUGESAN, K.; NAM, I.; KIM, Y.; CHANG, Y. Decolourization of reactive dyes by a thermostable laccase produced by Ganoderma lucidum in solid state culture. Enzyme Microb. Technol., v. 40, p.1662-1672, 2007.

NIDHEESH, P.V.; GAND HIMATHI, R.; RAMESH, S.T.; SINGH, T.S.A. Adsorption and desorption characteristics of crystal violet in bottom ash column. J. Urban and Environ. Eng., v. 6, n. 1, p 18-29, 2012. 
NIGAM, P. BANAT, I.M. SINGH, D. MARCHANT, R. Microbial Process for the Decolorization of Textile Effluent Containing Azo, Diazo and Reactive Dyes.

Process. Biochem., v. 31, p. 435-442, 1996.

NOROOZI, B.; SORIAL, G.A. Applicable models for multi-component adsorption of dyes: A review. J. Environ. Sci., v. 25, p. 419-429, 2013.

OLIVE IRA, C.R.; RÚBIO, J. Remoção de íons xantato por adsorção-flotação utilizando zeólitas naturais modificadas. XXII ENTMME/VIIMSHMT, Ouro Preto, Minas Gerais, 2007.

OLIVEIRA, MARCOS L.S.; WARD, COLIN R.; SAMPAIO, CARLOS H.; QUEROL, X.; CUTRUNEO, CÉSAR, M.N.L.; TAFFAREL, SILVIO R.; SILVA, LUIS F.O.

Partitioning of mineralogical and inorganic geochemical components of coals from Santa Catarina, Brazil, by ind ustrial beneficiation processes. Int. J. Coal Geol. v. 116-117, p. 75-92, 2013.

OLIVE IRA, D.P. Corantes como importante classe de contaminantes ambientais - um estudo de caso. 2005. Dissertação (mestrado)- Universidade de São Paulo, Ribeirão Preto.

ORTIZ, L.; TEIXEIRA, E.B. Influência das atividades de processamento do carvão sobre a qualidade dos recursos hídricos superficiais. In: Meio Ambiente e Carvão: Impactos da exploração e utilização. Porto Alegre, p. 301-340, 2002.

ÖZDEMIR Y.; DOGAN M.; ALKAN M. Adsorption of cationic dyes from aqueous solutions by sepiolite. Microporous and Mesoporous Mater., v. 96, p. 419-427, 2006.

OZDEMIR, O.; TURAN, M.; TURAN, A.Z.; FAKI, A.; ENGIN, A.B. Feasibility analysis of color removal from textile dyeing wastewater in a fixed-bed column system by surfactant-modified zeolite (SMZ), J. Hazard. Mater., v. 166, p. $647-654,2009$.

PAPROCKI, A. Síntese de zeólitas a partir de cinzas de carvão visando sua utilização na descontaminação de drenagem ácida de mina. 2009.

Dissertação (Mestrado) - Pontifícia Universidade Católica do Rio Grande do Sul, Porto Alegre. 
PAPROCKI, A.; CARDOSO, A.M.; LIGABUE, R.A.; AZEVEDO, A.M.N.; VILLWOCK, J.A.; PIRES, M. Caracterização de cinzas leves oriundas da combustão de carvão pulverizado visando sua aplicação na síntese de zeólitas. In: XVIII CONGRESSO BRASILEIRO DE ENGENHARIA E CIÊNCIA DOS MATERIAIS, Nov. 24-28, 2008, Porto de Galinhas, PE.

PERRICH, J.R.; Actived Carbon Adsorption for Waste Water Treatment, CRC Press: Boca Raton, 1981.

PIMRAKSA, K.; CHINDAPRASIRT, P.; SETTHAYA, N. Synthesis of zeolite phases from combustion by-products. Waste Manage. Res., p. 1-11, 2010.

QUEROL, X.; ALASTUEY, A.; LÓPEZ-SOLER, A.; PLANA, F.; ANDRÉS, J.M.; JUAN, R.; FERRER, P.; RUIZ, C.R. A fast method for recycling fly ash: microwave-assisted zeolite synthesis. Environ. Sci. Technol., v. 31, p. 25272533, 1997.

QUEROL, X.; MORENO, N.; UMANÃ, J.C.; ALASTUEY, A.; HERNÁNDEZ, E.; LÓPEZ-SOLER, A.; PLANA, F. Synthesis of zeolites from coal fly ash: an overview. Int. J. Coal Geol., v. 50, p. 413-423, 2002.

QUEROL, X.; UMAÑA, J. C.; PLANA, F.; ALASTUEY, A.; LÓPEZ-SOLER, A.; MEDINACELI, A.; VALERO, A.; DOMINGO, M. J.; GARCIA-ROJO, E. Synthesis of zeolites from fly ash at pilot plant scale. Examples of potential applications. Fuel, v.80, p. 857-865, 2001.

QUISPE, D.; PEREZ-LOPEZ, R.; SILVA, L.F.; NIETO, J.M. Changes in mobility of hazardous elements during coal combustion in Santa Catarina power plant (Brazil). Fuel, v. 94, p. 495-503, 2012.

RALSTON, J.; KITCHENER, J.A. The Surface Che mistry of Amosite Asbestos, an Amphibole Silicate. J. Colloid Interface Sci., vol. 50, p. 242-249, 1975.

RANCK, J.M.; BOWMAN, R.S.; WEEBER, J.L.; KATZ, L.E.; SULLIVAN, E.J. BTEX removal from produced water using surfactant-modified zeolite, J. Environ. Eng. ASCE, v. 131, p. 434-442, 2005.

RAYALU, S.S.; BANS WAL, A.K.; MESHRAM S.U.; LABHSETWAR, N.;

DEVOTTA, $S$. Fly ash based zeolite analogues: versatile materials for energy and environmental conservation. Catal. Surv. Asia., v. 10, p.74 - 88, 2006. 
REED, B.E.; MATSUMOTO, M.R. Modeling Cadmium Adsorption by Activated Carbon Using the Langmuir and Freundlich Isotherm Expressions. Sep. Sci. Technol., v.28, p. 2179-2195, 1993.

RÍOS, C.A.R; OVIEDO, J.A.V.; HENAO, J.A.M.; MACÍAS, M.A.L. A NaY zeolite synthesized from Colombian industrial coal by-products: Potential catalytic applications. Catal. Today, v. 190, p. 61-67, 2012.

RÍOS, C.A.; WILLIAMS, C.D.; CASTELLANOS, O.M. Síntesis y caracterización de zeolitas a partir de la activación alcalina de caolinita y subproductos industriales (cenizas volantes y clinker natural) en soluciones alcalinas", BISTUA, vol. 4, p. 60-71, 2006.

RíOS, C.A; WILLIAMS, C.D, ROBERTS, C.L. A comparative study of two methods for the synthesis of fly ash-basedsodium and potassium type zeolites. Fuel., v. 88, p. 1403-1416, 2009.

ROBINSON, T.; MCMULLAN, G.; MARCHANT, R. Remediation of dyes in textile effluent: a critical review on current treatment technologies with a proposed alternative. Biores. Technol., v.77, p. 247-255, 2001.

ROCHA JUNIOR, C.A.F.; SANTOS, S.C.A.; SOUZA, C.A.G.; ANGÉLICA, R.S.; Neves, R.F. Síntese de zeólitas a partir de cinza volante de caldeiras:

caracterização física, química e mineralógica. Cerâmica, v. 58, p. 43-52, 2012.

ROHDE, G.M.; ZWONOK, O.; CHIES, F.; SILVA, N.I.W. Cinzas de carvão fóssil no Brasil - Aspectos técnicos e ambientais. Porto Alegre: CIENTEC. v.1 (202 p), 2006.

RODHE, G.M. Cinzas, a outra metade do carvão fóssil - nova estratégia para a termeletricidade. In: IV CONGRESSO BRASILEIRO DE CARVÃO MINERAL, Agost. 22-24, 2013, Gramado, RS.

RUBIO, J.; SOUZA, M.L.; SMITH, R.W. Overview of flotation as a wastewater treatment technique. Miner. Eng., v. 15, p. 139-155, 2002.

RUEN-NGAM, D.; RUNGSUK, D.; APIRATIKUL, R.; PAVASANT, P. Zeolite Formation from Coal Fly Ash and Its Adsorption Potential. J. Air Waste Manage. Assoc., v. 59, p. 1140-1147, 2009. 
SABEDOT, S.; SUNDSTRON, M.G.; BÖER, S.C.; SAMPAIO, C.H.; DIAS, R.G.O.; RAMOS, C.G. Caracterização e aproveitamento de cinzas da combustão de carvão mineral geradas em usinas termelétricas.

SAEED, A.; SHARIF, M.; IQBAL, M. Adsorption potential of grape fruit peel as dye sorbent: kinetics, equilibrium and mechanism of Crystal violet adsorption. J. Hazard Mater., v. 179, p. 564-572, 2010.

SANGHI, R.; BHATTACHARYA, B. Review on decolorisation of aqueous dye solutions by low cost adsorbents. Color. Technol. v. 118, p. 256-269, 2002.

SARBAK, Z.; STANCZYK, A.; KRAMER-WACHOWIACK, M. Characterization of surface properties of various fly ashes. Powder Technol., v. 145, p. 82-87, 2004.

SARATALE, R.G.; SARATALE, G.D.; CHANG, J.S.; GOVINDWAR, S.P. Bacterial decolorization and degradation of azo dyes: A review. Journal of the Taiwan Institute of Chemical Engineers, vol. 42, p. 138-157, 2011.

SCAPIN, M. A. A plicação da difração e fluorescência de raios X (WDXRF): ensaios em argilominerais. 2003. Dissertação (Mestrado) - Instituto de Pesquisas Energéticas e Nucleares, São Paulo.

SCHULZE-MAKUCH, D.; BOWMAN, R.S.; PILLAI, S.D.; GUAN, H. Field evaluation of the effectiveness of surfactant modified zeolite and iron-oxide-coated sand for removing viruses and bacteria from ground water, Ground Water Monit. Rem., v. 23, p. 68-74, 2003.

SHIGEMOTO, N., HA YASHI, H., MIYUARA, K. Selective formation of Na-X zeolite from coal fly ash by fusion with hydroxide prior to hydrothermal reaction. J. Mater. Sci., v. 28, p. 4781-4786, 1993.

SHOUMKOVA, A. Zeolites for water and wastewater treatment: An overview. Australian Institute of High Energetic Materials. 2011.

SHOUMKOVA, A.; STOYANOVA, V. Zeolites formation by hydrothermal alkali activation of coal fly ash from thermal power station "Maritsa 3", Bulgaria. Fuel, v.103, p. 533-541, 2013.

SIJAKOVA-IVANOVA, T.; PANOV, Z.; BLAZEV, K.; ZAJKOVA-PANEVA, V. Investiqation of flv ash heavv metals content and physico che mical properties from thermal power plant, Republic of Macedonia. Int. J. Eng. Sci. Technol., v. 3, p. 8219-8225, 2011. 
SILVA, A.J. Estudo da viabilidade de utilização da cinza pesada em adição ao concreto compactado com rolo (ccr) destinado a camada de base de pavimentos híbridos. 2006. Dissertação (mestrado) - Universidade Federal De Santa Catarina, Florianóplois.

SILVA, L.F.O.; OLIVEIRA, M.L.S.; NEACE, E.R.; O’KEEFE, J.M.K.; HENKE, K.R.; Hower, J.C. Nanominerals and ultrafine particles in sublimates from the Ruth Mullins coal fire, Perry County, Eastern Kentucky, USA. Int. J. Coal Geol, v. 85, p. $237-45,2011$.

SILVA, L.F.O.; BOIT, ·K.M. Nanominerals and nanoparticles in feed coal and bottom ash: implications for human health effects. Environ. Monit. Assess., v. 174, p. 187-197, 2010.

SILVA, L.F.O.; WARD, C.R.; HOWER, J.J.; IZQUIERDO, M.; WAANDERS F.; OLIVE IRA, M.L.S.; LI, Z., HATCH, R.S.; QUEROL, X. Mineralogy and Leaching Characteristics of coal Ash from a Major Brazilian Power Plant. Coal Combustion and Gasification Products, v. 2, p. 51-65, 2010.

SIDIK, S.M.; JALIL, A.A; TRIWAHYONO, S.; ADAM, S.H.; SATAR, M.A.H.; HAMEED, B.H. Modified oil palm leaves adsorbent with enhanced hydrophobicity for crude oil removal. Chem. Eng. J., v. 203, p. 9-18, 2012.

SINGER, A., BERKGAUT, V. Cation exchange properties of hydrotermally treated coal fly ash. Environ. Sci. Technol., v. 29, p. 1748-1753, 1996.

SINGH, K.P.; GUPTA, S.; SINGH, A.K. ; SINHA, S. Optimizing adsorption of crystal violet dye from water by magnetic nanocomposite using response surface modeling approach. J. Hazard. Mat., v. 186, p. 462-1473, 2011.

SMART, L.; MOORE, E.; Solid State Chemistry. An introduction, Chapman \& Hall: London, 1992.

SPRYNSKYY, M.; LIGOR, T.; LEBEDYNETS, M.; BUSZEWSKI, B. Kinetic and equilibrium studies of phenol adsorption by natural and modified forms of the clinoptilolite, J. Hazard. Mater., v. 169, p. 847-854, 2009.

SRINIVASAN, A., GRUTZECH, M.W. The adsorption of $\mathrm{SO}_{2}$ by zeolites synthesized from fly ash. Environ. Sci. Technol., v.30, p. 1464-1469, 1999. 
STEFOV, V.; PEJOV, L.; SOPTRAJANOV, B. Experimental and quantum chemical study of pyrrole self-association through $\mathrm{N}-\mathrm{H} \pi$ hydrogen bonding. J. Molecular Str., v. 649, p. 231-243, 2003.

STYLIDI, M.; KONDARIDES, D.I.; VERYKIOS, X.E. Pathways of solar lightinduced photocatalytic degradation of azo dyes in aqueous $\mathrm{TiO}_{2}$ suspensions. Appl. Catal. B-Environ., v. 40, p. 271-286, 2003.

TAFFAREL, S.R.; RUBIO, J. Adsorption of sodium dodecyl benzene sulfona te from aqueous solution using a modified natural zeolite with CTAB. Miner. Eng., v. 23, p. 771-779, 2010.

THOMASS, W. J.; CRITTENDEN, B. Adsorption Technology and Design, Woburn: Butterwort-Heinemann, 1998.

TRACTEBEL ENERGIA < <ttp://www.tractebelenergia.com.br/>. Acessado em 08/09/2013.

UMANÃ-PENÃ, J.C. Síntesis de zeolitas a partir de cenizas volantes de centrales termoeléctricas de carbón. 2002. Tese (Doutorado) - Universitat Politécnica de Catalunya, Barcelona, Espanha.

UMBUZE IRO, G.A.; FREEMAN, H.; WARREN, S.H.; KUMMROW, F.; CLAXTON, L.D. Mutagenicity evaluation of the commercial product C.I. Disperse Blue 291 using different protocols of the Salmonella assay. Food Chem. Toxicol., vol. 43, p. 49-56, 2005.

UMBUZE IRO, G.A.; ROUBICEK, D.A.; RECH, C.M.; SATO, M.I.Z.; CLAXTON, L.D. Investigating the sources of the mutagenic activity found in a river using the Salmonella assay and different water extraction procedures. Chemosphere, vol. 54, p. $1589-1597,2004$.

VASSILEV, S.V.; VASSILEVA, C.G. A new approach for the classification of coal fly ashes based on their origin, composition, properties, and behavior. Fuel, v. 86, p. 1490-1512, 2007.

VASSILEV, S.V.; VASSILEVA, C.G. Occurrence, abundance and origin of minerals in coals and coal ashes. Fuel Process Technol., v. 48, p. 85-106, 1996.

VENTURA-CAMARGO, B.C.; MARIN-MORALES, MA. Azo Dyes: Characterization and Toxicity-A Review. Textiles and Light Industrial Science and Technology (TLIST), v. 2, p. 85-103, 2013. 
WANG, H.D.; YANG, Q.; NIU, C.H.; BADEA, I. Adsorption of azo dye onto nanodiamond surface. Diamond \& Related Materials, v. 26, p. 1-6, 2012.

WANG, L.; WANG, A. Adsorption properties of Congo Red from aqueous solution onto surfactant-modified montmorillonite. J. Hazard. Mat., v. 160, p. 173-180, 2008.

WANNGAH, W.S.; HANAFIAH, M.A.K.M. Removal of heavy metal ions from wastewater by chemically modified plant wastes as adsorbents: a review. Bioresour. Technol., v. 99, p. 3935-3948, 2008.

WEBER, W.J.; MORRIS, J.C. Kinetics of adsorption carbon from solutions. J. Sanit. Eng. Div., American Society Chemical Engineering, v. 89, p. 31-60, 1963.

WINGENFELDER, U.; FURRER, G.; SCHULIN, R. Sorption of antimonate by HDTMA-modified zeolite. Micropor. Mesopor. Mater., v. 95, p. 265-271, 2006.

YANG, R.T. Adsorbents - fundamentals and applications. New Jersey: John Wiley \& Sons, 2003.

YUEN, F.K.; HAMEED, B.H. Recent developments in the preparation and regeneration of activated carbons by microwaves. Adv. Colloid Interface Sci., v. 149, p. 19-27, 2009.

XIE, J.; LI, C.; CHI, L.; WU, D. Chitosan modified zeolite as a versatile adsorbent for the removal of different pollutants from water. Fuel. v. 103, p. 480-485, 2013.

XIE, J.; MENG, W.; WU, D.; ZHANG, Z.; KONG, H. Removal of organic pollutants by surfactant modified zeolite: Comparison between ionizable phenolic compounds and non-ionizable organic compounds. J. Hazard Mater, v. 231 - 232, p. 57-63, 2012.

XU, S., BOYD, S. Cationic Surfactant Adsorption by Swelling and Nonswelling Layer Silicates. Langmu ir, v. 11, p. 2508-2514, 1995.

ZANONI, M.V.B.; CARNEIRO, P.A. O descarte dos corantes têxteis. Ciência Hoje, v. 29, n. 174, p. 61-64, 2001. 
ZHANG, P.F.; AVUDZEGA, D.M.; BOWMAN, R.S. Removal of perchlorate from contaminated waters using surfactant-modified zeolite, J. Environ. Qual., v. 36, p. 1069-1075, 2007.

ZHOU, H.M.; LUO, Y.; YU, J.G.; QIAO, X.C. Feasibility of recovery alumina from coal fly ash. In: WORLD COAL ASH CONFERENCE, May 4-7, 2009, Lexington, KENTUCKY. Disponível em: <http://www.worldofcoalash.org/2009/as hpdf/a013qiao2009.pdf>. Acesso em: 08/09/2013.

ZUIM, D.R. Estudo da adsorção de componentes do aroma de café (benzaldeído e ácido acético) perdidos durante o processo de produção do café solúvel. 2010. Dissertação (Mestrado). Universidade Federal Do Paraná, Curitiba. 